THE SHORT-RUN DEMAND FOR WORKERS AND HOURS 


\section{CONTRIBUTIONS \\ TO}

ECONOMIC ANALYSIS

59

Edited by

J. JOHNSTON

J. SANDEE

R. H. STROTZ

J. TINBERGEN

P. J. VERDOORN

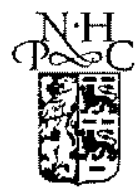

NORTH-HOLLAND PUBLISHING COMPANY AMSTERDAM - LONDON 


\title{
THE SHORT-RUN DEMAND FOR WORKERS AND HOURS
}

\author{
RAY C. FAIR \\ Department of Economics, \\ Princeton University
}

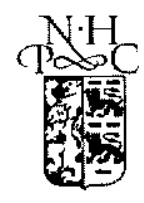

1969

NORTH-HOLLAND PUBLISHING COMPANY AMSTERDAM - LONDON 
(C) NORTH-HOLLAND PUBLISHING COMPANY - AMSTERDAM - 1969

All Rights Reserved. No part of this publication may be reproduced, stored in a retrieval system, or transmitted, in any form or by any means, electronic, mechanical, photocopying, recording or otherwise, without the prior permission of the Copyright owner.

Library of Congress Catalog Card Number: 71-87274

Standard Book Number: 720431557

PUBLISHERS:

NORTH-HOLLAND PUBLISHING COMPANY - AMSTERDAM NORTH-HOLLAND PUBLISHING COMPANY, LTD. - LONDON 


\section{INTRODUCTION TO THE SERIES}

This series consists of a number of hitherto unpublished studies, which are introduced by the editors in the belief that they represent fresh contributions to economic science.

The term economic analysis as used in the title of the series has been adopted because it covers both the activities of the theoretical economist and the research worker.

Although the analytical methods used by the various contributors are not the same, they are nevertheless conditioned by the common origin of their studies, namely theoretical problems encountered in practical research. Since for this reason, business cycle research and national accounting, research work on behalf of economic policy, and problems of planning are the main sources of the subjects dealt with, they necessarily determine the manner of approach adopted by the authors. Their methods tend to be "practical" in the sense of not being too far remote from application to actual economic conditions. In addition they are quantitative rather than qualitative.

It is the hope of the editors that the publication of these studies will help to stimulate the exchange of scientific information and to reinforce international cooperation in the field of economics.

THE EDITORS 
To JMF 


\section{PREFACE}

This study is a revised version of my Ph.D. thesis submitted to the Department of Economics at the Massachusetts Institute of Technology in 1968. I owe a great deal of gratitude to Professors Franklin M. Fisher, Edwin $\mathrm{Kuh}$, and Robert M. Solow for their many helpful comments and suggestions throughout the course of this work. I would also like to express my appreciation to William D. Nordhaus for help at various points in this study. Most of the computer work was done on the IBM 7094 computers at MIT and Princeton University. The research for this work was partly sponsored by the National Science Foundation and the Woodrow Wilson National Fellowship Foundation, to whom I am grateful. The revision was sponsored by a grant from the Office of Manpower Policy, Evaluation, and Research of the us Department of Labor.

Princeton, New Jersey

RAY C. FAIR

November 1968 


\section{CONTENTS}

INTRODUCTION TO THE SERIES . . . . . . . . . . . . . . . . . . . V V

Preface .............................. . VII

LIST Of TABLES . . . . . . . . . . . . . . . . . . . . XI

LIST OF FIGURES . . . . . . . . . . . . . . . . . . . . . . XIII

Chapter 1

INTRODUCTION . . . . . . . . . . . . . . . . . . . . . . . 1

Chapter 2

DESCRIPTION AND CRITIQUE OF PREVIOUS STUDIES . . . . . . . . . . . . . . 5

2.1. Introduction . . . . . . . . . . . . . . . . . . . . . . . . . . 5

2.2. Description of the models similar to the basic model . . . . . . . . . . . 6

2.3. Critique of the models similar to the basic model . . . . . . . . . . . . 17

2.4. Description of other studies of employment fluctuations . . . . . . . . . 26

2.5. Summary . . . . . . . . . . . . . . . . . . . . . 31

Chapter 3

A THEORETICAL MODEL OF THE SHORT-RUN DEMAND FOR PRODUCTION WORKERS . . . 32

3.1. Introduction . . . . . . . . . . . . . . . . . . . . . . . . 32

3.2. Some empirical evidence on short-run fluctuations in output per man hour . 33

3.3. The notation . . . . . . . . . . . . . . . . 36

3.4. The concept of excess labor . . . . . . . . . . . . . . . . . . 37

3.5. The short-run production function . . . . . . . . . . . . . . . . . . . 41

3.6. The measurement of excess labor . . . . . . . . . . . . . . . . . . . 47

3.7. The short-run demand for production workers . . . . . . . . . . . . . 50

3.8. The expectational hypotheses . . . . . . . . . . . . . . . . 55

3.9. Summary. . . . . . . . . . . . . . . . . . . . 57

Chapter 4

THE BASIC RESULTS FOR PRODUCTION WORKERS . . . . . . . . . . . . . . . . 59

4.1. Introduction . . . . . . . . . . . . . . . . . 59

4.2. The data . . . . . . . . . . . . . . . . . . . . . . 59 
4.3. The results for production workers . . . . . . . . . . . . . . . . . . 65

4.4. Summary. . . . . . . . . . . . . . . . . . . . . . . 84

\section{Chapter 5}

TESTS OF VARIOUS HYPOTHESES REGARDING THE SHORT-RUN DEMAND FOR PRODUCTION WORKERS

5.1. Introduction . . . . . . . . . . . . . . . . . . . . . . . . 85

5.2. The short-run substitution of hours for workers . . . . . . . . . . . . . 85

5.3. Tests for cyclical variations in the short-run demand for production workers . 90

5.4. The effect of the unemployment rate on short-run employment decisions . . 95

5.5. The relationship of the excess labor model to a lagged adjustment model . , 100

5.6. Alternative distributed lags . . . . . . . . . . . . . . . . . . 102

5.7. Possible capacity constraints . . . . . . . . . . . . . . . 107

5.8. Summary . . . . . . . . . . . . . . . . . . . . . 109

\section{Chapter 6}

PRODUCTION DECISIONS AND THE SHORT-RUN DEMAND FOR WORKERS . . . . . . 112

6.1. Introduction . . . . . . . . . . . . . . . . . . . . . . . . . 112

6.2. The Holt, Modigliani, Muth, and Simon model . . . . . . . . . . . . . 113

6.3. An alternative model of the short-run demand for production workers . . . 116

6.4. The data . . . . . . . . . . . . . . . . . . . . . . 119

6.5. Equation estimates . . . . . . . . . . . . . . . . . . 121

6.6. Bureau of Census data . . . . . . . . . . . . . . . . . . . . . . . 127

6.7. Summary . . . . . . . . . . . . . . . . . . . . . . . . . 133

\section{Chapter 7}

THE SHORT-RUN DEMAND FOR HOURS PAID-FOR PER WORKER . . . . . . . . 135

7.1. Introduction . . . . . . . . . . . . . . . . . . . 135

7.2. The theoretical model . . . . . . . . . . . . . . . . . . . 139

7.3. The basic results . . . . . . . . . . . . . . . . . . . . . . . . . 144

7.4. Tests for cyclical variations in the short-run demand for hours paid-for per worker . . . . . . . . . . . . . . . . . . . . . 150

7.5. Summary . . . . . . . . . . . . . . . . . . . 154

Chapter 8

THE SHORT-RUN DEMAND FOR TOTAL MAN HOURS PAID-FOR . . . . . . . . . 156

8.1. Introduction . . . . . . . . . . . . . . . . . . . 156

8.2. A comparison of the demand for workers and the demand for hours paid-for per worker 
8.3. The short-run demand for total man hours paid-for . . . . . . . . 159

8.4. Economy-wide implications . . . . . . . . . . . . . . 161

Chapter 9

FURTHER STATISTICAL RESULTS . . . . . . . . . . . . 166

9.1. Introduction . . . . . . . . . . . . . . . . . 166

9.2. Tests for first-order serial correlation . . . . . . . . . . 166

9.3. More efficient estimates . . . . . . . . . . . . . . . . . . . . . . . 177

9.4. A comparison of the short-run demand for workers across industries . . . . 186

Chapter 10

THE SHORT-RUN DEMAND FOR NON-PRODUCTION WORKERS . . . . . . 192

10.1. Introduction . . . . . . . . . . . . . . . . 192

10.2. The model . . . . . . . . . . . . . . . . . . . . . . . . . . . . . 192

10.3. The results . . . . . . . . . . . . . . . . . . . . 196

Chapter 11

SUMMARY AND CONCLUSIONS . . . . . . . . . . . . . . . . 201

11.1. Summary . . . . . . . . . . . . . . . . . 201

11.2. Concluding remarks ................ 208

DATA APPENDIX . . . . . . . . . . . . . . . . . . . 209

BIBLIOGRAPHY . . . . . . . . . . . . . . . . 222

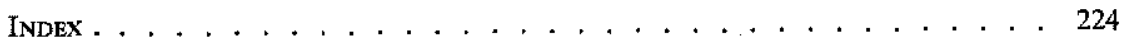




\section{LIST OF TABLES}

2.1. Notation used in ch. 2.................. 6

2.2. The percentage changes from the trough month to the peak month of the year in $Y, M$, and $H P$ for the years $1950,1955,1960$, and $1964 \ldots . .21$

2.3. Parameter estimates for eq. $(2.37)^{\prime} \ldots \ldots \ldots 23$

2.4. Parameter estimates for eq. $(2.37)^{\prime \prime} \ldots \ldots . . \ldots 24$

3.1. Notation used in ch. $3 \ldots \ldots$. . . . . . . . . . . . 36

4.1. The seventeen industries considered in this study . . . . . . . . . . . 60

4.2. Strikes involving 10,000 or mort workers . . . . . . . . . . 64

4.3. Parameter estimates for eq. (3.9)' under the expectational hypothesis which gave the better results for each industry . . . . . . . . . . 66

4.4. Parameter estimates for eq. (3.9) with $\alpha_{1} \log M_{2 w t-1}$ replacing $a_{1}(\log$ $\left.M_{2 w t-1}-\log M^{*}{ }_{2 w t-1} H^{*}{ }_{2 w t-1}\right)$

4.5. Parameter estimates for eq. (3.9) with $a_{1}\left(\log M_{2 w t-1}-\log M_{2 w t-2}\right)$ replacing $\alpha_{1}\left(\log M_{2 t w-1}-\log M_{2 t w t-1}^{*} H^{*}{ }_{2 w t-1}\right)$.

4.6. Parameter estimates for eq. (3.9) under the alternative (and inferior) expectational hypothesis to that used in table 4.3 for each industry . . .

4.7. Parameter estimates for eq. (3.9)' under the assumptions made in eq. (4.1) about expectations. Estimates presented only for the coefficients of the expectational variables

5.1. Parameter estimates for eq. (3.9)' with the additional term $\alpha_{2} \log H P_{2 w t-1}$. Estimates presented for $\alpha_{1}$ and $\alpha_{2}$ only . . . . . . . . . . . . .

5.2. Parameter estimates for eq. (3.9) with the additional term $\alpha_{3}\left(\log H P_{2 w b-1}-\right.$ $\left.\log H P_{\dot{z} w t-2}\right)$. Estimates presented for $\alpha_{1}$ and $\alpha_{s}$ only . . . . . . . . .

5.3. Parameter estimates for eq. (3.9)' with the additional terms $\alpha_{4}\left(\log P_{d t}-\log \right.$ $\left.P_{a t-1}\right)_{+}$and $\alpha_{5}\left(\log P_{a t}-\log P_{a t-1}\right)-$. Estimates presented for $\alpha_{1}, \gamma_{0}, \alpha_{4}$, and $\alpha_{5}$

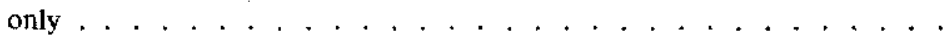

5.4. Parameter estimates for eq. (3.9) with the additional term $a_{6} D_{t}$. Estimates presented for $\alpha_{1}, \gamma_{0}$, and $\alpha_{6}$ only .

5.5. Parameter estimates for eq. (5.1). Estimates presented for $\psi_{0}$ only . . . .

5.6. Parameter estimates for eq. (3.9 $)^{\prime}$ with the additional term $\alpha_{7}\left(\log M_{26 i t-2}-\log \right.$ $M^{*}{ }_{2 w t-2} H^{*}{ }_{2 w t-2}$ ). Estimates presented for $\alpha_{1}$ and $\alpha_{7}$ only . . . . . . . .

5.7. Parameter estimates for eq. (3.9)' with the additional term $\alpha_{5}\left(\log M_{2 w t-1}-\log \right.$ $M^{\left.a_{2 u t-1}\right)^{2}}{ }_{ \pm}$. Estimates presented for $\alpha_{1}$ and $\alpha_{8}$ only . . . . . . . . . . .

5.8. Parameter estimates for eq. (3.9)' with the additional term $\alpha_{9} D K_{t}$. Estimates presented for $\gamma_{0}$ and $\alpha_{9}$ only . . . . . . . . . . . . 108

6.1. Additional notation used in ch. 6 . . . . . . . . . . 120

6.2. Parameter estimates for eq. $(6.7)^{\prime} \ldots \ldots . . . . . . . . . .123$

6.3. Parameter estimates for eq. $(6.8)^{\prime} \ldots \ldots \ldots \ldots . \ldots 124$

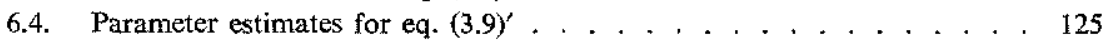

6.5. Parameter estimates for eq. (3.9)' using (a) FRB or RMA data and (b) Bureau of Census data . . . . . . . . . . . . . . . . . . . . . . . 129

6.6. Parameter estimates for eq. (6.8) using Bureau of Census data . . . . . . 130 
6.7. Parameter estimates for eq. (6.7)' using Bureau of Census data . . . . . , 132

7.1. Values of $H P_{2 w t}$ and $H_{2 x t}$ for 1962 . . . . . . . . . . . . . . . . . . 136

7.2. Parameter estimates for eq. $(7.2)^{\prime} . . . . . . . . . . . . . . .146$

7.3. Parameter estimates for eq. (7.2) with the additional term $\alpha_{3} B 1_{t}$. Estimates presented for $\gamma_{0}$ and $\alpha_{3}$ only . . . . . . . . . . . . . . . . . . . , 149

7.4. Parameter estimates for eq. (7.2) with the additional terms $\alpha_{4}\left(\log P_{a t}-\log \right.$ $\left.P_{d t-1}\right)_{\div}$and $\alpha_{5}\left(\log P_{d t-\cdots} \log P_{d t-1}\right)_{-}$. Estimates presented for $\gamma_{0}, \alpha_{4}$, and $\alpha_{5}$ only

7.5. Parameter estimates for eq. (7.2) with the additional term $\alpha_{B} D_{i}$. Estimates presented for $\gamma_{0}$ and $\alpha_{6}$ only

8.1. Sum of the coefficient estimates in table 4.3 and table 7.2 : derived coefficient estimates for the total man-hours paid-for equation .

9.1. Parameter estimates for eq. (3.9) under the assumption of first-order serial correlation of the residuals

9.2. Parameter estimates for eq. (7.2) under the assumption of first-order serial correlation of the residuals

9.3. Sum of the estimates of $\alpha_{1}$ in table 4.3 and table 9.2 and the estimate of $\alpha_{2}$ in table 9.2: derived coefficient estimates for the total man-hours paid-for equation

9.4. Correlation between the residuals of eq. $(3.9)^{\prime}$ and the residuals of eq. (7.2)' for each industry

9.5. Parameter estimates for eq. (3.9) using the two-stage Aitken estimator for each industry

9.6. Parameter estimates for eq. (7.2 $)^{\prime}$ using the two-stage Aitken estimator for each industry

9.7. Correlation between the residuals of eq. $(3.9)^{\prime}$ or eq. (7.2 $)^{\prime}$ for one industry and the residuals of eq. (3.9) $)^{\prime}$ or eq. (7.2) for another industry

9.8. Parameter estimates for eq. (3.9)' using the two-stage Ajtken estimator for three sets of industry groups

9.9. Parameter estimates for eq. (7.2) using the two-stage Aitken estimator for three sets of industry groups.

9.10. Estimates of $\gamma_{0}$ and of the amount of specific training required for fourteen industry groups.

9.11. Estimates of $y_{0}$ and of the percent of workers employed in establishments in which the majority of workers are unionized for ten industry groups . . .

9.12. Estimates of $\gamma_{0}$ and of the average wage level for the seventeen industries .

10.1. Parameter estimates for eq. $(10.1)^{\prime}$.

\section{Appendix}

A-1. Industries for which data were converted to average daily rates

A-2. Internal Revenue Service data on the number of cigarettes produced and shipped

A-3. Internal Revenue Service data on the number of cigars produced and shipped

A-4. Rubber Manufacturers Association data on the number of tires produced and held in inventory........................

A-5. Bureau of Mines data on the amount of cement produced and held in inventory 


\section{LIST OF FIGURES}

2.1. The relationship between the effective wage per man hour, $w_{H_{t}}$, and the number of hours worked per worker, $H_{t}$, in Ball and St Cyr's model . . . . 10

2.2. Wilson and Eckstein's man-hour requirements functions . . . . . . . . . 28

3.1. Expected relationship between output per man hour and output for any one year ....................... . . 33

3.2. Observed relationship between output per man hour and output for each year for each of the seventeen industries . . . . . . . . . . . . . . . . . 34

3.3. Expected relationship between output per paid-for man hour and output on the assumption of constant returns to scale . . . . . . . . . . . . . . . 44

6.1. Holt, Modigliani, Muth, and Simon's overtime cost approximation . . . . 113 


$$
+
$$




\section{INTRODUCTION}

In the past few years there has been a growing interest in cyclical or short-run fluctuations in output per man hour. An understanding of these fluctuations is important in the analysis of such things as short-run fluctuations in unit labor costs, the short-run distribution of income, the longer-run movements in output per man hour, and the growth of potential or full employment output. In the estimation of long-run aggregate production functions, which has become so popular recently, some account must be made of cyclical fluctuations in output per man hour and in capital stock utilization. For policy purposes, an understanding of the relationship between aggregate output changes and changes in the unemployment rate, of which the shortrun relationship between output and employment is a significant part, is also of considerable importance.

Beginning with the work of HULTGREN (1960) and KUH (1960), there have been a number of studies of short-run fluctuations in output and employment. ${ }^{1}$ There are two basic procedures which have been used in these studies. In some of the studies output per man hour has been examined directly in an attempt to discover how it fluctuates with respect to short-run fluctuations in output. In other studies models determining employment (men or man hours) as a function of output and other relevant variables have been developed and estimated, the results of which reveal the short- and long-run relationships between employment and output. Both of these kinds of studies seem to find that output per man hour varies directly with output in the short run, and the latter kind also appears to find evidence of increasing long-run returns to labor services alone. This rather universal finding is contrary to what would be expected from the law of diminishing marginal productivity of classical economic theory, and Solow has commented that

1 See Hultgren (1960, 1965), Kuh (1960, 1965a, 1965b), Neild (1963), Raines (1963), SoLOW (1964), WILSON and ECKSTEIN (1964), BRECHLING (1965), BALL and St CyR (1966), Solrgo (1966), Brechling and O'Brien (1967), Dhrymes (1967), Ireland and Smyth (1967), Masters (1967), and SMYTH and IRELAND (1967). 
it is one of two main paradoxes, "whose resolution would be a major step toward the unification of long-run and short-run theory". 1

In this study a model of the short-run demand for workers and for hours paid-for per worker is developed and estimated. The model provides an explanation of the observed phenomenon of increasing returns to labor services which is not inconsistent with the assumptions of classical economic theory, and it yields substantially better results than the basic model of many of the previous studies, which is based on the postulation of an observable short-run production function and a simple lagged adjustment process. Central to the model developed here is the idea that during much of the year firms have on hand too much labor for the amount of output produced and that during these times the observed number of hours paid-for per worker is greater than the unobserved number of hours actually worked per worker. In the course of this study estimates of the amount of "excess labor" on hand have been made for a number of industries over time, and the empirical results which have been achieved using these estimates strongly suggest that the amount of excess labor on hand is a significant determinant of the short-run demand for workers and for hours paid-for per worker. The results also suggest that the time stream of expected future output changes is a significant determinant of these short-run demands as well.

The relationship between the number of workers employed and the number of hours worked per worker has largely been ignored in previous studies. In this study both this relationship and the relationship between the number of workers employed and the number of hours paid-for per worker are examined in detail, and one of the major findings of this study is that the short-run demand for hours paid-for per worker is influenced by many of the same factors which influence the short-run demand for workers. From this analysis the short-run relationship between the number of hours paid-for per worker and the number of hours worked per worker is seen to be such that the former cannot be taken as an adequate measure of the latter except during peak output periods. Having determined the short-run demand for workers and for hours paid-for per worker, the short-run demand for total man hours paid-for can be derived, and this in turn provides an explanation of the relationship between total man hours paid-for and output.

The data which have been used in this study are considerably more

I Solow (1964, p. 19). 
disaggregated than those of previous studies. Monthly three-digit industry data have been used, as opposed to quarterly data for zero-, one-, or twodigit industries. In a short-run study the use of monthly data has obvious advantages over the use of quarterly data, and problems of aggregation bias should be lessened by the use of three-digit industry data. The question of seasonal adjustment is an important one in a study such as this, and it will be seen that the universal use of seasonally adjusted data or seasonal dummy variables in previous studies is unwarranted. All data used in this study are seasonally unadjusted.

The outline of this work is as follows. In ch. 2 the previous studies of short-run employment demand are summarized and discussed, and the basic model which is common to many of these studies is estimated using the same data and periods of estimation which are used to estimate the model developed in this study. In ch. 3 some empirical evidence on fluctuations in output per man hour is given; the properties assumed about the short-run production function are discussed; the concept of excess labor is discussed and estimates of the amount of excess labor on hand are made; the theoretical model of the short-run demand for workers is developed; and the various expectational hypotheses which have been tested are discussed. In ch. 4 the data which have been used are described, and the results of estimating the model developed in ch. 3 are presented. In this chapter a comparison of the expectational hypotheses is also made.

In ch. 5 a number of hypotheses regarding the short-run demand for workers are developed and tested, using the results presented in ch. 4 as a basis of comparison. The possible short-run substitution of hours for workers is examined; tests of possible cyclical variations in the short-run demand for workers are made; the possible effects of labor market conditions (as measured by the unemployment rate) on short-run employment decisions are examined; the relationship of the model developed in ch. 3 to an alternative "lagged adjustment" model is discussed and other possible reaction behavior is examined; and finally the possible effects of capacity constraints on the short-run demand for workers is examined. In ch. 6 the Holt, Modigliani, Muth, and Simon (HMMs) model is described and estimated, and an alternative model which is similar to the model developed in ch. 3 but which uses some of the HMMs ideas is developed and estimated. The results of estimating these two models are then compared with the results of estimating the model developed in ch. 3. Ch. 6 concludes with a discussion of some results achieved using different output data.

In ch. 7 a theoretical model of the short-run demand for hours paid-for 
per worker is developed and estimated. The effects of labor market conditions on the short-run demand for hours paid-for per worker are examined, and tests of possible cyclical variations in the short-run demand for hours paid-for per worker are also made. In ch. 8 the results of chs. 4 and 7 are brought together. The short-run demand for workers and for hours paidfor per worker are compared, and the short-run demand for total man hours paid-for is discussed. The relationship between the number of workers employed and the number of hours paid-for per worker is clearly seen in this chapter, as is the relationship between fluctuations in total man hours paid-for and fluctuations in output. The economy-wide implications of the results achieved in this study are also discussed in ch. 8 .

In ch. 9 some further statistical tests of the equations which were estimated in chs. 4 and 7 are presented. The residuals are tested for first-order serial correlation, and Zellner's two-stage Aitken estimator is used to estimate the workers and hours equations simultaneously. Zellner's method is also used to estimate a number of different industry equations simultaneously. The chapter concludes with a brief comparison of the short-run demand for workers across industries.

In ch. 10 a theoretical model of the short-run demand for non-production workers similar to the model developed in ch. 3 for production workers is developed and estimated, and the demands for the two kinds of workers are compared. In ch. 11 a summary of the major results and conclusions is presented, and in the data appendix the individual industry data and the adjustments which were made in these data are described. 


\section{DESCRIPTION AND CRITIQUE OF PREVIOUS STUDIES}

\subsection{Introduction}

In this chapter a brief description of each of the studies listed in footnote 1 on page 1 is given. The theoretical model of each of the studies is described, but no attempt is made to present the empirical results, since the data used and the periods of estimation vary widely from study to study. The theoretical models of many of the studies are quite similar, and for ease of exposition the basic model which is common to these studies is presented first. Having done this, it is relatively easy to see how the individual models differ from the basic model and thus from one another.

After summarizing the studies which develop and use a model similar to the basic model, an evaluation of these studies is made. The necessity of making some kind of a cost-minimizing assumption with respect to the workers-hours mix is emphasized, and the studies are criticized for using seasonally adjusted data or seasonal dummy variables. Results are then presented of estimating the basic model using the same data and periods of estimation which are used to estimate the model developed in this study. The results strongly suggest that the basic model is incorrectly specified, even under a slightly different interpretation of some of the coefficient estimates.

The chapter concludes with a description of those studies listed in footnote 1 on page 1 which are not based on a model similar to the basic model. Included in this list are those studies which do not develop a theoretical model of the short-run demand for workers at all, but instead examine output per worker or per man hour directly. In this section the Wilson and Eckstein model is examined in somewhat more detail than the others.

In any study of short-run behavior it is important to make explicit the time periods to which the variables refer. This is especially true in a study such as this one where monthly data are used. If, for example, $M_{t}$ is used to denote the number of workers employed, it is important to know whether it refers to the number employed at the beginning or end of period $t$, to the average number employed during period $t$, or to the number employed 
TABLE 2.1

Notation used in ch. 2

$Y_{t}$ the amount of output produced during period $t$.

$L_{t}$ the amount of labor services employed during period $t$.

$M_{t}$ the number of workers employed during period $t$.

$H_{t}$ the number of hours worked per worker during period $t$.

$K_{t}$ the stock of capital during period $t$.

$T_{t}$ the level of technology during period $t$.

$L^{*}{ }_{t}$ the amount of labor services needed during period $t$, given $Y_{t}, K_{t}$, and $T_{t}$.

$H S_{i}$ the standard (as opposed to overtime) number of hours of work per worker during period $t$.

at some other time during period $t$. When quarterly data are used this distinction is not as critical, and the question has largely been ignored in previous studies. Consequently, in this chapter the notation will be rather loose and reference will be made merely to the values of variables "during period $t$ ". The symbols used for the various variables are presented in the text as the variables are introduced, but for reference purposes the symbols for the more important variables are presented in table 2.1. Beginning in ch. 3 , the notation will be made more precise.

\subsection{Description of the models similar to the basic model}

\subsubsection{The basic model}

The model presented here as the "basic model" makes no assumption about cost-minimizing behavior of firms with respect to the short-run workershours mix. It is thus inconsistent, as will be seen in $\S 2.3$. Because some of the studies described below make no assumption about cost-minimizing behavior of firms, the basic model was framed in this way as well. It will be modified in $\S 2.3$ to correct for this inconsistency.

The basic model begins by postulating a short-run production function, where the amount of output produced during period $t, Y_{t}$, is taken to be a function of the amount of labor services used during period $t, L_{t}^{*}$, the stock of capital on hand during period $t, K_{t}$, and the existing level of technology, $T_{t}$ :

$$
Y_{t}=F\left(L_{t}^{*}, K_{t}, T_{t}\right)
$$

Specifically, it is assumed that the production function is of the Cobb- 
Douglas form and that technology grows smoothly over time at rate $\gamma$. Under these assumptions the production function (2.1) can be written

$$
Y_{t}=A L_{t}^{*}{ }^{x} K_{t}^{\beta} e^{\gamma t}
$$

The elasticity of output with respect to labor services is $\alpha$, and if there are diminishing returns to labor in the short run, $\alpha$ is less than one. If the assumption of constant returns to scale is made, then $\alpha+\beta=1$.

The firm is assumed to take the amount of output produced, the capital stock, and the level of technology as given in the short run and to adjust its employment according to changes in the three exogenous variables. The production function (2.2) can be solved for $L_{t}^{*}$ to yield

$$
L_{t}^{*}=A^{-1 / \alpha} Y_{t}^{1 / \alpha} K_{t}^{-\beta / \alpha} e^{-(\gamma / \alpha) t} .
$$

Given the stock of capital and the level of technology, $L_{t}^{*}$ is the amount of labor services required for the production of $Y_{t}$. A change in the amount of output produced, the stock of capital, or the level of technology from one period to the next will lead to a change in $L_{t}^{*}$. Rapid adjustments in $L_{t}^{*}$ may be costly for the firm, however, and only part of the change in $L_{t}^{*}$ may be made during any one period. To take this into account an adjustment process of the following form is postulated:

$$
L_{t} / L_{t-1}=\left(L_{t}^{*} / L_{t-1}\right)^{\lambda}, 0 \leqq \lambda \leqq 1 .
$$

$L_{t}$ is the amount of labor services employed during period $t$, whereas $L_{t}^{*}$ is the amount of labor services actually required in the production process during period $t$. The adjustment process (2.4) implies that only part of any required change in labor services will be made in any one period. A tenpercent increase in $L_{t}^{*} / L_{t-1}$, for example, will lead to a less than ten-percent increase in $L_{t} / L_{t-1}$, unless of course $\lambda$ equals one.

Solving for $L_{t}^{*}$ in (2.4), substituting into (2.3), and taking logarithms yields

$$
\begin{aligned}
& \log L_{t}-\log L_{t-1}=-\frac{1}{\alpha} \lambda \log A+\frac{1}{\alpha} \lambda \log Y_{t}-\frac{\beta}{\alpha} \lambda \log K_{t} \\
& -\frac{y}{\alpha} \lambda t-\lambda \log L_{t-1} .
\end{aligned}
$$

Given time series on the amount of labor services employed, the amount of output produced, and the stock of capital, eq. (2.5) can be estimated directly, and as is seen below, many empirical studies of the short-run 
demand for employment have been concerned with estimating equations very similar to (2.5).

\subsubsection{The Brechling model}

Brechling's model (BRECHLING, 1965) is similar to the basic model above, except that he does make an assumption regarding firms' cost-minimizing behavior with respect to the workers-hours mix. He begins by postulating a short-run production function like (2.1), where the amount of output produced, the stock of capital, and the level of technology are assumed to be exogenous. He then postulates that the amount of labor services, $L_{t}^{*}$, in the production function is some function of the number of workers employed, $M_{t}$, and the average number of hours worked per worker, $H_{t}$ :

$$
L_{t}^{*}=f\left(M_{t}, H_{t}\right)
$$

Brechling assumes that there are two hourly wage rates per period $t, w_{1 t}$ and $w_{2 t^{*}} w_{1 t}$ is the rate which is payable up to the standard number of hours of work per worker during period $t$, denoted as $H S_{t}$, and $w_{2 t}$ is the overtime rate. The total wage bill (short-run cost function) during period $t$ is then

$$
W_{t}=\left(H_{1 t} w_{1 t}+H_{2 t} w_{2 t}\right) M_{t}
$$

$W_{t}$ is the total wage bill, $M_{t}$ is again the number of workers employed during period $t$, and $H_{1 t}$ and $H_{2 t}$ are the average number of hours worked per worker during period $t$ for standard and overtime pay respectively.

Given the amount of labor services needed during period $t, L_{t}^{*}$, the wage bill (2.7) can be minimized with respect to $M_{t}$ and with respect to the average number of hours worked per worker, $H_{t}$. The cost-minimizing number of workers, denoted as $M_{t}^{d}$, turns out to be a function of $L_{t}^{*}, H S_{t}$, and $w_{1 t} / w_{2 t}{ }^{1}$

$$
M_{t}^{d}=g\left(L_{t}^{*}, H S_{t}, w_{1 t} / w_{2 t}\right)
$$

1 Brechling (1965, p. 190, footnote 1) points out that for a unique cost-minimizing solution to exist, $L^{*}{ }_{t}$ cannot equal $M_{t} H_{t}$ in eq. (2.6), i.e., labor services cannot be approximated by man hours. It should also be pointed out that since the iso-cost curve has a kink in it at the point where $H_{t}$ equals $H S_{t}$ in the iso-quant-iso-cost diagram for $M_{t}$ and $H_{t}$, it is likely, given reasonably smooth iso-quant curves, that the cost-minimizing solution will be at the point where $H^{a}{ }_{t}$ equals $H S_{t}$. In other words, it is likely that the cost-minimizing number of hours worked per worker, $H^{a_{t}}$, will be equal to the standard number of hours of work per worker. 
Solving for $L_{t}^{*}$ in the production function (2.1) yields

$$
L_{t}^{*}=G\left(Y_{t}, K_{t}, T_{t}\right),
$$

and substituting (2.9) into (2.8) yields

$$
M_{t}^{d}=g\left(Y_{t}, K_{t}, T_{t}, H S_{t}, w_{1 t} / w_{2 t}\right) .
$$

Brechling assumes that $g$ is a linear function and that the ratio of the standard wage rate to the overtime rate, $w_{1 t} / w_{2 t}$, is constant over time and thus can be ignored. He assumes an adjustment process like (2.4) of the basic model for $M_{t}^{d}:^{1}$

$$
M_{t}-M_{t-1}=\lambda\left(M_{t}^{d}-M_{t-1}\right), 0 \leqq \lambda \leqq 1 .
$$

The final equation which he estimates is like eq. (2.5) of the basic model with $M_{t}$ replacing $L_{t}$ as the labor variable, except that the variables are not in $\log$ form and a term in $H S_{t}$ has been added. $\left(H S_{t}\right.$ has fallen slowly over time in the United Kingdom.) In addition, Brechling adds the variable $t^{2}$ to his equation to allow for the possibility that technical progress has been accelerating over time, and he adds the change in output, $Y_{t}-Y_{t-1}$, to the equation, arguing that firms may build up their labor requirements in anticipation of high levels of activity. ${ }^{2}$

BRECHLING and O'BRIEN (1967) have gone on to estimate an equation like (2.5) of the basic model (this time in log form and without the capital stock variable) for a number of different countries and have analyzed the differences in results across countries.

\subsubsection{The Ball and St Cyr model}

Ball and St Cyr's model (BALL and ST CYR, 1966) is very similar to Brechling's model with a few modifications. They approximate capital stock by an exponential trend and assume that labor services, $L_{t}^{*}$, can be adequately

1 Brechling gives empirical results for both the linear and log forms of his equations. In this discussion attention is concentrated on the linear version of his model, since this is the version which Brechling concentrates on. The adjustment process for the linear version is thus in linear rather than ratio form.

${ }^{2}$ Brechling makes the assumption that $Y^{e}{ }_{t+1}=Y_{t}+\mathscr{\delta}\left(Y_{t}-Y_{t-1}\right)$, where $Y^{e{ }_{t+1}}$ is the amount of output which is expected to be produced during period $t+1$. Adding $Y_{t+1}{ }_{t+1}$ to an equation like (2.5) introduces the additional variable $Y_{t}-Y_{t-1}$ in the equation. Brechling also tries in his equation a four-quarter moving average of the first differences in output. 
approximated by man hours, $M_{t} H_{t}$, instead of some more complicated expression which Brechling is required to assume in eq. (2.6). $M_{t}$ is again the number of workers employed, and $H_{t}$ is the average number of hours worked per worker. The production function (2.2) for Ball and St Cyr is therefore of the form

$$
Y_{t}=A\left(M_{t} H_{t}\right)^{\alpha} e^{p t},
$$

where $\rho$ equals the rate of growth of technology ( $\gamma$ in eq. (2.2)) plus the rate of growth of the capital stock times the elasticity of output with respect to capital.

They postulate a short-run cost function of the form

$$
W_{t}=w_{H_{t}} M_{t} H_{t}+F_{t},
$$

where $w_{H_{\mathrm{t}}}$ is the "effective wage per man hour"1 during period $t$ and is a function of $H_{t}, F_{t}$ is the fixed cost during period $t$. Up to $H S_{t}$, the standard number of hours of work per worker during period $t$, the cost to the firm of one worker working one period is $w_{1} H S_{t}$ (workers are assumed to be paid for $H S_{t}$ hours during period $t$ regardless of how many hours they actually work), and after that the cost is $w_{1 t} H S_{t}+w_{2 t}\left(H_{t}-H S_{t}\right)$, where again $w_{1 t}$ is the standard wage rate and $w_{2 t}$ is the overtime rate during period $t$.

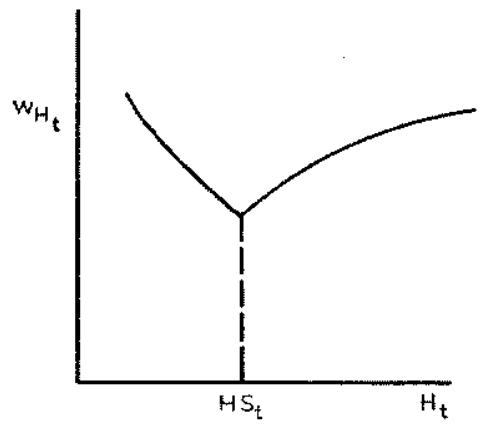

Fig. 2.1. The relationship between the effective wage per man hour, $w_{H_{t}}$, and the number of hours worked per worker, $H_{t}$, in Ball and St Cyr's model.

In figure 2.1 the relationship between $w_{H_{t}}$ and $H_{t}$ is depicted. Ball and St Cyr argue that a reasonable approximation for $w_{H_{t}}$ is the quadratic

$$
w_{H_{t}}=v_{0}-v_{1} H_{t}+v_{2} H_{t}^{2} \text {. }
$$

1 BALL and St CYr (1966, p. 180). 
Substituting this expression for $w_{H_{t}}$ into the cost function (2.13), solving for $H_{t}$ in the production function (2.12) and substituting the resulting expression for $H_{t}$ into the cost function, and then minimizing the resulting expression of the cost function with respect to $M_{\text {, yields }}$

$$
M_{\mathrm{t}}^{d}=2 v_{2} /\left(A^{1 / \alpha} v_{1}\right) e^{-(p / \alpha) t} Y_{t}^{1 / \alpha} .
$$

$M_{t}^{\mathrm{d}}$ is the cost-minimizing number of workers. Eq. (2.15) is of the same form as eq. (2.3) of the basic model without the capital stock variable.

Ball and St Cyr then assume an adjustment process like (2.4) of the basic model for $M_{t}^{d}$ :

$$
M_{t} / M_{t-1}=\left(M_{t}^{d} / M_{t-1}\right), 0 \leqq \lambda \leqq 1,
$$

and arrive at an estimating equation like (2.5) without the $\log K_{t}$ variable and with $M_{t}$ being used as the labor variable in the equation.

Ball and St Cyr's results show strongly increasing returns to labor services, even when direct (as opposed to overhead) labor is considered alone, and they believe that this may be due to the fact that measured man hours, denoted as $\left(M_{t} H_{t}\right)_{m}$, may not at all times be a good approximation of "productive" man hours. They postulate that

$$
M_{t} H_{\mathrm{t}}=\left(M_{t} H_{t}\right)_{m}\left(1-U_{t}\right)^{\mu},
$$

where $U_{t}$ is the "difference between the percentage unemployment ... and the percentage chosen to represent full employment". "In other words, "as unemployment rises the degree of underutilization of employed labor is likely to increase". ${ }^{2}$ Using relation (2.17), they estimate the parameters of the production function (2.12) directly (ignoring the adjustment process and using the variable $M_{t} H_{t}$ instead of $M_{t}$ in the estimated equation) to get an alternative estimate of returns to labor. The results in general give lower estimates of returns to labor services, but of the eleven industries for which estimates are made, two of them give non-sensible results and five of the remaining nine give labor input elasticities (i.e., elasticities of output with respect to labor services) greater than one. Ball and St Cyr remain agnostic as to "the extent to which the estimated labour input elasticities are determined by the time structure of the production functions [i.e., by equations like (2.5) of the basic model, which incorporate lagged

\footnotetext{
1 BALl and St CYR (1966, p. 189).

2 BaLl and ST CYR (1966, p. 189).
} 
adjustment mechanisms like (2.4)] or a widespread propensity to hoard labour permanently [as exemplified by eq. (2.17)]". ${ }^{1}$

\subsubsection{The Ireland and Smyth model}

The Ireland and Smyth model (IRELAND and SMYTH, 1967) is a slight modification of the Ball and St Cyr model, with a different interpretation being given to the estimate of returns to labor services. Instead of a CobbDouglas production function, they postulate a CES production function:

$$
Y_{t}=e^{\gamma t} A\left[\delta\left(M_{t} H_{t}\right)^{\alpha}+(1-\delta)(K U)_{t}^{\alpha}\right]^{\eta / \alpha} .
$$

The capital input variable, $(K U)_{t}$, is the capital utilized during period $t$ instead of the actual stock of capital in existence during the period. The CES production function is homogenous of degree $\eta, \eta$ being the measure of short-run returns to scale. Ireland and Smyth assume that the percentage change in $(K U)_{t}$ is proportional to the percentage change in $M_{t} H_{t}$ through time, arguing that as long as there is excess capacity this assumption seems more plausible than assuming that capital services grow at a constant rate through time, as, for example, Ball and St Cyr do.

They postulate the same short-run cost function, eqs. (2.13), (2.14), as Ball and St Cyr:

$$
W_{t}=w_{H_{t}} M_{t} H_{t}=v_{0}\left(M_{t} H_{t}\right)-v_{1}\left(M_{t} H_{t}\right) H_{t}+v_{2}\left(M_{t} H_{t}\right) H_{t}^{2} .
$$

Utilizing the above assumptions and minimizing $W_{t}$ in eq. (2.19) with respect to $M_{t}$, Ireland and Smyth arrive at the following equation:

$$
M_{t}^{d}=\text { constant } \times e^{(\eta / \eta) t} Y_{t}^{1 / \eta} .
$$

They next assume the familiar lagged adjustment process $(2.4)$ for $M_{t}^{d}$ :

$$
M_{t} / M_{t-1}=\left(M_{t}^{d} / M_{t-1}\right)^{\lambda}, 0 \leqq \lambda \leqq 1,
$$

and arrive at an estimating equation similar to (2.5) of the basic model with $M_{t}$ being used as the labor variable:

$$
\log M_{t}-\log M_{t-1}=\text { constant }+\frac{1}{\eta} \lambda \log Y_{t}-\frac{\gamma}{\eta} \lambda t-\lambda \log M_{t-1} .
$$

The only significant difference between eqs. (2.22) and (2.5) is that in eq. (2.22) $\eta$ has replaced $\alpha$ in the coefficients of $\log Y_{t}$ and $t$. In the Ireland

1 Ball and ST CYR (1966, p. 192). 
and Smyth model $\eta$ is the measure of short-run returns to scale, whereas $\alpha$ in the basic model is the elasticity of output with respect to labor alone. Most estimates of $\alpha$ in eq. (2.5) (or $\eta$ in eq. (2.22)) turn out to be greater than one, and Ireland and Smyth argue that a more realistic interpretation of the coefficient estimates is that they are measures of short-run returns to scale rather than returns to labor alone. If, for example, there are constant returns to scale and if, as Ireland and Smyth assume, the percentage change in capital services is always proportional to the percentage change in labor services, then $\eta$ equals one. To the extent that $\eta$ is greater than one, there are, under these assumptions, increasing short-run returns to scale.

SMYTH and IRELAND (1967) have estimated eq. (2.22) using Australian data. The results show, on their interpretation, evidence of increasing shortrun returns to scale (i.e., values of $\eta$ greater than one).

\subsubsection{The Solow model}

Solow's model (Solow, 1964) is very similar to the basic model. He estimates an equation like (2.5) in both linear and $\log$ forms, trying as the labor services variable both the number of workers employed and total man hours paid-for. To the $\log$ form of his equation he adds the variable $\log Y_{t}-$ $\log Y_{t-1}$, which he argues can be interpreted either as a carrier of expectations or as a variable which "simply converts a geometric distributed lag between employment and output to a slightly more general lag pattern, geometric only after the first term". 1

It is clear from his discussion that Solow is not very satisfied with this model and the results he obtains, and in the latter part of his paper he discusses, as a possible alternative to the Cobb-Douglas production function model, a vintage capital model with fixed coefficients both exante and expost.

\subsubsection{The Soligo model}

Soligo's model (Solrgo, 1966) is in the spirit of the basic model. He begins by postulating a Cobb-Douglas production function like (2.2):

$$
Y_{t}=A M_{t}^{*_{\alpha}} K_{t}^{\beta} e^{\gamma t}
$$

where the labor input variable is taken to be the number of workers, $M_{t}^{*}$. $\mathrm{He}$ is concerned with the problem that in the short run capital may not be

${ }^{1}$ Solow (1964, p. 18). 
perfectly adaptable; and if capital is not perfectly adaptable, employment will not be adjusted as much in the short run as it would if capital were perfectly adaptable. ${ }^{1}$

In the production function $(2.23), \mathrm{M}_{t}^{*}$ is the desired work force if capital were perfectly adaptable. Call $\mathrm{M}_{t}^{d}$ the desired work force for the capital stock in existence during period $t$. Soligo postulates that

$$
M_{t}^{*} / M_{t}^{d}=\left(C_{t}\right)^{v}, \quad v>0,
$$

where $C_{t}$ is the rate of capacity utilization during period $t$. What eq. (2.24) says is that the further the firm deviates from the maximum rate of capacity utilization, the greater will be the gap between the desired work force if capital were perfectly adaptable and the desired work force for the capital stock in existence. Solving for $\mathrm{M}_{t}^{*}$ in (2.24), substituting this expression into eq. (2.23), and then solving for $M_{t}^{d}$ yields:

$$
M_{t}^{d}=A^{-1 / \alpha} Y_{t}^{1 / \alpha} K_{t}^{-\beta / \alpha} C_{t}^{-v} .
$$

Eq. (2.25) is similar to eq. (2.3) of the basic model with the addition of the $C_{t}$ variable.

With respect to future output expectations Soligo assumes that

$$
Y_{t+1}^{e}=Y_{t}\left(Y_{t} / Y_{t-1}\right)
$$

where $Y_{t+1}^{e}$ is the output expected to be produced in the following period. If output increases by one percent during period $t$, for example, then according to eq. (2.26) it is expected to increase by one percent again during period $t+1$. Soligo assumes that the desired work force depends on future output expectations and adds the term $\left(Y_{t+1}^{e} / Y_{t}\right)^{\delta}$ [which by eq. (2.26) becomes $\left.\left(Y_{t} / Y_{t-1}\right)^{\delta}\right]$ to eq. (2.25), where $\delta$ is the "elasticity of the desired work force with respect to the predicted change in output". ${ }^{2}$

Soligo assumes an adjustment process like (2.4) of the basic model for $\mathrm{M}_{t}^{d}$ :

$$
M_{t} / M_{t-1}=\left(M_{t}^{d} / M_{t-1}\right)^{\hat{\lambda}}, 0 \leqq \lambda \leqq 1,
$$

and arrives at an estimating equation like (2.5) of the basic model with $M_{t}$ used as the labor input variable and with the additional terms $-(\lambda / \alpha) v \log C_{t}$ and $\lambda \delta\left(\log Y_{t}-\log Y_{t-1}\right)$ on the right-hand side.

1 Perfectly adaptable capital stock is like putty - the "marginal product curve of labor is congruent to the long-run or ex ante curve". Solıgo (1966, p. 166).

2 Soligo (1966, p. 172). 


\subsubsection{The Dhrymes model}

Dhrymes' model (DHRymes, 1967) deviates somewhat more from the basic model than do the models previously discussed. Dhrymes first postulates a CES production function:

$$
Y_{t}=A\left(\delta_{1} M_{t}^{* \alpha}+\delta_{2} K_{t}^{\alpha}\right)^{1 / \alpha}
$$

The labor input variable is taken to be the number of workers, $M_{t}^{*}$. Dhrymes assumes that optimal employment is given by

$$
\partial Y_{t} / \partial M_{t}^{*}=s w_{t}
$$

where " $s$ is a well defined function of the elasticity of the demand for output and supply of labor", 1 and $w_{t}$ is the product wage. $s$ is assumed to be a constant function. Solving (2.29) yields

$$
M_{t}^{d}=A^{\alpha /(1-\alpha)} s^{\alpha /(\alpha-1)} w_{t}^{1 /(\alpha-1)} Y_{t} \delta_{1}^{1 /(1-\alpha)} .
$$

$M_{t}^{d}$ is the desired number of workers for period $t$.

Dhrymes argues that $Y_{t}$ and $w_{t}$ in eq. (2.30) should be replaced by $Y_{t}^{e}$ and $w_{t}^{e}$, since $M_{t}^{d}$ is based on expected output and the expected wage rate for period $t$. He assumes that $w_{t}^{e}=A_{1} w_{t}$ and $Y_{t}^{e}=A_{2} Y_{t}^{\mu} Y_{t-1}^{v}$, i.e., that "expected wages are proportional to actual wages and expected output is proportional to some root of the actual output in the current period and the actual output of the period for which planning takes place". ${ }^{2}$ He assumes an adjustment process like (1.4) of the basic model for $M_{i}^{d}$ :

$$
M_{t} / M_{t-1}=\left(M_{t}^{d} / M_{t-1}\right)^{\lambda}, 0 \leqq \lambda \leqq 1 .
$$

Dhrymes is also concerned with the possible dependence of employment on investment, for "one might expect the (marginal) productivity of labor in general to depend on the type of capital equipment the unit employs". ${ }^{3}$ Since "capital goods of different vintages embody in them different levels of technical advance", ${ }^{4}$ he assumes that the parameter $\delta_{1}$ in the production function (2.28) depends with infinite lag on investment, $I$. Specifically, he assumes that:

\footnotetext{
1 Dhrymes (1967, p. 3).

2 DHRYMES (1967, p. 4).

3 Dhrymes (1967, p. 4).

4 DHRYMES (1967, pp. 4-5).
} 
$\frac{1}{1-\alpha} \log \delta_{1}=\frac{\gamma_{1} \log I_{t-1}+\gamma_{2} \log I_{t-2}+\gamma_{3} \log I_{t-3}+\gamma_{4} \log I_{t-4}}{\log I_{t}+\gamma_{5} \log I_{t-1}}$

Combining the above information Dhrymes arrives at the following nonlinear equation to estimate:

$$
\begin{aligned}
\log M_{t} & =\text { constant }+\frac{\lambda}{\alpha-1}\left(\log w_{t}+\gamma_{5} \log w_{t-1}\right) \\
& +\lambda \mu\left(\log Y_{t}+\gamma_{5} \log Y_{t-1}\right)+\lambda v\left(\log Y_{t-1}+\gamma_{5} \log Y_{t-2}\right) \\
& +(1-\lambda)\left(\log M_{t-1}+\gamma_{5} \log M_{t-2}\right)-\gamma_{5} \log M_{t-1} \\
& +\lambda \sum_{i=1}^{4} \gamma_{i} \log I_{t-i} .
\end{aligned}
$$

In other words, $\log M_{t}$ is a function of $\log Y_{t}, \log Y_{t-1}, \log Y_{t-2} ; \log M_{t-1}$, $\log M_{t-2} ; \log w_{t}, \log w_{t-1} ;$ and $\log I_{t-1}, \log I_{t-2}, \log I_{t-3}, \log I_{t-4}$. Dhrymes estimates the model for all employees and then for production workers and non-production workers separately.

\subsubsection{The Kuh model}

KUH (1965b) makes a distinction between production workers and nonproduction workers, the latter being more like "overhead" labor and thus more like a fixed factor in the short run than the former. For production workers Kuh regresses $\log M_{t}$ on a constant, $\log Y_{t}, \log Y_{t-1}, \log K_{t-1}$, $\log M_{t-1}$, and $\log H_{t-1}-\log H_{t-2}$ or $\log H_{t}-\log H_{t-1}$. It is clear from his discussion that his model is similar to the basic model discussed above. The lagged variables are added to the equation because they "depict the nature of the adjustment process".1

Kuh discusses the possibility that there may be some substitution in the short run between the number of hours worked per worker and the number of production workers employed, in the sense that the number of hours worked per worker may be used as the principle short-run adjustment tool with respect to changes in man-hour requirements. ${ }^{2}$ With respect to the addition of $\log H_{t-1}-\log H_{t-2}$ to the equation, he argues that one would expect that "the larger the rate of change in hours in the previous period,

$1 \mathrm{KUH}$ (1965b, p. 242).

${ }^{2} \mathrm{KUH}(1965$ b, p. 239). 
the greater will be employment in this period as a substitute, in order to reduce hours toward normal and thus minimize overtime production". 1

For non-production workers Kuh finds the coefficient of $\log Y_{t-1}$ to be insignificant, and for his final equation he regresses $\log N_{t}$ on a constant, $\log Y_{t}, \log K_{t-1}$, and $\log N_{t-1}$, where $N_{t}$ is the number of non-production workers employed during period $t$.

Kuh also estimates an equation determining the number of hours worked per week per production worker. He regresses $\log H_{t}$ on a constant, $\log Y_{t}-$ $\log Y_{t-1}$, and $\log H_{t-1}$. According to Kuh, the main determinant of the number of hours worked per week per worker "is a convention established through bargaining and a variety of social and institutional forces". ${ }^{2}$ But, "there is a lagged adjustment to the desired constant level of hours (more accurately, a gently declining trend) and a strong transient response to the rate of change of output". ${ }^{3}$ This leads to an equation of the form

$$
\log H_{t}-\log H_{t-1}=\alpha\left(\beta-\log H_{t-1}\right)+\gamma\left(\log Y_{t}-\log Y_{t-1}\right),
$$

or

$$
\log H_{t}=\alpha \beta+(1-\alpha) \log H_{t-1}+\gamma\left(\log Y_{t}-\log Y_{t-1}\right),
$$

which is the equation he estimates.

Kuh also argues that the relative scarcity of labor may be important in determining the demand for hours worked per worker, and he adds log $U_{t}$ and $\log U_{t}-\log U_{t-1}$ to eq. (2.35), where $U_{t}$ is the unemployment rate during period $t$, on the grounds that "tight labor markets generate a demand for additional hours". 4 When labor markets are tight, firms have more incentive to increase $H_{\mathrm{t}}$ rather than $M_{t}$, due among other things to the "deterioration in the quality of the marginal work force". ${ }^{5} \log U_{t}-\log U_{t-1}$ enters as an "expectational variable". ${ }^{6}$

\subsection{Critique of the models similar to the basic model}

\subsubsection{Introduction}

While the details of the various models described in $\S 2.2$ differ considerably

1 KuH (1965b, p. 239).

2 KuH (1965b, p. 239).

3. KUH (1965b, p. 239).

4 KUH (1965b, p. 240).

5 KuH (1965b, p. 240).

- KuH (1965b, p. 240). 
from one another, the models themselves are all based on the postulation of a short-run production function and a simple lagged adjustment process. Equations similar to (2.5) of the basic model have been the ones most often estimated in the above studies.

In this section the above studies are evaluated, and some empirical results of estimating the basic model are presented. It was mentioned at the beginning of $\S 2.2$ that the basic model as presented there is inconsistent because no assumption about cost-minimizing behavior of firms with respect to the workers-hours mix was made. This inconsistency will be discussed and eliminated first before a further evaluation of the above studies is made.

2.3.2. The necessity of cost-minimizing assumptions regarding the workershours mix

There are two different, though not mutually exclusive, cost-minimizing assumptions which can be made regarding the short-run employment decisions of firms. The first assumption which can be made is that firms are concerned with the optimal short-run allocation of total factor inputs between labor services and capital services; and the second assumption which can be made is that firms are concerned with the optimal short-run allocation of labor services between the number of workers employed and the number of hours worked per worker. Brechling, Ball and St Cyr, and Ireland and Smyth make the second assumption but not the first, i.e., they assume that in the short run firms are concerned with adjusting their workers-hours worked per worker mix so as to achieve a minimum wage bill, but that firms are not concerned with achieving an optimal capital-labor mix by adjusting the amounts of capital services and labor services used to changing factor prices. Dhrymes, on the other hand, makes the second assumption that firms are concerned with achieving an optimal capital-labor mix, but he does not discuss the optimal short-run allocation of labor services between workers and hours worked per worker. Kuh, Solow, and Soligo do not make any assumptions about short-run cost-minimizing behavior.

Without the assumption of cost-minimizing behavior with respect to the workers-hours worked per worker mix, there is a contradiction between the production function (2.2), or (2.1), of the basic model and the lagged adjustment process (2.4). Eq. (2.3) is derived from the production function (2.2) and gives $L_{t}^{*}$ (the amount of labor services needed in the production process) as a function of the exogenous variables, $Y_{t}, K_{t}$, and $t$. Assume that for period $t$ eq. (2.3), given $Y_{t}, K_{t}$, and $t$, calls for an $L_{t}^{*}$ greater than $L_{t-1}$. The lagged adjustment process (2.4) implies that $L_{t}$ (the amount of labor services 
used) will be less than $L_{t}^{*}$. The production function (2.2), however, reveals that, given $Y_{t}, K_{t}$, and $t$, this cannot be the case and still have $Y_{t}$ produced, i.e., it is not possible to have the amount of labor services used, $L_{t}$, be less than the amount of labor services needed, $L_{i}^{*}$. For $L_{t}^{*}$ less than $L_{t-1}$ no problem arises, but for $L_{t}^{*}$ greater than $L_{t-1}$ eqs. (2.2) and (2.4) are incompatible. In other words, for (2.2) and (2.4) to be compatible, the labor services input variable in the production function cannot be the same variable that is subjected to the lagged adjustment process (2.4).

The cost-minimizing assumptions made by Brechling, Ball and St Cyr, and Ireland and Smyth discussed above are sufficient for the compatibility of the production function and the lagged adjustment process. Actually, their assumptions are more complicated than is necessary. Assume, as Ball and St Cyr do, that labor services can be approximated by man hours, so that in the notation of the basic model, $L_{t}^{*}=\left(M_{t} H_{t}\right)^{*}$, where, as usual, $M_{t}$ denotes the number of workers employed and $H_{\mathrm{t}}$ denotes the number of hours worked per worker. A simpler assumption to make than either Brechling's or Ball and St Cyr's ${ }^{1}$ is that the cost-minimizing number of workers during period $t$, denoted as $M_{t}^{d}$, equals $\left(M_{t} H_{t}\right)^{*} / H S_{t} . H S_{t}$ is again the standard (as opposed to overtime) number of hours of work per worker for period $t .^{2}$ In other words, it is assumed that the cost-minimizing number of workers occurs at the point where no undertime or overtime is being worked, i.e., where each worker is working the standard number of hours per period. The adjustment process (2.4) can then be in terms of $M_{t}^{d}$ :

$$
M_{t} / M_{t-1}=\left(M_{t}^{d} / M_{t-1}\right)^{\lambda}, 0 \leqq \lambda \leqq 1,
$$

and whenever $M_{t}^{d}$ is greater than $M_{t-1}$ (so that $M_{t}$ is less than $M_{z}^{d}$ ), the number of hours worked per worker, $H_{t}$, can be assumed to make up the difference in the short run.

Ball and St Cyr approximate figure 2.1 by the quadratic (2.14) above, and their cost-minimizing level of hours is a function of the parameters of the quadratic function. The simpler assumption made here takes the least cost level of hours at $H S_{t}$ in figure 2.1, which is the least cost point before any quadratic approximation is made.

When the basic model is referred to from now on, the reference will be to the model as modified above. The lagged adjustment process will thus

1 Ireland and Smyth's assumption is the same as that of Ball and St Cyr.

2 The standard number of hours of work per worker may be subject to long-run trend influences, and this is the reason for the time subscript on $H S$. 
be taken to be (2.36) instead of (2.4) as before. The final equation of the basic model is an equation similar to (2.5) above, except that $M_{t}$ has replaced $L_{t}$ as the labor variable and the $\log H S_{t}$ variable has been added:

$$
\begin{gathered}
\log M_{t}-\log M_{t-1}=-\frac{1}{\alpha} \lambda \log A+\frac{1}{\alpha} \lambda \log Y_{t}- \\
\frac{\beta}{\alpha} \lambda \log K_{t}-\frac{\gamma}{\alpha} \lambda t-\lambda \log M_{t-1}-\lambda \log H S_{t} .
\end{gathered}
$$

It should be pointed out that Dhrymes' cost-minimizing assumption regarding the optimal capital services-labor services mix is not sufficient to remove the incompatibility between the production function (2.28) and the lagged adjustment process $(2.31)$ in his model. If the desired number of workers for period $t, M_{t}^{d}$, is less than $M_{\mathrm{t}-1}$, then by the adjustment process the actual number of workers employed during period $t, M_{\mathrm{t}}$, will be less than the desired number. If the amount of output produced, the stock of capital, and the wage rate are assumed to be exogenous in the short run, then his adjustment process (2.31) may yield an $M_{t}$ which, from the production function (2.28), is not sufficient to produce the output. It is possible to remove this incompatibility by assuming that the capital stock varies in such a way in the short run as to allow the output to be produced, given the $M_{t}$ resulting from the adjustment process. This, of course, is a very unrealistic assumption to make, and Dhrymes' model the way it stands has not accounted for the possible incompatibility between the production function and the lagged adjustment process.

In an appendix, Brechling (1965) presents estimates of his equations for man hours as well as for workers, and since the man-hours variable does not enter his model either as an input of the production function nor as the variable in the lagged adjustment process, it is not at all clear how these estimates relate to his theoretical model.

\subsubsection{The seasonal adjustment problem}

A more serious criticism relating to all of the above studies relates to the use of seasonally adjusted data. In all of the studies discussed above the authors either use seasonally adjusted data or seasonally unadjusted data with seasonal dummy variables to estimate their equations.

Many, if not most, industries have large seasonal fluctuations in output and, to a lesser extent, in employment. In table 2.2 the percentage changes from the trough month to the peak month of the year in output, $Y$, in the 


\section{TABLE 2.2}

The percentage changes from the trough month to the peak month of the year in $Y, M$, and HP for the years 1950, 1955, 1960, and 1964

\begin{tabular}{|c|c|c|c|c|c|c|c|c|c|c|c|c|}
\hline \multirow[b]{2}{*}{ Industry } & \multicolumn{3}{|c|}{1950} & \multicolumn{3}{|c|}{1955} & \multicolumn{3}{|c|}{1960} & \multicolumn{3}{|c|}{1964} \\
\hline & $Y$ & $M$ & $H P$ & $Y$ & $M$ & $H P$ & $Y$ & $M$ & $H P$ & $Y$ & $M$ & $H P$ \\
\hline 201 & 42.5 & 14.6 & 13.7 & 34.6 & 8.3 & 11.4 & 20.1 & 6.6 & 6.7 & 24.9 & 7.9 & 8.6 \\
\hline 207 & 93.1 & 32.1 & 9.1 & 79.0 & 25.5 & 7,2 & 76.0 & 23.4 & 6.8 & 79.7 & 17.2 & 3.1 \\
\hline 211 & 35.5 & 7.9 & 23.2 & 18.8 & 6.6 & 10.2 & 14.3 & 5.0 & 21.7 & 44.9 & 3.9 & 28.9 \\
\hline 212 & 32.1 & 10.4 & 18.1 & 19.5 & 11.2 & 10.3 & 15.1 & 5.0 & 13.3 & 79.3 & 19.2 & 15.3 \\
\hline 231 & 22.8 & 7.1 & 7,2 & 25.7 & 9.3 & 9.1 & 34.3 & 2.8 & 7.6 & 30.4 & 4.4 & 4.2 \\
\hline 232 & 41.3 & 7.3 & 8.0 & 24.3 & 6.4 & 7.7 & 28.9 & 6.0 & 7.4 & 24.8 & 6.6 & 7.1 \\
\hline 233 & 53.7 & 25.4 & 12.5 & 31.6 & 16.4 & 5.1 & 27.7 & 12.2 & 7.1 & 19.2 & 5.8 & 9.7 \\
\hline 242 & 66.2 & 23.3 & 9.4 & 24.4 & 11.5 & 4.8 & 42.1 & 19.2 & 8.8 & 28.7 & 10.8 & 8.1 \\
\hline 271 & 24.9 & 4.6 & 2.9 & 27.7 & 5.1 & 4.7 & 23.9 & 3.1 & 2.8 & 23.3 & 2.8 & 2.8 \\
\hline 301 & 27.1 & 11.9 & 9.8 & 28.9 & 5.8 & 8.2 & 30.4 & 10.5 & 9.7 & 19.9 & 5.0 & 12.0 \\
\hline 311 & 17.8 & 7.3 & 5.7 & 10.2 & 2.0 & 2.8 & 12.7 & 5.5 & 4.9 & 19.8 & 7.3 & 3.5 \\
\hline 314 & 21.4 & 7.1 & 13.5 & 23.5 & 8.8 & 6.9 & 22.5 & 5.8 & 10.4 & 17.0 & 4.8 & 6.7 \\
\hline 324 & 58.0 & 7.0 & 2.9 & 43.2 & 4.9 & 1.7 & 93.7 & 17,0 & 4.3 & 99.0 & 15.9 & 3.7 \\
\hline 331 & 19.8 & 9.2 & 9.6 & 19.6 & 14.5 & 4.0 & 108.3 & 38.0 & 16.0 & 25.3 & 13.3 & 3.7 \\
\hline 332 & 51.3 & 36.6 & 14,0 & 21.5 & 19.0 & 5.8 & 53.8 & 14.3 & 8.0 & 24.6 & 7.7 & 50 \\
\hline 336 & 60.3 & 35.7 & 10.4 & 17.1 & 12.1 & 4.0 & 34.4 & 13.1 & 4.3 & 13.2 & 4.6 & 2.9 \\
\hline 341 & 151.7 & 42.4 & 10.7 & 114.0 & 21.3 & 8.7 & 90.4 & 18.0 & 9.1 & 71.8 & 14.4 & 6.4 \\
\hline
\end{tabular}

number of production workers employed, $M$, and in the average number of hours paid-for per week per worker, $H P$, are presented for the years 1950, 1955, 1960, and 1964 for the seventeen three-digit United States manufacturing industries considered in this study. ${ }^{1}$ The output fluctuations in most cases are quite large, with output during the peak month being between 10.2 and 151.7 percent larger than during the trough month. The fluctuations in the number of workers employed and the number of hours paid-for per worker are in general much less, but still are reasonably large.

A major criticism of the above studies of short-run employment demand which are based on the concept of a short-run production function is that the use of seasonally adjusted data or seasonal dummy variables is in-

1 The data are discussed in ch. 4. As mentioned at the beginning of this chapter, for monthly data it is important to make explicit the time periods to which the variables refer. This will be done in ch. 4 . 
compatible with the production function concept. A production function is a technical relationship between certain physical inputs and a physical output and is not a relationship between seasonally adjusted inputs and a seasonally adjusted output. Unless one has reason to believe that the technical relationship itself fluctuates seasonally, and at least for manufacturing industries it is difficult to imagine very many instances where this is likely to be true, the use of seasonally adjusted data or seasonal dummy variables is unwarranted.

Likewise, when seasonally adjusted data or seasonal dummy variables are used, the lagged adjustment process (2.36) of the basic model must be interpreted as implying the lagged adjustment of the seasonally adjusted number of workers rather than the actual number of workers. Interpreted in this way, it implies that the adjustment coefficient $\lambda$ fluctuates seasonally. Here again there seems little reason to believe that $\lambda$ should fluctuate seasonally. It is possible to argue that the adjustment costs might be less in the spring and fall when a large number of students can be hired and then laid off, but in general the interpretation of (2.36) in seasonally adjusted terms seems theoretically less warranted than in seasonally unadjusted terms.

\subsubsection{Equation estimates of the basic model}

The proof of any model is how well it stands up under empirical tests. If the basic model above is to lead to any empirically meaningful results, seasonally unadjusted data must be used. In tables 2.3 and 2.4 the results of estimating two equations similar to eq. (2.37) of the basic model using seasonally unadjusted monthly data for the seventeen three-digit manufacturing industries considered in this study are presented. In both equations the $\log K_{t}$ variable in eq. (2.37) has been assumed to be absorbed in the time trend, as Ball and St Cyr have assumed, and in the second equation the lagged output variable, $\log Y_{t-1}$, has been added, as Bechling, Solow, Soligo, and Kuh have done under various expectational hypotheses. Also, the effects of the $\log H S_{t}$ variable have been assumed to be absorbed in the constant term and the time trend.

The data used to estimate the two equations are the basic data used to estimate the model developed in this study. The exact period of estimation used for each industry and the adjustments which have been made in the data are discussed in ch. 4 and the data appendix. In what follows, $M_{2 w t}$ denotes the number of production workers employed during the second week of month $t$ and $Y_{d t}$ denotes the average daily rate of output during month $t$. The following two equations were estimated: 
TABLE 2.3

Parameter estimates for eq. (2.37)

\begin{tabular}{|c|c|c|c|c|c|c|c|c|c|}
\hline Industry & $\begin{array}{c}\text { No. of } \\
\text { obs. }\end{array}$ & $a_{0}$ & $\hat{a}_{1}$ & $1000 a_{2}$ & $\hat{a}_{3}$ & $\mathbf{R}^{2}$ & $\mathrm{SE}$ & DW & $\begin{array}{c}\text { value of } \\
-a_{3} l a_{1}\end{array}$ \\
\hline 201 & 192 & $\begin{array}{r}.813 \\
(3.40)\end{array}$ & $\begin{array}{r}.032 \\
(1.94)\end{array}$ & $\begin{array}{l}-.062 \\
(1.45)\end{array}$ & $\begin{array}{l}-.131 \\
(3.83)\end{array}$ & .076 & .0194 & 1.03 & 4.09 \\
\hline 207 & 136 & $\begin{array}{r}.701 \\
(3.05)\end{array}$ & $\begin{array}{r}.226 \\
(13.34)\end{array}$ & $\begin{array}{l}-.847 \\
(8.92)\end{array}$ & $\begin{array}{l}-.333 \\
(7.64)\end{array}$ & .579 & .0299 & 1.36 & 1.47 \\
\hline 211 & 136 & $\begin{array}{l}-.109 \\
(0.55)\end{array}$ & $\begin{array}{r}.047 \\
(2.96)\end{array}$ & $\begin{array}{l}-.089 \\
(1.62)\end{array}$ & $\begin{array}{l}-.036 \\
(1.27)\end{array}$ & .084 & .0119 & 2.20 & 0.76 \\
\hline 212 & 136 & $\begin{array}{l}-.283 \\
(1.65)\end{array}$ & $\begin{array}{r}.097 \\
(6.17)\end{array}$ & $\begin{array}{l}-.420 \\
(3.52)\end{array}$ & $\begin{array}{l}-.058 \\
(2.20)\end{array}$ & .227 & .0188 & 2.57 & 0.60 \\
\hline 231 & 136 & $\begin{array}{r}.573 \\
(1.81)\end{array}$ & $\begin{array}{r}.118 \\
(6.15)\end{array}$ & $\begin{array}{l}-.221 \\
(2.97)\end{array}$ & $\begin{array}{l}-.196 \\
(4.13)\end{array}$ & .273 & .0245 & 2.00 & 1.66 \\
\hline 232 & 136 & $\begin{array}{r}.709 \\
(3.52)\end{array}$ & $\begin{array}{r}.057 \\
(4.72)\end{array}$ & $\begin{array}{l}-.105 \\
(2.18)\end{array}$ & $\begin{array}{l}-.137 \\
(4.87)\end{array}$ & .199 & .0132 & 1.43 & 2.40 \\
\hline 233 & 136 & $\begin{array}{r}.681 \\
(1.60)\end{array}$ & $\begin{array}{r}.163 \\
(6.24)\end{array}$ & $\begin{array}{l}-.271 \\
(2.89)\end{array}$ & $\begin{array}{l}-.220 \\
(4.15)\end{array}$ & .301 & .0348 & 1.32 & 1.35 \\
\hline 242 & 154 & $\begin{array}{r}.601 \\
(3.88)\end{array}$ & $\begin{array}{r}.210 \\
(14.16)\end{array}$ & $\begin{array}{l}-.797 \\
(9.35)\end{array}$ & $\begin{array}{r}-.245 \\
(10.96)\end{array}$ & .589 & .0171 & 0.98 & 1.17 \\
\hline 271 & 166 & $\begin{array}{r}.782 \\
(3.95)\end{array}$ & $\begin{array}{r}.043 \\
(7,43)\end{array}$ & $\begin{array}{r}.068 \\
(2.21)\end{array}$ & $\begin{array}{l}-.147 \\
(5.29)\end{array}$ & .312 & .0059 & 2.02 & 3.42 \\
\hline 301 & 134 & $\begin{array}{r}.187 \\
(1.12)\end{array}$ & $\begin{array}{r}.057 \\
(4.62)\end{array}$ & $\begin{array}{l}-.307 \\
(4.71)\end{array}$ & $\begin{array}{l}-.073 \\
(3.11)\end{array}$ & .173 & .0152 & 1.86 & 1.28 \\
\hline 311 & 170 & $\begin{array}{r}.196 \\
(1.33)\end{array}$ & $\begin{array}{r}.094 \\
(4.80)\end{array}$ & $\begin{array}{l}-.349 \\
(4.07)\end{array}$ & $\begin{array}{l}-.138 \\
(4.73)\end{array}$ & .146 & .0136 & 1.62 & 1.47 \\
\hline 314 & 136 & $\begin{array}{r}3.129 \\
(7.13)\end{array}$ & $\begin{array}{r}.178 \\
(7.28)\end{array}$ & $\begin{array}{l}-.407 \\
(6.67)\end{array}$ & $\begin{array}{l}-.560 \\
(8.30)\end{array}$ & .383 & .0190 & 1.30 & 3.15 \\
\hline 324 & 187 & $\begin{array}{r}.773 \\
(5.03)\end{array}$ & $\begin{array}{r}.096 \\
(9.82)\end{array}$ & $\begin{array}{l}-.379 \\
(8.43)\end{array}$ & $\begin{array}{l}-.234 \\
(8.07)\end{array}$ & .383 & .0228 & 1.27 & 2.44 \\
\hline 331 & 128 & $\begin{array}{r}1.493 \\
(12.87)\end{array}$ & $\begin{array}{r}.173 \\
(20.08)\end{array}$ & $\begin{array}{c}-.484 \\
(15.14)\end{array}$ & $\begin{array}{r}-.307 \\
(17.39)\end{array}$ & .772 & .0103 & 1.53 & 1.77 \\
\hline 332 & 170 & $\begin{array}{r}.424 \\
(4.05)\end{array}$ & $\begin{array}{r}.131 \\
(9.84)\end{array}$ & $\begin{array}{l}-.203 \\
(5.55)\end{array}$ & $\begin{array}{l}-.174 \\
(8.52)\end{array}$ & .382 & .0175 & 1.99 & 1.33 \\
\hline 336 & 170 & $\begin{array}{r}.006 \\
(0.05)\end{array}$ & $\begin{array}{r}.081 \\
(4.74)\end{array}$ & $\begin{array}{l}-.173 \\
(3.33)\end{array}$ & $\begin{array}{l}-.085 \\
(3.90)\end{array}$ & .126 & .0240 & 1.19 & 1.05 \\
\hline 341 & 191 & $\begin{array}{c}1.698 \\
(8.71)\end{array}$ & $\begin{array}{r}.121 \\
(10.65)\end{array}$ & $\begin{array}{l}-.088 \\
(2.14)\end{array}$ & $\begin{array}{c}-.402 \\
(10.59)\end{array}$ & .425 & .0282 & 0.77 & 3.32 \\
\hline
\end{tabular}

t-statistics are in parentheses.

a Implied value of the production function parameter $a$. 
TABLE 2.4

Parameter estimates for eq. (2.37)"

No. of

Industry obs. $\quad \hat{a}_{0} \quad \hat{a}_{1} \quad 1000 \hat{a}_{2} \quad \hat{a}_{3} \quad \hat{a}_{4} \quad \mathrm{R}^{2} \quad \mathrm{SE} \quad \mathrm{DW}-\hat{a}_{3} /\left(\hat{a}_{1}+a_{4}\right)$

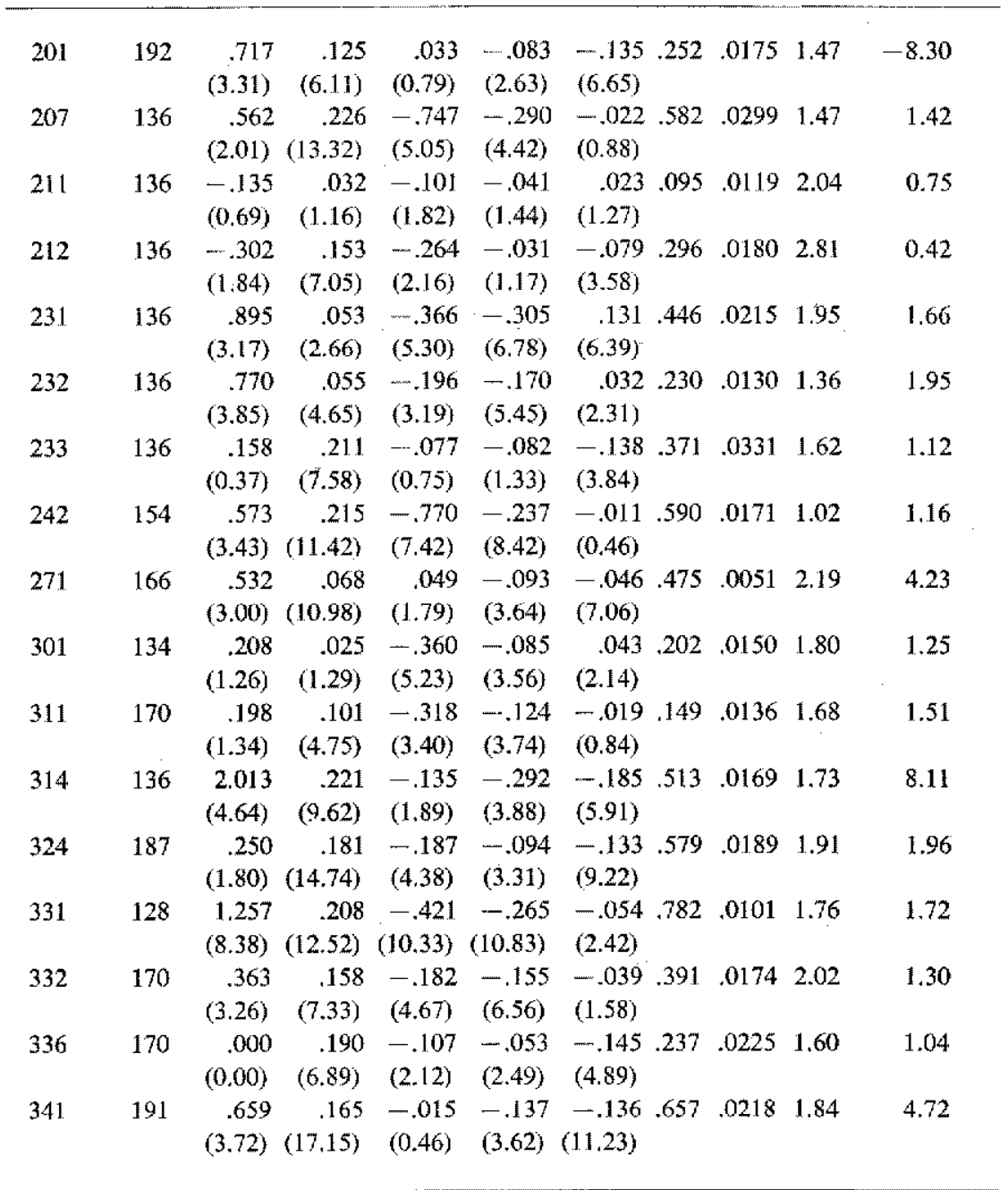

t-statistics are in parentheses.

a Implied value of the production function parameter $a$. 


$$
\begin{aligned}
\log M_{2 w t}-\log M_{2 w t-1}= & a_{0}+a_{1} \log Y_{d t}+a_{2} t+a_{3} \log M_{2 w t-1} \\
\log M_{2 w t}-\log M_{2 w t-1}= & a_{0}+a_{1} \log Y_{d t}+a_{2} t+a_{3} \log M_{2 w t-1} \\
& +a_{4} \log Y_{d t-1} .
\end{aligned}
$$

For eq. (2.37) , which does not include the $\log Y_{d t-1}$ variable, the implied value of the production function parameter $\alpha$ is $-a_{3} / a_{1}$, as can be seen from eq. (2.37). (The effects of omitting the $\log K_{t}$ variable in eq. (2.37) are merely reflected in the coefficient of the time trend if $K_{t}$ is growing smoothly through time, as Ball and St Cyr assume.) For eq. $(2.37)^{\prime \prime}$, which includes the $\log Y_{a t-1}$ variable, the steady state solution can be derived (by setting $M_{2 w t}=M_{2 w t-1}=\bar{M}$ and $Y_{d t}=Y_{d t-1}=\bar{Y}$ ), giving $\log \bar{M}$ as a function of a constant, $\log \bar{Y}$, and $t$, and the resulting coefficient of $\log \bar{Y}$ can then be taken to be $1 / \alpha$. This coefficient of $\log \bar{Y}$ is $-\left(a_{1}+a_{4}\right) / a_{3}$, so the implied value of $\alpha$ in eq. $(2.37)^{\prime \prime}$ is $-a_{3} /\left(a_{1}+a_{4}\right)$. In table 2.3 the results of estimating eq. $(2.37)^{\prime}$ are given, along with the implied estimate of $\alpha,-\hat{a}_{3} / \hat{a}_{1}$, and in table 2.4 the results of estimating eq. (2.37)" are given, along with the implied estimate of $\alpha, \hat{a}_{3} /\left(\hat{a}_{1}+\hat{a}_{4}\right)$.

In all but five of the thirty-four cases the implied value of $\alpha$ turns out to be greater than one, and in one of the remaining five cases it is negative. In nine of the thirty-four cases $\alpha$ is greater than two, and in seven of these cases it is greater than three. The results clearly do not appear to be consistent with the interpretation of $\alpha$ as the elasticity of output with respect to labor services.

Under the Ireland and Smyth interpretation, the implied value of $\alpha$ should be interpreted not as measuring returns to labor services alone but as measuring short-run returns to scale (capital services being expanded and contracted along with labor services in the short run). Even under this interpretation, however, one would expect that $\alpha$ (or $\eta$ in the Ireland and Smyth notation) should be equal to or slightly less than one, since during high rates of output, less (or at least not more) efficient capital is likely to be utilized and the additional workers hired are likely to be less (or at least not more) efficient. One would certainly not expect $\eta$ to be considerably greater than one, as is the case for most of the estimates presented in tables 2.3 and 2.4. The model, even under this alternative interpretation of $\alpha$, appears to be incorrectly specified.

In addition to the unrealistically large values of $\alpha$, the estimate of the constant term turns out to be negative as expected in only four of the thirty-four cases.

The Durbin-Watson statistics given in the tables are biased towards two 
because of the existence of a lagged dependent variable among the set of regressors in each equation. ${ }^{1}$ Even without considering this bias, however, the DW statistics presented in the tables reveal the existence of first-order serial correlation in about half of the thirty-four equations estimated. The existence of serial correlation appears to be less pronounced in the equations which include the $\log Y_{t-1}$ variable, but the problem still remains for at least five of the industries. In general, the DW statistics cast some doubt on the specification of the model.

Although seasonally unadjusted (monthly) data have been used to estimate the above equations, as this seemed to be the theoretically preferred procedure, in the previous studies, where seasonally adjusted (quarterly) data or seasonally unadjusted (quarterly) data and seasonal dummy variables have been used, the results in most cases also show strongly increasing returns to labor services (or, on the Ireland and Smyth interpretation, strongly increasing short-run returns to scale). The results presented in tables 2.3 and 2.4 are not unique to the type of data used.

\subsection{Description of other studies of employment fluctuations}

\subsubsection{The Neild model}

Neild's approach (NEJLD, 1963) is highly empirical in nature, his main concern being with forecasting. His basic postulate is that employment depends on a productivity trend and on "past and present levels of output". 2 He estimates two basic equations: ${ }^{3}$

$$
\begin{aligned}
\log M_{t}-\log M_{t-1} & =\alpha_{0}+\alpha_{1}\left(\log Y_{t}-\log Y_{t-1}\right) \\
& +\alpha_{2}\left(\log Y_{t-1}-\log Y_{t-2}\right) \\
& +\alpha_{3}\left(\log Y_{t-2}-\log Y_{t-3}\right),
\end{aligned}
$$

and

$$
\begin{aligned}
\log M_{t}-\log M_{t-1} & =\alpha_{0}+\alpha_{1}\left(\log Y_{t}-\log Y_{t-1}\right) \\
& +\alpha_{2}\left(\log Y_{t-1}-\log Y_{t-2}\right) \\
& +\beta_{1}\left(\log M_{t-1}-\log M_{t-2}\right)
\end{aligned}
$$

\footnotetext{
${ }^{1}$ See Nerlove and Wallis (1966).

2 NeILd (1963, p. 56).

${ }^{3}$ Neild estimates the same equations for both workers, $M_{t}$, and total man hours, $M_{t} H_{t}$.

The equations presented in this summary are for $M_{t}$ only.
} 
Eq. (2.39), which includes the lagged dependent variable on the right-hand side, implies that the number of workers employed is a geometrically declining function of all past levels of output after the second period, while eq. (2.38) implies that the number employed is a function of only the present and the past two levels of output.

\subsubsection{The Wilson and Eckstein model}

Description of the model. The Wilson and Eckstein model (WILson and ECKSTEIN, 1964) is considerably different from the basic model presented above. Wilson and Eckstein begin by postulating a long-run production function

$$
C_{t}=\frac{1}{\alpha}\left(M_{\mathrm{t}} H_{t}\right)_{p}
$$

which, when solved for $\left(M_{\mathrm{t}} H_{t}\right)_{p}$, they call the "long-run labor requirements function":

$$
\left(M_{t} H_{t}\right)_{p}=\alpha C_{t}
$$

$C_{t}$ is capacity output, and $\left(M_{t} H_{t}\right)_{p}$ is the number of man hours required to produce the capacity output.

In the short run the plant is fixed, and Wilson and Eckstein assume that the "plant man-hour requirements function" can be approximated by a straight line which intersects the long-run function from above at capacity output:

$$
\left(M_{t} H_{t}\right)_{e}=\alpha C_{t}+\beta\left(Y_{t}^{e}-C_{t}\right) .
$$

$Y_{t}^{e}$ is the output which is planned at the beginning of period $t$ to be produced during period $t$, and $\left(M_{\mathrm{r}} H_{t}\right)_{e}$ is the number of man hours required to produce the planned output. $\beta$ is assumed to be less than $\alpha$.

Wilson and Eckstein then define a "short-run maladjustment man-hour requirements function", which intersects the plant function from above at planned output:

$$
M_{t} H_{t}=\alpha C_{t}+\beta\left(Y_{t}^{e}-C_{t}\right)+\gamma\left(Y_{t}-Y_{t}^{e}\right) .
$$

$Y_{t}$ is the actual output produced during period $t$, and $M_{t} H_{t}$ is the actual number of man hours required to produce $Y_{t} . \gamma$ is assumed to be less than $\beta$. The relationships among the three man-hour requirements functions can be seen graphically in figure 2.2 . 


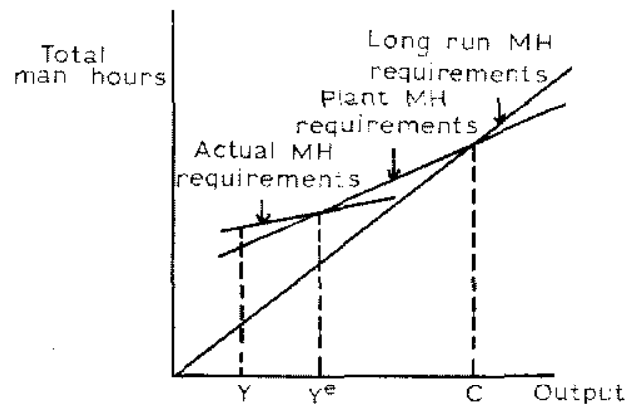

Fig. 2.2. Wilson and Eckstein's man-hour requirements functions.

Wilson and Eckstein include technical change in their model by assuming that

$$
\begin{aligned}
& \alpha=\alpha_{0}+\alpha_{1} t \\
& \beta=\beta_{0}+\beta_{1} t, \\
& \gamma=\gamma_{0}+\gamma_{1} t .
\end{aligned}
$$

They also assume that

$$
Y_{t}^{e}=\frac{S_{t}}{6}\left(3 Y_{t-1}^{*}+2 Y_{t-2}^{*}+Y_{t-3}^{*}\right)
$$

where $Y_{t-i}^{*}$ is seasonally adjusted output for period $t-i$ and $S_{t}$ is the seasonal factor for period $t$. They use seasonally unadjusted data and seasonal dummy variables in the estimation of eq. (2.43) and estimate the equation separately for production worker straight time hours and production worker overtime hours. They also estimate a modified version of eq. (2.43) for non-production workers.

Critique of the model. Wilson and Eckstein have three concepts of output capacity output, $C_{t}$, planned output, $Y_{t}^{e}$, and actual output, $Y_{t}$. Man-hour requirements differ to the extent that planned output differs from capacity output and to the extent that actual output differs from planned output. As can be seen from figure 2.2, the model has the rather odd implication that if actual output is greater than planned output, actual man-hour requirements per unit of output are less than plant man-hour requirements per unit of output. It also has the implication that if actual output is greater than capacity output (which they state can happen ${ }^{1}$ ), actual man-hour

1 Wilson and ECKSTEIN (1964, p. 42). 
requirements per unit of output are less than long-run man-hour requirements per unit of output. Wilson and Eckstein argue that by sacrificing maintenance work and using machinery more intensively actual man-hour requirements per unit of output may be less at high levels of output than plant or long-run man-hour requirements per unit of output. ${ }^{t}$ Even if this is true, however, it does not seem likely that the effects on man-hour requirements should be symmetrical for positive and negative deviations of planned output from capacity output or of actual output from planned output, as is implied in figure 2.2. It is also open to question whether actual man-hour requirements per unit of output really are less than long-run man-hour requirements per unit of output at output greater than capacity, especially if less efficient machines are brought into use at high levels of output.

Wilson and Eckstein estimate eq. (2.43) first for production worker standard hours, which are defined to be $37.5 M_{t}$, and then for production worker overtime hours, which are defined to be $M_{t}\left(H_{t}-37.5\right)$. This procedure appears to be inconsistent with their overall model. Eq. (2.43) is interpreted as a man-hour requirements function, and if $M_{t} H_{t}$ number of man hours are required to produce the output, $Y_{t}$, then the relevant dependent variable is $M_{t} H_{t}$ and not some fraction of it.

Actually, eq. (2.41) of their model might be better interpreted as expressing desired man hours as a function of capacity output, with eqs. (2.42) and (2.43) showing how, due to adjustment lags in the short run, desired man hours deviate from actual man hours used. Eq. (2.43) could perhaps then be interpreted as a reduced form equation of some more complicated employment demand equation, the reduced form equation being a combination of a man-hour requirements function and a lagged adjustment process. The theoretical underpinnings of the Wilson and Eckstein model do not appear to be well developed.

\subsubsection{The Hultgren, Raines, and Masters studies}

As mentioned in ch. 1, an alternative approach to the study of short-run fluctuations in output and employment is to examine output per worker (or per man hour) directly in an attempt to discover how it fluctuates with respect to short-run fluctuations in output. HULTGREN (1960, 1965), RaINES (1963), and MASTERs (1967) have used this approach, and although this is not the basic approach used in this study, these studies will be briefly summarized.

1 WILSON and ECKSTEIN (1964, p. 42). 
After seasonally adjusting the data, Hultaren (1960) examines how output per man hour fluctuates during contractions (falling output) and during expansions (rising output). He finds that output per man hour increases during expansions, although there is some evidence that near the end of the expansions this phenomenon is less widespread, and that output per man hour decreases during contractions, although again there is some evidence that this phenomenon is less widespread near the end of the contractions. In another study, using different data, Hultgren arrives at a similar conclusion. ${ }^{1}$

In the Raines model (RAINES, 1963) output per man hour is taken to be a function of capacity utilization (both the level and the change), the amount and quality of the capital stock, and time. Raines estimates the following equation:

$$
\begin{aligned}
\log \left(Y_{t} / M_{t} H_{t}\right) & =\alpha_{1} t+\alpha_{2}\left(Y_{t} / C_{t}\right)-\alpha_{3}\left(Y_{t} / C_{t}\right)^{2} \\
& +\alpha_{4} \Delta\left(Y_{t} / C_{t}\right)_{+}+\alpha_{5} \Delta\left(Y_{t} / C_{t}\right)_{-} \\
& +\alpha_{6} \Delta\left(Y_{t} / C_{t}\right)_{t-1}-\alpha_{7} A_{t} .
\end{aligned}
$$

$Y_{t} / C_{t}$ is the capacity utilization in period $t$, and $A_{t}$ is the average age of the capital stock. The notation $\Delta\left(Y_{t} / C_{t}\right)_{+}$means that when $\Delta\left(Y_{t} / C_{t}\right)$ is positive, $\Delta\left(Y_{t} / C_{t}\right)_{+}$is set equal to this value, and when it is negative, $\Delta\left(Y_{t} / C_{t}\right)_{+}$is set equal to zero; and conversely for $\Delta\left(Y_{t} / C_{t}\right)_{-}$.

Raines finds that output per man hour is positively related to the level of capacity utilization and also to the change in capacity utilization. The coefficient estimate of $\alpha_{4}$ is larger than the estimate of $\alpha_{5},{ }^{2}$ which implies that output per man hour is more positively related to positive changes in capacity utilization than it is negatively related to negative changes in capacity utilization.

MASTERS (1967), using seasonally adjusted data, examines how output per worker behaves during contractions. For the years 1947-1961 he finds 64 contractions occurring in 24 three- and four-digit industries. For each of these 64 cases he computes the change in output and the change in output per worker, using as end points the peak and the trough of the output series. Using these 64 observations, he regresses the change in output per worker on the change in output and a constant, and finds that the change in output per worker is positively related to the change in output, i.e., that output per worker decreases during contractions.

1 Hultgren (1965, pp. 39-42).

2 Raines (1963, Table I, p. 187). 


\subsection{Summary}

This completes the survey of previous studies of employment demand and output per man-hour fluctuations. The approach of many of the studies has been to postulate a short-run production function and a lagged adjustment process and from these two equations to derive an equation in which the production function parameter and adjustment coefficient can be estimated. Previous results using seasonally adjusted quarterly data and the results achieved in this chapter using seasonally unadjusted monthly data have indicated that there are strongly increasing returns to labor alone or, on the Ireland and Smyth interpretation, strongly increasing short-run returns to scale. These results are inconsistent with the assumptions of classical economic theory and in general cast doubt on the specification of the model. Previous studies which have examined output per man-hour fluctuations directly have found that output per man hour varies directly with output in the short run, which also seems to be inconsistent with what would be expected from the assumptions of classical economic theory.

In the next chapter an alternative model of the short-run demand for workers is developed. The model provides an explanation of the observed phenomenon of increasing returns to labor services and will be seen in ch. 4 to yield substantially better results than those presented in tables 2.3 and 2.4 for the basic model of previous studies. 


\section{A THEORETICAL MODEL OF THE SHORT-RUN DEMAND FOR PRODUCTION WORKERS}

\subsection{Introduction}

A necessary requirement of any theoretical model is that it explain to a reasonable degree of approximation empirical phenomena which are observed. One fact which has been observed so far is that the basic model introduced in ch. 2 leads to unrealistically large estimates of the production function parameter $\alpha$, even under the Ireland and Smyth interpretation of $\alpha$ as a measure of short-run returns to scale. For this reason and for the others which were discussed in ch. 2, the basic model appears to be incorrectly specified.

One limitation of the previous studies of short-run employment demand is that the relationship between the number of workers employed and the number of hours worked per worker does not appear to have been carefully examined. It was seen in ch. 2 that some of the previous models are in fact inconsistent because no assumption about firms' cost-minimizing behavior with respect to the workers-hours mix was made. On the empirical side, Kuh has been the only one who has done any work at all on explaining short-run fluctuations in the number of hours worked per worker.

In this chapter some empirical evidence on short-run fluctuations in output per man hour is presented which indicates that output per man hour and output are positively correlated even at high rates of output. An explanation is then provided of why this phenomenon of increasing returns to labor is so often observed. The explanation is based on the idea that during much of the year firms hold too much labor for the amount of output produced and that during these times the observed number of hours paidfor per worker is greater than the unobserved number of hours actually worked per worker. If this is true, then the properties of the short-run production function cannot be estimated (because the true production function inputs are not observed), and in this study various properties of the short-run production function have been postulated as opposed to being estimated. After the concept of excess labor is discussed and the postulates made about the properties of the short-run production function 
are introduced, measurements of the amount of excess labor on hand are made for the 1947-1965 period for the seventeen industries considered in this study. The measurements are based on the assumptions made about the properties of the short-run production function.

A theoretical model of the short-run demand for workers is then developed. Basically the short-run demand for workers is taken to be a function of the amount of excess labor on hand and the time stream of expected future output changes. The distinctions among the number of workers employed, the number of hours worked per worker, and the number of hours paidfor per worker are central to the entire analysis, and the model developed in this chapter opens the way to the development of a model of the shortrun demand for hours paid-for per worker in ch. 7. The chapter concludes with a discussion of the expectational hypotheses which were tested in this study.

\subsection{Some empirical evidence on short-run fluctuations in output per man hour}

From table 2.2 in ch. 2 it can be seen that for most industries and years the percentage change from the trough month to the peak month of the year in output is substantially greater than the percentage change in total man hours. The number of man hours appears to fluctuate much less in the short run than does the amount of output produced. Since this is true and

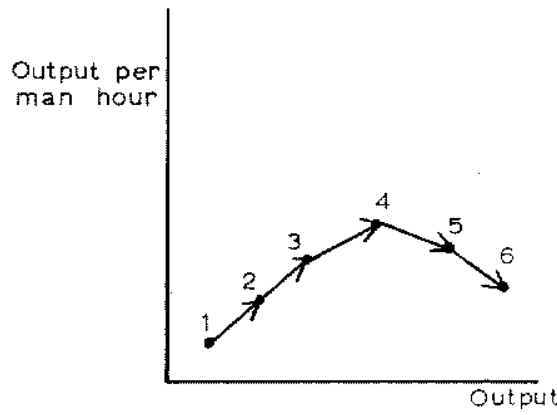

Fig. 3.I. Expected relationship between output per man hour and output for any one year.

since it is also true that the phases of the man-hours series and the output series are approximately the same, it is not too surprising that output per man hour is positively correlated with output and that estimates of increasing returns to labor services are obtained. 
If there is a production function which is at all observable in the short run, however, one should expect the properties of the function at least to become observable as output approaches peak rates of the year, since it is likely that there will be less slack at these high rates and thus that the production function constraint will be binding. Thus for any one year, where the stock of capital and the level of technical progress can be assumed to be fairly constant, one might expect to observe diminishing returns (or at least not

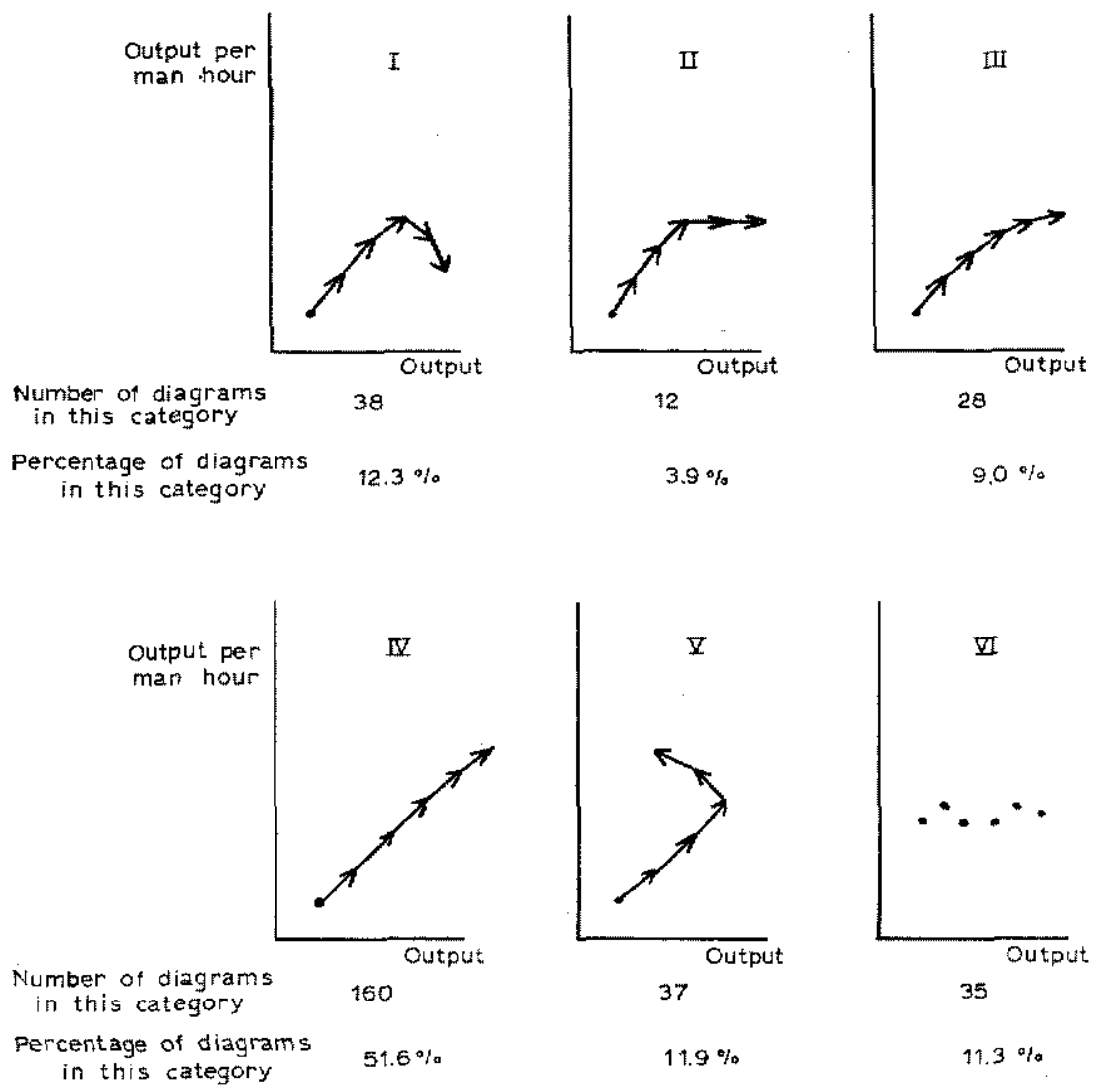

Fig. 3.2. Observed relationship between output per man hour and output for each year for each of the seventeen industries.

strongly increasing returns) to labor services at high rates of output. One thus might expect the relationship between output per man hour and output for any one year to look like that depicted in figure 3.1, provided perhaps that the year were not a recession year where even the rate of output in the 
peak month was low compared with past standards. ${ }^{1}$ In figure 3.1 output moves from its trough in month one to its peak in month six. From month one to month four slack is being taken up as output rises, and after month four the true properties of the short-run production function are being observed.

These scatter diagrams were computed for each of the seventeen industries listed in table 2.2 for each of the years ${ }^{2} 1947-1965$. There were a total of 310 diagrams computed. Six basic types of diagrams resulted from this exercise, and they are depicted in figure 3.2. The arrows in these diagrams point in the direction of calendar time movements. If diminishing or constant returns to labor services are observed in the short run at high rates of output, then the scatter diagrams should look like those depicted in figures $3.2 \mathrm{i}$, ii, and perhaps $v$. The number and percentage of diagrams which fell into each of the six categories are presented in figure 3.2.

Slightly over half of the diagrams (figure 3.2iv) showed no evidence that the growth in output per man hour even slowed down at high rates of output, let alone become negative. About twelve percent of the diagrams (figure 3.2i) showed a definite decline in output per man hour at high rates of output, and about twenty-five percent of the diagrams showed either a decline in output per man hour, a leveling off in output per man hour, or a slowing down in the growth rate of output per man hour (figures $3.2 \mathrm{i}$, ii, and iii). Eleven percent of the diagrams (figure 3.2vi) showed a less clear-cut scatter, but perhaps can be interpreted as showing that the same output per man-hour ceiling was reached more than once during the year at different rates of output. The twelve percent of the diagrams depicted by figure $3.2 \mathrm{v}$ are also difficult to interpret since the time movements are odd, ${ }^{3}$ but perhaps these diagrams can be interpreted as showing decreasing returns at high rates of output.

The general conclusion of this exercise is that there is some evidence that the growth in output per man hour at least slows down at high rates of output, but that for over half of the observations this is not the case and for only twelve to twenty-four percent of the cases (figure $3.2 \mathrm{i}$ and perhaps figure

1 If in fact technical progress and the stock of capital are growing smoothly over time, this will bias the scatter against a downward bend. Short-run fluctuations in output per man hour dominate the longer-run movements, however, and this bias is likely to be quite small.

${ }^{2}$ A year being defined in this case as the (approximate) twelve-month period between troughs.

3 See the discussion in footnote 1 on page 45 for a further elaboration of this point. 
$3.2 \mathrm{v})$ does output per man hour actually appear to decline. This seems to be rather conclusive evidence that a production function with the usual constant or diminishing returns property is only infrequently observed in the short run, even at high rates of output.

\subsection{The notation}

It was mentioned at the beginning of ch. 2 that for studies of short-run behavior it is important to make explicit the time periods to which the variables refer. For a monthly study such as this one, this can be quite important, and the theoretical model developed in this study is designed to be as consistent as possible with the available data. The Bureau of Labor Statistics data on the number of workers employed and the number of hours paid-for per worker, which are used in this study, are compiled from surveys

TABLE 3.1

Notation used in ch. 3

$Y_{2 \text { wit }}$ the amount of output produced during the second week of month $t$.

$M_{2 w t}$ the number of production workers employed during the second week of month $t$.

$M^{*}$ 2ut the number of production workers actually used during the second week of month $t$ to produce $Y_{\mathrm{z} u t}$.

$H_{2 w t}$ the average number of hours worked per employed worker $\left(M_{2 w t}\right)$ during the second week of month $t$.

$H^{*}{ }_{2 w t}$ the average number of hours worked per non-idle worker $\left(M^{*}{ }_{2 w t}\right)$ during the second week of month $t$.

$K_{2 w t}$ the number of machines on hand during the second week of month $t$.

$K^{*}{ }_{2 x t}$ the number of machines actually used during the second week of month $t$ to produce $Y_{2}$ w.

$H^{K_{2 u t}}$ the average number of hours each machine on hand $\left(K_{2 u k}\right)$ was used during the second week of month $t$.

$H^{*} \mathrm{~K}_{2 w t}$ the average number of hours each non-idle machine $\left(K^{*}{ }_{2 w k}\right)$ was used during the second week of month $t$.

$T_{2 u t}$ the level of technical knowledge during the second week of month $t$.

$H P_{2 w t}$ the average number of hours paid-for per employed worker during the second week of month $t$.

$H S_{2 w t}$ the standard number of hours of work per employed worker during the second week of month $t$.

$Y e_{2 u t+1}$ the amount of output expected to be produced during the second week of month $t+i(i=0,1,2 \ldots)$, the expectation being made during the second week of month $t-1$. 
taken during the week which include the twelfth of the month, or approximately during the second week of each month. The second week of the month was thus taken to be the basic period considered in this study, and the variables which are considered below reflect this fact.

The symbols for the variables which are considered in this chapter, and which are to some extent considered throughout the rest of the text, are presented in table 3.1. The variables will be discussed as they are introduced below. With respect to the notation in table 3.1, for symmetry purposes the number of hours worked per employed worker should be denoted as $H_{2 w t}^{M}$ instead of as $\mathrm{H}_{2 w r}$, but in order to simplify the notation slightly and to keep it reasonably consistent with that in ch. 2, the " $M$ " was dropped from $\mathrm{H}_{2 w t}^{M}$. For similar reasons the "M" was also dropped from $H_{2 w t}^{* M}$, $H P_{2 w t}^{M}$, and $H S_{2 w i}^{M}$.

One further comment regarding the variables listed in table 3.1. Except for $M_{2 w t}$ and $H P_{2 w t}$, data on the variables listed in the table are not directly available. For the empirical work, therefore, either some empirical approximation has to be found for each of the variables or assumptions have to be made so that data on the variables are not needed. It will be seen in ch. 4, for example, that while data on $Y_{2 w_{t}}$ are not available, data on the average daily rate of output for the month, denoted as $Y_{d t}$, are available, and that with a few modifications of the theoretical model $Y_{d t}$ can be used in place of $Y_{2 w r}$ in the empirical work. For the most part in this chapter reference will be made to the variables listed in table 3.1, with discussion of the data problems being postponed until ch. 4 .

\subsection{The concept of excess labor}

A theoretical model of the short-run demand for employment should provide an explanation of why increasing returns to labor are so often observed, even it appears at high rates of output. It is a major contention of this study that during much of the year firms hold too much labor for the amount of output produced, and that the observed number of hours paid-for per worker is a poor proxy for the number of hours actually worked per worker except during peak output periods. Let $H P_{2 w t}$ denote the number of hours paid-for per employed worker during the second week of month $t$, and let $H_{2 w t}$ denote the number of hours actually worked per employed worker during the second week of month $t$. When $H P_{2 w t}$ is greater than $H_{2 w t}$, a firm can be considered to be holding too much labor in the sense that it is paying workers for more hours than they are actually working. On the other 
hand, during peak output periods when $H P_{2 w t}$ and $H_{2 w t}$ are likely to be equal to one another and overtime is being worked, a firm can be considered to be holding too little labor in the sense that if output were to remain at peak rates, more workers would probably be hired and fewer hours worked per worker in order to decrease high overtime costs. A measure of "excess labor on hand" should incompass both of these situations and should be positive when $H P_{2 w t}$ is greater than $H_{2 w t}$ and negative when $H P_{2 w t}$ is equal to $H_{2 w t}$ and overtime is being worked.

Let $H S_{2 w t}$ denote the standard (as opposed to overtime) number of hours of work per worker during the second week of month $t$. As was mentioned in $\S 2.3, H S$ may be subject to long-run trend influences and this is the reason for the time subscript. Generally, $H S_{2 w t}$ should be around 40 hours a week for most industries. Since $H S_{2 w t}$ is the dividing line between standard hours and more costly overtime hours, it can be considered to be the number of hours a firm would like each of its workers to work in the long run if there were no problems with fluctuating rates of output. In other words, $H S_{2 w t}$ can be considered to be the long-run equilibrium number of hours worked per worker. Using this concept, the measure of excess labor on hand during the second week of month $t$ is taken to be $\log H S_{2 w t}-\log H_{2 w r}$, which is the difference between the long-run desired number of hours worked per worker and the actual number of hours worked per worker during the second week of month $t .{ }^{1}$ If $H S_{2 w t}$ is greater than $H_{2 w t}$, there is considered to be a positive amount of excess labor on hand, and if $H S_{2 w t}$ is less than $H_{2 w t}$, there is considered to be a negative amount of excess labor on hand (i.e., too few workers on hand).

If in fact firms hold positive amounts of excess labor during at least part of the year, this provides an explanation of why estimates of increasing returns to labor have so often been obtained. The properties of the shortrun production function are not being estimated because of the slack situation which exists during much of the year, and the estimates merely show that output fluctuates more in the short run than does the number of workers employed or the number of man hours paid-for.

There are a number of reasons why firms may knowingly hold positive amounts of excess labor during part of the year. Given the large short-run fluctuations in output which occur during the year, large fluctuations in the

1 The functional form chosen for the model is the log-linear form, but to ease matters of exposition and where no ambiguity is involved, the difference of the logs of two variables (e.g., $\log H S_{2 w t}-\log H_{2 w t}$ ) will be referred to merely as the difference of the variables. 
number of workers employed or in the number of hours paid-for per worker would be needed to keep $H P_{2 w t}$ always equal to $H_{2 w r}$. Soligo ${ }^{1}$ presents a comprehensive list of reasons why firms may be reluctant to allow large fluctuations in their work forces. The most important ones are: (1) Contractual commitments - such things as guaranteed annual wages, unemployment insurance compensation, severance pay, and seniority provisions where younger and perhaps more efficient workers must be laid off first. (2) Transactions costs - the size of the office space and the number of employees which must be used in the process of hiring and laying off workers will depend on the frequency and magnitude of lay-offs and rehirings. (3) Retraining costs and loss of acquired skills. (4) Morale and public relation factors - qualified workers may not be attracted to a firm which has a reputation of poor job security; large lay-offs may strain union-management relations and may affect the efficiency of the employees remaining on the job; and large lay-offs and rehirings may be harmful to its public image, which may be important to the firm. (5) Reorganization costs - large changes in the size of the work force may require considerable organizational changes, which may lower efficiency in the short run.

These reasons which Soligo lists pertain to fluctuations in the number of workers employed, but not necessarily to fluctuations in the number of hours paid-for per worker. Why do not firms allow larger fluctuations in the number of hours paid-for per worker corresponding to fluctuations in output? Here again firms may be reluctant to do this for some of the same reasons they are reluctant to allow large fluctuations in the number of workers employed, namely reasons (1) and (4) listed above. Workers may expect, for example, to be paid for a 40-hour work week, and firms may subject themselves to serious morale and public relation problems if they allowed this standard hourly work week to fluctuate very extensively.

It might be worthwhile at this point to discuss briefly how the concept of excess labor developed in this study relates to the concepts used in previous studies. The idea that firms may during any one period of time employ more workers than they actually need to produce the output of that period is, of course, not new. The lagged adjustment process (2.36) of the basic model, which is so widely used, implies that $M_{i}$, the number of workers employed, is not necessarily equal to $M_{t}^{d}$, the desired number of workers for the output $Y_{t}$. If $M_{t}$ is greater than $M_{t}^{d}$, then there are, in effect, too many workers employed for the current amount of output produced. Solow, for

1 SoLIGo (1966, pp. 174-175). 
example, uses the term "labor-hoarding" "as a catch-phrase to stand for all the frictions involved in meeting transitory variations in output with variations in employment".

What is not clear in much of the previous work is what happens to hours paid-for per worker during the phases of adjustment. If the labor input variable in the production function is taken to be man hours, then an $M_{t}$ greater than $M_{t}^{d}$ need not imply any "man hours paid-for hoarding" if the number of hours paid-for per worker is reduced sufficiently. In the previous studies this aspect of the short-run adjustment process has not been carefully examined.

Ball and St Cyr, working not within the context of a lagged adjustment model, but with the production function directly, do postulate that measured man hours $\left(M_{t} H_{t}\right)_{m}$ may differ from "productive man hours". ${ }^{2}$ Specifically, they postulated (2.17), which is repeated here:

$$
M_{t} H_{t}=\left(M_{t} H_{t}\right)_{m}\left(1-U_{t}\right)^{\mu} .
$$

$U_{t}$ is a measure of labor market tightness. Using (2.17), they estimated the parameters of a Cobb-Douglas production function directly, assuming no lagged adjustment process, but assuming that true labor services differ from measured labor services in the manner depicted by (2.17). As stated in $\S 2.2 .3$, Ball and St Cyr remain agnostic as to whether this model or the lagged adjustment model is more realistic. The postulate made in this study that the number of hours paid-for per worker does not necessarily equal the number of hours actually worked per worker is essentially the same as Ball and St Cyr's postulate that measured man hours may differ from productive man hours. Ball and St Cyr, however, did not follow up their idea beyond specifying (2.17) and attempting to estimate the parameters of their CobbDouglas production function directly.

Since the number of hours actually worked per worker, $H_{2 w \mathrm{f}}$, is not observed except during peak output periods, where it probably equals $H P_{2 w l}$, the amount of excess labor on hand, $\log H S_{2 w t}-\log H_{2 w t}$, cannot be computed directly, and some approximation to it must be found. In order for this to be done, however, more information is needed on the proporties of the short-run production function, and this is the subject of the next section.

1 Solow (1964, p. 8).

${ }^{2}$ See the discussion in $\$ 2.2 .3$. 


\subsection{The short-run production function}

Most of the studies discussed in ch. 2 postulated some kind of a short-run production function, the parameters of which were usually estimated by an equation similar to (2.37) of the basic model. A short-run production function is also postulated in the study, but it is assumed that the parameters of this function cannot be estimated in the usual fashion with the data which are available.

Notice from table 3.1 that a distinction is made between the number of workers employed during the second week of month $t, M_{2 w,}$, and the number of workers actually used in the production process during the second week of month $t, M_{2 w t}^{*}$. In other words, the possibility is allowed for that some workers may be completely idle during the period and contribute nothing toward the production of the period. The same possibility is allowed for with respect to the stock of capital: some machines may be completely idle during the period. It should also be noticed from the table that, by definition, $M_{2 w t} H_{2 w t}$ equals $M_{2 w t}^{*} H_{2 w t}^{*}$, since both of these variables equal the total number of man hours worked during the second week of month $t$. The difference between $H_{2 w t}$ and $H_{2 w t}^{*}$ is merely whether in computing the average number of hours worked per worker the average is taken over all of the employed workers or only over the non-idle workers. For similar reasons, $K_{2 w t} H_{2 w t}^{K}$ equals $K_{2 w i t}^{*} H_{2 w t}^{* K}$ in table 3.1.

The short-run production function is postulated to be:

$$
Y_{2 w t}=F\left(M_{2 w t}^{*} H_{2 w t}^{*}, K_{2 w t}^{*} H_{2 w t}^{* K}, T_{2 w t}\right)
$$

$Y_{2 w t}$ is the amount of output produced during the second week of month $t$, $M_{2 w t}^{*} H_{2 w t}^{*}$ is the number of production worker hours used during the second week of month $t$ to produce $Y_{2 w t}, K_{2 w t}^{*} H_{2 w t}^{* K}$ is the number of machine hours used, and $T_{2 w t}$ is the level of technical knowledge during the second week of month $t$.

$M_{2 w t}^{*}$ by itself denotes the number of production workers used in the production process during the second week of month $t$, and $H_{2 w t}^{*}$ by itself denotes the average number of hours worked per non-idle worker during the second week of month $t$. Likewise, $K_{2 w t}^{*}$ by itself denotes the number of machines used during the second week of month $t$, and $H_{2 w t}^{* K}$ by itself denotes the average number of hours each of these non-idle machines was utilized during the second week of month $t$. The total number of production worker hours is thus taken to be the labor services variable in the production 
function (3.1), and the total number of machine hours is taken to be the capital services variable.

Depending on the industry breakdown and the country, time series data are usually available on the number of workers employed. Time series estimates of the stock of capital are sometimes available as well, but data are seldom available on the utilization of the capital stock, especially for any kind of a detailed industry breakdown. For the United States, at least, rather detailed industry data are also available on the number of hours paid-for per production worker. For those studies described in ch. 2 which used an hours variable at all in their empirical work, the hours variable used was an hours paid-for variable. If the number of hours paid-for per worker is a poor estimate of the number of hours actually worked per worker, as is contended in this study, then good data on the number of hours worked per worker are not available; and since data on machine utilization are usually not available either, this means that the properties of the short-run production function (3.1) cannot be estimated using available data, even if the employment adjustment process can be correctly specified.

The approach taken in this study is to postulate certain properties about the short-run production function and to develop a theory of the short-run demand for workers using these postulates. Consequently, only indirect tests of the validity of these postulates will be available, which are the tests of how well the over-all model performs.

The first postulate relates to the short-run substitution possibilities between labor services and capital services. In the production function (3.1) the amount of labor services used, $M_{2 w t}^{*} H_{2 w t}^{*}$, can be changed either by changing the number of workers used, $M_{2 w t}^{*}$, or by changing the number of hours worked per worker, $H_{2 w r}^{*}$. In like manner, the amount of capital services used, $K_{2 w i}^{*} H_{2 w t}^{* K}$, can be changed either by changing the number of machines used, $K_{2 w t}^{*}$, or by changing the number of hours each machine is utilized, $H_{2 w t^{*}}^{*}$. Because of the different ways in which labor services and capital services can be changed, one must be careful when discussing substitution possibilities between capital services and labor services to specify exactly what he means. For example, increasing labor services by increasing the number of hours worked per worker and keeping the number of workers used constant need not require any additional machines used, since the existing machines can just be utilized more hours. Increasing labor services by increasing the number of workers used and keeping the number of hours worked per worker constant, however, is a different matter. Either the new workers hired work with the old workers on the same number of 
machines, or the new workers hired work on machines which have previously been idle.

It is postulated in this study that the short-run production process is of such a nature that a fixed number of workers is required per machine. If the worker-machine ratio is greater than this number, it is assumed that no additional output can be produced, and if the ratio is smaller than this number, it is assumed that no output can be produced at all. This assumption implies that when new workers are hired, they work on previously idle machines. ${ }^{1}$ Another implication of the assumption is that the average number of hours worked per non-idle worker, $H_{2 w i}^{*}$, and the average number of hours each non-idle machine is utilized, $H_{2 w t}^{* K}$, are the same. Machines, for example, cannot be run eight hours a day and have workers working on them only six hours a day.

The short-run production function is thus postulated to be (ignoring for the moment technical progress and the possibility of non-constant shortrun returns to scale):

$$
Y_{2 w t} / H_{2 w t}^{*}=\min \left\{\alpha M_{2 w t}^{*}, \beta K_{2 w t}^{*}\right\} \text {. }
$$

$Y_{2 w t} / H_{2 w t}^{*}$ in eq. (3.2) is the amount of output produced per hour by the non-idle workers and machines.

This postulate of no short-run "substitution possibilities" between workers and machines may not be an unreasonable approximation of reality, but no direct empirical evidence is given here to confirm it. The postulate would be difficult to verify directly without a detailed examination of each production process, an examination which has not been undertaken here. It will be seen later to what extent the model developed in this study depends on this postulate.

The second postulate made about the properties of the short-run production function relates to the degree of increasing or decreasing short-run returns to scale. In (3.2) it is implicitly assumed that there are constant returns to scale. If it is assumed that there are short-run returns to scale of

1 This last statement is not quite true if the possibility of second and third shift work is allowed for. If there is more than one shift, then new workers hired need not work on previously idle machines if they work on a second or third shift; the same machines can be used on all three shifts. For present purposes the distinction between first and second or third shift work can largely be ignored by considering any machine which is used on, say, two shifts as two different machines. The number of physically different machines used in the production process may thus be less than $K^{*} 2 u t$ above. 
size $\eta$ with respect to the number of workers and machines used, then (3.2) becomes

$$
Y_{2 w t} / H_{2 w t}^{*}=\min \left\{\alpha M_{2 w t}^{* \eta} \beta K_{2 w t}^{* \eta}\right\} .
$$

If $\eta$ is greater than one in (3.3), for example, then there are increasing returns to scale.

The way (3.3) is specified, there are constant returns to scale for changes in the number of hours worked per worker and machine, $H_{2 w t}^{*}$. If it is assumed that there are also short-run returns to scale (of size $v$ ) with respect to the number of hours worked per worker and machine, then (3.3) becomes

$$
Y_{2 w t} / H_{2 w t}^{* v}=\min \left\{\alpha M_{2 w t}^{* \eta}, \beta K_{2 w t}^{* \eta}\right\},
$$

or

$$
Y_{2 w t}=\min \left\{\alpha M_{2 w t}^{* \eta} H_{2 w t}^{* y}, \beta K_{2 w t}^{* \eta} H_{2 w t}^{* y}\right\} .
$$

$\eta$ and $v$ in eq. (3.5), of course, do not necessarily have to be equal.

It is possible that empirical evidence on the extent of increasing or decreasing short-run returns to scale can be gleaned from the scatter diagrams discussed in $\$ 3.2$. In these diagrams the variable actually plotted against output was not output per worked man hour but output per paid-for man hour. If it is assumed that there are no completely idle workers so that $M_{2 w t}^{*}$ equals $M_{2 w t}$ and $H_{2 w t}^{*}$ equals $H_{2 w t}$, and if it is assumed that there are constant short-run returns to scale both for changes in the number of workers employed and for changes in the number of hours worked per worker so that $\eta$ and $v$ are both equal to one in (3.5), then the scatter diagrams should look like the one depicted in figure 3.3.

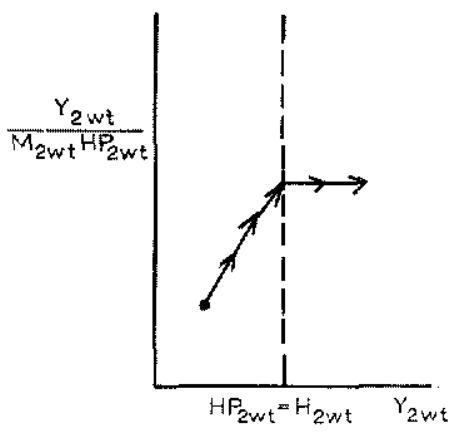

Fig. 3.3. Expected relationship between output per paid-for man hour and output on the assumption of constant returns to scale. 
Up to the point where the number of hours paid-for per worker, $H P_{2 w t}$, equals the number of hours actually worked per worker, $\mathrm{H}_{2 w t}$, one should observe an increasing output per paid-for man hour, $Y_{2 w t} / M_{2 w t} H P_{2 w t}$, as output increases, because, while the number of hours worked per worker needs to increase when output increases, the number of hours paid-for per worker needs to increase much less, if at all. At the point where the number of hours paid-for per worker equals the number of hours worked per worker the production function constraint becomes binding on the number of hours paid-for per worker, and the scatter beyond this point should reveal properties about the production function, such as the returns to scale property. ${ }^{1}$

If there are constant returns to scale, then beyond the point where the number of hours paid-for per worker equals the number of hours worked per worker the scatter should be on a horizontal line, as in figure 3.3. If there are increasing returns to scale so that $\eta$ and $v$ in (3.5) are greater than one, the scatter should lie on an upward sloping line, and if there are decreasing returns to scale so that $\eta$ and $v$ are less than one, the scatter should lie on a downward sloping line. If $\eta$ is less than one and $v$ is greater than one or vice versa, the scatter can, of course, lie either on a upward or downward sloping line depending on the size of $\eta$ and $v$ and on the size of the shortrun fluctuations in the number of workers employed and the number of hours worked per worker.

The results of the scatter diagrams were given in figure 3.2 and were discussed in $\S 3.2$ above. It is the author's general impression that there is not enough evidence from these results to determine which is the most realistic assumption about short-run returns to scale to make. The main reason for this is that it is difficult to know where the point where the number of hours paid-for per worker equals the number of hours worked per

1 One should at least expect this to be true for a continually increasing output. For a decrease in output, even from a high level, it is difficult to know whether the number of hours paid-for per worker decreases as much as the number of hours actually worked per worker during the period, or whether the number of hours paid-for per worker is adjusted downward with a lag. For a continually increasing output the problem is Jikely to be less serious, since at points beyond the point where the number of hours paid-for per worker equals the number of hours worked per worker, the number of hours paid-for per worker must increase at least as fast as the number of hours worked per worker and is probably not likely to increase much faster. This is the reason why attention was concentrated in $\$ 3.2$ on the points of the scatter diagrams where output was increasing and why diagrams like figure $3.2 \mathrm{v}$ were difficult to interpret. 
worker begins, and it may be that in many cases the point is reached only at the peak level of output for the year, so that no scatter is observed beyond this point. The results would tend to confirm the assumption of increasing short-run returns to scale if one had good reason for believing that scatter was actually observed beyond the point where the number of hours paid-for per worker equals the number of hours worked per worker, but since there is little evidence for believing this, the results are actually of little help.

The postulate made in this study is that both $\eta$ and $v$ in (3.5) are equal to one. In other words, it is assumed that the short-run production function is one of constant returns to scale, both with respect to changes in the number of workers and machines used and with respect to changes in the number of hours worked per worker and machine.

In eq. (3.5) it is implicitly assumed that all workers and all machines are of the same efficiency. In reality workers and machines are likely to differ in efficiency, and if workers are hired and machines utilized in order of their efficiency, this will have an effect similar to the existence of decreasing short-run returns to scale with respect to the number of workers and machines used (i.e., to $\eta$ being less than one). Likewise, if the efficiency of workers decreases the more hours they work per week (due to such things as fatigue, boredom, etc.), this will have an effect similar to the existence of decreasing short-run returns to scale with respect to the number of hours worked per worker and machine per week (i.e., to $v$ being less than one). It thus appears a priori that the assumption of $\eta$ and $v$ being less than one is more realistic than the assumption that they are equal to one or are greater than one. It was felt here, however, that it was better to make the assumption of constant returns to scale ( $\eta$ and $v$ both equal to one) than to arbitrarily specify a certain degree of decreasing returns to scale. It will be shown later to what extent the model developed in this study depends on this assumption.

The assumption that both $\eta$ and $v$ are equal to one implies that there is no difference in the effect on output whether labor services are changed by changing the number of workers used or by changing the number of hours worked per worker. If $M_{2 w r}^{*} H_{2 w t}^{*}$ is increased by, say, ten percent, then output will be increased by ten percent also, and it does not matter whether the ten percent increase in $M_{2 w t}^{*} H_{2 w t}^{*}$ comes from increasing $M_{2 w t}^{*}$ or $H_{2 w t}^{*}$ or some combination of the two.

Except for the possibility of the existence of technical progress, the shortrun production function is thus postulated to be as in eq. (3.2): no short-run substitution possibilities between workers and machines and constant short- 
run returns to scale both with respect to changes in the number of workers and machines used and with respect to changes in the number of hours worked per worker and machine per period. The assumption which is made about technical progress will be discussed in the next section.

\subsection{The measurement of excess labor}

Under the assumptions just made about the properties of the short-run production function, estimates of the amount excess labor on hand can be made. Estimates of the amount of excess labor on hand for each of the seventeen industries considered in this study were made in the following manner. For each of the industries, output per paid-for man hour, $Y_{2 w t} /$ $M_{2 w r} H P_{2 w t}$, was plotted monthly for the $1947-1965$ period. ${ }^{1}$ These points were then interpolated from peak to the next higher peak and so on for the nineteen-year period. The peaks in this output per paid-for man-hour series occurred at the corresponding peaks in the output series in most cases, as is implied by the results of the scatter diagrams above. Many yearly peaks were lower than the peaks of the previous years, and these were not used in the interpolations. For the beginning of each period the interpolation line was taken to be a horizontal line from the first month to the first peak, and for the end of each period the interpolation line was taken to be a horizontal line from the last peak to the last month.

The "cyclical" movements in output per paid-for man hour were quite noticeable for most industries, corresponding roughly to the cyclical movements in output. The long-run trend in output per paid-for man hour was upward for nearly all industries. The procedure of going from peak to next higher peak was not strictly adhered to in every case. For a small fraction of the cases a particular peak seemed to be high relative to both past and future values, and these peaks were not used as interpolation peaks. In other words, an effort was made to smooth out the interpolation lines as much as seemed warranted by the nature of the plots, and a few peaks were rejected as aberrations in the basic data. The over-all procedure of choosing the peaks is, of course, a highly subjective one, although in most cases the choices were fairly

\footnotetext{
1 All data were seasonally unadjusted. See ch. 4 and the data appendix for a discussion of the data. It should be pointed out here that the output series actually used was not the (unobserved) series on the amount of output produced during the second week of the month, but the (observed) series on the average daily rate of output for the month. As discussed in ch. 4 , this approximation should be reasonably good in most cases.
} 
unambiguous. In the data appendix the months which were used as the peaks for each of the seventeen industries are presented.

The following two assumptions are made regarding these interpolations. The first assumption which is made is the assumption that at the interpolation peaks there are no completely idle workers, so that, in the notation of table 3.1, $M_{2 w t}$ equals $M_{2 w t}^{*}$. As will be discussed in ch. 4, the BLs data on $M_{2 w t}$ include workers who are on vacation and on paid sick leave, and so this assumption that there are no completely idle workers at the peaks is not likely to be completely true. The assumption may not be too unrealistic, however, especially considering the fact that vacations are less likely to be scheduled during the peak output months of the year ${ }^{1}$ than during the more slack months. If $M_{2 w t}$ equals $M_{2 w t}^{*}$, then the number of hours worked per employed worker, $H_{2 w t}$, and the number worked per non-idle worker, $H_{2 w t}^{*}$, are the same. At the peaks, then, no distinction needs to be made between employed and non-idle workers. The second assumption which is made is the assumption that at the interpolation peaks the number of hours paidfor per worker equals the number of hours actually worked per worker, i.e., that $H P_{2 w t}$ equals $H_{2 w t}$ at the peaks. In other words, it is assumed that at the peaks firms are not paying workers for any more hours than they are actually working. This assumption appears to be fairly realistic, since it seems unlikely that firms will behave in such a way that they end up paying workers for unworked hours even at peak output rates.

These two assumptions imply that at the peaks the unobserved output per worked man hour, $Y_{2 w t} / M_{2 w t}^{*} H_{2 w t}^{*}$, equals the observed output per paidfor man hour, $Y_{2 w t} / M_{2 w t} H P_{2 w t}$. Therefore, from the postulated production function (3.2), an estimate of the parameter $\alpha$ is available at each of the peaks. The final assumption which is made is the assumption that $\alpha$ is a function of time and varies smoothly along the interpolation lines from peak to peak. In this way technical progress is introduced into the production function (3.2). This assumption is not equivalent to assuming that $\alpha$ grows smoothly throughout the sample period, because the interpolation lines in general had kinks in them at the peaks. From these assumptions and the interpolation results, then, estimates of $\alpha$ are available for each month throughout the sample period.

Notice that the assumptions of no short-run substitution possibilities between workers and machines and of constant returns to scale made in

1 Remember that the peaks in the output per paid-for man-hour series usually corresponded to the peaks in the output series. 
$\S 3.5$ are necessary for the above procedure to be valid. Otherwise, the estimates of $\alpha$ obtained above could not be considered to be estimates of a parameter of the short-run production function. The accuracy of the estimates of $\alpha$ also depends on the assumption that at the peaks used in the interpolations $M_{2 w t}$ equals $M_{2 w t}^{*}$ and $H P_{2 w t}$ equals $H_{2 w t}^{*}$ and on the assumption that $\alpha$ moves smoothly through time from peak to peak.

From the production function (3.2)

$$
M_{2 w t}^{*} H_{2 w t}^{*}=\frac{1}{\alpha_{2 w t}} Y_{2 w t}
$$

where the time subscript has been added to $\alpha$ to indicate that it varies through time. Given the estimates of $\alpha_{2 w t}$ constructed above and the output data, estimates of $M_{2 w t}^{*} H_{2 w t}^{*}$ can be constructed from eq. (3.6). $M_{2 w t}^{*} H_{2 w t}^{*}$ is then the estimate of the number of man hours actually required to produce $Y_{2 w t}$. When $M_{2 w t}^{*} H_{2 w t}^{*}$ is divided by $H S_{2 w t}$, the standard or long-run equilibrium number of hours of work per worker, the result, denoted as $M_{2 w t}^{d}$, can be considered to be the desired number of workers employed for the second week of month $t$ :

$$
M_{2 w t}^{d}=M_{2 w t}^{*} H_{2 w t}^{*} / H S_{2 w t}
$$

$M_{2 w r}^{d}$ is the desired number of workers employed in the sense that if manhour requirements were to remain at the level $M_{2 w s}^{*} H_{2 w t}^{*}, M_{2 w t}^{d}$ can be considered to be the number of workers the firm would want to employ in the long run. In the long run each worker would then be working the standard number of hours per week.

Using $M_{2 w t}^{d}$, the amount of (positive or negative) excess labor on hand is taken to be $\log M_{2 w t}-\log M_{2 w r}^{d}$, which is the difference between the actual number of workers employed and the desired number. In the discussion in $\S 3.4$ the amount of excess labor on hand was defined to be $\log H S_{2 w t}-\log H_{2 w t}$, which is the difference between the standard number of hours of work per worker and the actual number of hours worked per worker. It is easy to show that this measure and the measure just constructed are the same. Using (3.7) and remembering that $M_{2 w t} H_{2 w t}$ equals $M_{2 w t}^{*} H_{2 w t}^{*}$, it follows that:

$$
\begin{aligned}
\log M_{2 w t}-\log M_{2 w t}^{d} & =\log M_{2 w t}-\left(\log M_{2 w t}^{*} H_{2 w t}^{*}-\log H S_{2 w t}\right) \\
& =\log M_{2 w t}-\log M_{2 w t}^{*} H_{2 w t}^{*}+\log H S_{2 w t} \\
& +\log H_{2 w t}-\log H_{2 w t}
\end{aligned}
$$




$$
\begin{aligned}
& =\log M_{2 w t} H_{2 w t}-\log M_{2 w t}^{*} H_{2 w t}^{*}+\log H S_{2 w t} \\
& -\log H_{2 w t} \\
& =\log H S_{2 w t}-\log H_{2 w t} .
\end{aligned}
$$

In the rest of the text, therefore, these two expressions for excess labor will be used interchangeably. What (3.8) says is that the amount of excess labor on hand can be looked upon either as the difference between the number of workers employed and the desired number employed or as the difference between the standard number of hours of work per worker and the actual number of hours worked per worker.

\subsection{The short-run demand for production workers}

The model developed here of the short-run demand for production workers is not rigorous in that the employment behavior of firms is not derived from the minimization of a particular short-run cost function. One possible justification of not basing the model on the minimization of a short-run cost function is that the behavior of firms may be sufficiently complex that it cannot accurately be described in terms of the minimization of a simple analytic cost function. The model of Holt, Modigliani, Muth, and Simon, for example, is based on the minimization of a cost function, and it is seen in ch. 6 that one of the approximations which is made in order to enable this to be done is unrealistic and leads to rather poor empirical results for the over-all model. For the model developed in this study there is certainly some kind of a complex cost function in the background, the minimization of which implies the behavior postulated by the model, but the behavior pestulated below is sufficiently complex that it is doubtful whether this underlying cost function could be easily derived.

$\mathrm{M}_{2 w t}$ denotes the number of production workers on the payroll of the firm during the second week of month $t$. The problem is to explain the short-run fluctuations in $\log M_{2 w r}-\log M_{2 w t-1}$, the (logarithmic) change in the number of production workers employed from the second week of month $t-1$ to the second week of month $t$. In the model developed here production decisions are assumed to be made before employment decisions and are assumed not to be influenced by the number of workers on hand. A one-way causality is thus postulated from decisions on production to decisions on employment. This assumption is discussed in detail in ch. 6, but for present purposes production decisions are taken to be "exogenous" with respect to employment decisions. 
It was mentioned above that large and rapid adjustments in the work force of a firm are likely to be costly (from the point of view of actual costs as well as of worker morale), and firms are likely to attempt to smooth out their work force fluctuations. If output is expected to increase over the next few months, firms may be reluctant to lay off workers they do not actually need at present, and they may begin to build up their work force in anticipation of higher future man-hour requirements. Conversely, if output is expected to decrease over the next few months, firms may be less reluctant to lay off workers, and they certainly have no need to build up their work force any further. Therefore, the expected current change in output $\left(\log Y_{2 w t}^{e}-\log Y_{2 w t-1}\right)$ as well as expected future changes in output $\left(\log Y_{2 w t+i}^{e}-\log Y_{2 w t+i-1}^{e}, i=1,2, \ldots, \mathrm{n}\right)$ are likely to be significant factors in the determination of $\log M_{2 w t}-\log M_{2 w t-1}$. ( $Y_{2 w t+i}^{e}$ is the amount of output expected to be produced during the second week of month $t+i$, all expectations being made during the second week of month $t-1$.) In other words, because of adjustment costs, the time stream of expected future changes in man-hour requirements (and thus, roughly, of expected future changes in output) is likely to be a significant factor affecting shortrun employment decisions.

The amount of excess labor on hand during the second week of month $t-1$ would also be expected to have an effect on a firm's employment decisions. One would expect that, other things being equal, the larger the amount of positive excess labor on hand during the second week of month $t-1$, the larger would be the number of workers who would be laid off during the monthly decision period. Holding positive amounts of excess labor is costly, and the firm can be considered in the short run to be continuously trying to eliminate this excess labor in the light of such things as worker morale problems and other adjustment costs. Conversely, if there is negative excess labor on hand (too few workers employed), the firm can be considered to be constantly trying to add workers to achieve a zero amount of excess labor.

The amount of excess labor on hand during the second week of month $t-1$ is measured as $\log M_{2 w t-1}-\log M_{2 w t-1}^{d}$ and was constructed in the manner described above. Regarding the measurement of the amount of excess labor on hand, there is another set of variables which is worth considering as well. Since the number of man hours paid-for fluctuates much less than output in the short run and thus less than man-hour requirements, the past changes in output, $\log Y_{2 w: t-i}-\log Y_{2 w t-i-1}(i=1,2, \ldots$, $m$ ), may be useful proxies for the amount of excess labor on hand in the 
sense that if output has been declining in the past, there should be more excess labor on hand than if output has been rising in the past. ${ }^{1}$ Of course, $\log M_{2 w t-1}-\log M_{2 w t-1}^{d}$ and the $\log Y_{2 w t-i}-\log Y_{2 w t-i-1}$ variables will be highly correlated, and to the extent that the assumptions made above are true, $\log M_{2 w t-1}-\log M_{2 w t-1}^{d}$ is the better measure of excess labor on hand.

It is not inconceivable, however, that both $\log M_{2 w_{t-1}}-\log M_{2 w t-1}^{d}$ and the past changes in output are significant in the determination of $\log M_{2 w t}-\log M_{2 w t-1}$. Even though the variables $\log Y_{2 w t-i}-\log Y_{2 w t-i-1}$ $(i=1,2, \ldots, m)$ are measuring part of $\log M_{2 w t-1}-\log M_{2 w t-1}^{d}$, the reaction of the firm to the two types of variables may be sufficiently different to make both types of variables significant. Even if it is assumed that $\log$ $M_{2 w t-1}-\log M_{2 w t-1}^{d}$ is a perfect measure of the amount of excess labor on hand and that a firm reacts in a specified way to this variable, the firm still may react more strongly (weakly) in eliminating this excess labor when the increase (decrease) in part of the excess labor comes in the immediate past month or two. In other words, the past two or three months' activities may have a stronger effect on a firm's employment decision than effects which have been cumulating over a longer period of time.

In the development of the model some assumption has to be made regarding the influence of wage rate fluctuations on the short-run demand for workers. As mentioned in $\$ 2.3$, there are two different kinds of short-run cost-minimizing assumptions which can be made - one concerned with the optimal short-run workers-hours worked per worker mix and the other concerned with the optimal short-run capital services-labor services mix. DHRYMes (1967) has been the only one who has been concerned with this second assumption.

If there are no short-run substitution possibilities between the number of workers and machines, short-run changes in the wage rate can have no effect on the short-run worker-machine ratio. Since a firm is assumed to hold positive and negative amounts of excess labor during much of the year, however, a change in the wage rate will change the cost of holding this excess labor. If the wage rate rises, for example, and if adjustments costs do not increase proportionately with the wage rate, a firm may decide to hold less excess labor, other things being equal, because of the increased relative cost of holding this labor. Thus, an increase in the wage rate may

$1 Y_{2 w t-i}$ is the actual amount of output produced during the second week of month $t-i$. 
have a negative effect on the change in employment, and a decrease in the wage rate a positive effect.

In the model developed here it is assumed that the short-run employment decisions of firms are not significantly affected by short-run wage rate changes. ${ }^{1}$ This assumption does not appear too unreasonable, especially considering the fact that short-run wage rate fluctuations are likely to be rather small and that adjustment costs may increase nearly proportionately with the wage rate.

The long-run effects of the growth of technology on the number of production workers employed have already been accounted for in the construction of $M_{2 w t}^{d}$. If $\alpha$ in the production function (3.2) is increasing over time due to the growth of technology, then, other things being equal, $M_{2 w r}^{d}$ in eq. (3.7) will be falling, since man-hour requirements, $M_{2 w t}^{*} H_{2 w i}^{*}$, will be falling. The amount of excess labor on hand will thus be increasing. In the model developed here, therefore, the effects of the growth of technology on short-run employment decisions are taken care of by the firm's reaction to the amount of excess labor on hand.

The following equation is thus taken to be the basic equation determining $\log M_{2 w t}-\log M_{2 w t-1}$ :

$$
\begin{aligned}
\log M_{2 w t}-\log M_{2 w t-1} & =\propto_{1}\left(\log M_{2 w t-1}-\log M_{2 w t-1}^{d}\right) \\
& +\sum_{i=1}^{m} \beta_{i}\left(\log Y_{2 w t-i}-\log Y_{2 w t-i-1}\right) \\
& +\gamma_{0}\left(\log Y_{2 w t}^{e}-\log Y_{2 w t-1}\right) \\
& +\sum_{i=1}^{n} \gamma_{i}\left(\log Y_{2 w t+i}^{e}-\log Y_{2 w t+i-1}^{e}\right)
\end{aligned}
$$

In eq. (3.9) $\alpha_{1}$ is the partial "reaction coefficient" to the amount of (positive or negative) excess labor on hand, and it is expected to be negative. The reasons for the inclusion of the various output variables in eq. (3.9) have been discussed above. One would expect that the $\beta_{i}$ coefficients would decrease as $i$ increases (the more distant the change in output the smaller the effect on current behavior) and that the $\gamma_{i}$ coefficients would decrease

1 It would be better, of course, to test this assumption, but unfortunately data on standard hourly wage rates (as opposed to average hourly earnings, which reflect overtime earnings as well) are not available. 
as $i$ increases (the further in the future the expected change in output the smaller the effect on current behavior), with $\gamma_{0}$ being the largest of the coefficients.

With respect to the excess labor variable in eq. (3.9), $\log M_{2 w t-1}^{d}$ is defined from eq. (3.7) to be

$$
\log M_{2 w t-1}^{d}=\log M_{2 w t-1}^{*} H_{2 w t-1}^{*}-\log H S_{2 w f-1} .
$$

The variable $M_{2 w t-1}^{*} H_{2 w t-1}^{*}$ was constructed in the manner described in $\S 3.6$, but as yet no assumption has been made regarding $H S_{2 w t-1}$, the standard number of hours of work per worker for the second week of month $t-1$. The following assumption is made. It is assumed that $H S$ is either a constant or a smoothly trending variable, and specifically that

$$
H S_{2 w t-1}=\bar{H} e^{\mu t},
$$

where $\bar{H}$ and $\mu$ are constants. On this assumption $\log H S_{2 n t-1}$ in eq. (3.10) equals $\log \bar{H}+\mu t$, and so the excess labor variable in eq. (3.9) can be written

$$
\begin{aligned}
& \alpha_{1}\left(\log M_{2 w t-1}-\log M_{2 w t-1}^{d}\right)= \\
& \quad \alpha_{1}\left(\log M_{2 w t-1}-\log M_{2 w t-1}^{*} H_{2 w t-1}^{*}\right)+\alpha_{1} \log \bar{H}+\alpha_{1} \mu t .
\end{aligned}
$$

This introduces a constant term and a time trend in eq. (3.9).

There may also be an additional factor in the constant term of eq. (3.9) besides $\alpha_{1} \log \bar{H}$. The specification of eq. (3.9) implies that the desired amount of excess labor on hand is zero. It may be, however, that a firm desires to hold a certain positive amount of excess labor at all times as insurance against, say, a sudden unexpected increase in demand or a sudden increase in absenteeism. If $\log \vec{E}$ denotes this desired amount of excess labor, then the excess labor term in eq. (3.9) should be $\alpha_{1}\left(\log M_{2 w t-1}-\log M_{2 w t-1}^{d}\right.$ $-\log \bar{E}$ ), which adds the (constant) term $-\alpha_{1} \log \bar{E}$ to the equation. The possibility that $\log \bar{E}$ is greater than zero will be ignored in the discussion which follows, but it should be kept in mind in the interpretation of the estimate of the constant term of eq. (3.9). ${ }^{1}$

Eq. (3.9) is not yet in estimatable form because the expected output

1 It should also be pointed out here that if the assumption made above that at the interpolation peaks output per paid-for man hour equals output per worked man hour is wrong, but that the percentage difference between output per paid-for man hour and output per worked man hour is the same at each one of the peaks, then this error will be absorbed in the constant term in eq. (3.9). 
variables are not directly observed, and so in order for it to be estimated some assumption has to be made as to how expectations are formed. The expectational hypotheses which were tested in this study will be discussed in the next section.

\subsection{The expectational hypotheses}

Three basic expectational hypotheses were tested in this study. The first hypothesis which was tested is the hypothesis that expectations are perfect. In other words, the hypothesis states that

$$
\log Y_{2 w t+i}^{e}=\log Y_{2 w t+i}, \quad i=0,1, \ldots, n .
$$

The second hypothesis which was tested is the hypothesis that

$$
\begin{gathered}
\log Y_{2 w t+i}^{e}=\log Y_{2 w t+i-12}+\lambda_{i}\left(\log Y_{2 w t-1}-\log Y_{2 w t-13}\right), \\
i=0,1, \ldots, n .
\end{gathered}
$$

What this hypothesis says is that firms during the second week of month $t-1$ expect the amount of output to be produced during the second week of month $t+i$ to be equal to the amount of output produced during the second week of the same month last year, plus a factor to take into account whether output has been increasing or decreasing in the current year over the previous year, $\log Y_{2 w t-1}-\log Y_{2 w t-13}$. If, for example, output has been increasing in the sense that $\log Y_{2 w t-1}-\log Y_{2 w t-13}$ is positive, firms expect $\log Y_{2 w t+i}-\log Y_{2 w t+i-12}$ to be positive by a certain percentage, the expected percentage being based on the percentage increase of the past month. Similarly, if output has been declining, $\log Y_{2 w t+i}-\log Y_{2 w t+i-12}$ is expected to be negative. The $\lambda_{i}$ coefficients may conceivably be different for different $i$, since as the output to be predicted moves into the future, firms may put less reliance on immediate past behavior.

The third expectational hypothesis which was tested in this study is a combination of the first two. Specifically, it assumes that the hypothesis of perfect expectations holds for $Y_{2 w t}^{e}$ and that the second hypothesis holds for $Y_{2 w t+i}^{e}, i=1,2, \ldots, n$. It seems likely that firms will have a rather good idea of the amount of output they are going to produce in the forthcoming month, but a less clear-cut idea for more distant periods. If in fact employment decisions are made on less than a monthly basis, the hypothesis of perfect expectations for the current month appears quite reasonable, since presumably the number of workers employed will be adjusted throughout the month as the amount of output produced changes. 
The method which was used to test these hypotheses is as follows. For each expectational hypothesis the implied value of each $Y_{2 w t+i}^{e}$ was substituted into eq. (3.9), and the equation was estimated for each of the seventeen industries. The three equations for each industry were then compared with respect to the goodness of fit criterion and with respect to the significance of the $\gamma_{i}$ coefficients, and that hypothesis was chosen for each industry which yielded the best results. Because the $Y_{2 w t+i}^{e}$ variables cannot be directly observed, only this indirect test of the three hypotheses is available. The validity of this test, of course, depends on the assumption that eq. (3.9) is specified correctly to begin with.

For the perfect expectational hypothesis the actual future values of output are used as measures of the expected future values. Under the second expectational hypothesis, the expectational part of eq. (3.9) becomes (assuming $n$ to be three):

$$
\begin{gathered}
\gamma_{0}\left(\log Y_{2 w t}^{e}-\log Y_{2 w t-1}\right)+\sum_{i=1}^{3} \gamma_{i}\left(\log Y_{2 w t+i}^{e}-\log Y_{2 w t+i-1}^{e}\right) \\
=\gamma_{0}\left(\log Y_{2 w t-12}-\log Y_{2 w t-1}\right)+\gamma_{1}\left(\log Y_{2 w t-11}-\log Y_{2 w t-12}\right) \\
+\gamma_{2}\left(\log Y_{2 w t-10}-\log Y_{2 w t-11}\right)+\gamma_{3}\left(\log Y_{2 w t-9}-\log Y_{2 w t-10}\right) \\
+\left(\gamma_{0} \lambda_{0}+\gamma_{1} \lambda_{1}-\gamma_{1} \lambda_{0}+\gamma_{2} \lambda_{2}-\gamma_{2} \lambda_{1}+\gamma_{3} \lambda_{3}-\gamma_{3} \lambda_{2}\right)\left(\log Y_{2 w t-1}\right. \\
\left.-\log Y_{2 w t-13}\right) .
\end{gathered}
$$

For this second expectational hypothesis, if all of the $\lambda_{i}$ coefficients are equal (to, say, $\lambda$ ), then the coefficient of $\log Y_{2 w t-1}-\log Y_{2 w t-13}$ becomes $\gamma_{0} \lambda$, and $\lambda$ can be identified; otherwise the $\lambda_{i}$ coefficients cannot be identified.

Under the third expectational hypothesis, the expectational part of eq. (3.9) becomes (again assuming $n$ to be three):

$$
\begin{aligned}
\gamma_{0}\left(\log Y_{2 w t}^{e}-\log Y_{2 w t-1}\right)+\sum_{i=1}^{3} \gamma_{i}\left(\log Y_{2 w t+i}^{e}-\log Y_{2 w t+i-1}^{e}\right) \\
\quad=\gamma_{0}\left(\log Y_{2 w t}-\log Y_{2 w t-1}\right)+\gamma_{1}\left(\log Y_{2 w t-11}-\log Y_{2 w t}\right) \\
+\gamma_{2}\left(\log Y_{2 w t-10}-\log Y_{2 w t-11}\right)+\gamma_{3}\left(\log Y_{2 w t-9}-\log Y_{2 w t-10}\right) \\
+\left(\gamma_{1} \lambda_{1}+\gamma_{2} \lambda_{2}-\gamma_{2} \lambda_{1}+\gamma_{3} \lambda_{3}-\gamma_{3} \lambda_{2}\right)\left(\log Y_{2 w t-1}-\log Y_{2 w t-13}\right) .
\end{aligned}
$$

Again, only if all of the $\lambda_{i}$ coefficients are equal (to, say, $\lambda$ ) can $\lambda$ be identified.

The hypothesis that expectations are perfect may not be as unreasonable as it sounds. Firms are likely to have more information at their disposal regarding future demand conditions than merely information on the arnount 
of output they produced in the past or on past demand conditions. If firms do not use a naive equation like (3.14) to forecast and if the forecasting technique they do use is fairly accurate, then the perfect expectational hypothesis should be a better approximation of how expectations are formed than the other "non-perfect" expectational hypotheses. The hypothesis that expectations are perfect will, of course, be completely realistic if firms schedule production in advance and do not deviate from this schedule even if expected demand conditions change.

\subsection{Summary}

This completes the discussion of the theoretical model of the short-run demand for production workers developed in this study. It was seen that output per man hour and output appear to be positively related even during peak output periods and that there is little evidence of decreasing or constant returns to labor services. The explanation presented here of the widely observed phenomenon of increasing returns to labor is based on the idea that firms hold positive amounts of "excess labor" during much of the year and that the true production function inputs are not observed. A critical distinction is made between the (observed) number of hours paid-for per worker and the (unobserved) number of hours actually worked per worker, and it is contended that the former is a poor proxy for the latter except perhaps at peak rates of output. If this is true, then the properties of the short-run production function cannot be estimated because of lack of data, and in this study various properties of the short-run production function have been postulated. The short-run production process has been assumed to be of such a nature that a fixed number of workers is required per machine and that there are constant returns to scale both with respect to changes in the number of workers and machines used and with respect to changes in the number of hours worked per worker and machine.

The amount of excess labor on hand was defined to be the difference between the standard number of hours of work per worker and the actual number of hours worked per worker. A measurement of the amount of excess labor on hand was made for each industry for each month of the sample period by interpolating plots of output per paid-for man hour from peak to next higher peak; assuming that at the peaks output per paid-for man hour equals output per worked man hour so that an estimate of the production function parameter $\alpha$ is available at each of the peaks; assuming that $\alpha$ moves smoothly through time from peak to peak; using the estimates 
of $\alpha$ and the output data to compute estimates of man-hour requirements; dividing man-hour requirements by the standard number of hours of work per worker to get the desired number of workers employed; and then taking the (logarithmic) difference between the actual number of workers employed and the desired number employed. This latter measure is the same as the (logarithmic) difference between the standard number of hours of work per worker and the actual number of hours worked per worker. The entire procedure is based on the assumptions made about the properties of the short-run production function.

A model of the short-run demand for workers was then developed in which the change in the number of workers employed was taken to be a function of the amount of excess labor on hand and the time stream of expected future changes in output. The past change in output variables were also added on the assumption that they may help depict the nature of the reaction to the amount of excess labor on hand. Three expectational hypotheses were proposed to be tested in this study, one in which expectations were assumed to be perfect and the other two in which expectations were assumed to be based on past output behavior.

In the next chapter the data which have been used in this study are discussed, and then eq. (3.9) is estimated for each of the seventeen industries considered in this study under the three proposed expectational hypotheses. 


\section{THE BASIC RESULTS FOR PRODUCTION WORKERS}

\subsection{Introduction}

In this chapter the results are presented of estimating eq. (3.9) under the expectational hypotheses discussed above. These basic results are discussed in detail in this chapter, and then in ch. 5 , using eq. (3.9) as a starting point, various hypotheses regarding other possible determinants of short-run fluctuations in the number of workers employed are presented and tested. The data used in this study are considerably more detailed than the data used in previous studies, and these data will be discussed first.

\subsection{The data}

The basic model of previous studies discussed in ch. 2 and the model developed in this study take the firm as the basic behavioral unit. Data are not available by firm, however, and some amount of aggregating must be done. In many of the previous studies highly aggregate data have been used, such as for all of manufacturing. The use of highly aggregate data is likely to conceal certain relationships which may exist in the disaggregate data, and Hultgren has discovered in his work that the use of large statistical aggregates tends to conceal the disaggregate relationships between fluctuations in output and output per man hour. ${ }^{1}$ The basic reason for this is - that production cycles in different industries do not coincide with one another and to some extent tend to cancel each other out. Also, one might expect that hiring and firing practices would differ considerably across industries.

The two studies of the United States which have used quarterly two-digit industry data are those of DHRYMEs (1967) and KUH (1965b). Unfortunately, much of these data are nearly useless for the study of short-run relationships between output and employment. The quarterly two-digit industry data have been constructed by interpolating annual two-digit industry data using

1 Hultgren (1960, pp. 28-29). 
the Federal Reserve Board ( $F R B$ ) indices of industrial production. About half (by value added) of the FRB indices, however, are obtained by interpolating annual data using the Bureau of Labor Statistics (BLs) man-hour data and some assumption about how output per man hour fluctuates with output in the short run - and this is one of the very things the studies are concerned with estimating. When these data are used, combined with the BLS data on employment, to estimate the relationship between employment and output in the short run, the net result is to estimate the estimating technique used by the FRB to construct the output data in the first place. There are only four two-digit industries in which the data are not based at least in part on man-hour interpolations - 33 Primary metals, 26 Paper and allied products, 21 Tobacco manufacturing, and 29 Petroleum refining and related industries.

Fortunately, there are better United States data available, at a sacrifice, however, of complete coverage of all of United States manufacturing. There are seventeen three-digit industries for which FRB output data and BLS employment data are available monthly from 1947 to the present where

TABLE 4.1

The seventeen industries considered in this study

\begin{tabular}{ll}
\hline SIC number & \multicolumn{1}{c}{ Description } \\
\hline 201 & Meat products \\
207 & Confectionery and related products \\
211 & Cigarettes \\
212 & Cigars \\
231 & Men's and boys' suits and coats \\
232 & Men's and boy's' furnishings \\
233 & Women's, misses', and juniors' outerwear \\
242 & Sawmills and planing mills \\
271 & Newspaper publishing and printing \\
301 & Tires and inner tubes \\
311 & Leather tanning and finishing \\
314 & Footwear, except rubber \\
324 & Cement, hydraulic \\
331 & Blast furnace and basic steel products \\
332 & Iron and steel foundries \\
336 & Non-ferrous foundries \\
341 & Metal cans
\end{tabular}


the FRB output data are measured independently of BLS employment data. In addition there are about twenty four-digit industries for which these data are available monthly from 1958 to the present. ${ }^{1}$ The seventeen threedigit manufacturing industries considered in this study are listed in table 4.1. These industries constitute about eighteen percent of manufacturing by value added.

There are other advantages of using these data in addition to the output estimates being independent of the man-hour data. For the three-digit industries the degree of disaggregation is quite good, and many of the problems with using highly aggregate data should be mitigated. The threedigit industries are much more homogeneous groups than even the two-digit industries. The use of monthly data in a short-run study also seems very desirable, as some of the relationships between short-run fluctuations in employment and output may be covered up in quarterly data.

The BLS production worker data used in this study refer to persons on establishment pay-rolls who receive pay for any part of the pay period which includes the 12th of the month. Persons who are on paid sick leave, on paid holidays and vacations, or who work during part of the pay period and are on strike or unemployed during the rest of the period are counted as employed. These are the data which were used for $M_{2 w t}$. Data for the average number of hours paid-for per production worker during the second week of month $t, H P_{2 x: t}$, were also taken from the BLs. These data are compiled from the same survey as the data on the number of production workers employed.

The FRB data on output do not refer to the amount of output produced during the second week of the month, which from the point of view of the model developed in ch. 3 it would be desirable to have, but instead refer to the average daily rate of output for the month. For lack of a better alternative, however, the FRB data were used as the output data in this study. Unless the weekly rate of output fluctuates considerably during the month, the average daily rate of output for the month should be a fairly good approximation to the average daily rate of output for the second week of the month. The observed average daily rate of output for the month will be denoted as $Y_{d t}$ to distinguish it from the unobserved but theoretically preferred $Y_{2 w t}$ variable. Some of the consequences of using $Y_{d t}$ in place of $Y_{2 w t}$ will be discussed below.

1 There are also three three-digit mining industries for which data are available from 1947 to the present. 
The basic period of estimation was taken to be the period 1947-1965, but a number of adjustments in this basic period were made for each industry. For example, in all of the seventeen industries except 201, 271, 324, and 341, a significant percentage of firms shut down for vacations in July (usually the first two weeks), and in industries 207,211,212,231, 232, 233, and 314 a significant number of firms also shut down during the Christmas week in December. ${ }^{1}$ In July and December many of these firms find demand at low levels anyway, and they find it to their advantage to shut the entire plant down for a week or two for vacations, rather than to keep the plant open and spread the vacations over a longer period of time. For these shutdown periods production is clearly not exogenous, and thus it was decided to exclude from the periods of estimation the months in which shutdowns occurred. This means, for example, that for industries which shut down in July and December the values of $\log M_{2 w t}-\log M_{2 w t-1}$ for June to July, July to August, November to December, and December to January were excluded.

Since past and expected future output changes are assumed in the model developed above to have an effect on employment decisions, excluding the four July and December observations when shutdowns occur does not exclude the July and December output figures from entering the estimated equation. With respect to this problem, the use of the FRB data on the average daily rate of output for the month is probably more desirable than the use, if they were available, of data on the amount of output produced during the second week of the month. If firms shut down during the first two weeks of July, for example, little if any output will be produced during the second week, but the total effect on the average daily rate of output for the month will be less. Regarding the past and expected future output streams, for the months in which shutdowns occur firms are more likely to look at the average daily rate of output for the month than the rate during the second week. To the extent, however, that without the shutdown in, say, July, the average daily rate for July would have been larger and the June and August rates smaller, the $\log Y_{d J u l y}^{e}-\log Y_{d J u n e}^{e}$ and $\log Y_{d A u g .}^{e}-$ $\log Y_{d j u l y}^{e}$ variables are probably inadequate measures of the time stream of expected future output changes. This (hopefully slight) misspecification

1 This information was gathered mainly from industry and union officials. 
should be kept in mind when interpreting the estimates of the coefficients of the expected future output variables. ${ }^{1}$

In the development of the model in $\$ 3.7$ it was argued that the variables, $\log Y_{2 w t-i}-\log Y_{2 w i-i-1}(i=1,2, \ldots, \mathrm{m})$, might be significant in the determination of $\log M_{2 w t}-\log M_{2 w t-1}$. It was argued that these past output change variables might be picking up part of the reaction of the firm to the amount of excess labor on hand. Because of the fact that the output variable used in the empirical work is not the amount of output produced during the second week of the month, but is rather the average daily rate of output for the month, there is an additional reason why $\log Y_{d t-1}-\log$ $Y_{d t-2}$ may be a significant determinant of $\log M_{2 w t}-\log M_{2 n t-1}$ in addition to it possibly picking up part of the reaction to the amount of excess labor on hand. Remember that $\log M_{2 w t}-\log M_{2 w t-1}$ is the change in the number of production workers employed from the second week of month $t-1$ to the second week of month $t$. To the extent that output is, say, increasing throughout month $t-1$ and to the extent that the number of production workers employed responds to this increase during the last half of month $t-1, \log M_{2 w t}-\log M_{2 w t-1}$ will be influenced by the increase in output during the last two weeks of month $t-1$. It will therefore be influenced by $\log Y_{d t-1}-\log Y_{d t-2}$, since an increase in output in the last two weeks of month $t-1$ raises the average daily rate for the whole month, $Y_{d t-1}$. There is no way these two possible effects can be separated, and so the estimates of the coefficient of $\log Y_{d t-1}-\log Y_{d t-2}$ must be interpreted with caution.

In eight of the seventeen industries there were significant strikes (involving 10,000 workers or more) during the nineteen-year period of estimation. In table 4.2 these strikes are listed by industry, and the date of each strike and the number of workers involved are given. In the actual regressions these observations were omitted, as well as the observations for the two or three months before and after the strike. Some of the estimated equations had lags in output of up to 13 months, however, and either all of these observations had to be omitted or an output variable had to be constructed to use

\footnotetext{
1 For the Newspaper industry, 271, the December observations were omitted in the empirical work, since the average daily rate of output for this month was much lower than the rate during the second week, due to the heavy advertising before Christmas and the much lighter advertising after Christmas. There is still a problem here, of course, to the extent that the use of the December output observations is resulting in a bad approximation to the time stream of expected future output changes.
} 
TABLE 4.2

Strikes involving 10,000 of more workers

\begin{tabular}{|c|c|c|c|}
\hline \multirow{2}{*}{$\frac{\text { Industry }}{201}$} & \multicolumn{2}{|c|}{$\begin{array}{c}\text { Approximate } \\
\text { period of strike }\end{array}$} & \multirow{2}{*}{$\begin{array}{l}\text { No. of workers } \\
\text { involved } \\
83,000\end{array}$} \\
\hline & March 16, 1948 & June 5, 1948 & \\
\hline & September 4, 1959 & October 24,1959 & 18,000 \\
\hline 233 & February 17,1948 & February 19,1948 & 10,000 \\
\hline \multirow[t]{3}{*}{242} & April 29,1952 & May 31,1952 & 45,000 \\
\hline & June 21,1954 & September 13,1954 & 77,000 \\
\hline & June 5,1963 & August 18,1963 & 29,000 \\
\hline \multirow[t]{2}{*}{271} & December 8, 1962 & March 31,1963 & 20,000 \\
\hline & September 16,1965 & October 10,1965 & 17,000 \\
\hline \multirow[t]{10}{*}{301} & April 7, 1948 & April 11, 1948 & 10,000 \\
\hline & August 27, 1949 & September 30, 1949 & 15,000 \\
\hline & July 8,1954 & August 27, 1954 & 22,000 \\
\hline & August 13,1954 & September 5,1954 & 21,000 \\
\hline & November 1,1956 & November 19, 1956 & 21,000 \\
\hline & April 1, 1957 & April 16, 1957 & 14,000 \\
\hline & April 10,1959 & May 1, 1959 & 25,000 \\
\hline & April 16, 1959 & June 10,1959 & 13,000 \\
\hline & April 16, 1959 & June 15,1959 & 19,000 \\
\hline & June 2, 1965 & June 9,1965 & 22,000 \\
\hline 324 & May 15,1957 & September 16, 1957 & 16,000 \\
\hline \multirow[t]{5}{*}{331} & October 1,1949 & December 1,1949 & 500,000 \\
\hline & July 19, 1951 & July 24,1951 & 12,000 \\
\hline & April 29,1952 & August 15,1952 & 560,000 \\
\hline & July 1,1956 & August 5, 1956 & 500,000 \\
\hline & July 15,1959 & November 8, 1959 & 519,000 \\
\hline \multirow[t]{2}{*}{341} & December 2,1953 & January 12,1954 & 30,000 \\
\hline & March 1, 1965 & March 24, 1965 & 31,000 \\
\hline
\end{tabular}

for each strike month. For industries 242, 271, and 341, instead of omitting all of the necessary observations, in place of the actual value of the output variable which was recorded during the strike month, the value of the output variable during the same month of the previous year was used, multiplied by the ratio of the previous non-strike month's value to the same month of the previous year's value. [For example, if $t$ were a strike month and $t-1$ were a normal month, the value of $Y_{d}$ used for month $t$ would be $Y_{d r-12}$ $\left(Y_{d t-1} / Y_{d t-13}\right)$.] This variable is, in effect, trying to measure what output would have been if the strike had not taken place. In the data appendix 
these adjustments are presented for the respective industries. For industries 201,233 , and 324 , where strikes involving 10,000 or more workers occurred, the strikes did not seem to have a noticeable effect on output, and for these industries no adjustments in the output series were made. Also for the strike ridden industries, 301 and 331, no adjustments in the output series were made, but for these two industries all of the necessary observations were omitted.

Because of the adjustments for shutdowns and strikes, different periods of estimation were used for different industries. The actual period of estimation which was used for each industry is presented in the data appendix. It turned out that the same period of estimation was used for industries $207,211,212,231,232,233$, and 314 , and the same period for industries 311,332 , and 336 . For the remaining seven industries the period of estimation was unique to the specific industry.

For the Tires and inner tubes industry, 301, and the Cement industry, 324, monthly data on production were available from the Rubber Manufacturers Association (RMA) and the Bureau of Mines respectively. These data are essentially the same as the FRB data for the industries, since the FRB uses the RMA and Bureau of Mines data to construct the prodliction indices. In this study the RMA data have been used directly for industry 301, and the Bureau of Mines data have been used directly for industry 324 . The production data for industry 324 are not available beyond 1964. Whenever the output data were gathered from sources other than the FRB, the monthly figures were converted into average daily rates for the month using the FRB estimate of the number of working days in each month for each industry. This procedure is discussed in detail in the data appendix.

\subsection{The results for production workers}

\subsubsection{The basic results}

The basic equation determining the short-run demand for production workers is eq. (3.9), and it is repeated here in the form in which it was estimated:

$$
\begin{aligned}
\log M_{2 w t} & -\log M_{2 w t-1}=\alpha_{1}\left(\log M_{2 w t-1}-\log M_{2 w t-1}^{*} H_{2 w t-1}^{*}\right)+\alpha_{1} \log \bar{H} \\
& +\alpha_{1} \mu t+\sum_{i=1}^{m} \beta_{i}\left(\log Y_{d t-i}-\log Y_{d t-i-1}\right)+\gamma_{0}\left(\log Y_{d t}^{e}-\log Y_{d t-1}\right) \\
& +\sum_{i=1}^{n} \gamma_{i}\left(\log Y_{d t+i}^{e}-\log Y_{d t+i-1}^{e}\right)
\end{aligned}
$$


TABLE 4.3

Parameter estimates for eq. (3.9)' under the expectational hypothesis which gave the better results for each industry

\begin{tabular}{|c|c|c|c|c|c|c|c|c|c|}
\hline $\begin{array}{l}\text { 弮 } \\
\text { 总 }\end{array}$ & $\begin{array}{l}\dot{0} \\
0 \\
\dot{0} \\
\dot{0} \\
\dot{0} \\
\text { Z }\end{array}$ & $\alpha_{1} \log A$ & $\hat{Q}_{1}$ & $1000 \widehat{\alpha_{1} \mu}$ & $\hat{\beta}_{4}$ & $\hat{\beta}_{3}$ & $\hat{\beta}_{2}$ & $\hat{\beta}_{1}$ & $\hat{\gamma}_{0}$ \\
\hline \multirow[t]{2}{*}{201} & 192 & -1.039 & -.178 & -.077 & & & .074 & .067 & .265 \\
\hline & & $(4.54)$ & $(4.54)$ & $(3.90)$ & & & $(3.96)$ & $(3.60)$ & (10.16) \\
\hline \multirow[t]{2}{*}{207} & 136 & -.874 & -.151 & .121 & & & .064 & .091 & .262 \\
\hline & & $(3.41)$ & $(3.41)$ & $(3.21)$ & & & $(5.34)$ & $(4.70)$ & $(11.65)$ \\
\hline \multirow[t]{2}{*}{211} & 136 & -.775 & -.133 & -.050 & & & & & .086 \\
\hline & & $(5.79)$ & $(5.80)$ & $(3.20)$ & & & & & $(4.43)$ \\
\hline \multirow[t]{2}{*}{212} & 136 & -.636 & -.108 & -.038 & & & & .053 & .154 \\
\hline & & $(4.76)$ & $(4.73)$ & $(1.52)$ & & & & $(4.57)$ & $(7.76)$ \\
\hline \multirow[t]{2}{*}{231} & 136 & -1.056 & -.181 & .085 & & & .032 & .065 & .127 \\
\hline & & $(4.54)$ & $(4.44)$ & $(2.90)$ & & & $(3.06)$ & $(3.95)$ & $(4.03)$ \\
\hline \multirow[t]{2}{*}{232} & 136 & -.508 & -.090 & -.062 & & & & .021 & .118 \\
\hline & & $(5.50)$ & $(5.57)$ & $(3.40)$ & & & & $(2.93)$ & $(9.59)$ \\
\hline \multirow[t]{2}{*}{233} & 136 & -.048 & -.005 & .041 & & & & .129 & .164 \\
\hline & & $(0.28)$ & $(0.16)$ & $(0.78)$ & & & & $(6.08)$ & $(6.69)$ \\
\hline \multirow[t]{2}{*}{242} & 154 & -.260 & -.044 & -.011 & .060 & .105 & .146 & .150 & .218 \\
\hline & & $(1.42)$ & $(1.41)$ & $(0.55)$ & $(4.57)$ & $(7.35)$ & $(8.62)$ & $(6.87)$ & $(13.65)$ \\
\hline \multirow[t]{2}{*}{271} & 166 & -.258 & -.044 & -.001 & & & & & .120 \\
\hline & & $(2.57)$ & $(2.60)$ & $(0.09)$ & & & & & $(7.58)$ \\
\hline \multirow[t]{2}{*}{301} & 134 & -.626 & -.108 & -.062 & & & & & .055 \\
\hline & & $(7.20)$ & $(7.18)$ & $(2.79)$ & & & & & $(2.88)$ \\
\hline \multirow[t]{2}{*}{311} & 170 & -1.021 & -.174 & -.056 & & & & & .190 \\
\hline & & $(6.88)$ & $(6.87)$ & $(3.33)$ & & & & & $(8.12)$ \\
\hline \multirow[t]{2}{*}{314} & 136 & -.672 & -.115 & .042 & & & & & .322 \\
\hline & & $(2.51)$ & $(2.50)$ & $(2.03)$ & & & & & $(10.73)$ \\
\hline \multirow[t]{2}{*}{324} & 187 & -.653 & -.110 & .060 & & & & & .224 \\
\hline & & $(6.37)$ & $(6.34)$ & $(2.44)$ & & & & & $(16.50)$ \\
\hline \multirow[t]{2}{*}{331} & 128 & -.209 & -.035 & .016 & .044 & .067 & .037 & .121 & .184 \\
\hline & & $(3.05)$ & $(2.98)$ & $(1.01)$ & $(3.36)$ & $(4.78)$ & $(2.48)$ & $(6.29)$ & $(9.89)$ \\
\hline \multirow[t]{2}{*}{332} & 170 & -.734 & -.123 & .045 & & & & & .172 \\
\hline & & $(8.66)$ & $(8.63)$ & $(2.04)$ & & & & & $(8.26)$ \\
\hline \multirow[t]{2}{*}{336} & 170 & -.666 & -.113 & -.015 & & & & .090 & .164 \\
\hline & & $(5.61)$ & $(5.59)$ & $(0.62)$ & & & & $(4.62)$ & (6.53) \\
\hline \multirow[t]{2}{*}{341} & 191 & -.373 & -.067 & -.060 & & & & .038 & .182 \\
\hline & & $(3.60)$ & $(3.62)$ & $(2.38)$ & & & & $(3.88)$ & $(15.32)$ \\
\hline
\end{tabular}

$t$-statistics are in parentheses.

s $\hat{\delta}$ is the coefficient estimate of $\log Y_{d t-1}-\log Y_{d t-18}$ under the non-perfect expectational hypothesis. 


\begin{tabular}{|c|c|c|c|c|c|c|c|c|c|}
\hline$\hat{\gamma}_{1}$ & $\hat{\gamma}_{2}$ & $\hat{\gamma} \mathrm{s}$ & $\hat{\gamma}_{4}$ & $\hat{\gamma}_{5}$ & $\hat{\gamma}_{6}$ & ${ }^{a} \hat{\delta}$ & $\mathrm{R}^{2}$ & $\mathrm{SE}$ & DW \\
\hline .171 & .119 & .138 & .159 & .087 & .074 & .039 & .665 & .0120 & 1.93 \\
\hline$(7.31)$ & $(5.03)$ & $(7.10)$ & $(9.50)$ & $(5.65)$ & $(4.11)$ & $(2.22)$ & & & \\
\hline .182 & .125 & .080 & .034 & & & .056 & .855 & .0180 & 2.12 \\
\hline$(7.20)$ & $(7.25)$ & $(9.08)$ & $(3.77)$ & & & $(2.64)$ & & & \\
\hline \multirow{3}{*}{$\begin{array}{r}.024 \\
(1.92)\end{array}$} & .043 & & & & & -.010 & .343 & .0102 & 1.92 \\
\hline & $(4.96)$ & & & & & $(0.63)$ & & & \\
\hline & & & & & & & .454 & .0159 & 2.63 \\
\hline .021 & .061 & .035 & & & & -.017 & .567 & .0194 & 1.98 \\
\hline$(0.97)$ & $(3.95)$ & $(3.57)$ & & & & $(1.02)$ & & & \\
\hline .091 & .062 & .018 & & & & & .494 & .0107 & 1.45 \\
\hline \multirow[t]{2}{*}{$(6.77)$} & $(6.28)$ & $(2.54)$ & & & & & & & \\
\hline & & & & & & & .512 & .0292 & 1.45 \\
\hline . & & & & & & & & & \\
\hline .076 & .065 & & & & & & .783 & .0126 & 1.80 \\
\hline$(5.27)$ & $(5.20)$ & & & & & & & & \\
\hline .026 & .044 & .049 & .013 & .039 & & & $.5 \$ 2$ & .0048 & 2.12 \\
\hline$(1.68)$ & $(3.37)$ & $(4.26)$ & $(1.34)$ & $(4.06)$ & & & & & \\
\hline .059 & .030 & .036 & & & & & .297 & .0142 & 1.92 \\
\hline$(3.37)$ & (1.83) & $(2.29)$ & & & & & & & \\
\hline .082 & .115 & .084 & .056 & .038 & & & .413 & .0115 & 2.11 \\
\hline$(4,66)$ & $(7.51)$ & $(6.05)$ & $(4.52)$ & $(3.50)$ & & & & & \\
\hline .109 & .140 & .052 & & & & .078 & .661 & .0143 & 2.19 \\
\hline$(4.28)$ & $(8.04)$ & $(3.80)$ & & & & $(3.34)$ & & & \\
\hline .039 & .026 & .052 & .051 & & & .008 & .639 & .0177 & 2.01 \\
\hline \multirow[t]{2}{*}{$(2.40)$} & $(1.60)$ & $(3.36)$ & (3.42) & & & $(0.47)$ & & & \\
\hline & & & & & & & .790 & .0101 & 1.86 \\
\hline .049 & .058 & .041 & .033 & & & & .450 & .0167 & 2.24 \\
\hline$(3.46)$ & $(4.57)$ & $(3.45)$ & $(2.82)$ & & & & & & \\
\hline .086 & .091 & .076 & .044 & .027 & & & .551 & .0175 & 1.78 \\
\hline$(4.83)$ & $(6.00)$ & $(5.79)$ & $(3.42)$ & (2.13) & & & & & \\
\hline .067 & .044 & .036 & .022 & & & & .771 & .0180 & 1.99 \\
\hline$(6,02)$ & $(4.64)$ & $(3.87)$ & $(2.45)$ & & & & & & \\
\hline
\end{tabular}


Notice in eq. (3.9) that the output variables are the observed FRB variables and not the theoretically more correct $Y_{2 w}$ variables. From eq. (3.12) the excess labor variable in eq. (3.9), $\alpha_{1}\left(\log M_{2 w t-1}-\log M_{2 w t-1}^{d}\right)$, is equal to $\alpha_{1}\left(\log M_{2 w t-1}-\log M_{2 w t-1}^{*} H_{2 w t-1}^{*}\right)+\alpha_{1} \log \bar{H}+\alpha_{1} \mu t$, and this latter expression is the one presented in eq. (3.9 $)^{\prime}$. The $M_{2 w t-1}^{*} H_{2 w t-1}^{*}$ variable was constructed in the manner described in $\$ 3.6$.

Eq. (3.9) is, of course, different depending on which expectational hypothesis is assumed. For the perfect expectational hypothesis the actual values of the $Y_{d t+i}$ are used in the equation, and for the other two hypotheses the expectational part of eq. (3.9) takes the form presented (for $n=3$ ) in eqs. (3.15) and (3.16), with $Y_{d}$ replacing $Y_{2 w}$ in the equations. It was mentioned in $\S 3.8$ that for the two "non-perfect" expectational hypotheses the $\lambda_{i}$ coefficients can be identified only if they are all equal. For all hypotheses, however, the $\gamma_{i}$ coefficients can be identified.

Each expectational hypothesis for each industry was judged by the goodness of fit of the equation and by the significance of the $\gamma_{i}$ coefficients. It turned out that the expectational hypothesis which assumes non-perfect expectations for $Y_{d t}^{e}$ proved to be substantially inferior in every industry to either of the other two hypotheses, and the results achieved using this hypothesis will not be presented here. These results imply, not too surprisingly, that firms' expectations of the amount of output they are going to produce one month ahead are quite accurate.

The results of estimating eq. (3.9)' for each of the seventeen industries are presented in table 4.3. For each industry the expectational hypothesis which gave the better results has been used. For the non-perfect expectational hypothesis the coefficient of $\log Y_{d t-1}-\log Y_{d t-13}$ is denoted as $\delta$. The industries for which estimates of $\delta$ are given in the table are the industries in which the non-perfect expectational hypothesis proved to be better. In table 4.6 the results of estimating equation $(3.9)^{\prime}$ for each industry under the alternative expectational hypothesis to that assumed in table 4.3 are presented, and a comparison of both hypotheses for each industry can be made. Before this comparison is made, however, the results presented in table 4.3 will be discussed.

The results presented in table 4.3 appear to be quite good. For every industry the fit is better than the fit of the basic model of ch. 2 and in most cases substantially so. ${ }^{1}$ The coefficient estimates are of the right sign except for two of the estimates of $\delta$, and most of them are highly significant. ${ }^{2}$ All of the estimates of the coefficient $\alpha_{1}$ of the excess labor variable are negative, and in all but two industries they are highly significant. One of these two 
industries is industry 242 , where the past four changes in output are significant. Without these four variables included in the equation, the estimate of $\alpha_{1}$ was significant, but with these variables included it lost its significance. The size of the estimate of $\alpha_{1}$ for each industry appears reasonable, with a range of -.005 to -.181 . This implies, other things being equal, an elimination of the amount of excess labor on hand of between about one and twenty percent per month, excluding any effects of the past output change variables. From the results in table 4.3 the amount of excess labor on hand definitely appears to be a significant factor in the determination of short-run changes in the number of workers employed.

With respect to the past output change variables, ignoring the fact that $\log Y_{d t-1}-\log Y_{d t-2}$ is significant in ten of the industries (which may be merely because of the fact that $Y_{d}$ is used as the output variable instead of $Y_{2 w}$ ), one or more of the past output change variables are significant in only five of the seventeen industries. It appears, therefore, that the reaction to the amount of excess labor on hand is fairly well specified by the inclusion of the $\log M_{2 w t-1}-\log M_{2 w t-1}^{d}$ variable in the equation, and that adding the past output change variables does not add much to the explanation of $\log M_{2 w t}-\log M_{2 w t-1}$ for most industries.

For every industry the estimate of the coefficient $\gamma_{0}$ of the current output change variable is positive and highly significant. For all but three of the industries one or more of the expected future output change variables are

1 The results of estimating eq. (2.37) of the basic model of previous studies are presented in tables 2.3 and 2.4 .

2 In estimating eq. (3.9) the expected future output change variables were carried forward until they lost their significance, and the past output change variables were carried back until they lost their significance. In five of the industries - 211, 231, 271, 301, and 324 - one or two of the expected future output change variables were not significant, but the ones further out were. In these five cases the insignificant variables were left in.

Because the excess labor variable in eq. (3.9)' is of the nature of a lagged dependent variable, the classical $t$-test is only valid asymptotically. Consequently, in the discussion which follows the " $t$-statistics" will be interpreted somewhat loosely. A coefficient estimate will be said to be "significant" if its $t$-statistic (the absolute value of the ratio of the coefficient estimate to its standard error) is greater than two. A variable will be said to be "significant" if its coefficient estimate is significant. 
TABLE 4.4

Parameter estimates for eq. (3.9) with a $\log M_{2 e t-1}$ replacing $\alpha_{1}\left(\log M_{2 n i-1}-\log M_{2 u t-1} H^{*}{ }_{2 u t-1}\right)$

\begin{tabular}{|c|c|c|c|c|c|c|c|c|c|}
\hline 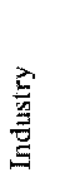 & $\begin{array}{l}\dot{8} \\
0 \\
0 \\
0 \\
\dot{0} \\
\dot{z}\end{array}$ & 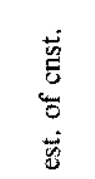 & $\hat{\alpha}_{1}$ & $\begin{array}{l}\omega \\
\dot{0} \\
\dot{3} \\
\dot{3} \\
\dot{8} \\
\dot{8}\end{array}$ & $\hat{\beta}_{ \pm}$ & $\hat{\beta}_{3}$ & $\hat{\beta}_{2}$ & $\hat{\beta}_{\mathrm{I}}$ & $\hat{\gamma}_{0}$ \\
\hline \multirow[t]{2}{*}{201} & 192 & .417 & -.053 & -.003 & & & .099 & .112 & .160 \\
\hline & & $(2.35)$ & $(2.34)$ & $(0.20)$ & & & $(5.22)$ & $(6.83)$ & $(9.93)$ \\
\hline \multirow[t]{2}{*}{207} & 136 & .238 & -.036 & -.014 & & & .096 & .144 & .197 \\
\hline & & $(1.17)$ & $(1.17)$ & $(0.26)$ & & & $(9.10)$ & $(11.16)$ & $(14.96)$ \\
\hline \multirow[t]{2}{*}{211} & 136 & .185 & -.033 & .017 & & & & & .015 \\
\hline & & $(1.18)$ & $(1.17)$ & $(0.47)$ & & & & & $(0.83)$ \\
\hline \multirow[t]{2}{*}{212} & 136 & -.101 & .016 & .064 & & & & .072 & .113 \\
\hline & & $(0.69)$ & $(0.66)$ & $(0.67)$ & & & & $(6.06)$ & $(5.84)$ \\
\hline \multirow[t]{2}{*}{231} & 136 & .377 & -.056 & .004 & & & .038 & .093 & .039 \\
\hline & & $(1.29)$ & $(1.37)$ & $(0.07)$ & & & $(3.41)$ & $(5.67)$ & $(1.47)$ \\
\hline \multirow[t]{2}{*}{232} & 136 & .292 & -.037 & .021 & & & & .035 & .076 \\
\hline & & $(1.55)$ & $(1.51)$ & $(0.76)$ & & & & $(4.72)$ & $(6.56)$ \\
\hline \multirow[t]{2}{*}{233} & 136 & .880 & -.112 & .082 & & & & .144 & .139 \\
\hline & & $(2.29)$ & $(2.35)$ & $(1.80)$ & " & & & (7.14) & $(5.86)$ \\
\hline \multirow[t]{2}{*}{242} & 154 & .210 & -.025 & -.092 & .068 & .115 & .161 & .173 & .204 \\
\hline & & $(1.60)$ & $(1.62)$ & (1.49) & $(5.24)$ & $(8.82)$ & $(12.87)$ & $(13.04)$ & (13.98) \\
\hline \multirow[t]{2}{*}{271} & 166 & .539 & -.074 & .068 & & & & & .082 \\
\hline & & $(3.15)$ & $(3.13)$ & $(2.59)$ & & & & & $(7.95)$ \\
\hline \multirow[t]{2}{*}{301} & 134 & .374 & -.054 & -.085 & & & & & -.003 \\
\hline & & $(2.01)$ & $(2.02)$ & $(1.67)$ & & & & & $(0.14)$ \\
\hline \multirow[t]{2}{*}{311} & 170 & .056 & -.009 & -.032 & & & & & .101 \\
\hline & & $(0.38)$ & $(0.39)$ & $(0.41)$ & & & & & $(4.43)$ \\
\hline \multirow[t]{2}{*}{314} & 136 & 1.386 & --.179 & -.052 & & & & & .249 \\
\hline & & $(3.22)$ & $(3.22)$ & $(1.43)$ & & & & & $(12.09)$ \\
\hline \multirow[t]{2}{*}{324} & 187 & .087 & -.015 & -.010 & & & & & .195 \\
\hline & & $(0.56)$ & $(0.58)$ & $(0.34)$ & & & & & $(12.82)$ \\
\hline \multirow[t]{2}{*}{331} & 128 & -.026 & .002 & .007 & .057 & .083 & .058 & .143 & .168 \\
\hline & & $(0.24)$ & $(0.20)$ & $(0.32)$ & $(4.40)$ & $(6.10)$ & $(4.25)$ & $(7,69)$ & $(8.78)$ \\
\hline \multirow[t]{2}{*}{332} & 170 & -.088 & .011 & .034 & & & & & .139 \\
\hline & & $(0.70)$ & $(0.67)$ & $(1.02)$ & & & & & $(5.54)$ \\
\hline \multirow[t]{2}{*}{336} & 170 & --.140 & .021 & .033 & & & & .119 & .122 \\
\hline & & $(1.56)$ & $(1.53)$ & $(1.19)$ & & & & $(5.85)$ & $(4.73)$ \\
\hline \multirow[t]{2}{*}{341} & 191 & .259 & -.042 & .005 & & & & .061 & .145 \\
\hline & & $(1.60)$ & $(1.59)$ & $(0.19)$ & & & & $(7.48)$ & $(17.56)$ \\
\hline
\end{tabular}

t-statistics are in parentheses.

a $\hat{\delta}$ is the coefficient estimate of $\log Y_{d t-1}-\log Y_{d t-13}$ under the non-perfect expectational hypothesis. 


\begin{tabular}{|c|c|c|c|c|c|c|c|c|c|}
\hline$\hat{\gamma}_{1}$ & $\hat{\gamma}_{2}$ & $\hat{7}$ & $\hat{\gamma}_{4}$ & $\hat{\gamma}_{5}$ & $\hat{\gamma}_{6}$ & $\mathrm{a} \hat{\partial}$ & $\mathrm{R}^{2}$ & SE & DW \\
\hline .079 & .041 & .076 & .119 & .058 & .060 & .058 & .638 & .0125 & 2.01 \\
\hline$(5.92)$ & $(2.30)$ & $(4.98)$ & $(7.47)$ & $(3.71)$ & $(3.16)$ & $(3.30)$ & & & \\
\hline .137 & .097 & .063 & .026 & & & .064 & .843 & .0187 & 2.20 \\
\hline$(5.95)$ & $(5.92)$ & $(7,18)$ & $(2.71)$ & & & $(2.90)$ & & & \\
\hline-.017 & .025 & & & & & .024 & .180 & .0114 & 2.16 \\
\hline \multirow[t]{2}{*}{$(1.40)$} & $(2.60)$ & & & & & (1.43) & & & \\
\hline & 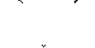 & & & & & & .363 & .0172 & 2.24 \\
\hline-.031 & .033 & .025 & & & & .018 & .506 & .0207 & 1.96 \\
\hline$(1.60)$ & $(2.20)$ & $(2.46)$ & & & & $(1.05)$ & & & \\
\hline .061 & .041 & .005 & & & & & .382 & .0118 & 1.27 \\
\hline \multirow[t]{2}{*}{$(4.18)$} & $(3.82)$ & $(0.62)$ & & & & & & & \\
\hline & & & & & & & .531 & .0286 & 1.40 \\
\hline .064 & .056 & & & & & & .784 & .0126 & 1.79 \\
\hline$(4.49)$ & $(4.40)$ & & & & & & & & \\
\hline-.010 & .017 & .029 & .003 & .031 & & & .560 & .0048 & 2.11 \\
\hline$(1.00)$ & $(1.72)$ & $(2.86)$ & $(0.27)$ & $(3.32)$ & & & & & \\
\hline .008 & -.007 & .010 & & & & & .042 & .0166 & 1.44 \\
\hline$(0.38)$ & $(0.35)$ & $(0.52)$ & & & & & & & \\
\hline .018 & .073 & .052 & .027 & .033 & & & .241 & .0130 & 2.12 \\
\hline$(1.03)$ & $(4.38)$ & $(3.30)$ & $(1.90)$ & $(2.56)$ & & & & & \\
\hline .067 & .082 & .013 & & & & .113 & .671 & .0141 & 2.20 \\
\hline$(3.14)$ & $(5.48)$ & $(0.93)$ & & & & $(4.67)$ & & & \\
\hline-.024 & -.026 & .027 & .003 & & & .029 & .559 & .0196 & 1.94 \\
\hline \multirow[t]{2}{*}{$(1.65)$} & $(1.65)$ & $(1.64)$ & $(0.23)$ & & & (1.51) & & & \\
\hline & & & & & & & .774 & .0105 & 1.80 \\
\hline .020 & .031 & .022 & .023 & & & & .200 & .0201 & 1.77 \\
\hline$(1.18)$ & $(2.03)$ & $(1.50)$ & $(1.57)$ & & & & & & \\
\hline .070 & .082 & .071 & .040 & .031 & & & .471 & .0190 & 1.77 \\
\hline (3.64) & $(4.95)$ & $(4.88)$ & $(2.81)$ & $(2.18)$ & & & & & \\
\hline .032 & .019 & .012 & .002 & & & & .758 & .0185 & 1.94 \\
\hline$(3.80)$ & $(2.27)$ & $(1.42)$ & $(0.21)$ & & & & & & \\
\hline
\end{tabular}


also significant. For the fourteen industries in which output expectations are significant, the horizon over which expectations are significant varies from two months for industries 211 and 242 to six months for industry 201 .

For the most part in the table the estimates of the $\gamma_{i}$ coefficients decrease in size as the expected output changes move further away, which is as expected. The estimate of the coefficient $\gamma_{0}$ of $\log Y_{d t}^{e}-\log Y_{d t-1}$ is the largest of the output variable coefficient estimates for all of the industries except 301 , where the estimate of $\gamma_{1}$ is slightly larger. ${ }^{1}$ The over-all results strongly indicate that expected future output changes are significant determinants of the change in the number of production workers employed.

The Durbin-Watson statistics presented in table 4.3 are biased toward two because the excess labor variable $\left(\log M_{2 w t-1}-\log M_{2 w t-1}^{*} H_{2 w t-1}^{*}\right)$ is of the nature of a lagged dependent variable. The bias can be significant, and there may be serial correlation in the model even though the DW statistics in table 4.3 do not indicate so except for industries 212,232 , and 233. This problem will be taken up in detail in ch. 9 , but what can be said here regarding the DW statistics is that in general the results show much less evidence of serial correlation than do the results presented in tables 2.3 and 2.4 of estimating the basic model of previous studies. It will be seen in ch. 9 that serial correlation is not a serious problem with respect to the estimates presented in table 4.3 .

Because of the fact that the excess labor variable is of the nature of a lagged dependent variable, it might be thought that its significance is due to this fact alone and not because it is measuring excess labor. In econometric time series equations, lagged dependent variables are often significant, and the theoretical reasons for why the lagged dependent variable should be significant are often hard to pin down. The excess labor variable in eq. (3.9)' is not a simple lagged dependent variable, however, because log $M_{2 w t-1}^{*} H_{2 w t-1}^{*}$ is substracted from $\log M_{2 w t-1}$. This is not a trivial difference, for $M_{2 w t-1}^{*} H_{2 w t-1}^{*}$ has a large short-run variance since it follows fluctuations in output closely. One possible test to use to see whether the excess labor variable is significant merely because $\log M_{2 w t-1}$ is significant is to estimate eq. (3.9) using $\log M_{2 w t-1}$ in place of $\log M_{2 w t-1}-\log M_{2 w^{\prime} t-1}^{*} H_{2 w t-1}^{*}$ and see whether $\log M_{2 w t-1}$ is significant and whether the fit has been improved by removing the "restriction" from $\log M_{2 w t-1}$. Another possible test to use is to estimate eq. (3.9)' using the lagged dependent variable, log

1.059 for $\hat{\gamma}_{1}$ vs. .055 for $\hat{\gamma}_{0}$. 
$M_{2 w t-1}-\log M_{2 w t-2}$, in place of the excess labor variable and see whether it is significant and whether the fit has been improved.

These two tests were performed, and the results are presented in tables 4.4 and 4.5. For each industry the same equation was estimated as was estimated in table 4.3 (same period of estimation, same number of expectational variables, etc.) except that $\log M_{2 w t-1}-\log M_{2 w t-1}^{*} H_{2 w t-1}^{*}$ was replaced by either $\log M_{2 w t-1}$ or $\log M_{2 w t-1}-\log M_{2 w t-2}$. The constant term and the time trend were left in both equations, although there is probably little theoretical justification for including them. There is actually little theoretical justification for either of the equations, and the estimates are meant merely to be used as a test to see whether the excess labor variable is significant merely because it is of the nature of a lagged dependent variable.

In table 4.4 the results of using $\log M_{2 w t-1}$ in place of the excess labor variable in eq. (3.9)' are presented, and in table 4.5 the results of using $\log M_{2 w t-1}-\log M_{2 w t-2}$ are presented. Looking at the results in table 4.4 first, it is seen that $\log M_{2 w t-1}$ is significant in only five of the seventeen industries $-201,233,271,301$, and 314 . For two of these five industries, 201 and 301, the fit is worse in table 4.4 than in table 4.3 with the excess labor variable included. For industry 301 the difference is substantial $\left(R^{2}=.042 \mathrm{vs} .297\right)$, and for this industry none of the output variables is significant in table 4.4. For the other three industries, 233, 271, and 314, the fit in table 4.4 is better than in table 4.3 , but only slightly so (for $233 R^{2}=$ .531 vs .512 ; for $271 R^{2}=.560$ vs .552 ; for $314 R^{2}=.671$ vs .661 ). For the twelve industries in which $\log M_{2 w t-1}$ is not significant, the fit is worse in table 4.4 than in table 4.3 except for industry 242 , where the fits are essentially the same. (Remember that the excess labor variable was not significant for industries 242 because of the inclusion of the past four output change variables.) For most of the twelve industries except 242 , the fits are not only worse in table 4.4 than in table 4.3 but are substantially worse, and many of the output variables are either not significant or less significant in table 4.4 than they were in table 4.3 . The over-all results definitely indicate that the excess labor variable, $\log M_{2 w t-1}-\log M_{2 w t-1}^{*} H_{2 w t-1}^{*}$, is not significant merely because $\log M_{2 w t-1}$ is: $\log M_{2 w t-1}$ is not in general significant by itself and using $\log M_{2 w t-1}$ in place of $\log M_{2 w t-1}-\log$ $M_{2 w t-1}^{*} H_{2 w t-1}^{*}$ has considerably worsened the over-all results.

Turning now to the results in table 4.5 , it is seen that $\log M_{2 w t-1}-\log$ $M_{2 w t-2}$ is significant in only six of the industries $-231,271,301,311,324$, and 332. For two of these industries the coefficient estimate of $\log M_{2 w t-1}-$ $\log M_{2 w t-2}$ is negative, and for the other four the estimate is positive. For 
TABLE 4.5

Parameter estimates for eq. (3.9)' with $\alpha_{1}\left(\log M_{2 t o t-1}-\log M_{2 u i-2}\right)$ replacing $a_{1}\left(\log M_{2 n t-1}-\right.$ $\log M^{*}\left(v t-1.1 H^{*}{ }_{2 w t-1}\right)$

\begin{tabular}{|c|c|c|c|c|c|c|c|c|c|}
\hline 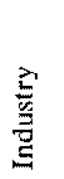 & $\begin{array}{l}\dot{0} \\
0 \\
0 \\
0 \\
\dot{0} \\
\dot{z}\end{array}$ & 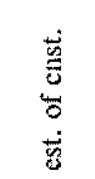 & $\hat{\alpha}_{1}$ & 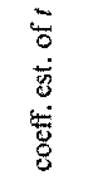 & $\hat{\beta}_{4}$ & $\hat{\beta}_{3}$ & $\hat{\beta}_{2}$ & $\hat{\beta}_{1}$ & $\hat{\gamma}_{0}$ \\
\hline 201 & 192 & $\begin{array}{r}.001 \\
(0.57)\end{array}$ & $\begin{array}{l}-.004 \\
(0.06)\end{array}$ & $\begin{array}{l}-.017 \\
(1.08)\end{array}$ & & & $\begin{array}{r}.096 \\
(4.55)\end{array}$ & $\begin{array}{r}.111 \\
(5.73)\end{array}$ & $\begin{array}{r}.169 \\
(10.20)\end{array}$ \\
\hline 207 & 136 & $\begin{array}{l}-.001 \\
(0.25)\end{array}$ & $\begin{array}{l}-.076 \\
(1.21)\end{array}$ & $\begin{array}{c}.036 \\
(1.21)\end{array}$ & & & $\begin{array}{r}.109 \\
(6.15)\end{array}$ & $\begin{array}{r}.153 \\
(9.64)\end{array}$ & $\begin{array}{r}.219 \\
(10.10)\end{array}$ \\
\hline 211 & 136 & $\begin{array}{r}.001 \\
(0.58)\end{array}$ & $\begin{array}{r}.106 \\
(1.48)\end{array}$ & $\begin{array}{l}-.019 \\
(1.18)\end{array}$ & & & & & $\begin{array}{r}.026 \\
(1.43)\end{array}$ \\
\hline 212 & 136 & $\begin{array}{l}-.003 \\
(0.98)\end{array}$ & $\begin{array}{r}-.091 \\
(1.96)\end{array}$ & $\begin{array}{r}.002 \\
(0.06)\end{array}$ & & & & $\begin{array}{r}.077 \\
(6.39)\end{array}$ & $\begin{array}{r}.103 \\
(5.42)\end{array}$ \\
\hline 231 & 136 & $\begin{array}{l}-.025 \\
(5.60)\end{array}$ & $\begin{array}{l}-.203 \\
(2.64)\end{array}$ & $\begin{array}{r}.072 \\
(2.37)\end{array}$ & & & $\begin{array}{r}.052 \\
(4.21)\end{array}$ & $\begin{array}{r}.128 \\
(6.15)\end{array}$ & $\begin{array}{r}.039 \\
(1.50)\end{array}$ \\
\hline 232 & 136 & $\begin{array}{r}.007 \\
(2.47)\end{array}$ & $\begin{array}{l}-.016 \\
(0.26)\end{array}$ & $\begin{array}{l}-0.12 \\
(0.69)\end{array}$ & & & & $\begin{array}{r}.036 \\
(4.68)\end{array}$ & $\begin{array}{r}.080 \\
(6.99)\end{array}$ \\
\hline 233 & 136 & $\begin{array}{l}-.020 \\
(3.43)\end{array}$ & $\begin{array}{r}.113 \\
(1.82)\end{array}$ & $\begin{array}{r}.050 \\
(1.14)\end{array}$ & & & & $\begin{array}{r}.103 \\
(4.16)\end{array}$ & $\begin{array}{r}.180 \\
(7.51)\end{array}$ \\
\hline 242 & 154 & $\begin{array}{l}-.003 \\
(1.29)\end{array}$ & $\begin{array}{r}.024 \\
(0.29)\end{array}$ & $\begin{array}{r}.005 \\
(0.26)\end{array}$ & $\begin{array}{r}.062 \\
(4.06)\end{array}$ & $\begin{array}{r}.109 \\
(6.04)\end{array}$ & $\begin{array}{r}.158 \\
(9.15)\end{array}$ & $\begin{array}{r}.170 \\
(8.38)\end{array}$ & $\begin{array}{r}.207 \\
(12.98)\end{array}$ \\
\hline 271 & 166 & $\begin{array}{r}.003 \\
(4.09)\end{array}$ & $\begin{array}{l}-.168 \\
(3.03)\end{array}$ & $\begin{array}{l}-.103 \\
(2.13)\end{array}$ & & & & & $\begin{array}{r}.080 \\
(7.67)\end{array}$ \\
\hline 301 & 134 & $\begin{array}{l}-.002 \\
(0.64)\end{array}$ & $\begin{array}{r}.216 \\
(2.62)\end{array}$ & $\begin{array}{r}.010 \\
(0.41)\end{array}$ & & & & & $\begin{array}{r}.001 \\
(0.04)\end{array}$ \\
\hline 311 & 170 & $\begin{array}{l}-.002 \\
(0.84)\end{array}$ & $\begin{array}{r}.164 \\
(2.49)\end{array}$ & $\begin{array}{l}-.002 \\
(0,13)\end{array}$ & & & & & $\begin{array}{r}.093 \\
(4.21)\end{array}$ \\
\hline 314 & 136 & $\begin{array}{l}-.003 \\
(1.01)\end{array}$ & $\begin{array}{r}.154 \\
(1.83)\end{array}$ & $\begin{array}{r}.045 \\
(2.15)\end{array}$ & & & & & $\begin{array}{r}.268 \\
(13.15)\end{array}$ \\
\hline 324 & 187 & $\begin{array}{l}-.002 \\
(0.66)\end{array}$ & $\begin{array}{r}.145 \\
(2.51)\end{array}$ & $\begin{array}{l}-.003 \\
(0.14)\end{array}$ & & & & & $\begin{array}{r}.184 \\
(12.22)\end{array}$ \\
\hline 331 & 128 & $\begin{array}{l}-.005 \\
(2.03)\end{array}$ & $\begin{array}{r}-.065 \\
(0.77)\end{array}$ & $\begin{array}{r}.004 \\
(0.25)\end{array}$ & $\begin{array}{r}.063 \\
(4.38)\end{array}$ & $\begin{array}{r}.086 \\
(6.05)\end{array}$ & $\begin{array}{r}.065 \\
(3.99)\end{array}$ & $\begin{array}{r}.155 \\
(6.37)\end{array}$ & $\begin{array}{r}.170 \\
(9.13)\end{array}$ \\
\hline 332 & 170 & $\begin{array}{l}-.003 \\
(0.85)\end{array}$ & $\begin{array}{r}.200 \\
(2.92)\end{array}$ & $\begin{array}{r}.019 \\
(0.74)\end{array}$ & & & & & $\begin{array}{r}.127 \\
(5.25)\end{array}$ \\
\hline 336 & 170 & $\begin{array}{l}-.003 \\
(0.76)\end{array}$ & $\begin{array}{c}.132 \\
(1.96)\end{array}$ & $\begin{array}{r}.010 \\
(0.42)\end{array}$ & & & & $\begin{array}{r}.105 \\
(4.87)\end{array}$ & $\begin{array}{r}.107 \\
(4.05)\end{array}$ \\
\hline 341 & 191 & $\begin{array}{r}.002 \\
(0.68)\end{array}$ & $\begin{array}{r}.003 \\
(0.04)\end{array}$ & $\begin{array}{l}-.018 \\
(0.78)\end{array}$ & & & & $\begin{array}{r}.059 \\
(4.68)\end{array}$ & $\begin{array}{r}.149 \\
(18.17)\end{array}$ \\
\hline
\end{tabular}

$t$-statistics are in parentheses.

${ }^{2} \hat{\delta}$ is the coefficient estimate of $\log Y_{d t m 1}-\log Y_{a t-1 s}$ under the non-perfect expectational hypothesis. 


\begin{tabular}{|c|c|c|c|c|c|c|c|c|c|}
\hline$\hat{\gamma}_{1}$ & $\hat{\jmath}_{2}$ & $\hat{\gamma}_{\mathrm{a}}$ & $\hat{\gamma}_{4}$ & $\hat{\gamma}^{\prime}$ & $\hat{\gamma}_{0}$ & $\mathrm{a} \hat{\delta}$ & $\mathbf{R}^{2}$ & $\mathrm{SE}$ & DW \\
\hline $\begin{array}{r}.082 \\
(6.06)\end{array}$ & $\begin{array}{r}.046 \\
(2.45)\end{array}$ & $\begin{array}{r}.080 \\
(4.84)\end{array}$ & $\begin{array}{r}.126 \\
(7.66)\end{array}$ & $\begin{array}{r}.065 \\
(4.16)\end{array}$ & $\begin{array}{r}.069 \\
(3.65)\end{array}$ & $\begin{array}{r}.061 \\
(3.43)\end{array}$ & .627 & .0127 & 2.04 \\
\hline .152 & .106 & .070 & .033 & & & .070 & .844 & .0187 & 2.09 \\
\hline$(6.09)$ & $(6.22)$ & (8.12) & $(3.36)$ & & & (3.14) & & & \\
\hline-.013 & .032 & & & & & .024 & .185 & .0114 & 2.54 \\
\hline \multirow[t]{2}{*}{$(1.10)$} & $(3.32)$ & & & & & $(1.48)$ & & & \\
\hline & & & & & & & .379 & .0170 & 1.74 \\
\hline-.037 & .028 & .018 & & & & .014 & .525 & .0203 & 1.87 \\
\hline$(2.07)$ & $(1.93)$ & $(1.67)$ & & & & $(0.86)$ & & & \\
\hline .067 & .045 & .006 & & & & & .371 & .0119 & 1.30 \\
\hline \multirow[t]{2}{*}{$(4.69)$} & $(4.27)$ & $(0.80)$ & & & & & & & \\
\hline & & & & & & & .524 & .0288 & 1.58 \\
\hline .069 & .062 & & & & & & .780 & .0127 & 1.88 \\
\hline$(4.82)$ & $(4.98)$ & & & & & & & & \\
\hline-.003 & .024 & .035 & .008 & .053 & & & .559 & .0048 & 1.88 \\
\hline$(0.29)$ & $(2.52)$ & $(3,42)$ & $(0.85)$ & $(4.82)$ & & & & & \\
\hline .021 & .001 & .019 & & & & & .062 & .0164 & 2.02 \\
\hline$(1.09)$ & $(0.08)$ & $(1.05)$ & & & & & & & \\
\hline .011 & .067 & .052 & .027 & .030 & & & .269 & .0128 & 2.49 \\
\hline$(0.61)$ & (4.19) & $(3.53)$ & (2.06) & $(2.38)$ & & & & & \\
\hline .080 & .125 & .055 & & & & .080 & .653 & .0144 & 2.28 \\
\hline$(3.67)$ & $(8.23)$ & $(3.37)$ & & & & $(3.40)$ & & & \\
\hline-.014 & -.018 & .021 & .017 & & & .023 & .573 & .0192 & 2.26 \\
\hline \multirow[t]{2}{*}{$(0.93)$} & (1.18) & $(1.30)$ & $(1.12)$ & & & $(1.22)$ & & & \\
\hline & & & & & & & .775 & .0104 & 1.64 \\
\hline .009 & .026 & .015 & .019 & & & & .238 & .0196 & 2.39 \\
\hline$(0.56)$ & (1.83) & $(1.10)$ & $(1.38)$ & & & & & & \\
\hline .058 & .070 & .063 & .032 & .026 & & & .476 & .0189 & 2.03 \\
\hline$(3.02)$ & $(4.17)$ & $(4.43)$ & $(2.34)$ & $(1.86)$ & & & & & \\
\hline .038 & .023 & .017 & .006 & & & & .755 & .0187 & 1.98 \\
\hline$(4.77)$ & $(2.94)$ & $(2.14)$ & $(0.78)$ & & & & & & \\
\hline
\end{tabular}


industry 271 the fit is slightly better in table 4.5 than in table $4.3\left(R^{2}=.559\right.$ vs .552), but for the other five industries the fit is substantially worse in table 4.5 (for $231 R^{2}=.525$ vs .567 ; for $301 R^{2}=.062$ vs .297 ; for 311 $R^{2}=.269$ vs .413 ; for $324 R^{2}=.573$ vs .639 ; for $332 R^{2}=.238$ vs .450 ). For the eleven industries in which $\log M_{2 w t-1}-\log M_{2 w t-2}$ is not significant, the fit is worse (and in many cases substantially worse) in table 4.5 than in table 4.3 except for industry 233 , where the fit is slightly better in table $4.5\left(R^{2}=.524\right.$ vs .512$)$. The output variables in table 4.5 are in general much less significant than in table 4.3. The use of $\log M_{2 w t-1}-\log M_{2 w t-2}$ in place of the excess labor variable, $\log M_{2 w t-1}-\log M_{2 w t-1}^{*} H_{2 w t-1}^{*}$, therefore, has considerably worsened the over-all results, and it seems safe to conclude from the results in tables 4.4 and 4.5 that the excess labor variable is significant in its own right and not because it is of the nature of a lagged dependent variable. Some further results will be presented in ch. 7 which indicate that the excess labor variable is also significant in the equation determining the change in the number of hours paid-for per worker, and these results are an independent confirmation of the hypothesis that the amount of excess labor on hand affects short-run employment decisions.

In a monthly model such as this one there is the possibility that the behavior of $\log M_{2 w t}-\log M_{2 w t-1}$ is significantly different during one specific month of the year than during the other eleven months. To the extent that the model is well specified this should not be the case, but there may be factors influencing $\log M_{2 w t}-\log M_{2 w t-1}$ in a systematic way during the same month each year which have not been taken into account in the model. One possible test to use to test whether this is true is the $F$-test, testing the hypothesis that the coefficients for one specific month of the year are the same as the coefficients for all of the other months. A cruder test was in fact performed in this study. For each industry for each month the number of positive and negative residuals was calculated to see if there was a systematic tendency for the estimated equation to underpredict or overpredict for a specific month. Assuming that the probability of any one residual being negative is one-half, the hypothesis that the residuals for any one month come from a binomial population (with $p=1 / 2$ ) was rejected (at the five-percent confidence level) in 37 of the 162 cases, or in about 23 percent of the cases. ${ }^{1}$

1 It should be emphasized that this test is crude and that the results of the test should be interpreted as indicating only general tendencies. 
Six of these cases occurred for the June-May period (where the model underpredicted) and seven for the October-September period (where the model overpredicted). The student influx in early June and outflow in middle September probably account for this situation. Four of the cases occurred for the December-November period (where the model underpredicted), and these are probably accounted for by the fact that for December the average daily rate of output for the month is likely to be much less than the rate during the second week. Five of the cases occurred for the March-February period (where the model overpredicted), and this may be accounted for by the fact that for March the average daily rate of output for the month may be greater than the rate during the second week if the spring upturn begins during the last half of March. The other fifteen cases were about evenly distributed over the remaining months and showed no systematic tendency to underpredict or overpredict for a particular month.

For the 77 percent of the cases where the hypothesis was not rejected, the residuals appeared to be fairly random. The general conclusion of this test is that while there are some systematic tendencies by month which the model fails to account for, some of which can be explained by faulty data and some by student inflows and outflows, the model in general seems to do reasonably well.

In summary, then, the results appear to be quite good. The amount of excess labor on hand definitely appears to be a significant factor in the determination of the change in the number of workers employed, and the time stream of expected future changes in output also appears to be a significant factor. The coefficient estimates are of the right sign and in most cases are highly significant. For every industry the fit is better than the fit of the basic model of previous studies, and for most industries it is substantially better. There seems to be only a few monthly systematic tendencies which the model has not explained, and it will be seen later that in general the residuals of the equations are not serially correlated.

\subsubsection{A comparison of the expectational hypotheses}

In table 4.6 the results are presented of estimating eq. $(3.9)^{\prime}$ for each industry under the alternative (and inferior) expectational hypothesis to that assumed 
TABLE 4.6

Parameter estimates for eq. (3.9)' under the alternative (and inferior) expectational hypothesis to that used in table 4.3 for each industry

\begin{tabular}{|c|c|c|c|c|c|c|c|c|c|}
\hline 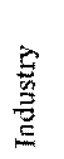 & $\begin{array}{l}\dot{8} \\
0 \\
0 \\
\dot{0} \\
\dot{0}\end{array}$ & $\alpha_{1} \log \bar{H}$ & $\hat{\alpha}_{1}$ & $1000 \widehat{a_{1} \mu}$ & $\hat{\beta}_{4}$ & $\hat{\beta}_{3}$ & $\hat{\beta}_{2}$ & $\hat{\beta}_{1}$ & $\hat{y}_{0}$ \\
\hline \multirow[t]{2}{*}{201} & 192 & -.430 & -.073 & -.026 & & & .064 & .103 & .201 \\
\hline & & $(2.52)$ & $(2.52)$ & $(1.46)$ & & & $(3.23)$ & $(5.68)$ & (8.74) \\
\hline \multirow[t]{2}{*}{207} & 136 & -.775 & -.134 & .074 & & & .064 & .109 & .245 \\
\hline & & $(2.80)$ & $(2.79)$ & $(2,03)$ & & & $(5.03)$ & $(5.16)$ & $(10.00)$ \\
\hline \multirow[t]{2}{*}{211} & 136 & -.674 & -.115 & -.047 & & & .079 & .012 & .039 \\
\hline & & $(5.82)$ & $(5.83)$ & $(3.00)$ & & & $(4.21)$ & $(0.94)$ & $(4.56)$ \\
\hline \multirow[t]{2}{*}{231} & 136 & -.805 & -.136 & .084 & & v & .031 & .066 & .094 \\
\hline & & $(6.27)$ & $(6.04)$ & $(2.88)$ & & & $(2.90)$ & $(4.05)$ & $(4,08)$ \\
\hline \multirow[t]{2}{*}{232} & 136 & -.385 & -.068 & -.031 & & & & .030 & .088 \\
\hline & & $(2.88)$ & $(2.89)$ & $(1.47)$ & & & & $(3.57)$ & $(5.25)$ \\
\hline \multirow[t]{2}{*}{242} & 154 & -.042 & -.006 & .006 & .066 & .111 & .156 & .166 & .222 \\
\hline & & $(0.23)$ & $(0.21)$ & $(0.31)$ & $(4.78)$ & $(7.39)$ & $(8.77)$ & $(7.37)$ & $(13.14)$ \\
\hline \multirow[t]{2}{*}{271} & 166 & -.304 & -.052 & .005 & & & & & .125 \\
\hline & & $(2.11)$ & $(2.12)$ & $(0.55)$ & & & & & (5.51) \\
\hline \multirow[t]{2}{*}{311} & 170 & -.911 & -.155 & -.044 & & & & & .164 \\
\hline & & (3.97) & $(3.96)$ & $(2.23)$ & & & & & $(4.60)$ \\
\hline \multirow[t]{2}{*}{314} & 136 & -.599 & -.102 & .043 & & & & & .300 \\
\hline & & $(2.86)$ & $(2.84)$ & $(2.02)$ & & & & & $(11.58)$ \\
\hline \multirow[t]{2}{*}{324} & 187 & -.668 & -.112 & .066 & & & & & .221 \\
\hline & & $(6.28)$ & $(6.29)$ & $(2.53)$ & & & & & $(13.99)$ \\
\hline \multirow[t]{2}{*}{332} & 170 & -.367 & -.061 & .035 & & & & & .133 \\
\hline & & $(2.51)$ & $(2.49)$ & $(1.42)$ & & & & & $(4.58)$ \\
\hline \multirow[t]{2}{*}{336} & 170 & -.228 & -.038 & -.001 & & & & .132 & .126 \\
\hline & & $(1.15)$ & $(1.12)$ & $(0,03)$ & & & & $(6.05)$ & (3.54) \\
\hline \multirow[t]{2}{*}{341} & 191 & -.227 & -.041 & -.045 & & & & .038 & .173 \\
\hline & & $(2.15)$ & $(2.16)$ & $(1.65)$ & & & & $(3.69)$ & $(14.24)$ \\
\hline \multirow[t]{4}{*}{301} & b99 & -.591 & -.102 & -.054 & & & & & .059 \\
\hline & & $(4.41)$ & $(4.36)$ & $(1.68)$ & & & & & $(2.23)$ \\
\hline & b99 & -.351 & -.060 & -.010 & & & & & -.007 \\
\hline & & $(1.80)$ & $(1.78)$ & $(0.31)$ & & & & & $(0.22)$ \\
\hline
\end{tabular}

$t$-statistics are in parentheses.

* $\hat{\delta}$ is the coefficient estimate of $\log Y_{a t-1}-\log Y_{a t-13}$ under the non-perfect expectational hypothesis.

b Different period of estimation used here than in table 4.3 . 


\begin{tabular}{|c|c|c|c|c|c|c|c|c|c|}
\hline$\hat{\gamma}_{1}$ & $\hat{\gamma}_{2}$ & $\hat{\gamma}_{3}$ & $p_{4}$ & $\hat{\gamma}_{5}$ & $\hat{\gamma}_{6}$ & $2 \hat{\delta}$ & $\mathbf{R}^{2}$ & SE & DW \\
\hline $\begin{array}{r}.106 \\
(5.07)\end{array}$ & $\begin{array}{r}.046 \\
(2.05)\end{array}$ & $\begin{array}{r}.124 \\
(6.70)\end{array}$ & $\begin{array}{r}.140 \\
(8.09)\end{array}$ & $\begin{array}{r}.058 \\
(3.42)\end{array}$ & $\begin{array}{r}.042 \\
(2.08)\end{array}$ & & .607 & .0130 & 1.72 \\
\hline \multirow[t]{2}{*}{$(5.86)$} & $\begin{array}{r}.126 \\
(7.06)\end{array}$ & $\begin{array}{r}.075 \\
(8.10)\end{array}$ & $\begin{array}{r}.034 \\
(3.46)\end{array}$ & & & & .830 & .0195 & 1.90 \\
\hline & & & & & & & .338 & .0102 & 1.93 \\
\hline $\begin{array}{l}-.019 \\
6999\end{array}$ & .037 & .020 & & & & & .562 & .0194 & 2.13 \\
\hline $\begin{array}{r}.021 \\
.021\end{array}$ & $\begin{array}{r}(2.60) \\
.023\end{array}$ & .000 & & & & .013 & .314 & .0124 & 1.54 \\
\hline$(1.46)$ & $(2.10)$ & $(0.03)$ & & & & $(1.10)$ & & & \\
\hline $\begin{array}{r}.052 \\
(3.74)\end{array}$ & $\begin{array}{r}.064 \\
(4.94)\end{array}$ & & & & & $\begin{array}{r}.034 \\
(2.30)\end{array}$ & .770 & .0131 & 1.88 \\
\hline .035 & .040 & .048 & .019 & .030 & & .024 & .517 & .0050 & 2.13 \\
\hline$(1.75)$ & $(2.23)$ & $(3.33)$ & $(1.59)$ & $(2.85)$ & & $(2.03)$ & & & \\
\hline .028 & .068 & .049 & .034 & .023 & & -.010 & .271 & .0128 & 1.92 \\
\hline$(1.25)$ & $(3.42)$ & $(2.84)$ & $(2.17)$ & $(1.67)$ & & $(0.63)$ & & & \\
\hline .114 & .133 & .040 & & & & & .637 & .0147 & 2.05 \\
\hline$(4.12)$ & $(8.34)$ & $(2.98)$ & & & & & & & \\
\hline .042 & .026 & .046 & .053 & & & & .630 & .0179 & 2.03 \\
\hline$(1.81)$ & $(1.31)$ & $(2,37)$ & $(2.86)$ & & & & & & \\
\hline-.027 & .001 & -.000 & .001 & & & -.006 & .371 & .0179 & 2.06 \\
\hline$(1.74)$ & $(0.06)$ & $(0.03)$ & $(0.08)$ & & & $(0.52)$ & & & \\
\hline-.032 & .023 & .032 & .019 & .017 & & -.019 & .447 & .0195 & 1.83 \\
\hline$(1.73)$ & $(1.26)$ & $(1.87)$ & $(1.17)$ & $(1.07)$ & & $(1.24)$ & & & \\
\hline .047 & .043 & .025 & .010 & & & .038 & .767 & .0183 & 1.97 \\
\hline (4.19) & $(4.47)$ & $(2.67)$ & $(1.03)$ & & & $(2.96)$ & & & \\
\hline .067 & .049 & .037 & & & & & .212 & .0151 & 2.06 \\
\hline (2.93) & $(2.37)$ & $(1.85)$ & & & & & & & \\
\hline-.032 & -.036 & -.041 & & & & -.034 & .180 & .0155 & 2.14 \\
\hline$(1.56)$ & $(1.41)$ & $(1.74)$ & & & & $(1.84)$ & & & \\
\hline
\end{tabular}


in table $4.3 .^{1}$ For each industry the same expectational time horizon (size of $n$ ) was used as proved to be significant for the estimates in table 4.3. For industries 212, 233, and 331 none of the expected future output change variables was significant under either expectational hypothesis, and thus no comparison for these industries is needed. ${ }^{2}$

For six industries - 201, 207,211,231, 314, and 324 - the non-perfect expectational hypothesis is superior. Examining the results for these industries in the two tables reveals that the perfect expectational hypothesis works almost as well in all six industries. For the perfect expectational hypothesis the estimates of the $\gamma_{i}$ coefficients are nearly as significant as for the other hypothesis, and the fits are nearly as good. Industry 201 shows the most difference between the two hypotheses, but even in this case the perfect expectational hypothesis does not perform badly.

In three of the six industries where the non-perfect expectational hypothesis gives the better results, the estimates of the coefficient $\dot{\delta}$ of $\log Y_{d t-1}-\log$ $Y_{d t-13}$ are not significant, which, under the assumption that all of the $\lambda_{i}$ coefficients are equal, implies that the rate of output in a specific future month is expected to be equal to what the rate of output was during the same month of the preceeding year. Expectations in this case are static.

For the remaining eight industries $-232,242,271,301,311,332,336$, and 341 - the perfect expectational hypothesis is superior. Examining the results for these industries in the two tables reveals that the non-perfect expectational hypothesis works almost as well for industries 242, 271, and 341. For the five industries, 232, 301, 311, 332, and 336, however, the non-perfect expectational hypothesis yields substantially inferior results than

1 As mentioned in $\$ 4.2$, for industry 301 none of the strike-period observations for output was changed and all of the necessary observations were omitted. Since the non-perfect expectational hypothesis involved longer lags, it was necessary to omit more observations under this hypothesis than under the perfect expectational hypothesis. To make the results for this industry comparable, therefore, the equation for the perfect expectational hypothesis was re-estimated using the same period of estimation as was used to estimate the equation for the non-perfect expectational hypothesis. In table 4.6 both of these results are presented, and a comparison of the expectational hypotheses for this industry is made using these results.

a For industry 331 none of the strike-period observations for output was changed, and when estimating eq. (3.9)' for this industry under the non-perfect expectational hypothesis, a different period of estimation (in which more observations were omitted) was used than was used in table 4.3. None of the expected future output change variables was significant for either period of estimation, and so the larger period of estimation was used for the estimates in table 4.3. 
does the perfect expectational hypothesis, both on grounds of goodness of fit and significance of the $\gamma_{i}$ coefficient estimates. The fits are much worse $^{1}$ and most of the estimates of the $\gamma_{i}$ coefficients are not significant.

It is thus quite evident that if one had to choose between the two hypotheses, he would choose the perfect expectational hypothesis as giving the better results. In all fourteen industries for which future output expectations are significant at all, the perfect expectational hypothesis gives good results and results better than the other hypothesis in eight of the fourteen industries. The non-perfect expectational hypothesis, on the other hand, gives good results for only nine of the fourteen industries. It was mentioned in $\S 3.8$ that the perfect expectational hypothesis may be a better approximation of reality if firms can in fact forecast more accurately than the naive, non-perfect expectational hypothesis says they can or if firms schedule production in advance and do not deviate much from this schedule even if demand conditions change. In this study and in the work which follows, an absolute choice was not in fact made between the two hypotheses, and the hypothesis which gave the better results for a particular industry was assumed to be true for that industry.

One other comparison was actually made of the two expectational hypotheses. In addition to the assumption that $Y_{t}^{e}=Y_{t}$, the following additional assumptions were made:

$$
\begin{aligned}
\log Y_{d t+1}^{e}-\log Y_{d t}=\zeta_{1} & \left(\log Y_{d t-11}-\log Y_{d t}\right) \\
& +\left(1-\zeta_{1}\right)\left(\log Y_{d t+1}-\log Y_{d t}\right), \\
\log Y_{d t+2}^{e}-\log Y_{d t+1}^{e}= & \zeta_{2}\left(\log Y_{d t-10}-\log Y_{d t-11}\right) \\
+ & \left(1-\zeta_{2}\right)\left(\log Y_{d t+2}-\log Y_{d t+1}\right), \\
\log Y_{d t+3}^{e}-\log Y_{d t+2}^{e}= & \zeta_{3}\left(\log Y_{d t-9}-\log Y_{d t-10}\right) \\
& +\left(1-\zeta_{3}\right)\left(\log Y_{d t+3}-\log Y_{d t+2}\right),
\end{aligned}
$$

and so on. These assumptions are in a sense a weighted average of the two expectational hypotheses. ${ }^{2}$ For the perfect expectational hypothesis all of

1 For $232, \mathrm{R}^{2}=.314$ vs .494 .

For $301, \mathrm{R}^{2}=.180$ vs .212 .

For $311, \mathrm{R}^{2}=.271$ vs .413 .

For $332, \mathrm{R}^{2}=.371$ vs .450 .

For $336, \mathrm{R}^{2}=.447$ vs .551 .

2 This type of assumption is similar to that made by Lovell in his study of inventory investment. See LovelL (1961, p. 305). 
TABLE 4.7

Parameter estimates for eq. (3.9 ' under the assumptions made in eq. (4.1) about expectations. Estimates presented only for the coefficients of the expectational variables

\begin{tabular}{|c|c|c|c|c|c|c|c|c|c|c|c|c|c|}
\hline 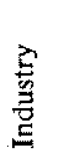 & $\begin{array}{l}\dot{0} \\
0 \\
0 \\
0 \\
0 \\
0\end{array}$ & $\widehat{\gamma_{1} \zeta_{1}}$ & $\widehat{\gamma_{2} \zeta_{2}}$ & $\widehat{\gamma_{3} \zeta_{3}}$ & $\widehat{\gamma_{4}}$ & $\widehat{\gamma_{5} \zeta_{5}}$ & $\gamma_{1}(1-$ & $\gamma_{2}(1-6$ & $\gamma_{3}\left(1-\zeta_{3}\right)$ & $\gamma_{4}\left(1-\xi_{4}\right)$ & $\gamma_{5}\left(1-\zeta_{5}\right)$ & $\mathrm{R}^{2}$ & SE \\
\hline 207 & 136 & $\begin{array}{r}.152 \\
(4.17)\end{array}$ & $\begin{array}{r}.089 \\
(2.76)\end{array}$ & $\begin{array}{r}.058 \\
(2.07)\end{array}$ & $\begin{array}{r}.029 \\
(1.30)\end{array}$ & & $\begin{array}{r}.051 \\
(1.30)\end{array}$ & $\begin{array}{r}.055 \\
(1.65)\end{array}$ & $\begin{array}{r}.021 \\
(0.76)\end{array}$ & $\begin{array}{r}.007 \\
(0.30)\end{array}$ & & .851 & .0185 \\
\hline 232 & 136 & $\begin{array}{r}.002 \\
(0.19)\end{array}$ & $\begin{array}{r}.014 \\
(1.28)\end{array}$ & $\begin{array}{r}.015 \\
(1.46)\end{array}$ & & & $\begin{array}{r}.089 \\
(6.45)\end{array}$ & $\begin{array}{r}.050 \\
(4.05)\end{array}$ & $\begin{array}{r}.005 \\
(0.52)\end{array}$ & & & .507 & .0106 \\
\hline 242 & 154 & $\begin{array}{r}.011 \\
(0.97)\end{array}$ & $\begin{array}{r}.032 \\
(1.64)\end{array}$ & & & & $\begin{array}{c}.066 \\
(4.11)\end{array}$ & $\begin{array}{r}.041 \\
(2.06)\end{array}$ & & & & .788 & .0126 \\
\hline 311 & 170 & $\begin{array}{r}.018 \\
(1.11)\end{array}$ & $\begin{array}{r}.041 \\
(1.82)\end{array}$ & $\begin{array}{r}.028 \\
(1.26)\end{array}$ & $\begin{array}{r}.021 \\
(1.02)\end{array}$ & $\begin{array}{l}-.023 \\
(1.14)\end{array}$ & $\begin{array}{r}.089 \\
(4.89)\end{array}$ & $\begin{array}{r}.095 \\
(4.73)\end{array}$ & $\begin{array}{r}.073 \\
(3.77)\end{array}$ & $\begin{array}{r}.047 \\
(2.51)\end{array}$ & $\begin{array}{r}.061 \\
(3.31)\end{array}$ & .435 & .0114 \\
\hline 314 & 136 & $\begin{array}{r}.046 \\
(2.08)\end{array}$ & $\begin{array}{r}.098 \\
(3.29)\end{array}$ & $\begin{array}{r}.047 \\
(1.65)\end{array}$ & & & $\begin{array}{r}.097 \\
(3.49)\end{array}$ & $\begin{array}{c}.060 \\
(2.09)\end{array}$ & $\begin{array}{r}.008 \\
(0.29)\end{array}$ & & & .666 & .0143 \\
\hline \multicolumn{14}{|c|}{ Implied values of the $\zeta_{i}$ coefficients } \\
\hline & & & & & $\zeta_{1}$ & $\zeta_{2}$ & $\zeta_{3}$ & $\xi_{4}$ & $\zeta_{5}$ & & & & \\
\hline 207 & & & & & .749 & .617 & .734 & .806 & & & & & \\
\hline 232 & & & & & .022 & .219 & .750 & & & & & & \\
\hline 242 & & & & & .143 & .438 & & & & & & & \\
\hline 311 & & & & & .168 & .301 & .277 & .309 & -.605 & & & & \\
\hline 314 & & & & & .322 & .620 & .855 & & & & & & \\
\hline
\end{tabular}

$t$-statistics are in parentheses. 
the $\zeta_{i}$ 's are zero, and for the non-perfect expectational hypothesis all of the $\zeta_{i}$ 's are one and the $\log Y_{d t-1}-\log Y_{d t-13}$ variable is added.

Eq. (3.9)' was then estimated under the assumptions made in (4.1) for each of the fourteen industries for which future output expectations are significant. Again, the same size of $n$ was used for each industry as proved to be significant in table 4.3. For five industries $-271,301,332,336$, and 341 - it was obvious that the $\zeta_{i}$ coefficients were not significantly different from zero. The output variables representing the perfect expectational hypothesis completely dominated the output variables representing the non-perfect expectational hypothesis. For four industries - 201, 211, 231, and 324 - it was obvious that the $\left(1-\zeta_{i}\right)$ coefficients were not significantly different from zero. For these industries the output variables representing the non-perfect expectational hypothesis completely dominated the output variables representing the perfect expectational hypothesis. These results are consistent with the results reported above of estimating eq. $(3.9)^{\prime}$ under each expectational hypothesis separately. As was seen in tables 4.3 and 4.6, for industries $271,301,332,336$, and 341 the perfect expectational hypothesis gave the better results, and for industries 201,211,231, and 324 the non-perfect expectational hypothesis performed better.

For the five remaining industries - 207, 232, 241, 311, and 314 - one hypothesis likewise appeared to dominate the other, but since this domination was not quite as evident for these industries, it is worthwhile to examine the results more closely. In table 4.7 the results of estimating eq. (3.9)' under the assumptions made in (4.1) are presented for these five industries. The estimates are given only for the coefficients of the expectational variables, as the other coefficient estimates were little changed. Also presented in table 4.7 are the derived values of the $\zeta_{i}$ coefficients.

For industry 207 the estimates of the coefficients of the output variables representing the non-perfect expectational hypothesis are larger and more significant than the estimates of the coefficients of the other output variables (which are small and not significant). The size of $\zeta_{i}$ coefficients ranges between .617 and .806 . For industries 232,242 , and 311 the estimates of the coefficients of the output variables representing the perfect expectational hypothesis are in general larger and more significant, but there does appear to be a tendency for the estimates of the coefficients of the output variables representing the non-perfect expectational hypothesis to become larger and more significant relative to the estimates of the coefficients of the other output variables as the period for which the expectation is made moves further into the future. In other words, there seems to be a tendency for $\zeta_{i}$ 
to increase as $i$ increases. This is definitely true for industries 232 and 242 , and slightly true for 311 , except for the last coefficient, $\zeta_{5}$, which is in fact negative. Industry 314 gives the best results for assumption (4.1). Except for the last period, the estimates of the coefficients of the output variables representing each hypothesis are significant. There is also clear evidence that $\zeta_{i}$ increases as $i$ increases for this industry.

This slight over-all evidence that $\zeta_{i}$ increases as $i$ increases is consistent with theoretical notions, as one would expect that as the periods for which the expectations are made move further into the future, there will be less ability to predict accurately and more of a tendency to rely on past behavior. The results in general indicate, however, that the "weighted average" assumptions made in (4.1) are not an improvement over either the perfect expectational hypothesis or the non-perfect expectational hypothesis considered separately. The fits are little changed over those in table 4.3 , and in general one set of output variables dominates the other set.

\subsection{Summary}

The results presented in this chapter appear to be an important confirmation of the model of the short-run demand for workers which was developed in ch. 3. Using monthly data for seventeen three-digit United States manufacturing industries, the basic equation of the model [eq. (3.9)'] was estimated under the perfect and non-perfect expectational hypotheses. For every industry the fit of eq. (3.9) was better than the fit of eq. (2.37) of the basic model of previous studies and for most industries was considerably better. The excess labor variable in eq. (3.9)' was significant in all but two industries, one in which the past four output change variables were significant. In all of the industries the current output change variable was significant, and for all but three of the industries at least two other expected future output change variables were also significant. The results indicate, therefore, that both the amount of excess labor on hand and the time stream of expected future output changes are significant determinants of the change in the number of production workers employed.

Regarding the expectational hypotheses, the perfect expectational hypothesis gave somewhat better over-all results than the non-perfect expectational hypothesis, but the latter gave slightly better results for six of the fourteen industries where future output expectations were significant. The decision was made to use the non-perfect expectational hypothesis for these six industries and the perfect expectational hypothesis for the eight others. 


\section{TESTS OF VARIOUS HYPOTHESES REGARDING THE SHORT-RUN DEMAND FOR PRODUCTION WORKERS}

\subsection{Introduction}

Eq. $(3.9)^{\prime}$, which was developed in ch. 3 and estimated in ch. 4, appears to be an adequate specification of the short-run demand for production workers. Both the amount of excess labor on hand and the time stream of expected future output changes appear to be significant factors in the determination of a firm's demand for production workers. In table 4.3 the results of estimating eq. (3.9)' for each of the seventeen industries under the best expectational hypothesis for that industry were presented. In this chapter various hypotheses regarding other possible determinants of the short-run demand for production workers are discussed, and using the estimates in table 4.3 as a base of reference, these hypotheses are tested. As was the case for the tests of the expectational hypotheses in ch. 4, the validity of these tests depends on the assumption that eq. (3.9)' is an adequate specification of the short-run demand for production workers to begin with.

\subsection{The short-run substitution of hours for workers}

As was seen in ch. 2, KUH (1965b) has been the only one who has done any empirical work at all on the short-run relationship between the number of workers employed and the number of hours worked per worker. Kuh adds the variable $\log H_{t-1}-\log H_{t-2}$ (using the notation of ch. 2) to an equation like (2.37) of the basic model, arguing that a positive rate of change of hours in the previous period will have a positive effect on the number of workers employed in the current period as firms try to reduce high overtime costs. The hours variable which Kuh uses is an hours paid-for variable.

In this study the view has been presented that $H_{2 w t}$, the actual number of hours effectively worked per worker during the second week of month $t$, is not observed and that the observed number of hours paid-for per worker during the second week of month $t, H P_{2 w r}$, is likely to be a poor measure of $H_{2 w t}$ during all but the peak output periods. Since $H_{2 w t}$ cannot be observed, no tests can be made on the possible short-run substitution of hours worked 
per worker and workers. In fact the model developed above assumes that the number of hours worked per worker is the major adjustment mechanism in the short run. The assumptions of no short-run substitution possibilities and of constant returns to scale, combined with the fact that output fluctuates more than the number of workers employed in the short run, imply that the number of hours worked per worker is the primary adjustment mechanism. From eq. (3.6) $H_{2 w t}$ is equal to $Y_{2 w t} / \alpha_{2 w t} M_{2 w t}{ }^{1}$ and since $\alpha_{2 w t}$ is fairly constant in the short run, if $Y_{2 w t}$ changes by a larger percentage than $M_{2 w t}, H_{2 w t}$ must adjust accordingly.

Due to this observational problem, tests can only be performed on $H P_{2 x t}$. It was seen above that the amount of excess labor on hand during the second week of month $t-1$, measured as $\log H S_{2 w t-1}-\log H_{2 w t-1}{ }^{2}$ definitely appears to be a significant factor affecting firms' employment decisions. The question arises whether a variable like $\log H S_{2 w t-1}-\log H P_{2 w t-1}$, which is the difference between the standard (or long-run equilibrium) number of hours of work per worker and the actual number of hours paid-for per worker, should be significant as well. $H P_{2 w}$ can never be less than $H_{2 w}$ (hours actually worked per worker must be paid for by the firm), and when $H P_{2 w}$ equals $H_{2 w}$, the excess labor variable and $\log H S_{2 w t-1}-\log H P_{2 w t-1}$ are equivalent. When $H P_{2 w}$ is greater than $H_{2 w}$, these two variables are not the same, and a priori there appears to be little reason why in this case $\log H S_{2 w t-1}-\log H P_{2 w t-1}$ should be a significant factor affecting employment decisions. If $H P_{2 w t-1}$ does not equal $H S_{2 w t-1}$, the obvious thing for the firm to do (if it wants to make any adjustment at all) is to change $H P_{2 w^{*}}$ It can raise $H P_{2 w}$ at will, and as long as $H P_{2 w}$ is greater than $H_{2 w}$, the firm can also lower $H P_{2 w}$ without the necessity of increasing $M_{2 w}$. The firm cannot, however, lower $H P_{2 w}$ at will if $H P_{2 w}$ equals $H_{2 w}$, and in this case it must increase $M_{2 w}$ in order to lower $H P_{2 w}$. This, however, is exactly what the excess labor variable implies the firm will do when $H_{2 w t-1}$ is greater than $H S_{2 w t-t}$. There thus seems to be little reason why $\log H S_{2 w t-1}-$ $\log H P_{2 w t-1}$ should be a significant determinant of $\log M_{2 w t}-\log M_{2 w t-1}$ other than at those times when $H^{P_{2 w t-1}}$ equals $H_{2 w t-1}$.

1 Eq. (3.6) is actually expressed in terms of $M^{*} *_{2 u t} H^{*}{ }_{2 u t}$ rather than $M_{2 u t} H_{2 u t}$, but since these two variables are equal to one another (both of them being equal to the total number of man hours worked), eq. (3.6) can be expressed in terms of $M_{2 n t} H_{2 n t}$, which then implies that $H_{2 w t}$ is equal to $Y_{2 w t} / \alpha_{2 w t} M_{2 w t}$.

${ }^{2}$ In this discussion the measure of the amount of excess labor on hand is referred to as $\log H S_{2 w t-1}-\log H_{2 w t-1}$ instead of the equivalent $\log M_{2 w t-1}-\log M_{2 v t-1}^{d_{2}}$. 
There also seems little reason why, as Kuh's argument suggests, log $H P_{2 w t-1}-\log H P_{2 w t-2}$ should be a significant factor affecting employment

\section{TABLE 5.1}

Parameter estimates for eq. (3.9)' with the additional term $\alpha_{2} \log H P_{2 w t-1}$. Estimates presented for $\alpha_{1}$ and $\alpha_{2}$ only

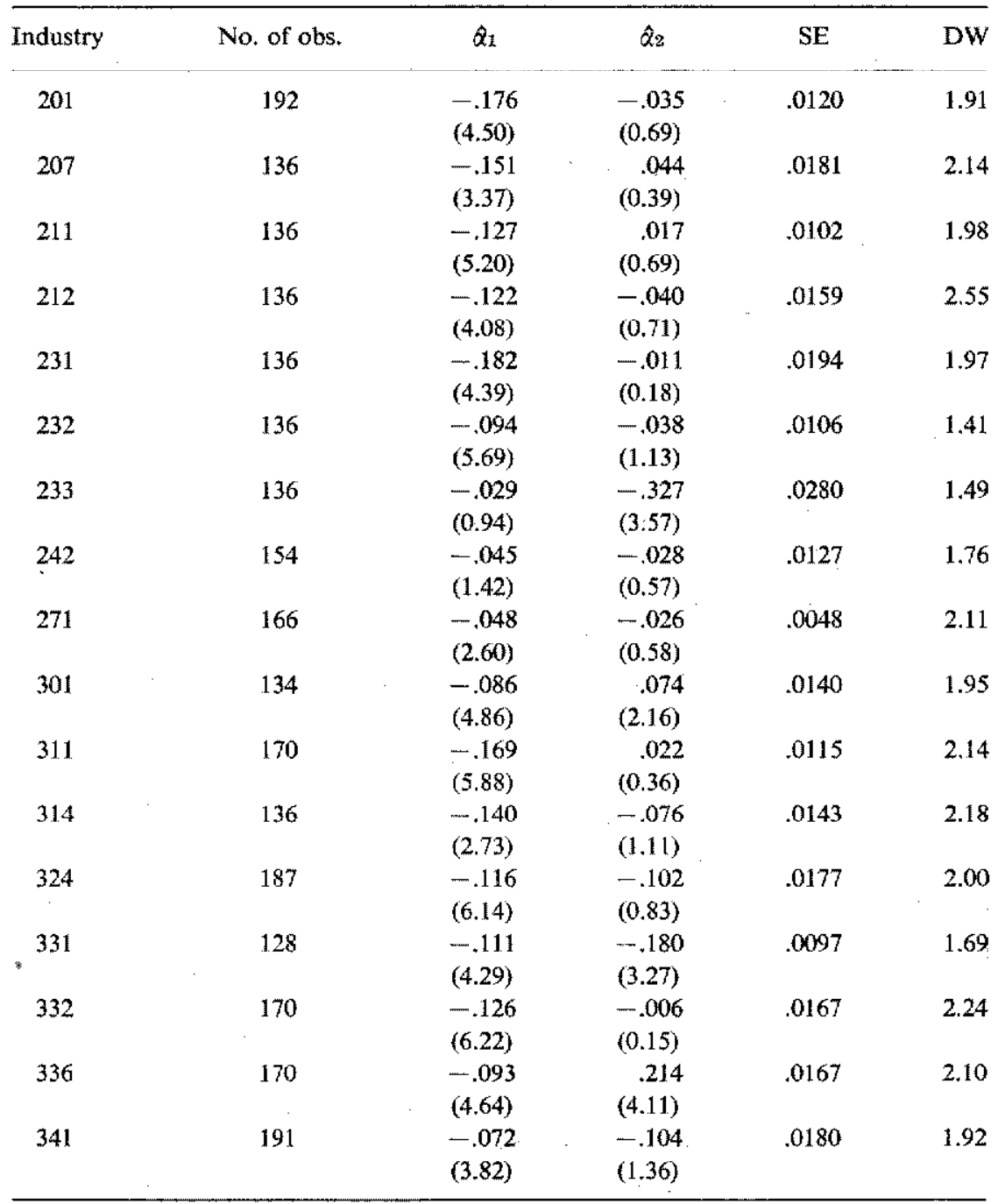

$t$-statistics are in parentheses. 
decisions. It is the level of $H P_{2 w t-1}$ (whether or not $H P_{2 w: t-1}$ is greater than $H_{2 w t-1}$ or $H S_{2 w t-1}$, etc.) which would seem to be appropriate for consideration and not the change in $H P_{2 w t-1}$ from whatever level last period.

For each of the seventeen industries the variable $\log H S_{2 w-1}-\log$ $H P_{2 w^{\prime}-1}$ was added to eq. (3.9)' to see if this variable had any of the same properties of the excess labor variable, $\log H S_{2 w t-1}-\log H_{2 w t-1}$. On the assumption that $\log H S_{2 w t-1}$ equals $\log \bar{H}+\mu t$, which was made in eq. (3.11), this is equivalent to adding the variable $\log H P_{2 w t-1}$ to eq. (3.9)'. Since the sign of the coefficient of $\log H S_{2 w t-1}-\log H P_{2 w t-1}$ is expected to be negative if this variable has any of the same properties of the excess labor variable, the estimate of the coefficient of $\log H P_{2 w t-1}$ should be positive in the estimated equation. The coefficient of $\log H P_{2 w+-1}$ is denoted as $\alpha_{2}$.

The results of adding $\log H P_{2 w t-1}$ to eq. (3.9) are presented in table 5.1. The same equation was estimated for each industry (same period of estimation, same expectational variables, etc.) as was estimated in table 4.3 , except that $\log H P_{2 w t-1}$ was added to the equation. The results in table 5.1 are thus directly comparable with the results in table 4.3. Since the addition of $\log H P_{2 w t-1}$ to the equation had little effect on the other coefficient estimates, only the estimates of $\alpha_{1}$ and $\alpha_{2}$ are presented. As is clearly evident in table 5.1, $\log H P_{2 w t-1}$ does not appear to be a significant determinant of $\log M_{2 n t}-$ $\log M_{2 w t-1}$. In only two industries -301 and 336 - is its coefficient estimate significantly positive, and in only five of the seventeen industries is it positive at all. Notice that in both industries 301 and 336 the absolute value of the estimate of the coefficient $\alpha_{1}$ of the excess labor variable has decreased in size from the absolute value of the estimate in table 4.3 (for 301 from .108 to .086 , and for 336 from .113 to .093 ), which is as expected, since the two variables are likely to be measuring the same thing during part of each year (the peak output months). For twelve of the industries the estimate of $\alpha_{2}$ is negative, and it is significantly negative for two of these industries - 233 and 331. No specific interpretation can be given for these negative signs, except that the results clearly seem to be inconsistent with the idea that a high level of hours paid-for per worker in the previous period leads to more workers hired in the current period (other than at those times when $H P_{2 w t-1}$ equals $H_{2 w t-1}$ ).

Most of the estimates of $\alpha_{2}$ are not significantly different from zero and the fit in table 5.1. for most of the industries has not been improved from the fit in table 4.3, and it seems reasonable to conclude that the level of hours paid-for per worker in the previous period is not a significant determinant 


\section{TABLE 5.2}

Parameter estimates for eq. $(3.9)^{\prime}$ with the additional term $\alpha_{3}\left(\log H P_{2 u t-1}-\log H P_{2 u t-2}\right)$. Estimates presented for $\alpha_{1}$ and $\alpha_{3}$ only

\begin{tabular}{|c|c|c|c|c|c|}
\hline Industry & No. of obs. & $\hat{\alpha}_{1}$ & $\hat{x}_{3}$ & SE & DW \\
\hline 201 & 192 & $\begin{array}{l}-.177 \\
(4.55)\end{array}$ & $\begin{array}{r}.066 \\
(1.26)\end{array}$ & .0120 & 2.00 \\
\hline 207 & 136 & $\begin{array}{l}-.152 \\
(3.39)\end{array}$ & $\begin{array}{r}.017 \\
(0.16)\end{array}$ & .0181 & 2.12 \\
\hline 211 & 136 & $\begin{array}{l}-.117 \\
(4.60)\end{array}$ & $\begin{array}{r}.027 \\
(1.45)\end{array}$ & .0102 & 2.07 \\
\hline 212 & 136 & $\begin{array}{l}-.111 \\
(4.72)\end{array}$ & $\begin{array}{l}-.021 \\
(0.49)\end{array}$ & .0159 & 2.57 \\
\hline 231 & 136 & $\begin{array}{c}-.180 \\
(4.46)\end{array}$ & $\begin{array}{r}.114 \\
(1.62)\end{array}$ & .0192 & 2.04 \\
\hline 232 & 136 & $\begin{array}{l}-.090 \\
(5.54)\end{array}$ & $\begin{array}{r}.052 \\
(1.07)\end{array}$ & .0106 & 1.54 \\
\hline 233 & 136 & $\begin{array}{l}-.007 \\
(0.23)\end{array}$ & $\begin{array}{l}-.043 \\
(0.50)\end{array}$ & .0293 & 1.45 \\
\hline 242 & 154 & $\begin{array}{l}-.042 \\
(1.34)\end{array}$ & $\begin{array}{l}-.046 \\
(0.77)\end{array}$ & .0127 & 1.74 \\
\hline 271 & 166 & $\begin{array}{r}-.043 \\
(2.52)\end{array}$ & $\begin{array}{l}-.060 \\
(1.47)\end{array}$ & .0048 & 2.09 \\
\hline 301 & 134 & $\begin{array}{l}.101 \\
(6.54)\end{array}$ & $\begin{array}{c}.068 \\
(1.44)\end{array}$ & .0141 & 1.94 \\
\hline 311 & 170 & $\begin{array}{l}-.164 \\
(6.36)\end{array}$ & $\begin{array}{r}.167 \\
(1.94)\end{array}$ & .0114 & 2.26 \\
\hline 314 & 136 & $\begin{array}{l}-.085 \\
(1.91)\end{array}$ & $\begin{array}{r}.221 \\
(3.69)\end{array}$ & .0136 & 2.05 \\
\hline 324 & 187 & $\begin{array}{l}-.109 \\
(6.18)\end{array}$ & $\begin{array}{r}.048 \\
(0.37)\end{array}$ & .0177 & 2.02 \\
\hline 331 & 128 & $\begin{array}{c}-.032 \\
(2.77)\end{array}$ & $(2.10)$ & .0099 & 1.68 \\
\hline 332 & 170 & $\begin{array}{l}-.111 \\
(7.43)\end{array}$ & $\begin{array}{r}.206 \\
(2.44)\end{array}$ & .0164 & 2.42 \\
\hline 336 & 170 & $\begin{array}{c}-.109 \\
(5.38)\end{array}$ & $\begin{array}{r}.182 \\
(1.59)\end{array}$ & .0174 & 1.85 \\
\hline 341 & 191 & $\begin{array}{l}-.066 \\
(3.58)\end{array}$ & $\begin{array}{r}-.012 \\
(0.18)\end{array}$ & .0181 & 1.98 \\
\hline
\end{tabular}

$t$-statistics are in parentheses.

of the number of workers hired or fired in the current period. This, of course, is as expected from the argument given above. 
In table 5.2 the results of adding the variable $\log H P_{2 w t-1}-\log H P_{2 w t-2}$ to eq. (3.9)' are presented. The coefficient of this variable is denoted as $x_{3}$, and again only estimates of $\alpha_{1}$ and $\alpha_{3}$ are presented, as the other estimates were not substantially affected. On the argument expounded by Kuh, $\alpha_{3}$ is expected to be positive.

For eleven of the industries the estimate of $\alpha_{3}$ is positive, and for two of these industries - 314 and 332 - the estimate of $\alpha_{3}$ is significant. In both of these industries the absolute value of the estimate of $\alpha_{1}$ has fallen from that presented in table 4.3 (for 314 from .115 to .085 , and for 332 from .123 to .111). For the six industries where the estimate of $\alpha_{3}$ is negative, it is significantly negative for one of them - 331. In fourteen industries the estimate of $\alpha_{3}$ is not significant. The fits in table 5.2 are little changed from those in table 4.3, and it seems safe to conclude from these results that $\log H P_{2 w t-1}-\log H P_{2 w t-2}$ is not a significant determinant of $\log M_{2 w t}-$ $\log M_{2 w t-1}$. This is also as expected, since there seems to be little theoretical reason why this variable should be significant.

\subsection{Tests for cyclical variations in the short-run demand for production workers}

The model developed in this study has been formulated as a monthly one, with seasonal fluctuations playing an important role. In most, but not all, of the industries seasonal fluctuations in output are so large that they tend to swamp the cyclical fluctuations. An important question is whether the employment behavior of firms is different during general contractionary periods of output than during general expansionary periods.

The hypothesis which is tested here is the hypothesis that during contractionary periods firms "hoard" labor in the sense that the model [eq. (3.9)'] predicts more workers fired (or fewer hired) than actually are during the period and that during expansionary periods firms "dishoard" labor in the sense that the model predicts fewer workers fired (or more hired) than actually are during the period. The idea behind this hypothesis is that firms might expect contractionary and expansionary periods to be temporary and react to them in a temporary way by letting hours worked per worker adjust more than they would if these conditions were expected to be permanent.

Two tests of this hypothesis were made for each industry. For the first test the output variable, $\log Y_{d t}$, was regressed against twelve seasonal 
dummy variables ${ }^{1}$ and time in an effort to eliminate the purely seasonal and trend fluctuations in $\log Y_{\mathrm{d} d}$. The residuals from this equation, denoted as $\log P_{d t}$, were then taken to be a measure of the cyclical fluctuation in $\log Y_{d t}$. Since the cyclical effects on employment decisions may not be symmetrical for contractions and expansions, the following two variables were constructed: $\left(\log P_{d t}-\log P_{d t-1}\right)_{+}$and $\left(\log P_{d t}-\log P_{d t-1}\right)_{-}$. The variable $\left(\log P_{d t}-\log P_{d t-1}\right)_{+}$was set equal to $\log P_{d t}-\log P_{d t-1}$ when $\log P_{d t}-\log P_{d t-1}$ was positive and was set equal to zero otherwise. The variable $\left(\log P_{d t}-\log P_{d t-1}\right)$ - was set equal to $\log P_{d t}-\log P_{d t-1}$ when $\log P_{d t}-\log P_{d t-1}$ was negative and set equal to zero otherwise. These two variables were then added to eq. (3.9)'. If the above hypothesis is true, these variables should have significantly negative, though not necessarily equal, coefficient estimates. When $\log P_{d t}-\log P_{d t-1}$ is positive (expansionary period), the model on the above hypothesis should predict too few workers hired or too many fired, and when $\log P_{d t}-\log P_{d t-1}$ is negative (contractionary period), the model should predict too few workers fired or too many hired.

In table 5.3 the results of adding $\left(\log P_{d t}-\log P_{d t-1}\right)_{+}$and $\left(\log P_{d t}-\right.$ $\left.\log P_{d t-1}\right)_{-}$to eq. (3.9)' are presented. The coefficients of these two variables are denoted as $\alpha_{4}$ and $\alpha_{5}$ respectively. In table 5.3 estimates of $\alpha_{1}, \gamma_{0}, \alpha_{4}$, and $\alpha_{5}$ are presented; the effects on the other coefficient estimates were slight. Comparing the SE's in table 5.3 with those in table 4.3 , it is seen that only in industries $212,233,324$, and 331 has the fit been noticeably improved by adding the two variables. For 212 and 233 the estimates of $\alpha_{4}$ and $\alpha_{5}$ are negative, as expected, but for 324 and 331 the estimates are positive. For the other thirteen industries, only in 301 and 336 is the estimate of either $\alpha_{4}$ or $\alpha_{5}$ significant, and in both cases the estimate is of the wrong positive sign. Of the 34 estimates of $\alpha_{4}$ and $\alpha_{5}, 16$ are negative and 18 are positive.

For industries 212 and 233, where the fit is improved and the estimates of $\alpha_{4}$ and $\alpha_{5}$ are negative, the estimate of the coefficient $\gamma_{0}$ of $\log Y_{d t}^{e}-\log$ $Y_{d t-1}$ is larger than it was in table 4.3 without the inclusion of the two variables. This is consistent with the above hypothesis, since presumably with the inclusion of the two variables the "hoarding" phenomenon is explicitly taken account of and is not erroneously included in the $\log Y_{d t}^{e}-\log Y_{d t-1}$ variable. For industries 324 and 331, where the fit is also improved but where

1 Dummy variable one being set equal to one in January and zero otherwise, dummy variable two being set equal to one in February and zero otherwise, and so on. 
TABLE 5.3

Parameter estimates for eq. (3.9)' with the additional terms $\alpha_{4}\left(\log P_{a t}-\log P_{a t-1}\right)+$ and $\alpha_{5}\left(\log P_{a t}-\log P_{a t-1}\right)_{-}$. Esimates presented for $\alpha_{1}, \gamma_{0}, \alpha_{4}$, and $\alpha_{3}$ anly

\begin{tabular}{|c|c|c|c|c|c|c|c|}
\hline Industry & No, of obs. & $\hat{\otimes}_{1}$ & $\hat{\gamma}_{0}$ & $\hat{x}_{4}$ & $\hat{\alpha}_{s}$ & $\mathrm{SE}$ & DW \\
\hline 201 & 192 & $\begin{array}{l}-.177 \\
(4.33)\end{array}$ & $\begin{array}{r}.268 \\
(7.89)\end{array}$ & $\begin{array}{l}-.008 \\
(0.16)\end{array}$ & $\begin{array}{l}-.007 \\
(0.13)\end{array}$ & .0121 & 1.92 \\
\hline 207 & 136 & $\begin{array}{l}-.154 \\
(3.44)\end{array}$ & $\begin{array}{r}.264 \\
(10.98)\end{array}$ & $\begin{array}{r}.021 \\
(0.44)\end{array}$ & $\begin{array}{l}-.032 \\
(0.65)\end{array}$ & .0181 & 2.13 \\
\hline 211 & 136 & $\begin{array}{l}--.138 \\
(5.87)\end{array}$ & $\begin{array}{r}.099 \\
(3.91)\end{array}$ & $\begin{array}{r}.011 \\
(0.23)\end{array}$ & $\begin{array}{l}-.050 \\
(1.16)\end{array}$ & .0102 & 1.91 \\
\hline 212 & 136 & $\begin{array}{l}-.119 \\
(5.01)\end{array}$ & $\begin{array}{r}.230 \\
(7.59)\end{array}$ & $\begin{array}{l}-.128 \\
(2.43)\end{array}$ & $\begin{array}{l}-.116 \\
(2.64)\end{array}$ & .0154 & 2.55 \\
\hline 231 & 136 & $\begin{array}{l}-.169 \\
(4.01)\end{array}$ & $\begin{array}{r}.188 \\
(3.38)\end{array}$ & $\begin{array}{l}-.071 \\
(1.15)\end{array}$ & $\begin{array}{l}-.074 \\
(1.15)\end{array}$ & .0194 & 2.01 \\
\hline 232 & 136 & $\begin{array}{l}-.086 \\
(5.08)\end{array}$ & $\begin{array}{r}.116 \\
(6.87)\end{array}$ & $\begin{array}{l}-.022 \\
(0.84)\end{array}$ & $\begin{array}{r}.016 \\
(0.65)\end{array}$ & .0107 & 1.43 \\
\hline 233 & 136 & $\begin{array}{l}-.007 \\
(0.25)\end{array}$ & $\begin{array}{r}.239 \\
(7.01)\end{array}$ & $\begin{array}{l}-.170 \\
(2.50)\end{array}$ & $\begin{array}{l}-.098 \\
(1.62)\end{array}$ & .0284 & 1.59 \\
\hline 242 & 154 & $\begin{array}{r}-.031 \\
(0.99)\end{array}$ & $\begin{array}{r}.245 \\
(11.69)\end{array}$ & $\begin{array}{l}.047 \\
(0.94)\end{array}$ & $\begin{array}{r}-.088 \\
(1.82)\end{array}$ & .0125 & 1.83 \\
\hline 271 & 166 & $\begin{array}{l}-.038 \\
(2.24)\end{array}$ & $\begin{array}{r}.113 \\
(6.86)\end{array}$ & $\begin{array}{r}.069 \\
(1.71)\end{array}$ & $\begin{array}{l}-.042 \\
(0.82)\end{array}$ & .0048 & 2.16 \\
\hline 301 & 134 & $\begin{array}{l}-.101 \\
(6.63)\end{array}$ & $\begin{array}{r}.009 \\
(0.34)\end{array}$ & $\begin{array}{r}.121 \\
(2.17)\end{array}$ & $\begin{array}{r}.045 \\
(0.88)\end{array}$ & .0140 & 1.98 \\
\hline 311 & 170 & $\begin{array}{l}-.169 \\
(6.63)\end{array}$ & $\begin{array}{r}.153 \\
(3.56)\end{array}$ & $\begin{array}{r}.102 \\
(1.65)\end{array}$ & $\begin{array}{r}.001 \\
(0.01)\end{array}$ & .0114 & 2.14 \\
\hline 314 & 136 & $\begin{array}{l}-.115 \\
(2.50)\end{array}$ & $\begin{array}{r}.309 \\
(9.82)\end{array}$ & $\begin{array}{r}.013 \\
(0.17)\end{array}$ & $\begin{array}{r}.085 \\
(1.25)\end{array}$ & .0143 & 2.23 \\
\hline 324 & 187 & $\begin{array}{l}-.120 \\
(7.30)\end{array}$ & $\begin{array}{r}.179 \\
(11.89)\end{array}$ & $\begin{array}{r}.204 \\
(4.32)\end{array}$ & $\begin{array}{r}.076 \\
(1.65)\end{array}$ & .0164 & 2.29 \\
\hline 331 & 128 & $\begin{array}{l}-.038 \\
(3.35)\end{array}$ & $\begin{array}{r}.071 \\
(2.23)\end{array}$ & $\begin{array}{r}.147 \\
(4.05)\end{array}$ & $\begin{array}{r}.142 \\
(2.84)\end{array}$ & .0094 & 2.15 \\
\hline 332 & 170 & $\begin{array}{l}-.119 \\
(8.08)\end{array}$ & $\begin{array}{r}.102 \\
(2.28)\end{array}$ & $\begin{array}{r}.110 \\
(1.92)\end{array}$ & $\begin{array}{r}.064 \\
(0.99)\end{array}$ & .0166 & 2.30 \\
\hline 336 & 170 & $\begin{array}{l}-.103 \\
(4.65)\end{array}$ & $\begin{array}{r}.105 \\
(2.06)\end{array}$ & $\begin{array}{r}.001 \\
(0.02)\end{array}$ & $\begin{array}{r}.140 \\
(2.14)\end{array}$ & .0174 & 1.84 \\
\hline 341 & 191 & $\begin{array}{l}-.068 \\
(3.64)\end{array}$ & $\begin{array}{r}.191 \\
(13.21)\end{array}$ & $\begin{array}{l}-.026 \\
(0.84)\end{array}$ & $\begin{array}{l}-.021 \\
(0.84)\end{array}$ & .0181 & 1.98 \\
\hline
\end{tabular}

t-statistics are in parentheses. 
the estimates of $x_{4}$ and $\alpha_{5}$ are positive, the estimate of $\gamma_{0}$ is smaller than it was in table 4.3 ; adding the two variables took away some of the influence of the $\log Y_{d t}^{e}-\log Y_{d t-1}$ variable.

In summary, then, the results for industries 212 and 231 are consistent with the hypothesis that firms hire fewer workers or fire more than predicted during expansions and conversely during contractions, while the results for industries 324 and 331 are consistent with the counter hypothesis that firms hire more workers or fire fewer than predicted during expansions and conversely during contractions. Considering all of the industries together, however, the general conclusion appears to be that this test has not revealed any substantive evidence that firms behave differently than the model predicts they should during contractions or during expansions, that the model as exemplified by eq. (3.9)' appears to be adequately specified for "cyclical" short-run employment behavior.

The above test has the disadvantage that the variable $\log P_{d t}$, the residual from the regression of $\log Y_{d t}$ on twelve seasonal dummies and time, includes the random error term in the $\log Y_{d t}$ series as well as the cyclical term. Taking first differences of the $\log P_{d t}$ series aggravates this problem, and it may be the case that the random error term in the $\log P_{d t}-\log P_{d t-1}$ series dominates the cyclical term.

Because of this possible difficulty, another test was made of the above hypothesis. The National Bureau of Economic Research has divided over-all economic activity into upswings and downswings. ${ }^{1}$ Using their definitions of peaks and troughs in the post-war period, a dummy variable, denoted at $D_{t}$, was constructed which was set equal to one for each month when over-all economic activity was declining (NBER peak to trough) and zero otherwise. $D_{t}$ was then added to eq. (3.9)', and if the above hypothesis is true, the estimate of the coefficient of $D_{t}$ should be significantly positive (more workers hired or fewer fired during contractions than predicted). The disadvantage of this variable for testing the above hypothesis is that it relates to over-all economic activity and not necessarily to the activity of the particular industry in question; but the variable may be a rough indicator of general tendencies in the industry.

The results of adding $D_{t}$ to eq. (3.9) are presented in table 5.4. The coefficient of $D_{t}$ is denoted as $\alpha_{6}$, and estimates of $\alpha_{1}, \gamma_{0}$, and $\alpha_{6}$ are presented in the table. The other coefficient estimates were little affected.

1 See, for example, us Department of Commerce (1967a). 
TABLE 5.4

Parameter estimates for eq. (3.9)' with the additional term $\alpha_{6} D_{t}$. Estimates presented for $\alpha_{1}, \gamma_{0}$, and $\alpha_{6}$ only

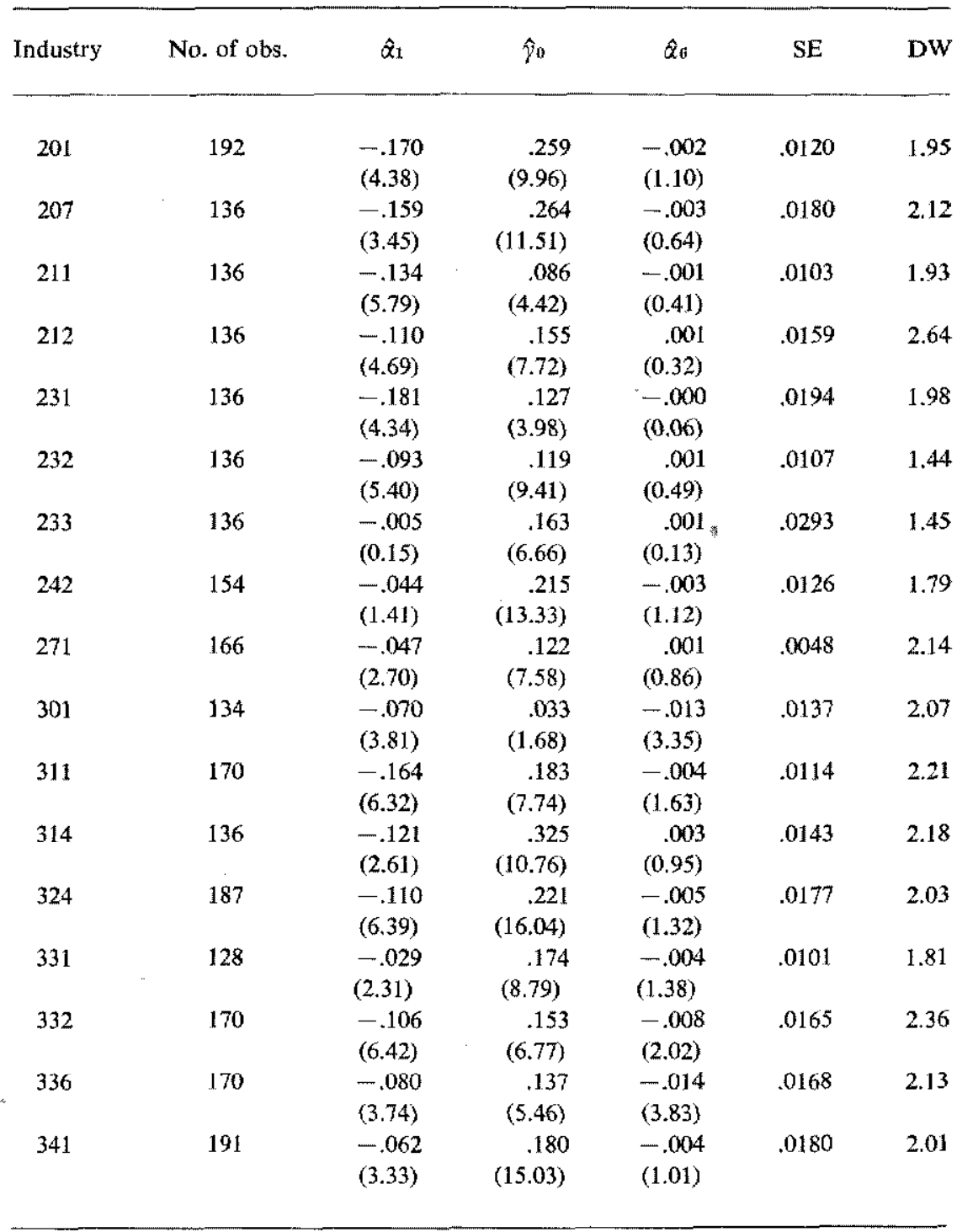

$t$-statistics are in parentheses. 
The estimate of $\alpha_{6}$ is positive as expected in only five industries, and it is not significant for any of these five. For the remaining twelve industries where the estimate of $\alpha_{6}$ is negative, it is significant for three of them -301 , 332 , and 336. For these three industries the estimate of the coefficient $\gamma_{0}$ of $\log Y_{d t}^{e}-\log Y_{d t-1}$ is smaller than it was in table 4.3 with $D_{t}$ not included in the equation, and for 301 the estimate of $\gamma_{0}$ in table 5.4 is no longer significant. This phenomenon is probably due to collinearity between $D_{t}$ and $\log Y_{d t}^{e}-\log Y_{d t-1}$ in the equation.

These results clearly give no indication that the model underpredicts during the contractions as defined by the NBER. The insignificance of all but three of the estimates of $\alpha_{6}$ implies, according to this rather crude test, that firms do not behave differently than predicted during contractionary periods.

The two tests together thus indicate that firms do not appear to behave differently than predicted during general contractionary periods of output or during general expansionary periods.

\subsection{The effect of the unemployment rate on short-run employment decisions}

So far the effect of possible supply constraints on the number of workers employed has not been considered. It has been implicitly assumed that a firm has no trouble in the short run in finding and hiring the number of workers that it wants. In tight labor markets, of course, this may not be the case.

The hypothesis which is tested here is the hypothesis that a tight labor market (measured by a low unemployment rate) tends to damp short-run changes in the number of production workers employed, i.e., that a tight labor market causes a firm to hire less (because workers are difficult and expensive to find) or fire less (because of fear of not being able to hire the workers back when needed), and that a loose labor market (measured by a high unemployment rate) tends to increase short-run changes in the number of production workers employed (because workers are easier to find and the firm need worry less about rehiring workers it has laid off).

Let $\bar{U}$ denote the unemployment rate at which, in the eyes of the firm, the labor market switches from being relatively tight to being relatively loose, and let $U_{2 w t}$ denote the unemployment rate diring the decision period, from the end of the second week of month $t-1$ to the end of the second week of month $t$. According to the above hypothesis, the effect of a positive $\log U_{2 w t}-\log \bar{U}$ (loose labor market) on $\log M_{2 w t}-\log M_{2 w t-1}$ in eq. 
(3.9)' is expected to be positive for $\log M_{2 w t}-\log M_{2 w t-1}$ positive and negative for $\log M_{2 w t}-\log M_{2 w t-1}$ negative, and the effect of a negative $\log U_{2 w t}-\log \bar{U}$ (tight labor market) is expected to be negative for $\log$ $M_{2 w t}-\log M_{2 w t-1}$ positive and positive for $\log M_{2 w t}-\log M_{2 w t-1}$ negative.

Because of this asymmetry of effects, $\log U_{2 w t}-\log \bar{U}$ cannot be added to eq. (3.9)' in any simple linear way, and it is assumed to enter in the following way:

$$
\begin{array}{r}
\log M_{2 w t}-\log M_{2 w t-1}=\alpha_{1}\left(\log M_{2 w t-1}-\log M_{2 w t-1}^{*} H_{2 w t-1}^{*}\right) \\
+\alpha_{1} \log \bar{H}+\alpha_{1} \mu t \\
+\sum_{i=1}^{m} \beta_{i}\left(\log Y_{d t-i}-\log Y_{d t-i-1}\right)+\gamma_{0}\left(\log Y_{d t}^{e}-\log Y_{d t-1}\right) \\
+\sum_{i=1}^{n} \gamma_{i}\left(\log Y_{d t+i}^{e}-\log Y_{d t+i-1}^{e}\right)+\psi\left(\log U_{2 w t}-\log \bar{U}\right)+\varepsilon_{t},
\end{array}
$$

where

$$
\begin{array}{r}
\psi=\psi_{0}\left[\alpha_{1}\left(\log M_{2 w t-1}-\log M_{2 w t-1}^{*} H_{2 w t-1}^{*}\right)+\alpha_{1} \log \bar{H}\right. \\
+\alpha_{1} \mu t+\sum_{i=1}^{m} \beta_{i}\left(\log Y_{d t-i}-\log Y_{d t-i-1}\right) \\
\left.+\gamma_{0}\left(\log Y_{d t}^{e}-\log Y_{d t-1}\right)+\sum_{i=1}^{n} \gamma_{i}\left(\log Y_{d t+i}^{e}-\log Y_{d t+i-1}^{e}\right)\right] .
\end{array}
$$

The error term $\varepsilon_{t}$ is explicitly introduced in eq. (5.1) to avoid possible ambiguity as to how it is assumed to enter in the specification of the equation.

What eq. (5.1) says is that the size and sign of the coefficient $\psi$ of $\log$ $U_{2 w^{\prime} t}-\log \bar{U}$ are determined by the other determinates of $\log M_{2 w^{\prime} t}-$ $\log M_{2 w t-1}$. If, for example, the other determinates imply that $\log M_{2 w t}-$ $\log M_{2 w t-1}$ should be positive and large, then this implies that $\psi$ will be positive and large; and if furthermore $\log U_{2 w t}-\log \bar{U}$ is, say, negative, then eq. (5.1) implies that $\log M_{2 w t}-\log M_{2 w t-1}$ will be smaller than it would have been if $\log U_{2 w t}-\log \bar{U}$ had been zero or positive. The specification of this equation is consistent with the above hypothesis that tight 
labor markets damp fluctuations in $\log M_{2 w t}-\log M_{2 w t-1}$ while loose labor markets tend to increase these fluctuations.

Eq. (5.1) is non-linear in the parameters and thus cannot be estimated by ordinary least squares. It is also the case that the parameter $\bar{U}$ in eq. (5.1) is not identified. $\bar{U}$ is supposed to be the unemployment rate which divides loose from tight labor markets. Since $\bar{U}$ could not be estimated simultaneously with the other coefficients in eq. (5.1), it was rather arbitrarily taken to be the average of $U_{2 w t}$ over the sample period. Hopefully this measure is a rough approximation to the unemployment rate in the "average" (from the point of view of the firm) labor market.

The coefficients in eq. (5.1) were estimated by minimizing the sum of the squared residuals of the equation. The sum was minimized by the use of the quadratic hill-climbing technique of GoldFeld et al. (1966). ${ }^{1}$ On the assumption that $\varepsilon_{t}$ in eq. (5.1) is normally distributed, the estimates attained by this procedure are maximum likelihood estimates, ${ }^{2}$ and so an estimate of the asymptotic variance-covariance matrix of the parameter estimates can be obtained as $\left[-\partial^{2} \log L / \partial \phi^{2}\right]^{-1}$, where $L$ is the likelihood function, $\phi$ is the vector of parameters, and where the derivatives are evaluated at the coefficient estimates. ${ }^{3}$ In the present context the asymptotic variance-covariance matrix of the parameters other than $\sigma^{2}$ is $2 \sigma^{2}\left[\partial^{2} \varepsilon^{\prime} \varepsilon / \partial \theta^{2}\right]^{-1}$, where $\varepsilon$ is the $T \times 1$ vector of errors $\varepsilon_{t}, \sigma^{2}$ is the variance of $\varepsilon_{t}$, and $\theta$ is the vector of parameters other than $\sigma^{2}$. The maximum likelihood estimate of $\sigma^{2}$ is $\hat{\varepsilon^{\prime}} \hat{\varepsilon} / T$, where $\hat{\mathbf{\varepsilon}}$ is the vector of calculated residuals and $T$ is the number of observations. For present purposes, however, the estimate of $\sigma^{2}$ was taken to be $\hat{\varepsilon}^{\prime} \hat{\varepsilon} /(T-K)$, where $K$ is the number of coefficients estimated. Both of these estimates of $\sigma^{2}$ are consistent, and the estimate of $\sigma^{2}$ used here has the advantage of being more comparable with the ordinary least squares results in table 4.3 . The estimate of asymptotic variance-covariance matrix

1 See also Goldfeld, QuandT, and TrotTer (1968).

2 Note that eq. (5.1) includes the $\log M_{2 u t-1}-\log M^{*}{ }_{2 w t-1} H^{*}{ }_{2 u t-1}$ variable, which is of the nature of a lagged dependent variable. For equations with no lagged dependent variables the properties of the maximum likelihood estimates are well established (e.g., consistency and asymptotic efficiency), but the properties are less established for equations with lagged dependent variables. The results which have been achieved for a few cases (see KoOPMANS and HOOD, 1953, pp. 146-147), however, indicate that for equations with lagged dependent variables the maximum likelihood estimates retain their desirable properties.

s See, for example, Goldberger (1964, p. 131). 
which was finally calculated was, therefore, $2\left(\hat{\varepsilon}^{\prime} \hat{\varepsilon} /(T-K)\right)\left[\partial^{2} \varepsilon^{\prime} \varepsilon / \partial \theta^{2}\right]^{-1}$, where the derivatives are evaluated at $\theta=\hat{\theta}$.

The unemployment rate data used for $U_{2 w^{t}}$ were unpublished and were obtained from the BLS directly. Data were available on a monthly basis seasonally unadjusted from 1948 to the present for durable goods and nondurable goods industries, as well as for the over-all economy and other categories. Given these data, it seems that the most relevant measure of the tightness of the labor market facing any one firm is the unemployment rate in the durable or non-durable goods industry, depending on which category the firm is in. Durable and non-durable is as fine a level of disaggregation as is available for the unemployment rate data, although with workers being able to move from one industry to another, it is not clear that the degree of disaggregation should be any greater even if it were possible to get more disaggregated data. Thus the durable-non-durable breakdown was used for the unemployment rate data.

Prior to 1955 the BLS unemployment data refer to the week containing the 8th day of the month, and since 1955 they refer to the week containing the 12 th day of the month. Ideally the $U_{2 w t}$ variable above should refer to the state of the labor market from the end of the second week of month $t-1$ to the end of the second week of month $t$. The $U_{2 w t}$ actually observed relates approximately to the second week of month $t$, or a little earlier before 1955. On theoretical grounds $U_{2 w t}$ would appear to be a closer approximation to the relevant decision period than, say, $U_{2 w t-1}$, which actually relates to the week before the decision period. $U_{2 w t}$ was thus chosen as the more relevant variable.

There is a possible simultaneous equation bias which could creep into the estimates of eq. (5.1), since a firm's employment policy obviously affects the number of workers unemployed. Since each of the three-digit industries studied here is a relatively small part of total durable or nondurable manufacturing, this bias is not likely to be serious, and the unemployment rate has been taken to be exogenous to each industry.

The results of estimating eq. (5.1) are presented in table 5.5. Since the other coefficient estimates were not substantially changed, only the estimate of $\psi_{0}$ is presented. Under the hypothesis discussed above, $\psi_{0}$ is expected to be positive if in fact tight labor markets tend to damp short-run fluctuations in the number of production workers employed and loose labor markets tend to increase the fluctuations. The " $t$-statistic" presented in table 5.5 is the absolute value of the ratio of the coefficient estimate to its 
TABLE 5.5

Parameter estimates for eq, (5.1). Estimates presented for $\psi_{0}$ only

\begin{tabular}{|c|c|c|c|}
\hline Industry & No. of obs. & $\hat{\psi}_{0}$ & SE \\
\hline 201 & 192 & $\begin{array}{r}.431 \\
(2.73)\end{array}$ & .0118 \\
\hline 207 & 136 & $\begin{array}{r}.072 \\
(0.65)\end{array}$ & .0180 \\
\hline 211 & 136 & $\begin{array}{c}-.252 \\
(0.57)\end{array}$ & .0102 \\
\hline 212 & 136 & $\begin{array}{l}-.049 \\
(0.14)\end{array}$ & .0159 \\
\hline 231 & 136 & $\begin{array}{r}.594 \\
(2.93)\end{array}$ & .0188 \\
\hline 232 & 136 & $\begin{array}{r}.451 \\
(1.80)\end{array}$ & .0106 \\
\hline 233 & 136 & $\begin{array}{r}.271 \\
(1.19)\end{array}$ & .0292 \\
\hline 242 & 154 & $\begin{array}{r}.079 \\
(0.80)\end{array}$ & .0127 \\
\hline 271 & 166 & $\begin{array}{r}.074 \\
(1.21)\end{array}$ & .0048 \\
\hline 301 & 134 & $\begin{array}{r}.087 \\
(1.57)\end{array}$ & .0141 \\
\hline 311 & 170 & $\begin{array}{r}.356 \\
(1.09)\end{array}$ & .0114 \\
\hline 314 & 130 & $\begin{array}{r}.022 \\
(0.12)\end{array}$ & .0143 \\
\hline 324 & 187 & $\begin{array}{r}.147 \\
(0.90)\end{array}$ & .0177 \\
\hline 331 & 128 & $\begin{array}{r}.275 \\
(1.66)\end{array}$ & .0100 \\
\hline 332 & 170 & $\begin{array}{r}.583 \\
(2.37)\end{array}$ & .0164 \\
\hline 336 & 170 & $\begin{array}{r}.693 \\
(3.33)\end{array}$ & .0170 \\
\hline 341 & 191 & $\begin{array}{l}-.009 \\
(0.10)\end{array}$ & .0181 \\
\hline
\end{tabular}

$t$-statistics are in parentheses. 
asymptotic standard error, the latter being computed from the asymptotic variance-covariance matrix discussed above.

In all but three industries - 211,212, and 341 - the estimate of $\psi_{0}$ is positive. For four of these industries - 201, 231, 332, and 336 - the $t$-statistic is larger than two, and for six others it is larger than one. For about half of the industries the SE for eq. (5.1) is smaller than the SE for eq. (3.9)' presented in table 4.3 .

The fact that all but three of the estimates of $\psi_{0}$ are positive and the fact that ten of the estimates are larger than their asymptotic standard error indicate that the degree of labor market tightness may affect short-run employment decisions. The evidence is not strong and any conclusion must be tentative, but the hypothesis under consideration here appears to have some validity. Some evidence on the significance of labor market tightness for the change in hours paid-for per worker will be given in ch. 7 , and these results will shed some further light on the possible validity of the above hypothesis.

\subsection{The relationship of the excess labor model to a lagged adjustment model}

The empirical results which were discussed in ch. 4 regarding the expectational hypotheses indicated that the expectational hypothesis which assumes nonperfect expectations for $Y_{2 w^{\prime} t}^{c}$ is not realistic, ${ }^{1}$ and this hypothesis was dropped from further consideration. Assuming, then, that $Y_{2 w i t}^{e}$ equals $Y_{2 \text { wt }}$ in eq. (3.9) and ignoring for the moment the past change in output variables, the equation can be written

$$
\begin{aligned}
& \log M_{2 w t}-\log M_{2 w t-1}=\alpha_{1}\left(\log M_{2 w t-1}-\log M_{2 w t-1}^{d}\right) \\
& \quad+\gamma_{0}\left(\log Y_{2 w t}-\log Y_{2 w t-1}\right)+\sum_{i=1}^{n} \gamma_{i}\left(\log Y_{2 w t+i}^{e}-\log Y_{2 w f+i-1}^{e}\right) .
\end{aligned}
$$

$M_{2 w t-1}^{d}$ is the desired number of workers employed for the second week of month $t-1$ for the output $Y_{2 w-1}$. Since the firm is assumed to know $Y_{2 w i}$ in advance (perfect expectations for $Y_{2 w i}$ ), it can also be assumed to

1 For sake of consistency with the discussion in ch. 3, the discussion in this section is couched in terms of $Y_{2 w t}$ instead of the observed $Y_{a t}$. 
know $M_{2 w t}^{d}$ in advance. Therefore, the following "lagged adjustment" model could be constructed and estimated:

$$
\begin{aligned}
\log M_{2 w t}-\log M_{2 w t-1} & =\lambda\left(\log M_{2 w t}^{d}-\log M_{2 w t-1}\right) \\
& +\sum_{i=1}^{n} \gamma_{i}\left(\log Y_{2 w t+i}^{e}-\log Y_{2 w t+i-1}^{e}\right)
\end{aligned}
$$

$M_{2 w t}^{d}$ is the desired number of workers employed for the second week of month $t$, desired as of the second week of month $t-1$. Using the definition of $M_{2 w t}^{d}$ in eq. (3.7) and the assumptions made about $H S_{2 w t}$ in eq. (3.11), eq. (5.3) could be estimated in a manner analogous to eq. $(3.9)^{r}$, the basic equation of the "excess labor" model.

The lagged adjustment model as exemplified by eq. (5.3) appears to be more in the spirit of the basic model of ch. 2, with the expected future change in output variables being added. Of course, the basic difference between this model and the basic model of ch. 2 is that here $M_{2 w t}^{d}$ is constructed, under the assumptions of no substitution possibilities and constant returns to scale, from the interpolations discussed in $\S 3.6$, whereas in the basic model of ch. $2, M_{2 w t}^{d}$ is assumed to be derived from a Cobb-Douglas production function, the parameters of which are assumed to be estimatable from the derived equation (2.37).

The relationship between the excess labor equation (5.2) and the lagged adjustment equation (5.3) is easy to see. Since in eq. (3.6) [which is derived from the production function (3.2)] the production function parameter $\alpha_{2 w i t}$ is assumed to move slowly through time from peak to peak, for shortrun considerations $x_{2 w i}$ can be approximated by a constant, say $\bar{\alpha}$. If it is assumed that the standard number of hours of work per worker per week is constant over time so that $H S_{2 w t-1}=H S_{2 w t}=\vec{H}$, which is approximately true in the short run even if $H S$ is a slowly trending variable as assumed in eq. (3.11), then from eqs. (3.6) and (3.7)

$$
M_{2 w t}^{d}=\frac{1}{\bar{\alpha}} \frac{Y_{2 w t}}{\bar{H}}
$$

and

$$
M_{2 w t-1}^{d}=\frac{1}{\bar{\alpha}} \frac{Y_{2 w t-1}}{\bar{H}} .
$$


Therefore,

or

$$
\log M_{2 w t}^{d}-\log M_{2 w t-1}^{d}=\log Y_{2 w t}-\log Y_{2 w t-1},
$$

$$
\log M_{2 w t}^{d}=\log M_{2 w t-1}^{d}+\log Y_{2 w t}-\log Y_{2 w-1} .
$$

Substituting this value of $\log M_{2 w t}^{d}$ into the lagged adjustment equation (5.3) yields

$$
\begin{aligned}
& \log M_{2 w t}-\log M_{2 w t-1}=\lambda\left(\log M_{2 w t-1}^{d}-\log M_{2 w t-1}\right) \\
& +\lambda\left(\log Y_{2 w t}-\log Y_{2 w t-1}\right)+\sum_{i=1}^{n} \gamma_{i}\left(\log Y_{2 w t+i}^{e}-\log Y_{2 w t+i-1}^{e}\right)
\end{aligned}
$$

Comparing eqs. (5.8) and (5.2), it is seen that the lagged adjustment model is equivalent to the excess labor model with the additional restriction that $\alpha_{1} \mid$ equals $\gamma_{0} \mid$ in eq. (5.2). In other words, the lagged adjustment model can be considered to be special case of the excess labor model. The results of estimating the excess labor equation, which were presented in table 4.3, strongly indicate that $\left|\alpha_{1}\right|$ does not equal $\gamma_{0} \mid$ (even considering the fact that for some of the industries the past output change variables are taking away some of the influence of the excess labor variable and thus are decreasing the size of $\left|x_{1}\right|$ ), so that the model of the short-run demand for production workers appears to be better specified in terms of the "excess labor reaction" equation (5.2) than in terms of the "lagged adjustment" equation (5.3).

\subsection{Alternative distributed lags}

Eq. (3.9) implies that $\log M_{2 w t}$ is a distributed lag of past values of the desired number of workers employed, $\log M_{2 w}^{d}$, and of the past values of the various change in output variables in the equation. Jorgenson has shown that any arbitrary distributed lag function can be approximated by a rational distributed lag function. ${ }^{1}$ Let the lag operator $L$ be defined such that $L^{i} X_{t}=$ $X_{t-i}$, and let $\mu(L)$ and $v(L)$ be polynomials in $L$. Then eq. (3.9) can be written

$v(L) \log M_{2 w t}=\mu(L) \log M_{2 w t-1}^{d}+\sum_{i=1}^{m} \beta_{i}\left(\log Y_{2 w t-i}-\log Y_{2 w t-i-1}\right)$

1 JORGENSON (1966, p. 142). 


$$
\begin{aligned}
& +\gamma_{0}\left(\log Y_{2 w t}^{e}-\log Y_{2 w t-1}\right) \\
& +\sum_{i=1}^{n} \gamma_{i}\left(\log Y_{2 w t+i}^{e}-\log Y_{2 w t+i-1}^{e}\right)
\end{aligned}
$$

where

$$
v(L)=1-\left(1+\alpha_{1}\right) L
$$

and

$$
\mu(L)=-\alpha_{1} \text {. }
$$

Eq. (5.9) can be divided through by $v(L)$ to give $\log M_{2 w t}$ as a rational distributed lag of past values of $\log M_{2 w}^{d}$ and past values of the change in output variables.

A more complicated lag than that implied by eq. (3.9) is implied by an equation like (3.9) with the variable $\log M_{2 w t-2}-\log M_{2 w t-2}^{d}$ added to it. This variable is a measure of the amount of excess labor on hand during the second week of month $t-2$, and adding it to eq. (3.9) (with coefficient $\alpha_{7}$ ) implies that in eq. (5.9)

$$
v(L)=1-\left(1+\alpha_{1}\right) L-\alpha_{7} L^{2}
$$

and

$$
\mu(L)=-\alpha_{1}-\alpha_{7} L
$$

In an effort to test for a more complicated lag structure than that specified in eq. (3.9), the variable $\log M_{2 w t-2}-\log M_{2 w t-2}^{d}$ was added to eq. (3.9)'. From eq. (3.7) $M_{2 w t-2}^{d}$ equals $M_{2 w t-2}^{*} H_{2 w t-2}^{*} / H S_{2 w t-2}$, and if it is assumed that the effects of $\log H S_{2 w t-2}$ can be absorbed in the constant term and time trend in the equation, then adding $\log M_{2 w t-2}-\log M_{2 w t-2}^{d}$ to eq. (3.9)' is equivalent to adding $\log M_{2 w t-2}-\log M_{2 w t-2}^{*} H_{2 w t-2}^{*}$ to the equation. The results of adding $\log M_{2 w t-2}-\log M_{2 w t-2}^{*} H_{2 w t-2}^{*}$ to eq. (3.9) ${ }^{\prime}$ are presented in table 5.6. Only the estimates of the coefficients of $\log M_{2 w t-1}-\log M_{2 w t-1}^{*} H_{2 w t-1}^{*}$ and $\log M_{2 w t-2}-\log M_{2 w t-2}^{*} H_{2 w t-2}^{*}$ are presented, the coefficient of the latter being denoted as $\alpha_{7}$.

In only one industry - 212 - is the estimate of $\alpha_{7}$ significant, where it is significantly positive. In seven industries the estimate of $\alpha_{7}$ is negative and in the other ten it is positive. When the estimate of $\alpha_{7}$ is negative, the estimate of $\alpha_{1}$ is smaller in absolute value than it was in table 4.3 when $\log M_{2 w t-2}-\log M_{2 w t-2}^{*} H_{2 w t-2}^{*}$ was not included in the equation; and when the estimate of $\alpha_{7}$ is positive, the estimate of $\alpha_{1}$ is larger in absolute 
TABLE 5.6

Parameter estimates for eq. (3.9)' with the additional term $a_{7}\left(\log M_{2 u t-2}-\log M_{2 w t-2^{-}}\right.$ $\left.H^{*} *_{2 t,-2}\right)$. Estimates presented for $\alpha_{1}$ and $\alpha_{7}$ only

\begin{tabular}{|c|c|c|c|c|c|}
\hline Industry & No, of obs. & $\hat{\chi}_{1}$ & $\hat{x}_{7}$ & SE & DW \\
\hline 201 & 192 & $\begin{array}{l}-.127 \\
(1.81)\end{array}$ & $\begin{array}{l}-.056 \\
(0.84)\end{array}$ & .0120 & 2.02 \\
\hline 207 & 136 & $\begin{array}{l}-.202 \\
(2.85)\end{array}$ & $\begin{array}{r}.055 \\
(0.90)\end{array}$ & .0180 & 2.04 \\
\hline 211 & 136 & $\begin{array}{l}-.131 \\
(5.63)\end{array}$ & $\begin{array}{l}-.004 \\
(0.40)\end{array}$ & .0103 & 1.93 \\
\hline 212 & 136 & $\begin{array}{l}-.325 \\
(5.87)\end{array}$ & $\begin{array}{r}.184 \\
(4.25)\end{array}$ & .0149 & 1.76 \\
\hline 231 & 136 & $\begin{array}{c}-.296 \\
(3.89)\end{array}$ & $\begin{array}{r}.135 \\
(1.79)\end{array}$ & .0192 & 1.89 \\
\hline 232 & 136 & $\begin{array}{l}-.092 \\
(1.66)\end{array}$ & $\begin{array}{r}.001 \\
(0.03)\end{array}$ & .0107 & 1.45 \\
\hline 233 & 136 & $\begin{array}{c}+.105 \\
(1.57)\end{array}$ & $\begin{array}{l}-.116 \\
(1.85)\end{array}$ & .0289 & 1.57 \\
\hline 242 & 154 & $\begin{array}{l}-.014 \\
(0.17)\end{array}$ & $\begin{array}{l}-.032 \\
(0.39)\end{array}$ & .0127 & 1.85 \\
\hline 271 & 166 & $\begin{array}{l}-.033 \\
(1.81)\end{array}$ & $\begin{array}{l}-.021 \\
(1.81)\end{array}$ & .0048 & 2.22 \\
\hline 301 & 134 & $\begin{array}{c}-.093 \\
(4.85)\end{array}$ & $\begin{array}{l}-.022 \\
(1.20)\end{array}$ & .0142 & 1.99 \\
\hline 311 & 170 & $\begin{array}{l}-.176 \\
(6.70)\end{array}$ & $\begin{array}{r}.003 \\
(0.26)\end{array}$ & .0115 & 2.12 \\
\hline 314 & 136 & $\begin{array}{l}-.126 \\
(2.68)\end{array}$ & $\begin{array}{r}.022 \\
(1.09)\end{array}$ & .0143 & 2.09 \\
\hline 324 & 187 & $\begin{array}{l}-.104 \\
(5.11)\end{array}$ & $\begin{array}{l}-.012 \\
(0.49)\end{array}$ & .0177 & 2.02 \\
\hline 331 & 128 & $\begin{array}{l}-.156 \\
(1.84)\end{array}$ & $\begin{array}{r}.119 \\
(1.44)\end{array}$ & .0100 & 1.61 \\
\hline 332 & 170 & $\begin{array}{l}-.145 \\
(6.77)\end{array}$ & $\begin{array}{r}.024 \\
(1.35)\end{array}$ & .0166 & 2.22 \\
\hline 336 & 170 & $\begin{array}{l}-.128 \\
(1.77)\end{array}$ & $\begin{array}{r}.014 \\
(0.22)\end{array}$ & .0176 & 1.74 \\
\hline 341 & 191 & $\begin{array}{r}-.119 \\
(1.68)\end{array}$ & $\begin{array}{r}.049 \\
(0.77)\end{array}$ & .0180 & 1.89 \\
\hline
\end{tabular}

$t$-statistics are in parentheses. 
value. There is also a strong tendency for the addition of $\log M_{2 w t-2}-$ $\log M_{2 w t-2}^{*} H_{2 w t-2}^{*}$ to decrease the significance of the estimate of $\alpha_{1}$. The effect on the other coefficient estimates was small except on the estimate of the coefficient $\beta_{1}$ of $\log Y_{d t-1}-\log Y_{d t-2}$. The introduction of $\log M_{2 w t-2}-$ $\log M_{2 w t-2}^{*} H_{2 w t-2}^{*}$ tended to decrease substantially the significance of the estimate of $\beta_{1}$ (for those industries, that is, where the estimate of $\beta_{1}$ was significant to begin with). This is probably due to the fact that $\log M_{2 w t-2}^{d}$ approximately equals ${ }^{1} \log M_{2 w t-1}^{d}-\left(\log Y_{d t-1}-\log Y_{d t-2}\right)$, and adding the variable $\log M_{2 w t-2}-\log M_{2 w t-2}^{d},{ }^{2}$ which approximately equals $\log$ $M_{2 w t-2}-\log M_{2 w t-1}^{d}+\log Y_{d t-1}-\log Y_{d t-2}$, to eq. (3.9)' is likely to lead to collinearity problems between this variable and $\log Y_{d t-1}-\log Y_{d t-2}$.

Because of the insignificance of all but one of the estimates of $\alpha_{7}$ and because the introduction of $\log M_{2 w t-2}-\log M_{2 w t-2}^{*} H_{2 w t-2}^{*}$ had negligible effects on the standard errors except for industry 212 , there appears to be little evidence of the existence of a more complicated lag structure as exemplified by adding this variable to eq. (3.9)'.

Regarding the reaction of firms to the amount of excess labor on hand, it may be the case that firms react differently depending on the size of the amount of excess labor on hand, i.e., firms may react in a non-linear way to the amount of excess labor on hand. The hypothesis which is tested here is the hypothesis that the larger the amount of positive excess labor on hand the stronger is the reaction of firms in eliminating it and the larger the amount of negative excess labor on hand the stronger is the reaction of firms in adding more workers. The hypothesis was tested by adding the variable $\left(\log M_{2 w t-1}-\log M_{2 w t-1}^{d}\right)_{ \pm}^{2}$ to eq. (3.9) ${ }^{3}$ The notation \pm indicates that when $\log M_{2 w t-1}-\log M_{2 w t-1}^{d}$ was negative, the squared term was taken to be negative as well. This is consistent with the idea that $\left(\log M_{2 w t-1}-\log M_{2 w t-1}^{\mathrm{d}}\right)_{ \pm}^{2}$ should be positive when there is a positive amount of excess labor on hand and negative when there is a negative amount of excess labor on hand.

1 See eq. $(5.7)$.

2 Remember that adding the variable $\log M_{2 n t-2}-\log M_{2 t z-2}^{*_{2} H^{*}{ }_{2 u t-2}}$ to the equation (which was actually done) is equivalent to adding $\log M_{2 w t-2}-\log M_{2 w t-2}^{d_{2}}$, under the assumption made about $\log H S_{2 w t-2}$ above.

${ }^{3}$ For this variable, $M^{d}{ }_{2 w t-1}$ had to be constructed, and it was constructed in the following way. $\log H P_{2 w t}$ was regressed against a constant and time for the basic period of estimation for each industry, and the predicted values of this equation were taken to be the values of $\log H S_{2 w t}$. The already constructed $M^{*}{ }_{2 v t-1} H^{*_{2 y z-1}}$ was then divided by $H S_{2 t t-1}$ to yield $M^{a_{2} w t-1}$. 
TABLE 5.7

Parameter estimates for eq. (3.9)' with the additional term $\alpha_{8}\left(\log M_{2 k t-1}-\log M_{2 u t-1}^{d{ }^{2}}{ }_{ \pm}\right.$. Estimates presented for $\alpha_{1}$ and $\alpha_{8}$ only

\begin{tabular}{|c|c|c|c|c|c|}
\hline Industry & No. of obs. & $\hat{\alpha}_{1}$ & $\hat{\alpha}_{8}$ & SE & DW \\
\hline 201 & 192 & $\begin{array}{l}-.135 \\
(3.01)\end{array}$ & $\begin{array}{c}-.196 \\
(1.74)\end{array}$ & .0119 & 1.93 \\
\hline 207 & 136 & $\begin{array}{l}-.072 \\
(1.00)\end{array}$ & $\begin{array}{c}-.154 \\
(1.42)\end{array}$ & .0179 & 2.12 \\
\hline 211 & 136 & $\begin{array}{l}-.161 \\
(5.13)\end{array}$ & $\begin{array}{r}.190 \\
(1.31)\end{array}$ & .0102 & 1.89 \\
\hline 212 & 130 & $\begin{array}{l}-.056 \\
(1.32)\end{array}$ & $\begin{array}{l}-.336 \\
(1.48)\end{array}$ & .0158 & 2.60 \\
\hline 231 & 136 & $\begin{array}{l}-.090 \\
(1.57)\end{array}$ & $\begin{array}{l}-.217 \\
(2.19)\end{array}$ & .0191 & 1.99 \\
\hline 232 & 136 & $\begin{array}{r}-.061 \\
(1.75)\end{array}$ & $\begin{array}{l}-.127 \\
(0.96)\end{array}$ & .0107 & 1.48 \\
\hline 233 & 136 & $\begin{array}{r}.150 \\
(1.98)\end{array}$ & $\begin{array}{l}-.405 \\
(2.24)\end{array}$ & .0288 & 1.50 \\
\hline 242 & 154 & $\begin{array}{l}-.079 \\
(1.59)\end{array}$ & $\begin{array}{r}.137 \\
(0.90)\end{array}$ & .0127 & 1.81 \\
\hline 271 & 166 & $\begin{array}{r}-.032 \\
(1.26)\end{array}$ & $\begin{array}{l}-.057 \\
(0.64)\end{array}$ & .0048 & 2.11 \\
\hline 301 & 134 & $\begin{array}{l}-.072 \\
(2.20)\end{array}$ & $\begin{array}{l}-.140 \\
(1.22)\end{array}$ & .0142 & 1.97 \\
\hline 311 & 170 & $\begin{array}{l}-.235 \\
(3.60)\end{array}$ & $\begin{array}{r}.298 \\
(1.02)\end{array}$ & .0115 & 2.14 \\
\hline 314 & 136 & $\begin{array}{l}-.191 \\
(2.49)\end{array}$ & $\begin{array}{r}.577 \\
(1.25)\end{array}$ & .0143 & 2.22 \\
\hline 324 & 187 & $\begin{array}{l}-.136 \\
(4.01)\end{array}$ & $\begin{array}{r}.052 \\
(0.90)\end{array}$ & .0177 & 2.02 \\
\hline 331 & 128 & $\frac{-.052}{(2.26)}$ & $\begin{array}{r}.066 \\
(0.88)\end{array}$ & .0101 & 1.87 \\
\hline 332 & 170 & $\begin{array}{l}-.156 \\
(4.62)\end{array}$ & $\begin{array}{r}.103 \\
(1.06)\end{array}$ & .0167 & 2.20 \\
\hline 336 & 170 & $\begin{array}{l}-.167 \\
(3.01)\end{array}$ & $\begin{array}{r}.231 \\
(1.04)\end{array}$ & .0175 & 1.81 \\
\hline 341 & 191 & $\begin{array}{r}.009 \\
(0.24)\end{array}$ & $\begin{array}{l}-.106 \\
(2.36)\end{array}$ & .0178 & 2.02 \\
\hline
\end{tabular}

$t$-statistics are in parentheses. 
In table 5.7 the results of adding ( $\left.\log M_{2 w t-1}-\log M_{2 w t-1}^{d}\right)_{ \pm}^{2}$ to eq. (3.9)' are presented. The coefficient of this variable, denoted as $\alpha_{8}$, is expected to be negative if in fact the larger the amount of excess labor on hand the stronger the reaction is. In table 5.7 only the estimates of $\alpha_{1}$ and $\alpha_{8}$ are presented; the effects on the other coefficient estimates were minor.

In nine of the industries the estimate of $x_{8}$ is negative (as expected), and in three of these industries - 231, 233, and 341 - the estimate is significant. When the estimate of $\alpha_{8}$ is negative, the estimate of $\alpha_{1}$ decreases in absolute value compared with the estimate of $\alpha_{1}$ in table 4.3 without $\left(\log M_{2 w t-1}-\right.$ $\left.\log M_{2 w t-1}^{d}\right)_{ \pm}^{2}$ included, and when the estimate of $\alpha_{8}$ is positive, the estimate of $\alpha_{1}$ increases in absolute value. The introduction of $\left(\log M_{2 \text { w:t-1 }}-\log \right.$ $\left.M_{2 w t-1}^{d}\right)_{ \pm}^{2}$ tends to decrease the significance of the estimate of $\alpha_{1}$. Except for perhaps industry 233, the effects on the standard errors are slight. The results rather strongly suggest that the reaction to the amount of excess labor on hand is not stronger the larger the amount held.

It appears, therefore, from the two tests performed here that the introduction of the excess labor variable, $\log M_{2 w t-1}-\log M_{2 w t-1}^{d}$, and (for a few industries) the past change in output variables to the equation determining the short-run demand for workers adequately approximates the reaction of firms to the amount of excess labor on hand.

\subsection{Possible capacity constraints}

By specifying the short-run production function as one of fixed proportions and constant returns to scale, it is implied that when new workers are hired they work on previously idle machines (or on a previously non-existence second or third shift). ${ }^{1}$ Labor services (measured in this study as man hours) can, of course, be increased by increasing the number of hours worked per worker without having to add more machines, since the existing machines can just be utilized more hours. At high rates of output firms are not likely to have idle machines on hand, and if they want to increase the rate of output even more from an already high rate, they may have no choice but to increase labor services by increasing the number of hours worked per worker rather than by adding new workers. This would imply that for further increases in the rate of output from an already high rate $\log M_{2 w t}-\log$ $M_{2 w t-1}$ should be smaller, other things being equal, than for the same

1. See the discussion in $\$ 3.5$. 
TABLE 5.8

Parameter estimates for eq. (3.9)' with the additional term $\alpha_{9} D K_{t}$. Estimates presented for $\gamma_{0}$ and $\alpha_{9}$ only

\begin{tabular}{|c|c|c|c|c|c|c|}
\hline Industry & No. of obs. & $\hat{\gamma}_{0}$ & $\hat{\alpha}_{9}$ & SE & DW & $a \%$ \\
\hline 201 & 192 & $\begin{array}{r}.261 \\
(9.84)\end{array}$ & $\begin{array}{l}.0005 \\
(0.11)\end{array}$ & .0120 & 1.94 & 6.8 \\
\hline 207 & 136 & $\begin{array}{r}.261 \\
(10.09)\end{array}$ & $\begin{array}{c}.0002 \\
(0.02)\end{array}$ & .0181 & 2.12 & 9.6 \\
\hline 211 & 136 & $\begin{array}{r}.084 \\
(4.15)\end{array}$ & $\begin{array}{c}.0007 \\
(0.17)\end{array}$ & .0103 & 1.93 & 6.6 \\
\hline 212 & 136 & $\begin{array}{c}.158 \\
(7.22)\end{array}$ & $\begin{array}{l}-.0018 \\
(0.41)\end{array}$ & .0159 & 2.61 & 13.2 \\
\hline 231 & 136 & $\begin{array}{r}.129 \\
(3.95)\end{array}$ & $\begin{array}{l}-.0017 \\
(0.24)\end{array}$ & .0194 & 1.98 & 7.4 \\
\hline 232 & 136 & $\begin{array}{r}.125 \\
(9.58)\end{array}$ & $\begin{array}{l}-.0051 \\
(1.58)\end{array}$ & .0106 & 1.46 & 11.8 \\
\hline 233 & 136 & $\begin{array}{r}.173 \\
(6.67)\end{array}$ & $\begin{array}{l}-.0107 \\
(1.09)\end{array}$ & .0292 & 1.49 & 9.6 \\
\hline 242 & 154 & $\begin{array}{r}.223 \\
(13.63)\end{array}$ & $\begin{array}{l}-.0056 \\
(1.32)\end{array}$ & .0126 & 1.79 & 7.1 \\
\hline 271 & 166 & $\begin{array}{r}.124 \\
(8.13)\end{array}$ & $\begin{array}{l}-.0039 \\
(3.59)\end{array}$ & .0046 & 2.13 & 19.3 \\
\hline 301 & 134 & $\begin{array}{r}.070 \\
(3.53)\end{array}$ & $\begin{array}{l}-.0101 \\
(2.25)\end{array}$ & .0140 & 1.88 & 11.2 \\
\hline 311 & 170 & $\begin{array}{r}.188 \\
(7.89)\end{array}$ & $\begin{array}{l}.0014 \\
(0.31)\end{array}$ & .0115 & 2.12 & 5.3 \\
\hline 314 & 136 & $\begin{array}{r}.324 \\
(10.21)\end{array}$ & $\begin{array}{l}-.0016 \\
(0.29)\end{array}$ & .0143 & 2.19 & 7.4 \\
\hline 324 & 187 & $\begin{array}{r}.224 \\
(16.46)\end{array}$ & $\begin{array}{l}.0020 \\
(0.45)\end{array}$ & .0177 & 2.01 & 12.3 \\
\hline 331 & 128 & $\begin{array}{r}.189 \\
(9.94)\end{array}$ & $\begin{array}{l}-.0040 \\
(1.24)\end{array}$ & .0101 & 1.89 & 10.2 \\
\hline 332 & 170 & $\begin{array}{r}.176 \\
(8.24)\end{array}$ & $\begin{array}{l}-.0046 \\
(0.91)\end{array}$ & .0167 & 2.22 & 8.2 \\
\hline 336 & 170 & $\begin{array}{r}.158 \\
(6.02)\end{array}$ & $\begin{array}{c}.0036 \\
(0.69)\end{array}$ & .0176 & 1.78 & 10.6 \\
\hline 341 & 191 & $\begin{array}{r}.176 \\
(14.34)\end{array}$ & $\begin{array}{c}.0095 \\
(1.51)\end{array}$ & .0180 & 1.97 & 6.8 \\
\hline
\end{tabular}

$t$-statistics are in parentheses.

a Percentage of observations for which $D K_{t}$ was set equal to one. 
increase in the rate of output from a lower rate, since hours worked per worker would take up more of the adjustment at high rates of output.

This hypothesis that $\log M_{2 w t}-\log M_{2 w t-1}$ is smaller, other things being equal, at high rates of output was tested in the following manner. For each industry, output $Y_{d t}$ was plotted monthly for the nineteen-year period, and a dummy variable, denoted as $D K_{t}$, was set equal to one for those observations where $Y_{d t}-Y_{d t-1}$ was positive and $Y_{d t-1}$ appeared to be large relative to surrounding observations, and was set equal to zero otherwise. On the above hypothesis the coefficient of $D K_{t}$ should be negative. This test is of course somewhat subjective in that the construction of $D K_{s}$ is subjective, but the test should give a general indication whether $\log M_{2 w t}$ $\log M_{2 w t-1}$ behaves differently, other things being equal, when the rate of output is high and increasing.

The results of adding $D K_{t}$ to eq. (3.9)' are presented in table 5.8. The coefficient of $D K_{t}$ is denoted as $\alpha_{9}$, and estimates of $\gamma_{0}$ and $\alpha_{9}$ are presented in the table. Presented also in the table for each industry is the percentage of observations for which $D K_{t}$ was set equal to one. For ten of the seventeen industries the estimate of $\alpha_{9}$ is negative, as expected, but significantly so for only two of them -271 and 301 . The estimates of $\gamma_{0}$ are little affected by the introduction of $D K_{t}$ and the other coefficient estimates were little affected either. Only for industries 232, 271, and 301 has the standard error gone down even slightly compared with the standard error in table 4.3. It is rather clear that $D K_{t}$ is not a significant variable, and at least on this test the behavior of $\log M_{2 w t}-\log M_{2 w t-1}$ does not appear to be different when the rate of output is high and increasing.

If the above assumptions about the short-run production function are true, these results indicate that at least for rates of output which are actually observed there does not appear to be machine capacity problems at high rates of output. The crude nature of the above test should be emphasized, however, and perhaps not too much weight should be put on the results.

\subsection{Summary}

In this chapter various hypotheses regarding the short-run demand for production workers were proposed and tested. For the most part these hypotheses were rejected. Neither the past level of hours paid-for per worker, $\log H P_{2 w-1}$, nor the past change in the number of hours paid-for per worker, $\log H P_{2 w t-1}-\log H P_{2 w t-2}$, appears to be a significant determinant of the change in the number of workers employed, although as was 
seen in ch. 4, the amount of excess labor on hand, which is measured as $\log H S_{2 w t-1}-\log H_{2 w t-1}$, definitely appears to be significant. These results are as expected from the theory discussed above.

Since seasonal fluctuations are quite pronounced in many of the industries; two tests were made to see whether the behavior of firms is different than the model predicts it should be during general contractionary periods of output and general expansionary periods. The hypothesis that firms "hoard" labor during contractions and "dishoard" labor during expansions (in the sense that the model predicts more workers fired or fewer hired than actually are during contractions and conversely during expansions) was tested. Although the tests were rather crude, there did not seem to be any evidence that this hypothesis is true.

The one hypothesis which appeared to have some evidence in its favor is the hypothesis that labor market conditions (as measured by the unemployment rate) affect the employment behavior of firms. The hypothesis that tight labor markets tend to damp fluctuations in the number of workers employed and that loose labor markets tend to increase these fluctuations was tested by the means of a non-linear estimating technique, and the results were such that the hypothesis could not be completely rejected. Some further results will be presented in ch. 7 which add indirect support to this hypothesis.

The relationship between the "excess labor" model developed in this study and a "lagged adjustment" model which is more in the tradition of previous models was discussed, and the lagged adjustment model was seen to be (approximately) a special case of the excess labor model. From the results presented in table 4.3 the lagged adjustment model appears to be unduely restrictive. With respect to the excess labor model, a more complicated distributed lag equation was estimated in which the variable $\log M_{2 w t-2}-$ $\log M_{2 w t-2}^{d}$, which is the amount of excess labor on hand during the second week of month $t-2$, was added to eq. (3.9). This variable was not significant, and there was no evidence of a more complicated distributed lag on this score. In another test the variable $\left(\log M_{2 w i t-1}-\log M_{2 w t-1}^{d}\right)_{ \pm}^{2}$, which is the square (adjusted for negative signs) of the amount of excess labor on hand during the second week of month $t-1$, was added to eq. (3.9) to see whether firms react in a non-linear way to the amount of excess labor on hand. This also does not appear to be the case, since the variable was not significant. From the results of these last two tests, the reaction of firms to the amount of excess labor on hand appears to be adequately specified by eq. (3.9).

Finally, a test was made to see whether possible machine capacity problems 
cause the behavior of firms to be different, other things being equal, at high rates of output. The hypothesis that the change in the number of production workers employed is smaller, other things being equal, at high rates of output was tested, and the results indicated that this is not the case. 


\section{PRODUCTION DECISIONS \\ AND THE SHORT-RUN DEMAND FOR WORKERS}

\subsection{Introduction}

In the model developed in ch. 3 little was said about the production decisions of firms. The change in the number of workers employed was taken to be a function of current and expected future output changes, but the factors which determine the change in output were not discussed. Implicit in the specification of eq. (3.9) is the assumption that production decisions are in no way influenced by the number of workers on hand. Such factors as the level of inventories, the backlog of unfilled orders, and expected future sales are likely to influence production decisions, and if these decisions are also influenced by the number of workers on hand, then the one-way causality from decisions on production to decisions on employment implied by eq. (3.9) is not valid. This is not to say that in order for eq. (3.9) to be valid production has to be "exogenous" in the sense that firms have no control over the amount they produce, but only that among the factors which influence production decisions the number of workers on hand is not one of them.

Holt, Modigliani, MUth, and Simon (1960) - (hereafter referred to as HMMS) - in a path-breaking work on production and employment decisions have developed a model in which the level of sales is taken to be exogenous and in which decisions on production and employment are made simultaneously. Their model is actually a normative one - a model of how firms ought to behave in order to maximize profits - as opposed to a descriptive one-a model of how firms do in fact behave. Nevertheless, the HMMs model can be interpreted as a descriptive one and tested to see if firms do behave the way the model suggests they should. In this chapter the HMMs model is described and tested, and using the HMMs model as a guide, an alternative model to that developed in ch. 3 is also described and tested. The results achieved using the HMMS model are compared with the results achieved using the alternative model developed in this chapter, and then both of these sets of results are compared with the results achieved using the model developed in ch. 3 . The chapter concludes with a discussion of some results achieved using Bureau of Census data. 


\subsection{The Holt, Modigliani, Muth, and Simon model}

HMMS specify a quadratic cost function for the firm and then minimize the sum of expected future costs with respect to the relevant decision variables, production and employment, to arrive at equations determining the amount of output to produce and the size of the work force. They take sales and prices as exogenous, so that minimizing costs is equivalent to maximizing profits. Their cost function is composed of the following items: ${ }^{1}$

Regular payroll cost:

$$
w_{1} M_{t}+A_{0}
$$

where $M_{t}$ is the size of the work force, $w_{1}$ is the wage rate, and $A_{0}$ is the "fixed cost term".

Cost of hiring and layoffs:

$$
\lambda_{0}\left(M_{t}-M_{t-1}-A_{1}\right)^{2}
$$

The costs in (6.2) are the costs associated with changing the size of the work force in any one period. The constant term $A_{1}$ provides for asymmetry in costs of hiring and firing.

Expected cost of overtime (given $M_{t}$ ):

$$
\lambda_{1}\left(Y_{t}-v_{0} M_{t}\right)^{2}+v_{1} Y_{t}-v_{2} M_{t}+v_{3} Y_{t} M_{t}
$$

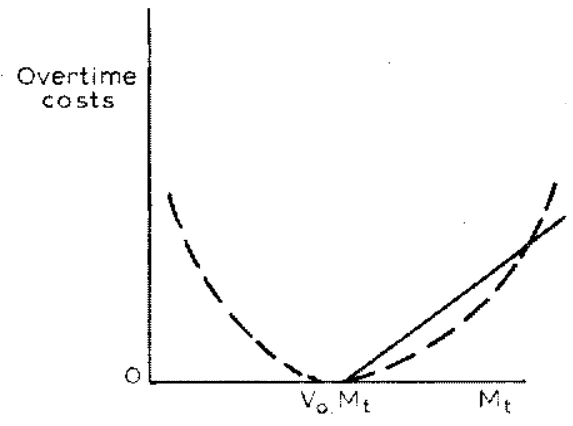

Fig. 6.1. Holt, Modighiani, Muth, and Simon's overtime cost approximation.

1 See Holt et al. (1960, pp. 47-130). 
The cost of overtime in eq. (6.3) depends both on the size of the work force, $M_{t}$, and on the amount of output produced, $Y_{t}$. The cost relation of which (6.3) is an approximation is presented in figure 6.1. Given $M_{\mathrm{f}}$ and the average output per worker $v_{0}, v_{0} M_{t}$ is the maximum amount of output which can be produced without working overtime. At levels of output higher than this the cost of overtime rises, the cost depending on the size of the overtime premium. HMMS argue that random disturbances and discontinuities will smooth out the solid line in figure 6.1. The dotted line in figure 6.1 is the quadratic approximation given in (6.3). HMMs do point out that to the extent that production falls to a low level of output relative to the work force the approximation becomes poor. ${ }^{1}$ Since (6.3) is based on a given size of the work force, $M_{t}$, there is a family of overtime cost curves, one for each value of $M_{t}$.

HMMS next define net inventories as inventories minus back orders and assume that the optimal level of net inventories equals $v_{4}+v_{5} S_{t}$, where $S_{t}$ is the aggregate order rate. As the actual level of net inventories deviates from optimal in either direction, costs rise, and they postulate the following costs.

Expected inventory, back order, and set up costs:

$$
\lambda_{2}\left[V_{t}-\left(v_{4}+v_{5} S_{t}\right)\right]^{2},
$$

where $V_{t}$ is the level of net inventories.

The HMMS cost function is the sum of eqs. (6.1)-(6.4). Since future orders are uncertain, the problem is to minimize the expected value of the sum of future costs with respect to the employment and production variables, subject to certain initial and terminal conditions. This minimization procedure yields the following two linear equations:

$$
\begin{aligned}
& Y_{t}=\zeta_{0}+\zeta_{1} M_{t-1}+\zeta_{2} V_{t-1}+\sum_{i=1}^{n} \psi_{i} S_{t+i}^{e} \\
& M_{t}=\alpha_{0}^{\prime}+\alpha_{1}^{\prime} M_{t-1}+\rho_{0}^{\prime} V_{t-1}+\sum_{i=1}^{n} \gamma_{i}^{\prime} S_{t+i}^{e}
\end{aligned}
$$

$\mathrm{S}_{t+i}^{e}$ is the level of orders expected for period $t+i$, and $n$ is the length of the decision period. Because of the quadratic nature of the cost function, the decisions reached by minimizing the sum of expected future costs using

1 Holt et al. (1960, p. 55, footnote 6). 
merely the expected values of the $S_{t+i}^{e}$ are the same as the decisions which would be reached using complete knowledge of the probability distribution functions of the $S_{t+i}^{e}$.

In the employment equation (6.6), which is of concern here, the number of workers employed during period $t$ is seen to be a function of the number employed during period $t-1$, the level of net inventories at the end of period $t-1$, and expected future orders. $\alpha_{1}^{\prime}$ in eq. (6.6) is expected to be positive under the HMMS interpretation, and $\rho_{0}^{\prime}$ is expected to be negative. Taking the functional form of eq. (6.6) to be log-linear instead of linear and taking first differences yields the following equation: ${ }^{1}$

$$
\begin{aligned}
\log M_{t}-\log M_{t-1} & =\theta_{0}^{\prime}+\alpha_{1}^{\prime}\left(\log M_{t-1}-\log M_{t-2}\right) \\
& +\rho_{0}\left(\log V_{t-1}-\log V_{t-2}\right)+\gamma_{0}\left(\log S_{t}^{e}-\log S_{t-1}\right) \\
& +\sum_{i=1}^{n} \gamma^{\prime}\left(\log S_{t+i}^{e}-\log S_{t+i-1}^{e}\right)
\end{aligned}
$$

This equation will be discussed in more detail below.

The main drawback to the HMMS approach would appear to be their quadratic approximation to overtime costs, eq. (6.3). As mentioned above, they state that this approximation is poor to the extent that production falls to a low level of output relative to the work force, but they add that the approximation may be good in the "relevant range". 2 In the previous chapters, however, it has been seen that output does fall to a low level relative to the work force in the course of the year, and if the assumptions made in this study are true, firms hold a considerable amount of positive excess labor during much of the year. This implies that the HMMs approximation (6.3) is a very poor one indeed, and a model derived from this approximation is likely to be unrealistic. Fortunately, the HMMS model can be compared with the model developed in ch. 3 by estimating an equation like (6.7) when data on sales and inventories are available. Before these estimates are made, however, an alternative model to that developed in ch. 3 will be described. This model is in the spirit of the HMMs model in that production decisions are not assumed to be independent of the size of the work force, but it avoids their unrealistic overtime cost approximation.

1 The constant term $\theta_{0}^{\prime}$ has been added to eq. (6.7) to allow for the possibility of a time trend in $\log M_{t}$.

${ }^{2}$ Holt et al. (1960, p. 55, footnote 6). 


\subsection{An alternative model of the short-run demand for production workers}

The model developed in this section is similar to the model developed in ch. 3 except that here expected future changes in sales (or shipments) rather than expected future changes in output are assumed to be the basic determinants of the change in the number of workers employed. In addition, the stock of inventories on hand is assumed to be a significant factor determining the change in the number of workers employed. Let $S_{2 w t+i}^{e}$ denote the level of sales expected for the second week of month $t+i, V_{2 w t-1}$ the actual stock of inventories on hand at the end of the second week of month $t-1$, and $V_{2 w t-1}^{d}$ the desired stock of inventories on hand for the end of the second week of month $t-1$. Then the basic equation determining $\log M_{2 w t}-\log M_{2 w t-1}$ is assumed to be

$$
\begin{aligned}
& \log M_{2 w t}-\log M_{2 w t-1}= \\
& \quad \alpha_{1}^{\prime \prime}\left(\log M_{2 w t-1}-\log M_{2 w t-1}^{d}\right)+\sum_{i=1}^{m} \beta_{i}^{\prime \prime}\left(\log Y_{2 w t-i}-\log Y_{2 w t-i-1}\right) \\
& +\rho_{0}^{\prime \prime}\left(\log V_{2 w t-1}-\log V_{2 w t-1}^{d}\right)+\gamma_{0}^{\prime \prime}\left(\log S_{2 w t}^{e}-\log S_{2 w t-1}\right) \\
& \quad+\sum_{i=1}^{n} \gamma_{i}^{\prime \prime}\left(\log S_{2 w t+i}^{e}-\log S_{2 w t+i-1}^{e}\right) .
\end{aligned}
$$

In eq. (6.8) the excess labor variable and the past output change variables have been left as they are in eq. (3.9) of the model developed in ch. 3; the expected future sales variables have replaced the expected future output variables; and $\log V_{2 w t-1}-\log V_{2 w t-1}^{d}$, which is the difference between the actual stock of inventories at the end of the second week of month $t-1$ and the desired stock, has been added.

Another way of looking at eq. (6.8) is that it is similar to the HMMS equation (6.7) in that the change in the number of workers employed is taken to be a function of expected future changes in sales in both equations. In eq. (6.8), however, the excess labor variable has replaced the lagged dependent variable, $\log M_{t-1}-\log M_{t-2}$; the past output change variables have been added (to perhaps help depict the firm's reaction to the amount of excess labor on hand); and the inventory variable has been taken to be the difference between the actual and desired stock of inventories on hand rather than the past change in the stock on hand, $\log V_{t-1}-\log V_{t-2}$. Unlike the 
HMMS equation, eq. (6.8) was not derived from the minimization of a particular cost function. As discussed in $\S 3.7$, there is undoubtedly some cost function the minimization of which would yield an equation like (3.9) or (6.8), but it is likely to be quite complex. In order for HMMs to derive their equations from the minimization of a cost function, they are forced to make the quadratic approximation to overtime costs depicted in figure 6.1 , which, as discussed above, is likely to be quite unrealistic.

The rationale for including the inventory variable, $\log V_{2 w t-1}-\log$ $V_{2 w t-1}^{d}$, in the equation determining the change in the number of workers employed is the following. If the stock of inventories is, say, larger than desired, the firm will presumably draw down inventories, other things being equal, by producing less in the future. This implies that man-hour requirements will be less in the future than they would otherwise have been, which should have a negative effect on the current change in the number of workers employed. Conversely, if the stock of inventories is smaller than desired, the firm will presumably build up its inventories, other things being equal, by producing more in the future. This implies that man-hour requirements will be greater in the future than they would otherwise have been, which should have a positive effect on the current change in the number of workers employed. The relevant inventory variable to use in the equation would appear to be this $\log V_{2 w t-1}-\log V_{2 w t-1}^{d}$ variable, which measures how large or small the stock of inventories on hand is relative to the desired stock, and not the HMms variable, $\log V_{t-1}-\log V_{t-2}$, which merely measures how large or small the change in the stock of inventories (from whatever level) has been.

The desired stock of inventories $V_{2 w t-1}^{d}$ is, of course, not directly observed, and some approximation for it must be found. Inventories can be used to meet part of any expected increase in sales, and by the accumulation and decumulation of inventories firms can smooth out fluctuations in production relative to fluctuations in sales. If sales were constant through time, finished goods inventories would really not be needed at all except for such things as insurance against a sudden increase in sales or a breakdown in production, and the desired stock of inventories could be taken to be constant through time. Since sales do fluctuate, it would appear that the desired stock of inventories will fluctuate also. If sales are expected to increase over the next few months, the desired stock of inventories is likely to be large so that part of the increase in sales can come from drawing down inventories rather than by increasing production to the full extent of the increase in sales, and if sales are expected to decrease over the next few months, the desired stock 
of inventories is likely to be small so that part of the decrease in sales can come from building up inventories rather than by decreasing production to the full extent of the decrease in sales. If sales are traditionally lowest in January and highest in July, for example, one would expect that the desired stock of inventories for the end of January would be greater than the desired stock of inventories for the end of July as firms attempt to smooth fluctuations in production relative to fluctuations in sales by accumulating and decumulating inventories throughout the year. The desired stock of inventories is thus assumed to be a function of expected future changes in sales:

$$
\begin{aligned}
\log V_{2 w t-1}^{d}=\log \bar{V}+\tau_{0} t & +\phi_{0}\left(\log S_{2 w t}^{e}-\log S_{2 w t-1}\right) \\
& +\sum_{i=1}^{n} \phi_{i}\left(\log S_{2 w t+i}^{e}-\log S_{2 w t+i-1}^{e}\right) .
\end{aligned}
$$

The time trend has been added to eq. (6.9), since there may be unaccounted for trend factors affecting the desired stock of inventories.

The expression for $\log V_{2 w t-1}^{d}$ in eq. (6.9) can be substituted into eq. (6.8), which merely adds a constant term and a time trend to the equation and changes slightly the interpretation of the coefficients of the expected future change in sales variables. Notice that if the $\phi_{i}$ coefficients are all zero in eq. (6.9) so that the desired stock of inventories is merely a slowly trending variable, substituting eq. (6.9) (erroneously) into eq. (6.8) will merely mean that the interpretation of the coefficients of the expected future change in sales variables is slightly wrong and will not bias the estimates in any way.

Eq. (6.8) is thus seen to combine the HMMs idea that expected future sales rather than expected future production should be considered to be the relevant exogenous variable affecting the level of the work force; the idea of the model of ch. 3 that firms react in a certain way to the amount of excess labor on hand; and the idea that the difference between the actual and desired stock of inventories should affect employment decisions. Given data on inventories and sales, eq. (6.8) and the HMms equation (6.7) can be estimated and compared, and this will be done in $\S 6.5$ after a discussion of the data in $\$ 6.4$.

It should perhaps be noted here that if no inventories are held in a particular industry, then the alternative model developed in this chapter [as exemplified by eq. (6.8)] and the model developed in ch. 3 [as exemplified by eq. (3.9)] are equivalent: the inventory variable disappears from eq. (6.8) and sales and production are the same. Of the industries considered in this study, the 
Newspaper publishing and printing industry, 271, obviously holds no inventories to speak of, and it also appears to be the case that the Apparel industries, 231, 232, and 232, the Footwear industry, 314, and the Metal cans industry, 341 , hold inventories only in small amounts relative to shortrun changes in the amount of output produced.

\subsection{The data}

Let $S_{t}$ denote the amount of output shipped (or sold) during month $t$, $Y_{t}$ the amount produced during month $t$, and $V_{t}$ the stock of inventories on hand at the end of month $t$. Then by definition

$$
Y_{t}=S_{t}+V_{t}-V_{t-1},
$$

which says that the amount of output produced during month $t$ is equal to the amount shipped during the month plus the amount by which the stock of inventories has been changed. It was mentioned in $\$ 4.2$ that when data were gathered from sources other than the FRB, the monthly figures were converted into average daily rates for the month using the FRB estimate of the number of working days in each month for each industry. Let $d_{t}$ denote the number of working days in month $t$. (The construction of $d_{t}$ is discussed in detail in the data appendix.) If eq. (6.10) is divided through by $d_{t}$, it can then be written

$$
Y_{d t}=S_{d t}+\left(V_{t}-V_{t-1}\right)_{d}
$$

where as before the subscript $d t$ denotes the average daily rate for month $t$ and where $\left(V_{t}-V_{t-1}\right)_{d}$ denotes the average daily rate of inventory investment for month $t$. In table 6.1 the additional notation used in the rest of this chapter is presented.

For four of the industries considered in this study - the Tobacco industries, 211 and 212, and Tires and inner tubes industry, 301, and the Cement industry, 324 - sufficient data were available so that eqs. (6.7) and (6.8) could be estimated. It was mentioned in $\S 4.2$ that for industries 301 and 324 output data (i.e., data on $Y_{t}$ ) were available from the Rubber Manufacturers Association (RMA) and the Bureau of Mines respectively. These data were used for the estimates presented in the previous chapters. From the RMA and the Bureau of Mines, data on the stock of inventories at the end of the month, $V_{t}$, were also available, which meant that for industries 301 and 324 data on $S_{t}$ could be constructed from the data on $Y_{t}$ and $V_{t}$ using eq. $(6.10)$. For industries 211 and 212, FRB data were used for the estimates presented 
TABLE 6.1

Additional notation used in ch. 6

$\begin{array}{ll}Y_{t} & \text { the amount of output produced during month } t . \\ S_{t} & \text { the amount of goods sold during month } t . \\ S_{2 w t} & \text { the amount of goods sold during the second week of month } t . \\ S_{i t} & \text { the average daily rate of sales for month } t . \\ V_{i} & \text { the stock of inventories on hand at the end of month } t . \\ V_{2 w t} & \text { the stock of inventories on hand at the end of the second week of month } t . \\ \left(V_{t}-V_{t-1}\right) d & \text { the average daily rate of inventory investment for month } t . \\ S^{e_{2 w t}+i} & \text { the amount of goods expected to be sold during the second week of month } \\ & t+i(i=0,1,2, \ldots), \text { the expectation being made during the second week } \\ V^{a_{2 w t}} & \text { of month } t-1 . \\ \text { the desired stock of inventories on hand for the end of the second week of }\end{array}$

in the previous chapters, but data were also available from the Internal Revenue Service (IRS) on $Y_{t}$ and $S_{t}$ for each of these industries. ${ }^{1}$

From data on $Y_{t}$ and $S_{t}$, data on the stock of inventories, $V_{t}$, cannot be constructed using eq. (6.10), and for industries 211 and 212 data on $V_{t}$ were constructed in the following manner. For December 1965 (denoted as 6512 ) the ratio of the dollar value of shipments to the dollar value of the stock of inventories (denoted as $R$ ) was computed using Bureau of Census data on the Tobacco industry 21 . For each industry, $S_{6512}$ (IRS data) was divided by $R$ to give a value of $V_{6512}$ for each industry. Using this figure as a base for each industry, the other values of $V_{t}$ were constructed using the formula [from eq. (6.10)], $V_{t-1}=V_{t}+S_{t}-Y_{t}$. Any errors resulting from this construction will merely mean that the values of $V_{t}$ are off by a constant amount.

From the RMA, Bureau of Mines, and IRs, data were thus available on $Y_{t}, S_{t}$, and $V_{t}$ for industries $301,324,211$, and 212 , and from these data and the data on $d_{t}$ for each of the industries, data on $Y_{d t}\left(=Y_{t} / d_{t}\right)$ and $S_{d t}(=$ $S_{t} / d_{t}$ ) were also available. These data were used to estimate eqs. (6.7) and

1 The FRB and IRs data are not independent data, since the FRB uses the IRS data to construct the production indices for industries 211 and 212. For this study the IRs data were collected from 1953 through 1965. Since the RMA, Bureau of Mines, and IRS data are not available in a convenient summary form anywhere, these data are presented in tabular form in the data appendix. 
(6.8) after some necessary modifications of the equations were made. These modifications will be discussed in the next section before the equation estimates are presented.

\subsection{Equation estimates}

Neither the HMms equation (6.7) nor eq. (6.8) is in an estimatable form, since not all of the variables in the equations are observed. Looking first at eq. (6.7), the observed $M_{2 w}$ variable can be used as the employment variable (in place of $M$ ) in the equation, and the observed $S_{d}$ variable can be used as the sales variable (in place of $S$ ). Because $M_{2 w}$ is the number of workers employed during the second week and $S_{d}$ is the average daily rate of sales for the entire month, for reasons analogous to those discussed in $\S 4.3$, $\log S_{d t-1}-\log S_{d t-2}$ may be a significant determinant of $\log M_{2 w t}-\log$ $M_{2 w t-1}$ in eq. (6.7) under the HMms model, and this variable should be included in the equation. To be consistent with the other variables which are to be used in eq. (6.7), the inventory investment variable should be the average daily rate of inventory investment for the monthly decision period between the end of the second week of month $t-2$ and the end of the second week of month $t-1$, rather than the absolute amount of inventory investment for the period unadjusted for the number of working days. This rate, of course, has to be approximated by the average daily rate for month $t-1$, since data on the stock of inventories at the end of the second week are not available. The average daily rate of inventory investment for month $t-1$ is $\left(V_{t-1}-V_{t-2}\right) / d_{t-1}$, where $d_{t-1}$ is the number of working days in month $t-1$, and since eq. (6.7) is in $\log$ form, the inventory investment variable is taken to be $\log V_{t-1}-\log V_{t-2}-\log d_{t-1}$, which will be denoted as $\left(\log V_{t-1}-\log V_{t-2}\right)_{d}$. For purposes of estimation eq. (6.7) thus becomes

$$
\begin{aligned}
& \log M_{2 w t}-\log M_{2 w t-1}= \\
& \theta_{0}^{\prime}+\alpha_{1}^{\prime}\left(\log M_{2 w t-1}-\log M_{2 w t-2}\right) \\
& +\rho_{0}^{\prime}\left(\log V_{t-1}-\log V_{t-2}\right)_{d}+\beta_{1}^{\prime}\left(\log S_{d t-1}-\log S_{d t-2}\right) \\
& \quad+\gamma_{0}^{\prime}\left(\log S_{d t}^{e}-\log S_{d t-1}\right)+\sum_{i=1}^{n} \gamma_{i}^{\prime}\left(\log S_{d t+i}^{e}-\log S_{d t+i-1}^{e}\right)
\end{aligned}
$$

Eq. (6.7)' is, of course, different depending on which expectational hypothesis is assumed. 
Looking next at eq. (6.8), the observed $Y_{d}$ variable can be used as the output variable in the equation (in place of $Y_{2 w}$ ) and the observed $S_{d}$ variable can be used as the sales variable (in place of $S_{2 w}$ ). The unobserved stock of inventories at the end of the second week of month $t-1, V_{2 w t-1}$, can be approximated by the observed stock of inventories at the end of month $t-1$, $V_{t-1}$. The desired stock of inventories in eq. (6.8) should thus be taken to be the desired stock for the end of month $t-1$ (denoted, say, as $V_{t-1}^{d}$ ), and in eq. (6.9) for $\log V_{t-1}^{d}$, the observed $S_{d}$ variable can be used as the sales variable (in place of $S_{2 w}$ ). From eq. (3.12) the excess labor variable in eq. (6.8), $\alpha_{1}^{\prime \prime}\left(\log M_{2 w t-1}-\log M_{2 w t-1}^{d}\right)$, is equal to $\alpha_{1}^{\prime \prime}\left(\log M_{2 w t-1}-\log \right.$ $\left.M_{2 w t-1}^{*} H_{2 w t-1}^{*}\right)+\alpha_{1}^{\prime \prime} \log \bar{H}+\alpha_{1}^{\prime \prime} \mu t$. Data for $M_{2 w t-1}^{*} H_{2 w t-1}^{*}$ were constructed in the manner described in $\$ 3.6$. In the construction of $M_{2 w t-1}^{*} H_{2 w t-1}^{*}$ for industries 301 and 324, the RMA and Bureau of Mines output data were used directly (after conversion into average daily rates), but for industries 211 and 212 the FRB data were used rather than the IRS data. Since the FRB data are constructed using the IRS data, no new relevant information is available from the IRS data with respect to the construction of $M_{2 w t-1}^{*} H_{2 w t-1}^{*}$ for industries 211 and 212 , and so the values constructed in ch. 3 for these two industries using FRB data can be used here. For purposes of estimation, eq. (6.8) thus becomes [combining eqs. (6.8) and (6.9)]:

$$
\begin{aligned}
& \log M_{2 w t}-\log M_{2 w t-1}=\left(-\alpha_{1}^{\prime \prime} \log \bar{H}-\rho_{0} \log \bar{V}\right) \\
&+\left(\mu-\rho_{0}^{\prime \prime} \tau_{1}\right) t+\alpha_{1}^{\prime \prime}\left(\log M_{2 w t-1}-\log M_{2 w t-1}^{*} H_{2 w t-1}^{*}\right) \\
&+\rho_{0}^{\prime \prime} \log V_{t-1}+\sum_{\begin{array}{c}
m \\
i_{i=1}^{\prime \prime}
\end{array} \beta_{i}^{\prime \prime}\left(\log Y_{d t-i}-\log Y_{d t-i-1}\right)}+\left(\gamma_{0}^{\prime \prime}-\rho_{0}^{\prime \prime} \phi_{0}\right)\left(\log S_{d t}^{e}-\log S_{d t-1}\right) \\
&+\sum_{i=1}^{n}\left(\gamma_{i}^{\prime \prime}-\rho_{0}^{\prime \prime} \phi_{i}\right)\left(\log S_{d t+i}^{e}-\log S_{d t+i-1}^{e}\right)(6.8)^{\prime}
\end{aligned}
$$

Eq. $(6.8)^{\prime}$ is also different depending on which expectational hypothesis is assumed.

For each industry the expectational hypothesis which gave the better results for eq. (3.9)' in table 4.3 was assumed to be the correct one for that industry and was used in the estimation of eqs. $(6.7)^{\prime}$ and $(6.8)^{\prime}$. For the work here, of course, the expectational hypotheses were taken to be in terms of sales rather than production. In other words, eqs. (3.13) and (3.14) were taken to be in terms of $S_{d}$ rather than $Y_{2 w}$. For each industry the horizon 
TABle 6.2

Parameter estimates for eq. $(6.7)^{\prime}$

\begin{tabular}{|c|c|c|c|c|c|c|c|c|c|c|c|c|c|c|}
\hline $\begin{array}{l}\text { 莺 } \\
\text { 总 }\end{array}$ & $\begin{array}{l}\dot{8} \\
0 \\
0 \\
\dot{z} \\
\dot{z}\end{array}$ & $\hat{\theta}_{0}^{\prime}$ & $\hat{\alpha}_{1}^{\prime}$ & $\hat{\rho}_{0}^{\prime}$ & $\hat{\beta}_{1}^{\prime}$ & $\hat{\gamma}_{0}^{\prime}$ & $\hat{\gamma}_{1}^{\prime}$ & $\hat{\gamma}_{z}^{\prime}$ & $\hat{\gamma}_{3}^{\prime}$ & $\hat{\gamma}_{4}^{\prime}$ & $\mathrm{s} \hat{\delta}^{\prime}$ & $\mathbf{R}^{2}$ & $\mathrm{SE}$ & DW \\
\hline 211 & 96 & $\begin{array}{l}-.080 \\
(1.25)\end{array}$ & $\begin{array}{r}.168 \\
(2.27)\end{array}$ & $\begin{array}{l}-.026 \\
(1.24)\end{array}$ & & $\begin{array}{r}.038 \\
(2.09)\end{array}$ & $\begin{array}{l}.010 \\
(0.82)\end{array}$ & $\begin{array}{r}.049 \\
(4.61)\end{array}$ & & & $\begin{array}{r}.013 \\
(0.81)\end{array}$ & .318 & .0091 & 2.02 \\
\hline 212 & 107 & $\begin{array}{l}-.082 \\
(0.78)\end{array}$ & $\begin{array}{l}-.106 \\
(1.84)\end{array}$ & $\begin{array}{l}-.026 \\
(0.76)\end{array}$ & $\begin{array}{r}.090 \\
(3.84)\end{array}$ & $\begin{array}{r}.021 \\
(0.84)\end{array}$ & & & & & & .190 & .0187 & 1.64 \\
\hline 301 & 134 & $\begin{array}{l}-.023 \\
(0.39)\end{array}$ & $\begin{array}{r}.222 \\
(2.68)\end{array}$ & $\begin{array}{l}-.007 \\
(0.36)\end{array}$ & & $\begin{array}{r}.003 \\
(0.26)\end{array}$ & $\begin{array}{r}.008 \\
(0.67)\end{array}$ & $\begin{array}{l}-.020 \\
(1.76)\end{array}$ & $\begin{array}{l}-.008 \\
(0.76)\end{array}$ & & & .095 & .0162 & 2.01 \\
\hline 324 & 187 & $\begin{array}{l}-.004 \\
(0.07)\end{array}$ & $\begin{array}{r}.201 \\
(2.90)\end{array}$ & $\begin{array}{l}(0.007) \\
(0.001\end{array}$ & $\begin{array}{r}.056 \\
(4.22)\end{array}$ & $\begin{array}{r}.030 \\
(2.56)\end{array}$ & $\begin{array}{c}.014 \\
(1.15)\end{array}$ & $\begin{array}{r}.025 \\
(2.28)\end{array}$ & $\begin{array}{r}.001 \\
(0.05)\end{array}$ & $\begin{array}{l}-.001 \\
(0.10)\end{array}$ & $\begin{array}{l}-.006 \\
(0.31)\end{array}$ & .378 & .0234 & 2.08 \\
\hline
\end{tabular}

$t$-statistics are in parentheses.

a $\hat{\delta}^{\prime}$ is the coefficient estimate of $\log S_{d t-1}-\log S_{a t-13}$ under the non-perfect expectational hypothesis. 
Parameter estimates for eq. $(6.8)^{\prime}$

\begin{tabular}{|c|c|c|c|c|c|c|c|c|c|c|c|c|c|c|c|}
\hline 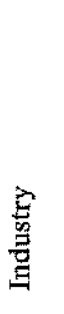 & $\begin{array}{l}\dot{0} \\
\dot{0} \\
\dot{0} \\
\dot{0}\end{array}$ & $\begin{array}{c}0 \\
00 \\
0 \\
0 \\
01 \\
1 \\
0 \\
0 \\
0 \\
0 \\
0 \\
0 \\
0 \\
0\end{array}$ & $\hat{\chi}_{1}^{\prime \prime}$ & $\widehat{\mu-Q^{\prime \prime}{ }_{0} \tau_{1}}$ & $\hat{\rho}_{0}^{\prime \prime}$ & $\hat{\beta}_{1}^{\prime \prime}$ & & & बa & $z^{\infty}$ & 2 & ${ }^{n} \hat{\delta}^{\prime \prime}$ & $\mathbf{R}^{2}$ & $\mathrm{SE}$ & DW \\
\hline 211 & 96 & b & $\begin{array}{l}-.072 \\
(2.96)\end{array}$ & $\begin{array}{l}-.061 \\
(2.57)\end{array}$ & $\begin{array}{l}-.033 \\
(2.92)\end{array}$ & & $\begin{array}{r}.066 \\
(3.09)\end{array}$ & $\begin{array}{r}.013 \\
(0.88)\end{array}$ & $\begin{array}{r}.053 \\
(5.04)\end{array}$ & & & $\begin{array}{r}.004 \\
(0.24)\end{array}$ & .352 & .0089 & 1.67 \\
\hline 212 & 107 & $\begin{array}{l}-.242 \\
(0.83)\end{array}$ & $\begin{array}{l}-.038 \\
(1.48)\end{array}$ & $\begin{array}{l}-.006 \\
(0.12)\end{array}$ & $\begin{array}{r}.001 \\
(0.06)\end{array}$ & $\begin{array}{r}.060 \\
(4.17)\end{array}$ & $\begin{array}{c}.036 \\
(1.45)\end{array}$ & & & & & & .201 & .0186 & 2.85 \\
\hline 301 & 134 & $\begin{array}{l}-.399 \\
(4.58)\end{array}$ & $\begin{array}{l}-.084 \\
(5.97)\end{array}$ & $\begin{array}{c}.036 \\
(0.91)\end{array}$ & $\begin{array}{l}-.010 \\
(2.52)\end{array}$ & & $\begin{array}{c}.016 \\
(1.76)\end{array}$ & $\begin{array}{r}.010 \\
(1.03)\end{array}$ & $\begin{array}{l}-.014 \\
(1.38)\end{array}$ & $\begin{array}{c}.002 \\
(0.26)\end{array}$ & & & .278 & .0145 & 1.80 \\
\hline 324 & 187 & $\begin{array}{r}.364 \\
(2.65)\end{array}$ & $\begin{array}{r}.003 \\
(0.14)\end{array}$ & $\begin{array}{r}.227 \\
(3.81)\end{array}$ & $\begin{array}{l}-.037 \\
(4.97)\end{array}$ & $\begin{array}{r}.156 \\
(9.10)\end{array}$ & $\begin{array}{r}.056 \\
(4.16)\end{array}$ & $\begin{array}{r}.007 \\
(0.57)\end{array}$ & $\begin{array}{r}.044 \\
(4.28)\end{array}$ & $\begin{array}{r}.000 \\
(0.03)\end{array}$ & $\begin{array}{l}-.010 \\
(0.99)\end{array}$ & $\begin{array}{r}.000 \\
(0.01)\end{array}$ & .522 & .0205 & 2.40 \\
\hline
\end{tabular}

$t$-statistics are in parentheses.

${ }^{a} \hat{\delta}^{\prime \prime}$ is the coefficient estimate of $\log S_{i t-1}-\log S_{a t-13}$ under the non-perfect expectational hypothesis.

b The constant was excluded from the equation because of its strong collinearity with $\log V_{t-1}$. 
TABLE 6.4

Parameter estimates for eq. $(3.9)^{\prime}$

\begin{tabular}{|c|c|c|c|c|c|c|c|c|c|c|c|c|c|c|}
\hline 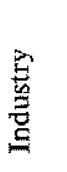 & $\begin{array}{l}\dot{8} \\
\dot{0} \\
\dot{0} \\
\dot{Z}\end{array}$ & $\widehat{a_{1}} \log \vec{H}$ & $\hat{\alpha}_{1}$ & $1000 \widehat{a_{1} \mu}$ & $\hat{\beta}_{1}$ & $\hat{\gamma}_{0}$ & $\hat{\gamma}_{1}$ & $\hat{\gamma}_{2}$ & $\hat{\gamma}^{2}$ & $\hat{\gamma}_{4}$ & $\mathrm{a} \hat{\delta}$ & $\mathrm{R}^{2}$ & $\mathrm{SE}$ & DW \\
\hline 211 & 96 & $\begin{array}{l}-.464 \\
(3.47)\end{array}$ & $\begin{array}{l}-.080 \\
(3.52)\end{array}$ & $\begin{array}{l}-.066 \\
(2.93)\end{array}$ & & $\begin{array}{r}.083 \\
(4.21)\end{array}$ & $\begin{array}{r}.020 \\
(1.52)\end{array}$ & $\begin{array}{r}.052 \\
(5.69)\end{array}$ & & & $\begin{array}{r}.005 \\
(0.34)\end{array}$ & .401 & .0085 & 1.55 \\
\hline 212 & 107 & $\begin{array}{l}-.430 \\
(2.99)\end{array}$ & $\begin{array}{l}-.073 \\
(2.97)\end{array}$ & $\begin{array}{l}-.018 \\
(0.49)\end{array}$ & $\begin{array}{r}.058 \\
(4.64)\end{array}$ & $\begin{array}{r}.088 \\
(4.73)\end{array}$ & & & & & & .331 & .0169 & 2.98 \\
\hline 301 & 134 & $\begin{array}{l}-.626 \\
(7.20)\end{array}$ & $\begin{array}{c}-.108 \\
(7.18)\end{array}$ & $\begin{array}{l}-.062 \\
(2.79)\end{array}$ & & $\begin{array}{r}.055 \\
(2.88)\end{array}$ & $\begin{array}{r}.059 \\
(3.37)\end{array}$ & $\begin{array}{r}.030 \\
(1.83)\end{array}$ & $\begin{array}{r}.036 \\
(2.29)\end{array}$ & & & .297 & .0142 & 1.92 \\
\hline 324 & 187 & $\begin{array}{c}-.653 \\
(6.37)\end{array}$ & $\begin{array}{l}-.110 \\
(6.34)\end{array}$ & $\begin{array}{r}.060 \\
(2.44)\end{array}$ & & $\begin{array}{r}.224 \\
(16.50)\end{array}$ & $\begin{array}{r}.039 \\
(2.40)\end{array}$ & $\begin{array}{r}.026 \\
(1.60)\end{array}$ & $\begin{array}{r}.052 \\
(3.36)\end{array}$ & $\begin{array}{r}.051 \\
(3.42)\end{array}$ & $\begin{array}{r}.008 \\
(0.47)\end{array}$ & .639 & .0177 & 2.01 \\
\hline
\end{tabular}

$t$-statistics are in parentheses.

a $\hat{\delta}$ is the coefficient estimate of $\log Y_{d t-1}-\log Y_{d t-13}$ under the non-perfect expectational hypothesis. 
(i.e., the size of $n$ ) over which the expectational variables were significant in the estimation of eq. (3.9 $)^{\prime}$ was used in the estimation of eqs. $(6.7)^{\prime}$ and $(6.8)^{\prime}$, even if not all of the expectation variables proved to be significant in the equations, in order that the various results could be compared. For eq. (6.7) $\log S_{d t-1}-\log S_{d t-2}$ was included in the final equation estimated only if it proved to be significant. For industries 301 and 324 the same period of estimation was used to estimate eqs. $(6.7)^{\prime}$ and $(6.8)^{\prime}$ as was used to estimate eq. (3.9) $)^{\prime}$ above, but for industries 211 and 212 a shorter period had to be used since the IRs data were only collected from 1953 on.

The results of estimating the HMMs equation (6.7)' for industries 211,212 , 301 , and 324 are presented in table 6.2 ; the results of estimating eq. $(6.8)^{\prime}$ are presented in table 6.3; and for purposes of comparison, the results of estimating eq. (3.9)' are presented in table 6.4. For industries 301 and 324 the results presented in table 6.4 are the same as those presented in table 4.3 , but for industries 211 and 212 eq. (3.9)' was re-estimated using the IRS data and the shorter period of estimation to insure a valid comparison with eqs. (6.7)' and (6.8)'.

Looking at the HMms equation first, the results in table 6.2 are not very good. The fits are low compared with those for eq. (3.9)' in table 6.4; for none of the industries is the estimate of the coefficient $p_{0}$ of the inventory investment variable significant, although it is of the expected negative sign; for industry 212 the estimate of the coefficient $\alpha_{0}$ of $\log M_{2 w r-1}-\log M_{2 w-2}$ is not significant and is of the wrong sign; for industries 212 and 301 the estimate of the coefficient $\gamma_{0}^{\prime}$ of $\log S_{d t}^{e}-\log S_{d t-1}$ is not significant; and only two other of the expected future change in sales variables are significant.

Looking at the equation developed in this chapter next, the results presented in table 6.3 are somewhat better. The fits are better than those of the HMMs equation in table 6.2 , but they are still not as good as those for eq. (3.9)' in table 6.4. For industry 212 the estimate of the coefficient $\rho_{0}^{\prime \prime}$ of the inventory variable is not significant; the excess labor variable is significant only for industries 211 and 301 ; as was the case for the HMms equation, only for industries 211 and 324 is the estimate of the coefficient $\gamma_{0}^{\prime \prime}$ of $\log S_{d t}^{e}-\log S_{d t-1}$ significant; and only two other of the expected future change in sales variables are significant in the table.

Turning finally to eq. (3.9)', the results presented in table 6.4 are by far the best. The fits are much better; for every industry the excess labor variable is significant; for every industry the estimate of the coefficient 
$\gamma_{0}$ of $\log Y_{d t}^{e}-\log Y_{d t-1}$ is significant; and for the most part the expected future change in output variables are significant.

Although the sample is small, the results achieved here strongly indicate that neither the HMMs model nor the alternative model developed in this chapter gives as good an explanation of short-run changes in the number of workers employed as the model developed in ch. 3 . If one had to choose between the HMMS model and the model developed in this chapter, the latter gives consistently better results, but the model developed in ch. 3 , in which decisions on production are assumed not to be influenced by the number of workers on hand, seems to dominate even this model. The results suggest, in other words, that models which specify a one-way causality from decisions on production to decisions on employment are more realistic than models which specify that these decisions are made simultaneously.

This conclusion should perhaps be qualified by noting that for industries $207,332,336$, and about 34 percent of 331 the FRB data on production are really data on sales or shipments. The results presented in table 4.3 of estimating eq. (3.9)' using these data are not noticeably worse than the results of estimating the other equations, and there is no way of knowing whether the use of data on production would have lead to better results for these industries, as would be expected from the results achieved in this chapter. Because of the small sample size, the conclusion of this chapter must remain somewhat tentative.

\subsection{Bureau of Census data}

For four of the seventeen industries considered in this study - 201, 301, 331 , and 332 - unpublished Bureau of Census data on the value of shipments and the value of inventories were available monthly from 1948 or 1953 to the present. The basic disadvantage of these data compared with the FRB (or RMA or Bureau of Mines) data is that they are based on dollar values rather than physical magnitudes. Price deflators could be used, but the deflators themselves are of questionable accuracy. Moreover, the Census data are based on sample surveys, whereas most of the output data used in this study are based on the whole population. One of the reasons the threedigit Census data are not published is the questionable reliability of the estimates, particularly the estimates before 1960 .

Nevertheless, the Bureau of Census data were used to estimate eq. (3.9) to see how the results compared with the results achieved using FRB or RMA data. The Census data were also used to estimate eq. $(6.8)^{\prime}$ developed in 
this chapter to see if the same conclusion was reached using these data as was reached in the previous section, namely, that eq. (3.9)' gives better results than eq. (6.8)'. From the Census data on the value of shipments for month $t, S_{t}$, and on the value of inventories at the end of month $t, V_{t}$, data on the value of production for month $t, Y_{t}$, were constructed using eq. (6.10). $S_{t}$ and $Y_{t}$ were then divided by $d_{t}$, the number of working days in month $t$, to yield the average daily rate of sales and production for month $t$, $S_{d t}$ and $Y_{d t}$. This procedure is described in the data appendix.

As an example of how the Bureau of Census data compare with the data used in this study, for industry 201 the square of the correlation coefficient between the first differences (of the logs) of the FRB output series and the first differences (of the logs) of the Census output series over the sample period was only .001 . For industry 331 it was .351 . For industry 332 the square of the correlation coefficient between the first differences (of the logs) of the FRB (shipments) series and the Census shipments series was .338. For industry 301 the square of the correlation coefficient between the first differences (of the logs) of the Census output series and the RMA output series was .402, and between the first differences (of the logs) of the Census shipments series and the RMA shipments series it was .364. It is thus evident that the Census data and the FRB or RMA data are quite different, and the results achieved using Census data should be interpreted with caution.

The results of estimating eq. (3.9)' using Census data are presented in table 6.5 for industries 201,301,331, and 322, along with the results of estimating the same equation using FRB or RMA data. For industries 201, 331, and 336 the Census data were available for a shorter period of time than the FRB data, and so eq. (3.9)' was re-estimated using FRB data for the same period of estimation as was used for the Census data to insure a valid comparison. These are the results presented in table 6.5. For industry 301 the results presented in table 6.5 of estimating eq. (3.9)' using RMA data are the same as the results presented in table 4.3 (and in table 6.4). When Census data were used to estimate the equation, the excess labor variable was constructed using the Census data on production instead of the FRB or RMA data. In the data appendix the exact periods of estimation which were used in table 6.5 are presented, and the months which were used as peaks in the output per paid-for man-hour interpolations when Census data were used are presented for each of the four industries. When estimating eq. (3.9)', the same expectational variables were used here as were used in table 4.3, except for industry 331. For this industry when Census data were used, two expected future output change variables were significant which were not 
Parameter estimates for eq. (3.9) using (a) FRB or RMA data and (b) Bureau of Census data

\begin{tabular}{|c|c|c|c|c|c|c|c|c|c|c|c|c|c|c|c|c|c|c|c|}
\hline 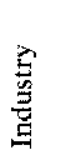 & $\begin{array}{l}\dot{0} \\
\stackrel{0}{0} \\
\ddot{0} \\
\dot{0} \\
z\end{array}$ & $\begin{array}{l}0 \\
\frac{60}{8} \\
\frac{8}{3}\end{array}$ & $\hat{\alpha}_{1}$ & $\left\langle\begin{array}{l}\text { < } \\
8 \\
8 \\
8\end{array}\right.$ & $\hat{\beta}_{4}$ & $\hat{\beta}_{3}$ & $\hat{\beta}_{2}$ & $\hat{\beta}_{1}$ & $\hat{\gamma}_{0}$ & $\hat{\gamma}_{1}$ & $\hat{\gamma}_{2}$ & $\hat{\gamma}_{3}$ & $\hat{\gamma}_{4}$ & $\hat{\gamma}_{5}$ & $\hat{\gamma}_{6}$ & ${ }^{\mathrm{a}} \hat{\delta}$ & $\mathrm{R}^{2}$ & SE & DW \\
\hline 201 & 182(a) & $\begin{array}{l}-.979 \\
(4.02)\end{array}$ & $\begin{array}{l}168 \\
(4.02)\end{array}$ & $\begin{array}{r}.075 \\
(3.31)\end{array}$ & & & $\begin{array}{c}.066 \\
(3.36)\end{array}$ & $\begin{array}{r}.073 \\
(3.77)\end{array}$ & $\begin{array}{r}.259 \\
(9.25)\end{array}$ & $\begin{array}{r}.164 \\
(6.53)\end{array}$ & $\begin{array}{r}.109 \\
(4.43)\end{array}$ & $\begin{array}{r}.138 \\
(6.84)\end{array}$ & $\begin{array}{r}.153 \\
(8.71)\end{array}$ & $\begin{array}{r}.091 \\
(5.58)\end{array}$ & $\begin{array}{r}.064 \\
(3.45)\end{array}$ & $\begin{array}{r}.041 \\
(2.12)\end{array}$ & .643 & .0120 & 1.86 \\
\hline & $182(b)$ & $\begin{array}{c}-.422 \\
(2.44)\end{array}$ & $\begin{array}{l}-.073 \\
(2.46)\end{array}$ & $\begin{array}{l}-.042 \\
(1.70)\end{array}$ & & & $\begin{array}{r}.054 \\
(3.22)\end{array}$ & $\begin{array}{r}.087 \\
(3.77)\end{array}$ & $\begin{array}{r}.137 \\
(4.94)\end{array}$ & $\begin{array}{r}.126 \\
(5.24)\end{array}$ & $\begin{array}{r}.127 \\
(5.57)\end{array}$ & $\begin{array}{r}.126 \\
(5.49)\end{array}$ & $\begin{array}{r}.097 \\
(4.18)\end{array}$ & $\begin{array}{r}.049 \\
(2.28)\end{array}$ & $\begin{array}{r}.014 \\
(0.87)\end{array}$ & $\begin{array}{r}.021 \\
(1.12)\end{array}$ & .242 & .0174 & 1.24 \\
\hline 301 & 134(a) & $\begin{array}{l}-.626 \\
(7.20)\end{array}$ & $\begin{array}{c}-.108 \\
(7.18)\end{array}$ & $\begin{array}{l}-.062 \\
(2.79)\end{array}$ & & & & & $\begin{array}{r}.055 \\
(2.88)\end{array}$ & $\begin{array}{r}.059 \\
(3.37)\end{array}$ & $\begin{array}{r}.030 \\
(1.83)\end{array}$ & $\begin{array}{r}.036 \\
(2.29)\end{array}$ & & & & & .297 & .0142 & 1.92 \\
\hline & $134(b)$ & $\begin{array}{l}-.483 \\
(4.77)\end{array}$ & $\begin{array}{c}.083 \\
(4.76)\end{array}$ & $\begin{array}{l}-.017 \\
(0.81)\end{array}$ & & & & & $\begin{array}{r}.073 \\
(3.63)\end{array}$ & $\begin{array}{r}.057 \\
(2.97)\end{array}$ & $\begin{array}{r}.033 \\
(1.71)\end{array}$ & $\begin{array}{r}.038 \\
(2.40)\end{array}$ & & & & & .196 & .0152 & 1.66 \\
\hline 331 & 118 (a) & $\begin{array}{l}-.207 \\
(2.93)\end{array}$ & $\begin{array}{l}-.035 \\
(2.89)\end{array}$ & $\begin{array}{r}.006 \\
(0.33)\end{array}$ & $\begin{array}{r}.047 \\
(3.39)\end{array}$ & $\begin{array}{r}.067 \\
(4.63)\end{array}$ & $\begin{array}{r}.036 \\
(2.37)\end{array}$ & $\begin{array}{r}.124 \\
(6.17)\end{array}$ & $\begin{array}{r}.185 \\
(9.61)\end{array}$ & & & & & & & & .794 & .0103 & 1.90 \\
\hline & $118(b)$ & $\begin{array}{l}-.010 \\
(1.19)\end{array}$ & $\begin{array}{l}-.016 \\
(1.13)\end{array}$ & $\begin{array}{r}.018 \\
(0.83)\end{array}$ & $\begin{array}{r}.034 \\
(2.70)\end{array}$ & $\begin{array}{r}.054 \\
(3.99)\end{array}$ & $\begin{array}{c}.062 \\
(4.38)\end{array}$ & $\begin{array}{c}.100 \\
(6.06)\end{array}$ & $\begin{array}{r}.133 \\
(9.18)\end{array}$ & $\begin{array}{r}.057 \\
(4.45)\end{array}$ & $\begin{array}{c}.030 \\
(2.46)\end{array}$ & & & & & & .695 & .0127 & 1.37 \\
\hline 332 & $120(a)$ & $\begin{array}{l}-.642 \\
(6.28)\end{array}$ & $\begin{array}{l}-.108 \\
(6.18)\end{array}$ & $\begin{array}{r}.045 \\
(1.14)\end{array}$ & & & & & $\begin{array}{r}.167 \\
(5.87)\end{array}$ & $\begin{array}{r}.027 \\
(1.44)\end{array}$ & $\begin{array}{r}.040 \\
(2.31)\end{array}$ & $\begin{array}{r}.019 \\
(1.15)\end{array}$ & $\begin{array}{r}.025 \\
(1.52)\end{array}$ & & & & .381 & .0178 & 2.51 \\
\hline & $120(\mathrm{~b})$ & $\begin{array}{l}-.640 \\
(6.60)\end{array}$ & $\begin{array}{l}-.108 \\
(6.50)\end{array}$ & $\begin{array}{r}.047 \\
(1.18)\end{array}$ & & & & & $\begin{array}{r}.082 \\
(5.19)\end{array}$ & $\begin{array}{r}.064 \\
(4.20)\end{array}$ & $\begin{array}{r}.071 \\
(5.04)\end{array}$ & $\begin{array}{r}.032 \\
(2.53)\end{array}$ & $\begin{array}{r}.018 \\
(1.78)\end{array}$ & & & & .354 & .0182 & 2.59 \\
\hline
\end{tabular}

$t$-statistics are in parentheses.

${ }^{a} \hat{\delta}$ is the coefficient estimate of $\log Y_{t t-1}-\log Y_{d t-13}$ under the non-perfect expectational hypothesis. 
TABLe 6.6

Parameter estimates for eq. $(6.8)^{\prime}$ using Bureau of Census data

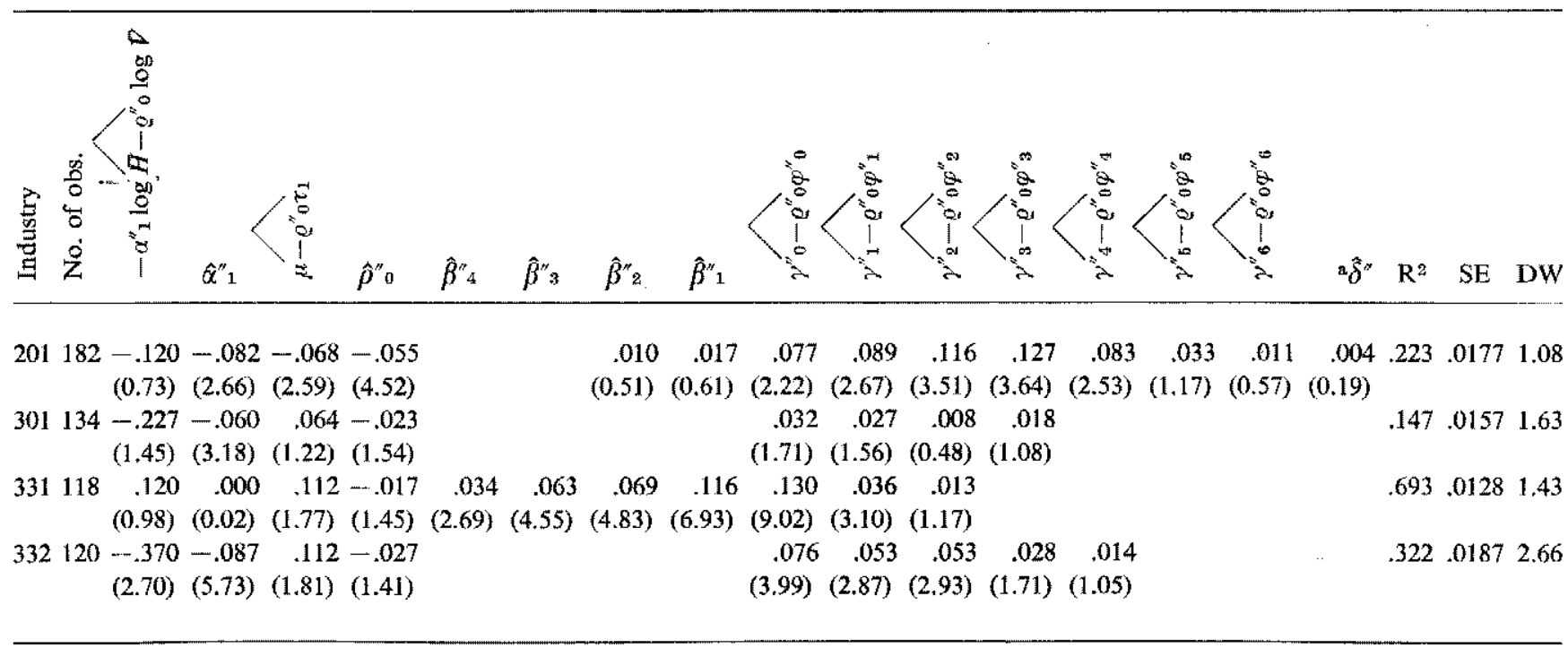

$t$-statistics are in parentheses.

a $\hat{\delta}^{\prime \prime}$ is the coefficient estimate of $\log S_{d t-1}-\log S_{d t-13}$ under the non-perfect expectational hypothesis. 
significant when FRB data were used, and these two variables were included in the equation which used Census data.

Comparing the results in table 6.5 , it is seen that the use of FRB or RMA data yields better fits in all four industries, especially in industry 201 where the $R^{2}$ decreases from .643 using FRB data to .242 using Census data. Except for industry 331 the excess labor variable is significant in the equations which used Census data, and for the most part the expected future output change variables are significant as well. As was just mentioned, for industry 331 two of the expected future output change variables were significant when Census data were used which were not significant when FRB data were used. The over-all results indicate that while the use of Census data leads to poorer results than the use of FRB or RMA data, the Census data do not appear to be completely worthless.

Assuming, then, that the Census data are of some use, eq. $(6.8)^{\prime}$ was estimated using the Census data, and the results are presented in table 6.6. For each industry the same expectational horizon was used in estimating eq. (6.8) as was used in table 6.5 for the Census data equations. The results in the two tables are thus directly comparable. Examining the results achieved using Census data in the two tables, it is seen that for all four industries eq. (3.9)' give better results than eq. $(6.8)^{\prime}$. Only for industry 201 is the inventory variable significant in eq. $(6.8)^{\prime}$ in table 6.6 , and for all of the industries the expected change in output variables in eq. (3.9) ${ }^{\prime}$ are more significant than the expected change in sales variable in eq. $(6.8)^{\prime}$. The fit of eq. (3.9) is better than the fit of eq. (6.8) for all four industries. The results achieved here using Census data are, therefore, consistent with the results achieved in the previous section using IRS, RMA, and Bureau of Mines data: eq. (3.9) appears to be more realistic than eq. (6.8). Since the Census data are probably not as accurate as the other data, however, less reliance can be put on the results achieved here.

For a final comparison using the Census data, the HMMs equation (6.7) was estimated for the four industries using the same expectational variables as those used in table 6.6 for eq. (6.8)'. The results are presented in table 6.7. For eq. $(6.7)^{\prime} \log S_{d t-1}-\log S_{d t-2}$ was included in the final equation estimated only if it proved to be significant. Looking at the results in tables 6.6 and 6.7 , the HMMs equation $(6.7)^{\prime}$ gives poorer results than eq. $(6.8)^{\prime}$ for three of the four industries. For industries 301, 331, and 332 the fit is worse for eq. $(6.7)^{\prime}$ than for eq. $(6.8)^{\prime}$; for 301 none of the expected future change in sales variables is significant in table 6.7 and the inventory variable is not significant; for industry 331 the inventory variable is not significant; and 
TABLE 6.7

Parameter estimates for eq. (6.7)' using Bureau of Census data

\begin{tabular}{|c|c|c|c|c|c|c|c|c|c|c|c|c|c|c|c|c|}
\hline 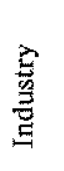 & 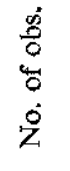 & $\hat{\theta}_{0}^{\prime}$ & $\hat{\alpha}_{1}^{\prime}$ & $\hat{\rho}_{0}^{\prime}$ & $\hat{\beta}_{1}^{\prime}$ & $\hat{\gamma}_{0}^{\prime}$ & $\gamma_{1}^{\prime}$ & $\hat{\gamma}_{2}^{\prime}$ & $\hat{\gamma}_{3}^{\prime}$ & $\hat{\gamma}_{4}^{\prime}$ & $\hat{\gamma}_{5}^{\prime}$ & $\hat{\gamma}_{6}^{\prime}$ & $\mathrm{a} \hat{\delta}^{\prime}$ & $\mathbf{R}^{2}$ & $\mathrm{SE}$ & DW \\
\hline 201 & 182 & $\begin{array}{l}-.176 \\
(2.53)\end{array}$ & $\begin{array}{r}.436 \\
(6.36)\end{array}$ & $\begin{array}{l}-.055 \\
(2.54)\end{array}$ & & $\begin{array}{r}-.039 \\
(1.93)\end{array}$ & $\begin{array}{l}-.017 \\
(0.66)\end{array}$ & $\begin{array}{r}.031 \\
(1.07)\end{array}$ & $\begin{array}{r}.066 \\
(2.05)\end{array}$ & $\begin{array}{r}.052 \\
(1.73)\end{array}$ & $\begin{array}{r}.020 \\
(0.76)\end{array}$ & $\begin{array}{r}.015 \\
(0.85)\end{array}$ & $\begin{array}{r}-.014 \\
(0.68)\end{array}$ & .286 & .0168 & 2.00 \\
\hline 301 & 134 & $\begin{array}{l}-.173 \\
(1.56)\end{array}$ & $\begin{array}{r}.215 \\
(2.64)\end{array}$ & $\begin{array}{l}-.054 \\
(1.55)\end{array}$ & & $\begin{array}{l}-.005 \\
(0.26)\end{array}$ & $\begin{array}{r}.025 \\
(1.41)\end{array}$ & $\begin{array}{r}.005 \\
(0.30)\end{array}$ & $\begin{array}{r}.017 \\
(1.02)\end{array}$ & & & & & .088 & .0162 & 1.96 \\
\hline 331 & 118 & $\begin{array}{r}.003 \\
(0.02)\end{array}$ & $\begin{array}{r}.462 \\
(6.36)\end{array}$ & $\begin{array}{r}.001 \\
(0.04)\end{array}$ & $\begin{array}{r}.055 \\
(3.09)\end{array}$ & $\begin{array}{r}.095 \\
(5.68)\end{array}$ & $\begin{array}{r}.033 \\
(2.65)\end{array}$ & $\begin{array}{r}.022 \\
(1.88)\end{array}$ & & : & & & & .613 & .0141 & 2.13 \\
\hline 332 & 120 & $\begin{array}{r}.319 \\
(2.89)\end{array}$ & $\begin{array}{l}-.023 \\
(0.26)\end{array}$ & $\begin{array}{r}.104 \\
(2.88)\end{array}$ & & $\begin{array}{r}.066 \\
(3.12)\end{array}$ & $\begin{array}{r}.040 \\
(2.13)\end{array}$ & $\begin{array}{r}.042 \\
(2.32)\end{array}$ & $\begin{array}{r}.027 \\
(1.62)\end{array}$ & $\begin{array}{r}.014 \\
(1.00)\end{array}$ & & & & .150 & .0208 & 2.15 \\
\hline
\end{tabular}

-statistics are in parentheses.

a $\hat{\delta}^{\prime}$ is the coefficient estimate of $\log S_{d t-1}-\log S_{d t-13}$ under the non-perfect expectational hypothesis. 
for industry 332 the estimate of the coefficient $x_{1}^{\prime}$ of the lagged dependent variable is not significant and of the wrong negative sign, and the estimate of the coefficient $\rho_{0}$ of the inventory variable is significant but of the wrong positive sign. For these three industries the same conclusion is reached here using Census data than was reached above using IRs, RMA, and Bureau of Mines data: the equation developed in this chapter gives better results than the HMMs equation. [Neither, of course, gives results as good as eq. (3.9)'.]

For industry 201 the HMMS equation in table 6.7 gives better results from the point of view of goodness of fit than either eq. (6.8)' in table 6.6 or eq. (3.9)' in table 6.5. In table 6.7, however, only one of the expected future changes in sales variable is significant for industry 201, and most of the explanatory power comes from the lagged dependent variable, although the coefficient estimate of the inventory variable is significant and of the right sign. The results for industry 201 using Census data are so much worse than the results achieved using FRB data that comparisons of the different equations using Census data are probably of little value.

\subsection{Summary}

The major conclusion of this chapter is that models such as the one developed in ch. 3 which specify a one-way causality from decisions on production to decisions on employment appear to be more realistic than models such as the one of HMMs or the one developed in this chapter which assume that production and employment decisions are made simultaneously. The HMMS model, which is based on the minimization of a short-run cost function and in which the level of sales rather than the level of production is assumed to be exogenous in the short run, yielded the worst results of the three models tested. This was not unexpected since the HMMS overtime cost approximation, which is depicted in figure 6.1, is likely to be quite unrealistic if firms do in fact hold positive amounts of excess labor during much of the year. The alternative model developed in this chapter, which combines the HMMs idea that production and employment decisions are made simultaneously with the idea of the model developed in ch. 3 that the amount of excess labor on hand should affect employment decisions, yielded better results than the HMMS model, but still not as good as the model developed in ch. 3: the expected future change in output variables were more significant in eq. (3.9)' than the expected future change in sales variables were in eq. $(6.8)^{\prime}$.

Some results were presented using Bureau of Census data which indicate that the Census data, which are in value terms, are not as good as the FRB 
and RMA data, which are based on physical quantities. Nevertheless, the results achieved using Census data were consistent with the results achieved using the other data in that eq. (3.9 $)^{\prime}$ gave better results than eq. $(6.8)^{\prime}$ and, except for industry 201 , eq. (6.8)' gave better results than the HMMS equation $(6.7)^{\prime}$. 


\section{THE SHORT-RUN DEMAND \\ FOR HOURS PAID-FOR PER WORKER}

\subsection{Introduction}

In the short-run production function postulated in this study the labor input variable is taken to be the number of man hours worked, $M_{2 w t} H_{2 w t}$. In ch. 3 a theoretical model of the short-run demand for the number of workers employed, $M_{2 w t}$, was developed. The amount of excess labor on hand and the time stream of expected future changes in output were assumed to be significant determinants of the short-run demand for workers, and the empirical results presented in ch. 4 indicated that this is in fact the case. Because of the properties of the short-run production function, once the number of workers employed is determined, the number of hours worked per worker, $H_{2 w t}$, is automatically determined. From eq. (3.6) ${ }^{1}$

$$
H_{2 w t}=\alpha_{2 w t} Y_{2 w t} / M_{2 w t},
$$

where $\alpha_{2 w t}$ is the production function parameter for month $t$. Since $\alpha_{2 w t}$ and $Y_{2 w t}$ are taken to be exogenous, $H_{2 w t}$ is determined from eq. (7.1) once $M_{2 w t}$ is determined.

It was seen in table 2.2 that in general $M_{2 w t}$ fluctuates much less than output in the short run, and since $\alpha_{2 w t}$ moves only slowly through time, $H_{2 w t}$ is seen from eq. (7.1) to be subject to large short-run fluctuations and to account for a large percentage of the short-run fluctuations in $M_{2 w i} H_{2 w i}$. In other words, a large percentage of the short-run fluctuations in labor services is accounted for by fluctuations in the number of hours worked per worker rather than by fluctuations in the number of workers employed. This, of course, does not imply that the number of hours paid-for per worker, $H P_{2 w i}$, fluctuates to the same extent that the number of hours worked per worker does, and the model developed in ch. 3 did not provide an explanation of the short-run demand for the number of hours paid-for

1 Remember that by definition $M_{2 i o t} H_{2 w t}$ equals $M^{*_{2 w t}} H^{*}{ }_{2 w t}$ so that eq. (3.6) can be expressed in terms of $M_{2 w t} H_{3 t a t}$ rather than $M^{*_{2 u t}} H^{*}{ }_{2 u t}$. 
TABLE 7.1

Values of $\mathrm{HP}_{2 w 6}$ and $\mathrm{H}_{2 v 0}$ for 1962

\begin{tabular}{|c|c|c|c|c|c|c|c|c|c|}
\hline & \multicolumn{3}{|c|}{201} & \multicolumn{3}{|c|}{207} & \multicolumn{3}{|c|}{211} \\
\hline & $H P$ & $H$ & $H P-H$ & $H P$ & $H$ & $H P-H$ & $H P$ & $H$ & $H P-H$ \\
\hline 6201 & 39.6 & 38.5 & 1.1 & 39.3 & 28.2 & 11.1 & 36.0 & 36.0 & 0.0 \\
\hline 02 & 38.7 & 37.7 & 1.0 & 39.4 & 31.4 & 8.0 & 37.8 & 36.7 & 1.1 \\
\hline 03 & 39.1 & 39.1 & 0.0 & 39.7 & 30.6 & 9.1 & 38.4 & 38.5 & -.1 \\
\hline 04 & 40.1 & 38.1 & 2.0 & 39.1 & 26.7 & 12.4 & 39.3 & 36.6 & 2.7 \\
\hline 05 & 41.4 & 37.6 & 3.8 & 39.5 & 22.5 & 17.0 & 39.9 & 38.9 & 1.0 \\
\hline 06 & 41.5 & 35.8 & 5.7 & 39.7 & 25.5 & 14.2 & 39.7 & 38.0 & 1.7 \\
\hline 07 & 41.5 & 34.1 & 7.4 & $\mathfrak{a}$ & a & a & a & * & $\mathrm{a}$ \\
\hline 08 & 40.5 & 35.0 & 5.5 & 40.3 & 28.1 & 12.2 & 39.2 & 38.9 & 3.4 \\
\hline 09 & 40.9 & 35.6 & 5.3 & 41.3 & 41.3 & 0.0 & 40.1 & 38.2 & 1.9 \\
\hline 10 & 40.9 & 40.2 & .7 & 40.7 & 33.5 & 7.2 & 37.8 & 38.0 & -.2 \\
\hline 11 & 41.5 & 38.7 & 2.8 & 40.2 & 27.6 & 12.6 & 41.0 & 38.2 & 2.8 \\
\hline \multirow[t]{3}{*}{12} & 41.4 & 36.7 & 4.7 & a & a & a & a & \% & a \\
\hline & & 212 & & & 231 & . & & 232 & \\
\hline & $H P$ & $H$ & $H P-H$ & $H P$ & $H$ & $H P-H$ & $H P$ & $H$ & $H P-H$ \\
\hline 6201 & 36.6 & 34.7 & 1.9 & 35.4 & 26.9 & 8.5 & 35.0 & 34.8 & .2 \\
\hline 02 & 36.8 & 37.1 & -.3 & 36.1 & 30.1 & 6.0 & 37.6 & 37.3 & .3 \\
\hline 03 & 37.1 & 37.1 & 0.0 & 36.8 & 30.5 & 6.3 & 37.9 & 36.4 & 1.5 \\
\hline 04 & 36.5 & 35.8 & .7 & 37.2 & 32.8 & 4.4 & 37.9 & 35.2 & 2.7 \\
\hline 05 & 36.4 & 36.5 & -.1 & 37.5 & 30.5 & 7.0 & 38.0 & 33.8 & 4.2 \\
\hline 06 & 36.9 & 37.3 & -.4 & 37.8 & 30.4 & 7,4 & 38.7 & 34.1 & 4.6 \\
\hline 07 & a & a & a & $\mathbf{a}$ & a & $\mathrm{a}$ & a & a & a \\
\hline 08 & 38.0 & 38.8 & -.8 & 37.7 & 32.4 & 5.3 & 38.7 & 34.0 & 4.7 \\
\hline 09 & 38.1 & 37.7 & .4 & 37.8 & 32.4 & 5.4 & 38.1 & 33.8 & 4.3 \\
\hline 10 & 38.6 & 40.2 & $-1,6$ & 36.7 & 33.6 & 3.1 & 37.6 & 32.6 & 5.0 \\
\hline 11 & 39.0 & 36.9 & 2.1 & 37.2 & 31.3 & 5.9 & 37.6 & 32.1 & 5.5 \\
\hline \multirow[t]{3}{*}{12} & a & $\mathrm{a}$ & $\mathbf{a}$ & a & a & a & a & $\mathbf{s}$ & 3 \\
\hline & \multicolumn{3}{|c|}{233} & \multicolumn{3}{|c|}{242} & \multicolumn{3}{|c|}{271} \\
\hline & $H P$ & $H$ & $H P-H$ & $H P$ & $H$ & $H P-H$ & $H P$ & $H$ & $H P-H$ \\
\hline 6201 & 32.7 & 26.6 & 6.1 & 35.6 & 30.0 & 5.6 & 35.8 & 31.3 & 4.5 \\
\hline 02 & 33.9 & 32.6 & 1.3 & 38.7 & 38.7 & 0.0 & 35.8 & 32.8 & 3.0 \\
\hline 03 & 35.0 & 33.6 & 1.4 & 38.5 & 37.9 & .6 & 36.0 & 34.4 & 1.6 \\
\hline 04 & 35.3 & 31.8 & 3.5 & 39.0 & 38.0 & 1.0 & 36.5 & 35.2 & 1.3 \\
\hline 05 & 34.7 & 31.0 & 3.7 & 40.4 & 38.2 & 2.2 & 36.6 & 35.5 & 1.1 \\
\hline 06 & 34.4 & 29.1 & 5.3 & 40.0 & 37.6 & 2.4 & 36.5 & 33.4 & 3.1 \\
\hline 07 & $\mathrm{a}$ & a & a & a & a & a & 36.5 & 29.8 & 6.7 \\
\hline 08 & 34.8 & 28.1 & 6.7 & 40.7 & 36.8 & 3.9 & 36.3 & 31.0 & 5.3 \\
\hline 09 & 33.8 & 27.0 & 6.8 & 40.7 & 39.2 & 1.5 & 36.4 & 34.0 & 2.4 \\
\hline 10 & 32.8 & 28.2 & 4.6 & 40.1 & 37.1 & 3.0 & 36.2 & 35.4 & .8 \\
\hline 11 & 33.6 & 26.7 & 6.9 & 39.3 & 36.1 & 3.2 & 36.6 & 36.0 & .6 \\
\hline 12 & a & a & a & 38.6 & 33.9 & 4.7 & a & a & a \\
\hline
\end{tabular}


TABLE 7,1 (continued)

\begin{tabular}{|c|c|c|c|c|c|c|c|c|c|}
\hline & \multicolumn{3}{|c|}{301} & \multicolumn{3}{|c|}{311} & \multicolumn{3}{|c|}{314} \\
\hline & $H P$ & $H$ & $H P-H$ & $H P$ & $H$ & $H P-H$ & $H P$ & $H$ & $H P-H$ \\
\hline 6201 & 40.4 & 38.3 & 2.1 & 37.9 & 34.8 & 4.9 & 38.8 & 33.7 & 5.1 \\
\hline 02 & 39.2 & 39.2 & 0.0 & 40.0 & 38.9 & 1.1 & 37.9 & 37.0 & .9 \\
\hline 03 & 39.5 & 38.2 & 1.3 & 39.8 & 35.8 & 4.0 & 37.6 & 37.2 & .4 \\
\hline 04 & 40.2 & 39.4 & .8 & 40.0 & 37.7 & 2.3 & 36.5 & 35.5 & 1.0 \\
\hline 05 & 41.2 & 38.3 & 2.9 & 40.4 & 37.3 & 3.1 & 36.7 & 32.9 & 3.8 \\
\hline 06 & 42.5 & 40.7 & 1.8 & 40.5 & 38.3 & 2.2 & 38.1 & 33.8 & 4.3 \\
\hline 07 & a & a & a & B & $\mathrm{a}$ & $\&$ & a & $\mathrm{a}$ & $\mathrm{a}$ \\
\hline 08 & 40.9 & 33.8 & 7.1 & 40.1 & 35.9 & 4.2 & 37.9 & 35.4 & 2.5 \\
\hline 09 & 40.8 & 36.5 & 4.3 & 40.3 & 37.3 & 3.0 & 36.5 & 34.9 & 1.6 \\
\hline 10 & 40.9 & 39.6 & 1.3 & 40.2 & 37.8 & 2.4 & 35.5 & 33.9 & 1.4 \\
\hline 11 & 41.1 & 34.5 & 6.6 & 39.9 & 37.1 & 2.8 & 35.9 & 30.9 & 5.0 \\
\hline \multirow[t]{3}{*}{12} & 41.4 & 34.1 & 7.3 & 40.2 & 34.4 & 5.8 & $\mathbf{a}$ & $a$ & a \\
\hline & \multicolumn{3}{|c|}{324} & \multicolumn{3}{|c|}{331} & \multicolumn{3}{|c|}{332} \\
\hline & $H P$ & $H$ & $H P-H$ & $H P$ & $H$ & $H P-H$ & $H P$ & $H$ & $H P-H$ \\
\hline 6201 & 39.7 & 23.3 & 16.4 & 40.7 & 39.4 & 1.3 & 39.2 & 34.2 & 5.0 \\
\hline 02 & 39.7 & 24.1 & 15.6 & 40.7 & 40.7 & 0.0 & 40.0 & 36.7 & 3.3 \\
\hline 03 & 40.4 & 28.6 & 11.8 & 40.7 & 40.5 & .2 & 40.4 & 38.3 & 2.1 \\
\hline 04 & 40.9 & 37.0 & 3.9 & 40.5 & 37.1 & 3.4 & 40.5 & 38.0 & 2.5 \\
\hline 05 & 41.4 & 41.4 & 0.0 & 38.6 & 31.8 & 6.8 & 40.8 & 35.8 & 5.0 \\
\hline 06 & 41.2 & 39.3 & 1.9 & 38.3 & 30.3 & 8.0 & 41.6 & 37.0 & 4.6 \\
\hline 07 & 42.0 & 38.8 & 3.2 & a & $\mathbf{a}$ & a & a & a & a \\
\hline 08 & 41.7 & 41.7 & 0.0 & 38.1 & 31.4 & 6.7 & 39.9 & 30.6 & 9.3 \\
\hline 09 & 41.5 & 40.3 & 1.2 & 38.7 & 32.6 & 6.1 & 40.7 & 35.8 & 4.9 \\
\hline 10 & 41.1 & 39.7 & 1.4 & 37.9 & 33.8 & 4.1 & 40.5 & 35.5 & 5.0 \\
\hline 11 & 41.0 & 35.8 & 5.2 & 38.2 & 35.2 & 3.0 & 40.5 & 35.1 & 5.4 \\
\hline \multirow[t]{3}{*}{12} & 40.4 & 29.1 & 11.3 & 39.1 & 33.8 & 5.3 & 41.0 & 33.4 & 7.6 \\
\hline & & 336 & & & 341 & & & & \\
\hline & $H P$ & $H$ & $H P-H$ & $H P$ & $H$ & $H P-H$ & & & \\
\hline 6201 & 41.2 & 36.5 & 4.7 & 40.8 & 25.6 & 15.2 & & & \\
\hline 02 & 41.2 & 38.9 & 2.3 & 41.2 & 27.6 & 13.6 & & & \\
\hline 03 & 41.2 & 38.1 & 3.1 & 41.4 & 29.4 & 12.0 & & & \\
\hline 04 & 41.4 & 38.0 & 3.4 & 41.9 & 30.9 & 11.0 & & & \\
\hline 05 & 41.1 & 36.2 & 4.9 & 42.2 & 32.1 & 10.1 & & & \\
\hline 06 & 41.6 & 38.8 & 2.8 & 43.6 & 34.9 & 8.7 & & & \\
\hline 07 & a & a & a & 43.8 & 35.4 & 8.4 & & & \\
\hline 08 & 40.2 & 31.8 & 8.4 & 43.4 & 41.9 & 1.5 & & & \\
\hline 09 & 40.8 & 37.9 & 2.9 & 43.5 & 43.5 & 0.0 & & & \\
\hline 10 & 40.7 & 37.4 & 3.3 & 41.5 & 31.6 & 9.9 & & & \\
\hline 11 & 40.8 & 36.5 & 4.3 & 40.4 & 26.8 & 13.6 & & & \\
\hline 12 & 41.4 & 34.6 & 6.8 & 41.1 & 27.1 & 14.0 & & & \\
\hline
\end{tabular}

a Excluded from period of estimation because of shutdowns. 
per worker. In this chapter a model of the short-run demand for hours paidfor per worker is developed and estimated. From this model and the model of the short-run demand for workers developed in ch. 3 the model of the shortrun demand for total man hours paid-for can be derived, and this is the subject matter of ch. 8 .

Before developing the model explaining the short-run demand for the number of hours paid-for per worker, it is informative to see how $H P_{2 w t}$ and $H_{2 w t}$ compare. From eq. (7.1) data on $M_{2 w t}$ are available directly; data on $Y_{2 w t}$ can be approximated by the available data on $Y_{d t}$; and data on $\alpha_{2 w t}$ are available from the interpolations discussed in ch. 3 . Consequently, data on $H_{2 w t}$ for each industry can be constructed using eq. (7.1). Data on $H P_{2 w t}$ are available directly, and so for any one month $H_{2 w t}$ and $H P_{2 w t}$ can be compared. In table 7.1 the values for $H P_{2 w t}, H_{2 w t}$, and the difference between them, $H P_{2 w t}-H_{2 w t}$, are presented for each of the seventeen industries for the year 1962. 1962 was free from any significant strikes in the industries, and it was arbitrarily chosen to be used as a representative year. The July and December observations are not given in the table for those industries in which shutdowns occurred during these months, since the months were omitted from the periods of estimation and the observations for these months have little meaning.

Theoretically $H P_{2 w t}$ can never be less than $H_{2 w t}$, since hours actually worked must be paid for, and so no negative values of $H P_{2 w t}-H_{2 w t}$ should be found in table 7.1. In fact, there are a few small negative values of $H P_{2 w t}-H_{2 w t}$ in the table. This is due to the fact that, as mentioned in $\S 3.6$, in the interpolation work the procedure of going from peak to next higher peak was not strictly adhered to in every case. For a small fraction of the cases a particular peak seemed to be high relative to past and future values, and these peaks were not used as interpolation peaks. For these peaks, then, the computed value of $H_{2 w t}$ is greater than the actual value of $H P_{2 w t}$, which accounts for the negative values of $H P_{2 w t}-H_{2 w t}$ given in table 7.1.

$H P_{2 w t}-H_{2 w t}$ is the number of hours which are paid-for per worker but which are not actually worked, i.e., the number of "non-productive" hours paid-for per worker. This (or the $\log$ version of it, $\log H P_{2 w t}-\log H_{2 w t}$ ) is not the measure of excess labor on hand, which is defined to be $\log$ $H S_{2 w t}-\log H_{2 w t}$, where $H S_{2 w t}$ is the standard number of hours of work per worker. The excess labor variable can be positive or negative depending on whether the number of hours worked per worker is smaller or larger than the standard number of hours of work per worker, but theoretically log $H P_{2 w t}-\log H_{2 w t}$ is always positive. $H P_{2 w t}-H_{2 w t}$ should thus be inter- 
preted as measuring the number of non-productive hours paid-for per worker, but not as the measure of excess labor. Ignoring the negative numbers in table 7.1 , the values of $H P_{2 w t}-H_{2 w t}$ range from zero in a number of industries to 17.0 in the Confectionery industry, 207. Looking at the individual industries, the Tobacco industries, 211 and 212, appear to have the least number of non-productive hours paid-for, while the Confectionery, Cement, and Metal cans industries, 207, 324, and 341, appear to have the most, especially during certain months of the year.

One question which arises when examining the figures for $H P_{2 w t}-H_{2 w t}$ in the table is why firms do not allow larger fluctuations in $H P_{2 w t}$ in order to avoid paying for so many non-productive hours. This question sets the stage for the development of the model of the short-run demand for the number of hours paid-for per worker.

\subsection{The theoretical model}

The basic idea of the model developed here is that with respect to such things as worker morale problems and some of the others discussed in $\S 3.4$ firms view short-run fluctuations in the number of hours paid-for per worker in a similar manner as they view fluctuations in the number of workers employed. Firms may be reluctant in periods of low output, for example, to decrease the number of hours paid-for per worker sufficiently so that they are paying for no non-productive hours. Just as with the number of workers employed, firms may subject themselves to serious worker morale problems and other costs if they allow large short-run fluctuations in the number of hours paid-for per worker.

Based on this idea, it would appear that some of the same factors which determine the change in the number of workers employed, $\log M_{2 w t}$ $\log M_{2 w t-1}$, might also determine the change in the number of hours paidfor per worker, $\log H P_{2 w t}-\log H P_{2 w t-1}$. Indeed, when $\log H P_{2 w t}-\log$ $H P_{2 w t-1}$ was regressed on $\log M_{2 w t}-\log M_{2 w t-1}$ for each industry, the coefficient of $\log M_{2 w: t}-\log M_{2 w t-1}$ was nearly always significant and positive, which tends to confirm this conclusion.

One would thus expect that the amount of excess labor on hand and expected future changes in output would contribute significantly to the determination of short-run changes in the number of hours paid-for per worker. Firms may be reluctant, for example, to decrease the number of hours paid-for per worker because of such things as worker morale problems and the like, but they may be more likely to do this if there is much excess 
labor on hand and if the amount of output to be produced is expected to decrease over the next few months than if there is little excess labor on hand and output is expected to increase over the next few months.

There is, however, one main difference between hours paid-for per worker and workers, which is probably best summarized by Kuh: "The main determinant of hours to be worked is a convention established through bargaining and a variety of social and institutional forces". "Unlike the number of workers employed, which can move steadily upward or downward over time, the number of hours paid-for per workers fluctuates around a relatively constant level of hours (such a 40 hours per week). If the number of hours paid-for per worker is greater than this level, this should, other things being equal, bring forces into play causing it to decline back to this level. Therefore, the difference between the number of hours paid-for per worker during the second week of month $t-1$ and the standard number of hours of work per worker for that week, $\log H P_{2 w t-1}-\log H S_{2 w t-1}$, should be a significant factor in the determination of $\log H P_{2 w t}-\log$ $H P_{2 w t-1}$.

The following equation might thus be considered to be the basic equation determining the change in the number of hours paid-for per worker:

$\log H P_{2 w t}-\log H P_{2 w t-1}=$

$$
\begin{aligned}
& \alpha_{1}\left(\log M_{2 w t-1}-\log M_{2 w t-1}^{d}\right)+\alpha_{2}\left(\log H P_{2 w t-1}-\log H S_{2 w t-1}\right) \\
+ & \sum_{i=1}^{m} \beta_{i}\left(\log Y_{2 w t-i}-\log Y_{2 w t-i-1}\right)+\gamma_{0}\left(\log Y_{2 w t}^{e}-\log Y_{2 w t-1}\right) \\
+ & \sum_{i=1}^{n} \gamma_{i}\left(\log Y_{2 w t+i}^{e}-\log Y_{2 w t+i-1}^{e}\right) .
\end{aligned}
$$

As was the case in eq. (3.9) for workers, the past output change variables are added to eq. (7.2) on the hypothesis that they may help depict the reaction of firms to the amount of excess labor on hand. ${ }^{2}$ The coefficient $\alpha_{1}$ of the excess labor variable and the coefficient $\alpha_{2}$ of the variable depicting the difference between the number of hours paid-for per worker and the

1 KUH (1965b, p. 253). Kuh, of course, does not make a distinction between hours paid-for per worker and hours worked per worker.

2 See the discussion in $\$ 3.7$. 
standard number of hours of work per worker are expected to be negative in eq. (7.2).

Because adjustment costs for the firm are likely to be smaller with respect to the number of hours paid-for per worker than with respect to the number of workers employed, one would expect that the size of the $\gamma_{i}$ coefficients of the expected future output change variables would be smaller in eq. (7.2) than in the corresponding equation for workers, eq. (3.9). In general, one would expect that the adjustment of the number of hours paid-for per worker to the standard level would be more rapid than the adjustment of the number of workers employed to its desired level.

There is a problem which may arise in estimating eq. (7.2) for hours paid-for per worker which did not arise in estimating eq. (3.9) for workers. As mentioned above, one of the constraints implied by the model developed in this study is that the number of hours paid-for per worker can never be less than the number of hours worked per worker; the number of hours worked must be paid-for. At least during certain times of the year, $H P_{2 w t}$ is likely to be equal to $H_{2 w t}$, and depending on $M_{2 w t}, Y_{2 w t}$, and $\alpha_{2 w t}$ [see eq. (7.1)], eq. (7.2) could call for an $H P_{2 w t}$ which is less than $H_{2 w i t}$, which cannot happen. This possible constraint would not be taken into account if eq. (7.2) were estimated as it is.

Another way of looking at this problem is the following. When the number of hours paid-for per worker, $H P_{2 w}$, equals the number of hours worked per worker, $H_{2 w}$, the production function constraint becomes binding on $H P_{2 w}$ and it is no longer free to fluctuate as much as it is when it is greater than $H_{2 w}$. When $H P_{2 w}$ equals $H_{2 w}, H P_{2 w}$ can only decrease as fast as $H_{2 w}$ decreases, and it must increase if $H_{2 w}$ increases and as fast as $H_{2 w}$ increases. The behavior of $\log H P_{2 w t}-\log H P_{2 w t-1}$ may be different, therefore, when it equals $\log H_{2 w t}-\log H_{2 w t-1}$ than otherwise.

Fortunately, a test of this possible difference in behavior can be made. It was seen at the beginning of this chapter that estimates of $H_{2 w t}$ are available for each industry and that these estimates can be compared with the actual values of $H P_{2 w t}$ for any one period of time. From these data the following dummy variable, denoted as $B 1_{t}$, was constructed. When both $H P_{2 w t}-H_{2 w t}$ and $H P_{2 w t-1}-H_{2 w t-1}$ were less than $1.0, B 1_{t}$ was set equal to one, otherwise it was set equal to zero. In other words, $B 1_{t}$ was set equal to one when $\log H P_{2 w t}-\log H P_{2 w t-1}$ seemed to be equal or nearly equal to $\log H_{2 w r}-\log H_{2 w t-1}$. If $\log H P_{2 w t}-\log H P_{2 w t-1}$ behaves differently when it equals $\log H_{2 w t}-\log H_{2 w t-1}$ than otherwise and if $B 1$, adequately reflects the cases where $\log H P_{2 w t}-\log H P_{2 w t-1}$ equals $\log H_{2 w t}-\log$ 
$H_{2 w t-1}$, then adding $B 1_{t}$ to eq. (7.2) should result in a significant coefficient estimate for $B 1_{t}$. If, for example, $\log H P_{2 w t}-\log H P_{2 w t-1}$ responds more to current output changes when it equals $\log H_{2 w t}-\log H_{2 w t-1}$ (due to the fact that the production function constraint is binding on $H_{2 w}$ ) than otherwise, then the coefficient estimate for $B 1_{t}$ should be positive and the estimate of the coefficient $\gamma_{0}$ of $\log Y_{2 w t}-\log Y_{2 w t-1}$ should be smaller when $B 1_{t}$ is included in the equation than otherwise.

For industries 207,231,233,311, and 341 the estimated values of $H_{2 w}$ were such that only one or two observations were found where both $H P_{2 w t}$ $H_{2 w t}$ and $H P_{2 w t-1}-H_{2 w t-1}$ were less than 1.0, and so for these industries the 1.0 figure was increased. For 233 and 311 the figure was taken to be 2.0 , and for 207, 231, and 341 it was necessary to raise the figure to 5.0 before a non-negligible number of observations was available. The dummy variable for 233 and 311 is denoted as $B 2$, and for 207,231 , and 341 it is denoted as $B 5_{i}$. While it may be unreasonable with respect to the last three industries to suppose that the "true" $\log H_{2 w t}-\log H_{2 w t-1}$ is equal to $\log H P_{2 w: t}-$ $\log H P_{2 w t-1}$ when the "estimated" values of $H_{2 w t}$ and $H_{2 w r-1}$ are about 4 or 5 hours less than $H P_{2 w t}$ and $H P_{2 w t-1}$ respectively, adding $B 5_{t}$ to eq. (7.2) for these industries can at least be taken to indicate whether the behavior of $\log H P_{2 w t}-\log H P_{2 w t-1}$ is different during those times when it is "most nearly equal" to $\log H_{2 w t}-\log H_{2 w t-1}$.

One other factor which has not yet been considered as a possible determinant of the short-run demand for hours paid-for per worker is the degree of labor market tightness. According to the hypothesis discussed in $\$ 5.4$, a tight labor market (measured by a negative $\log U_{2 w t}-\log \bar{U}$, where $U_{2 w t}$ is the unemployment rate prevailing from the end of the second week of month $t-1$ to the end of the second week of month $t$ and where $\bar{O}$ is the rate at which the market switches from being tight to being loose) leads to fewer workers hired and fired in the short run, and a loose labor market (measured by a positive $\log U_{2 w t}-\log \bar{U}$ ) leads to more workers hired and fired in the short run. In other words, in tight labor markets short-run fluctuations in the number of workers employed are damped, while in loose labor markets the fluctuations are increased. In eq. (5.1) $\log U_{2 w t}-\log \bar{O}$ enters the equation determining the short-run demand for production workers in a non-linear way. The results presented in $\S 5.4$ provided some support for this hypothesis, but the evidence was not very strong.

Considering the constraint on $H P_{2 w^{*}}$, just discussed and the fact that the same factors which determine the short-run demand for workers may also influence the short-run demand for hours paid-for per worker, an argument 
can be made why $\log U_{2 w t}-\log \bar{U}$ should enter eq. (7.2) in a simple linear way and have a negative effect on $\log H P_{2 w t}-\log H P_{2 w t-1}$.

Consider, first of all, what happens in a tight labor market. The number of workers hired and fired fluctuates less, and so the number of hours worked per worker, $H_{2 w}$, fluctuates more. For those cases where $H P_{2 w}$ equals $H_{2 w}, H P_{2 w}$ should then fluctuate more when the labor market is tight. Since it has been postulated above that firms are reluctant to lay off workers or have workers quit when labor markets are tight, an added inducement to keep workers from moving to other jobs might be to keep the level of hours paid-for per worker high. This "inducement effect" should lead, then, to larger increases and smaller decreases in $H P_{2 w}$ when labor markets are tight. This "inducement effect" reinforces the "production function constraint effect" (i.e., the effect when $H P_{2 w}$ equals $H_{2 w}$ ) for increases in $H P_{2 w}$, but runs counter to it for decreases in $H P_{2 w}$. (The production function constraint implies that when $H P_{2 w}$ equals $H_{2 w}, H P_{2 w}$ should decrease more when labor markets are tight, while the inducement effect implies that $H P_{2 w}$ should decrease less when labor markets are tight.) Since $H P_{2 w}$ seems to be equal to $H_{2 w}$ only for at most a few months out of the year, it seems likely that the counter influence of the production function constraint effect for decreases in $H_{2}{ }_{2 w}$ will be outweighed by the inducement effect. Thus in tight labor markets $H P_{2 w t}$ is likely to increase more and decrease less, and so $\log U_{2 w t}-\log \bar{U}$ (which is negative when labor markets are tight) should have a negative influence on $\log H P_{2 w t}-\log H P_{2 w t-1}$.

A similar reasoning holds for loose labor markets. The production function constraint effect implies that, since $H_{2 w}$ fluctuates less in loose labor markets due to the number of workers fluctuating more, $H P_{2 w}$ should fluctuate less (increase less and decrease less) when $H P_{2 w}$ equals $H_{2 w}$. The inducement effect implies that $H P_{2 w}$ should increase less and decrease more (less inducement needed to keep the workers). The conflict between the two effects occurs for decreases in $H P_{2 w}$ when $H_{2 w}$ equals $H_{2 w}$. Again if this conflict is not significant, $\log U_{2 w t}-\log \bar{U}$ should have a negative influence on $\log H P_{2 w t}-\log H P_{2 w t-1}$ during loose labor markets as well. Therefore, if $\log V_{2 w t}-\log \tilde{O}$ is added to eq. (7.2), its coefficient estimate should be negative if the above hypothesis is valid.

Eq. (7.2) is not in a form which can be estimated since many of the variables in the equation are not directly observed. The observed $Y_{d}$ variable can be used as the output variable in the equation (in place of $Y_{2 w}$ ), and from eq. (3.12) the excess labor variable in the equation, $\alpha_{1}\left(\log M_{2 w t-1}\right.$ $\left.\log M_{2 w t-1}^{d}\right)$, is equal to $\alpha_{1}\left(\log M_{2 w t-1}-\log M_{2 w t-1}^{*} H_{2 w t-1}^{*}\right)+\alpha_{1} \log \bar{H}+$ 
$\alpha_{1} \mu i$. Data on $M_{2 w t-1}^{*} H_{2 w t-1}^{*}$ are available from the interpolation work in ch. 3. From the assumption made about $H S_{2 w t-1}$ in eq. (3.11) [namely, that it is a slowly trending variable], the term $-\alpha_{2} \log H S_{2 \times t-1}$ in eq. (7.2) is equal to $-\alpha_{2} \log \bar{H}-x_{2} \mu t$. With respect to the unemployment rate variable, as was done in $\$ 5.4$, the BLS data on the unemployment rate prevailing during the second week of month $t$ can be taken as a proxy for the rate prevailing during the period from the end of the second week of month $t-1$ to the end of the second week of month $t$.

Adding the term $\psi_{1}\left(\log U_{2 w t}-\log \bar{U}\right)$ to eq. (7.2) [the addition of $B 1_{t}$ to the equation will be discussed later] and using these approximations, eq. (7.2) becomes

$$
\begin{aligned}
\log H P_{2 w t}-\log H P_{2 w t-1}= \\
\quad \alpha_{1}\left(\log M_{2 w t-1}-\log M_{2 w t-1}^{*} H_{2 w t-1}^{*}\right)+\alpha_{2} \log H P_{2 w t-1} \\
+\left[\left(\alpha_{1}-\alpha_{2}\right) \log \bar{H}-\psi_{1} \log \bar{U}\right]+\left(\alpha_{1}-\alpha_{2}\right) \mu t \\
+\sum_{i=1}^{m} \beta_{i}\left(\log Y_{d t-i}-\log Y_{d t-i-1}\right)+\gamma_{0}\left(\log Y_{d t}^{e}-\log Y_{d t-1}\right) \\
+\sum_{i=1}^{n} \gamma_{i}\left(\log Y_{d t+i}^{e}-\log Y_{d t+i-1}^{e}\right)+\psi_{1} \log U_{2 w t} .
\end{aligned}
$$

Eq. (7.2)' is different depending on which expectational hypothesis is assumed. Remember also that the use of data on $Y_{d}$ rather than on $Y_{2 w}$ gives an additional reason why $\log Y_{d t-1}-\log Y_{d t-2}$ may be significant in the determination of $\log H P_{2 w^{t}}-\log H P_{2 w t-1}{ }^{1}$

\subsection{The basic results}

The results of estimating eq. (7.2)' are presented in table 7.2. For each industry the expectational hypothesis which gave the better results for eq. $(3.9)^{\prime}$ in table 4.3 was assumed to be the correct one for that industry and was used in the estimation of eq. (7.2)'. As was done for eq. (3.9)', the past output change variables were carried back and the expected future output change variables were carried forward until they lost their significance. The same periods of estimation were used here as were used for eq. $(3.9)^{\prime}$ in

1 See the discussion in $\$ 4.2$. 
table 4.3. $\hat{\delta}$ in table 7.2 denotes the estimate of the coefficient of $\log Y_{d t-1}-$ $\log Y_{d t-13}$ for those industries in which the non-perfect expectational hypothesis was used.

The results presented in table 7.2 appear to be quite good. For every industry the estimate of the coefficient $\alpha_{2}$ of $\log H P_{2 w t-1}$ is negative, as expected, and highly significant. For every industry the estimate of the coefficient $\alpha_{1}$ of the excess labor variable is negative and is significant for every industry except 242 , where two of the past four output change variables are significant. These results rather strongly indicate that the amount of excess labor on hand is a significant factor determining the short-run demand for hours paid-for per worker, and they support the results presented in table 4.3 which indicate that the amount of excess labor on hand is a significant factor determining the short-run demand for workers. The significance of all of the estimates of $\alpha_{2}$ in table 7.2 indicates that the amount by which $H P_{2 w t-1}$ differs from the standard number of hours of work per worker is also an important factor determining the short-run demand for hours paid-for per worker.

With respect to the past output change variables, only for industries 201 and 242 are any of them significant in table 7.2. These variables do not appear to be of much help in depicting the reaction of firms to the amount of excess labor on hand with respect to changes in the number of hours paid-for per worker. A similar conclusion was also reached in ch. 4 with respect to changes in the number of workers employed.

The estimate of the coefficient $\gamma_{0}$ of the current output change variable in table 7.2 is positive and significant for every industry, and many of the estimates of the $\gamma_{i}$ coefficients of the expected future output changes variables are significant as well. The size of the estimate of $\gamma_{i}$ for the most part decreases as $i$ increases. The time stream of expected future output changes thus appears to be a significant determinant of the short-run demand for hours paid-for per worker. Taken together, the over-all results strongly confirm the hypothesis that many of the same factors which influence changes in the number of workers employed also influence changes in the number of hours paid-for per worker, i.e., that firms view fluctuations in the number of hours paid-for per worker in a similar manner as they view fluctuations in the number of workers employed.

Turning now to the unemployment rate variable, the estimate of the coefficient $\psi_{1}$ of $\log U_{2 w t}$ in table 7.2 is negative, as expected, for fifteen of the seventeen industries and significantly negative for eleven of these fifteen. For the two industries where the estimate of $\psi_{1}$ is positive -211 and $314-$ 
TABLE 7.2

Parameter estimates for eq. $(7.2)^{\prime}$

\begin{tabular}{|c|c|c|c|c|c|c|c|c|c|c|}
\hline 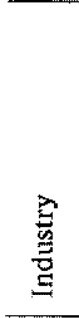 & $\begin{array}{l}\dot{0} \\
0 \\
0 \\
0 \\
0 \\
z\end{array}$ & (1) & $\hat{Q}_{1}$ & $\hat{Q}_{2}$ & $\frac{\bar{y}}{8}$ & $\hat{\beta}_{4}$ & $\hat{\beta}_{3}$ & $\hat{\beta}_{2}$ & $\hat{\beta}_{1}$ & po \\
\hline 201 & 192 & $\begin{array}{r}2.119 \\
(4.46)\end{array}$ & $\begin{array}{l}-.118 \\
(2.38)\end{array}$ & $\begin{array}{l}-.458 \\
(7.15)\end{array}$ & $\begin{array}{l}-.028 \\
(1.16)\end{array}$ & & & $\begin{array}{r}.118 \\
(5.14)\end{array}$ & $\begin{array}{r}.051 \\
(2.20)\end{array}$ & $\begin{array}{r}.251 \\
(7.77)\end{array}$ \\
\hline 207 & 136 & $\begin{array}{r}2.433 \\
(6.83)\end{array}$ & $\begin{array}{l}-.052 \\
(3.05)\end{array}$ & $\begin{array}{l}-.456 \\
(6.79)\end{array}$ & $\begin{array}{r}.034 \\
(1.51)\end{array}$ & & & & & $\begin{array}{r}.094 \\
(10.29)\end{array}$ \\
\hline 211 & 136 & $\begin{array}{r}1.330 \\
(3.05)\end{array}$ & $\begin{array}{r}-.387 \\
(5.70)\end{array}$ & $\begin{array}{l}-.612 \\
(7.87)\end{array}$ & $\begin{array}{c}.024 \\
(0.44)\end{array}$ & & & & & $\begin{array}{r}.503 \\
(8.93)\end{array}$ \\
\hline 212 & 136 & $\begin{array}{c}2.464 \\
(6.29)\end{array}$ & $\begin{array}{l}-.177 \\
(4.07)\end{array}$ & $\begin{array}{l}-.583 \\
(7.00)\end{array}$ & $\begin{array}{r}.103 \\
(2.52)\end{array}$ & - & & & & $\begin{array}{r}.232 \\
(7.92)\end{array}$ \\
\hline 231 & 136 & $\begin{array}{c}1.129 \\
(2.68)\end{array}$ & $\begin{array}{l}-.264 \\
(6.83)\end{array}$ & $\begin{array}{l}-.439 \\
(6.82)\end{array}$ & $\begin{array}{r}.022 \\
(0.68)\end{array}$ & & & & & $\begin{array}{r}.183 \\
(5.58)\end{array}$ \\
\hline 232 & 136 & $\begin{array}{c}1.404 \\
(4.35)\end{array}$ & $\begin{array}{l}-.129 \\
(6.10)\end{array}$ & $\begin{array}{l}-.355 \\
(6.58)\end{array}$ & $\begin{array}{r}.007 \\
(0.25)\end{array}$ & & & & & $\begin{array}{r}.127 \\
(7.55)\end{array}$ \\
\hline 233 & 136 & $\begin{array}{r}3.839 \\
(8.26)\end{array}$ & $\begin{array}{l}-.084 \\
(2.86)\end{array}$ & $\begin{array}{l}-.733 \\
(8.64)\end{array}$ & $\begin{array}{l}-.057 \\
(1.22)\end{array}$ & & & & & $\begin{array}{r}.095 \\
(4.53)\end{array}$ \\
\hline 242 & 154 & $\begin{array}{r}2.254 \\
(5.47)\end{array}$ & $\begin{array}{l}-.045 \\
(1.23)\end{array}$ & $\begin{array}{l}-.417 \\
(6.79)\end{array}$ & $\begin{array}{r}.005 \\
(0.19)\end{array}$ & $\begin{array}{r}.052 \\
(3.23)\end{array}$ & $\begin{array}{r}.031 \\
(1.75)\end{array}$ & $\begin{array}{r}.065 \\
(3.18)\end{array}$ & $\begin{array}{r}.021 \\
(0.79)\end{array}$ & $\begin{array}{r}.123 \\
(6.30)\end{array}$ \\
\hline 271 & 166 & $\begin{array}{c}1.492 \\
(5.71)\end{array}$ & $\begin{array}{l}-.054 \\
(2.72)\end{array}$ & $\begin{array}{l}-.304 \\
(6.31)\end{array}$ & $\begin{array}{l}-.081 \\
(5.29)\end{array}$ & & & & & $\begin{array}{r}.081 \\
(4.45)\end{array}$ \\
\hline 301 & 134 & $\begin{array}{r}1.294 \\
(4.08)\end{array}$ & $\begin{array}{l}-.169 \\
(5.58)\end{array}$ & $\begin{array}{l}-.370 \\
(5.92)\end{array}$ & $\begin{array}{r}.052 \\
(1.25)\end{array}$ & & & & & $\begin{array}{r}.149 \\
(4.46)\end{array}$ \\
\hline 311 & 170 & $\begin{array}{r}1.589 \\
(5.35)\end{array}$ & $\begin{array}{l}-.114 \\
(4.69)\end{array}$ & $\begin{array}{l}-.372 \\
(6.80)\end{array}$ & $\begin{array}{r}.035 \\
(2.16)\end{array}$ & & & & & $\begin{array}{r}.119 \\
(5.80)\end{array}$ \\
\hline 314 & 136 & $\begin{array}{r}1.203 \\
(2.39)\end{array}$ & $\begin{array}{l}-.190 \\
(3.12)\end{array}$ & $\begin{array}{l}-.393 \\
(4.53)\end{array}$ & $\begin{array}{r}.061 \\
(2.25)\end{array}$ & & & & & $\begin{array}{r}.416 \\
(11.43)\end{array}$ \\
\hline 324 & 187 & $\begin{array}{r}3.290 \\
(8.62)\end{array}$ & $\begin{array}{l}-.032 \\
(5.71)\end{array}$ & $\begin{array}{l}-.574 \\
(8.68)\end{array}$ & $\begin{array}{l}-.034 \\
(2.64)\end{array}$ & & & & & $\begin{array}{r}.042 \\
(7.55)\end{array}$ \\
\hline 331 & 128 & $\begin{array}{r}2.764 \\
(7.88)\end{array}$ & $\begin{array}{l}-.182 \\
(6.82)\end{array}$ & $\begin{array}{l}-.633 \\
(8.18)\end{array}$ & $\begin{array}{r}.113 \\
(4.66)\end{array}$ & & & & & $\begin{array}{r}.192 \\
(9.09)\end{array}$ \\
\hline 332 & 170 & $\begin{array}{r}.995 \\
(4.77)\end{array}$ & $\begin{array}{l}-.109 \\
(6.72)\end{array}$ & $\begin{array}{l}-.265 \\
(6.60)\end{array}$ & $\begin{array}{r}.063 \\
(3.21)\end{array}$ & & & & & $\begin{array}{r}.126 \\
(7.29)\end{array}$ \\
\hline 336 & 170 & $\begin{array}{c}2.035 \\
(6.51)\end{array}$ & $\begin{array}{l}-.043 \\
(3.23)\end{array}$ & $\begin{array}{l}-.371 \\
(6.79)\end{array}$ & $\begin{array}{r}.050 \\
(2.92)\end{array}$ & & & & & $\begin{array}{r}.078 \\
(5.33)\end{array}$ \\
\hline 341 & 191 & $\begin{array}{r}3.603 \\
(10.07)\end{array}$ & $\begin{array}{r}-.071 \\
(6.37)\end{array}$ & $\begin{array}{c}-.660 \\
(10.02)\end{array}$ & $\begin{array}{r}.092 \\
(3.84)\end{array}$ & & & & & $\begin{array}{r}.095 \\
(13.09)\end{array}$ \\
\hline
\end{tabular}

$t$-statistics are in parentheses.

a $\hat{\delta}$ is the coefficient estimate of $\log Y_{d t-1}-\log Y_{d t-13}$ under the non-perfect expectational hypothesis. 


\begin{tabular}{|c|c|c|c|c|c|c|c|c|c|c|}
\hline$\hat{\gamma}_{1}$ & $\hat{\gamma}_{2}$ & $\hat{\gamma}_{s}$ & $\hat{\gamma}_{4}$ & $\hat{75}$ & $\hat{\gamma}_{i}$ & ${ }^{\mathrm{a}} \hat{\delta}$ & $\hat{\psi}_{1}$ & $\mathbf{R}^{2}$ & $\mathrm{SE}$ & DW \\
\hline .064 & .069 & .058 & .145 & .015 & .068 & -.001 & -.0068 & .635 & .0145 & 2.33 \\
\hline (2.18) & $(2.40)$ & $(2.45)$ & $(6.88)$ & $(0.75)$ & $(2.82)$ & $(0.05)$ & $(1.72)$ & & & \\
\hline .023 & .010 & .039 & & & & .007 & -.0027 & .639 & .0116 & 2.16 \\
\hline \multirow[t]{3}{*}{$(1.46)$} & $(0.96)$ & $(7.43)$ & & & & $(0.52)$ & $(0.76)$ & & & \\
\hline & & & & & & & $\begin{array}{l}.0071 \\
(0.70)\end{array}$ & .607 & .0340 & 1.93 \\
\hline & & & & & & & $\begin{array}{l}-.0174 \\
(2.37)\end{array}$ & .462 & .0232 & 2.13 \\
\hline .046 & .047 & .038 & & & & -.003 & -.0132 & .563 & .0200 & 2.29 \\
\hline$(2.06)$ & $(2.90)$ & $(3.66)$ & & & & $(0.16)$ & $(2.00)$ & & & \\
\hline .095 & .080 & .046 & & & & & -.0123 & .479 & .0145 & 1.88 \\
\hline \multirow[t]{3}{*}{$(5.38)$} & $(6.20)$ & $(4.71)$ & & & & & $(2.47)$ & & & \\
\hline & & & & & & & $\begin{array}{l}-.0100 \\
(1.20)\end{array}$ & .487 & .0256 & 2.15 \\
\hline & & & & & & & $\begin{array}{l}-.0067 \\
(2.22)\end{array}$ & .490 & .0153 & 2.19 \\
\hline .055 & .023 & .046 & .017 & .044 & & & -.0005 & .521 & .0151 & 1.79 \\
\hline$(3.02)$ & $(1.46)$ & (3.34) & $(1.38)$ & $(3.96)$ & & & $(0.37)$ & & & \\
\hline .068 & .033 & .067 & & & & & -.0199 & .283 & .0232 & 1.90 \\
\hline$(2.29)$ & $(1.21)$ & $(2.59)$ & & & & & $(2.38)$ & & & \\
\hline .043 & .061 & .032 & .020 & .018 & & & -.0093 & .369 & .0097 & 2.04 \\
\hline$(2.80)$ & $(4.68)$ & $(2.69)$ & $(1.90)$ & (1.93) & & & $(3.25)$ & & & \\
\hline .141 & .150 & .092 & & & & .133 & .0017 & .737 & .0169 & 1.84 \\
\hline \multirow[t]{3}{*}{$(4.56)$} & $(6.15)$ & $(4.24)$ & & & & $(4.60)$ & $(0.30)$ & & & \\
\hline & & & & & & & $\begin{array}{l}-.0057 \\
(3.50)\end{array}$ & .430 & .0088 & 2.25 \\
\hline & & & & & & & $\begin{array}{l}-.0158 \\
(3.89)\end{array}$ & .532 & .0137 & 2.39 \\
\hline .033 & .045 & .040 & 0.23 & & & & -.0132 & .377 & .0133 & 2.29 \\
\hline$(2.75)$ & $(4.38)$ & $(4.19)$ & $(2.45)$ & & & & $(3.71)$ & & & \\
\hline .034 & .030 & .035 & & & & & -.0168 & .347 & .0111 & 2.26 \\
\hline$(3.10)$ & $(3.06)$ & $(4.34)$ & & & & & $(5.50)$ & & & \\
\hline $\begin{array}{r}.022 \\
(3.02)\end{array}$ & & & & & & & $\begin{array}{l}-.0088 \\
(3.23)\end{array}$ & .595 & .0159 & 1.91 \\
\hline
\end{tabular}


it is not significant. These results indicate that the degree of labor market tightness is a significant factor affecting the short-run demand for hours paid-for per worker - that the "inducement effect" does appear to exist. The evidence is much stronger here regarding the influence of the unemployment rate on changes in the number of hours paid-for per worker than it was in table 5.5 regarding the influence of the unemployment rate on changes in the number of workers employed. When $\log U_{2 w t}-\log \bar{U}$ was added to eq. (3.9) in the manner depicted in eq. (5.1), its coefficient estimate was positive, as expected, for all but three of the industries, but was only significant for four of them. The results achieved in table 7.2 add some support to the idea that labor market conditions affect employment decisions, but this effect seems to be more pronounced with respect to decisions on the number of hours to pay each worker for than with respect to decisions on the number of workers to hire or lay off.

As mentioned above, the behavior of $\log H P_{2 w t}-\log H P_{2 w t-1}$ may be different when it equals $\log H_{2 w t}-\log H_{2 w t-1}$ than otherwise, and this possibility has not been allowed for in the estimates presented in table 7.2. In order to test for this possible difference in behavior the dummy variable $B 1_{t}$ described above was added to eq. $(7.2)^{\prime} .{ }^{1}$ The results are presented in table 7.3. The coefficient of $B 1_{t}$ is denoted as $\alpha_{3}$, and the estimate of $\alpha_{3}$ is presented in the table for each industry along with the estimate of the coefficient $\gamma_{0}$ of $\log Y_{d t}-\log Y_{d t-1}$. If in fact $\log H P_{2 w t}-\log H P_{2 w t-1}$ responds to current output changes more when it equals $\log H_{2 w t}-\log$ $H_{2 w t-1}$, the estimate of $\alpha_{3}$ should be positive and the estimate of $\gamma_{0}$ should be smaller when $B 1_{t}$ is included in the equation than otherwise. Presented also in table 7.3 for each industry is the percentage of the observations for which $B 1_{t}$ (or $B 2_{t}$ or $B 5_{t}$ ) was set equal to one.

For thirteen of the seventeen industries the estimate of $\alpha_{3}$ is negative, contrary to what might be expected, but it is significant for only four of the thirteen industries. Of the four industries where the estimate of $\alpha_{3}$ is positive, it is significant for only one of them - industry 271. The estimates of $\gamma_{0}$ are little changed from those in table 7.2 and there is certainly no consistent pattern of them being smaller when $B 1_{t}$ is added than otherwise. No specific interpretation can be given as to why so many of the estimates of $x_{3}$ are negative, but given the insignificance of most of the estimates, the results

1 For industries 233 and $311 B 2_{t}$ was added instead of $B 1_{t}$, and for industries 207, 231, and $341 B S_{t}$ was added instead of $B 1_{t}$. See the discussion of these variables in $\$ 7.2$. 
TABLE 7.3

Parameter estimates for eq. (7.2)' with the additional term $\alpha_{3} B 1_{t .}{ }^{\mathrm{a}}$ Estimates presented for $y_{0}$ and $\mathrm{d}_{3}$ only

\begin{tabular}{|c|c|c|c|c|c|c|}
\hline Industry & No. of obs. & $\hat{\gamma}_{0}$ & $\hat{\alpha}_{3}$ & SE & DW & $b \%$ \\
\hline 201 & 192 & $\begin{array}{r}.258 \\
(8.05)\end{array}$ & $\begin{array}{l}-.022 \\
(2.48)\end{array}$ & .0143 & 2.30 & 1.6 \\
\hline 207 & 136 & $\begin{array}{r}.094 \\
(9.83)\end{array}$ & $\begin{array}{l}-.001 \\
(0.32)\end{array}$ & .0117 & 2.19 & 10.3 \\
\hline 211 & 136 & $\begin{array}{r}.509 \\
(8.77)\end{array}$ & $\begin{array}{l}-.005 \\
(0.40)\end{array}$ & .0341 & 1.93 & 8.8 \\
\hline 212 & 136 & $\begin{array}{r}.241 \\
(8.27)\end{array}$ & $\begin{array}{l}-.012 \\
(2.18)\end{array}$ & .0229 & 2.14 & 16.9 \\
\hline 231 & 136 & $\begin{array}{r}.199 \\
(6.03)\end{array}$ & $\begin{array}{c}-.012 \\
(2.23)\end{array}$ & .0197 & 2.23 & 19.1 \\
\hline 232 & 136 & $\begin{array}{r}.127 \\
(7.51)\end{array}$ & $\begin{array}{l}-.002 \\
(0.24)\end{array}$ & .0140 & 1.90 & 3.7 \\
\hline 233 & 136 & $\begin{array}{r}.095 \\
(4.48)\end{array}$ & $\begin{array}{r}.005 \\
(0.54)\end{array}$ & .0257 & 2.17 & 6.6 \\
\hline 242 & 154 & $\begin{array}{r}.119 \\
(6.07)\end{array}$ & $\begin{array}{c}-.010 \\
(1.64)\end{array}$ & .0152 & 2.16 & 5.8 \\
\hline 271 & 166 & $\begin{array}{r}.076 \\
(4.19)\end{array}$ & $\begin{array}{r}.003 \\
(2.01)\end{array}$ & .0050 & 1.77 & 16.9 \\
\hline 301 & 134 & $\begin{array}{r}.154 \\
(4.59)\end{array}$ & $\begin{array}{l}-.011 \\
(1.16)\end{array}$ & .0232 & 1.91 & 6.0 \\
\hline 311 & 170 & $\begin{array}{r}.118 \\
(5.61)\end{array}$ & $\begin{array}{r}.000 \\
(0.12)\end{array}$ & .0097 & 2.06 & 6.5 \\
\hline 314 & 136 & $\begin{array}{r}.433 \\
(12.12)\end{array}$ & $\begin{array}{l}-.014 \\
(2.92)\end{array}$ & .0164 & 1.78 & 14.0 \\
\hline 324 & 187 & $\begin{array}{r}.043 \\
(7.64)\end{array}$ & $\begin{array}{l}-.002 \\
(1.00)\end{array}$ & .0088 & 2.31 & 15.0 \\
\hline 331 & 128 & $\begin{array}{r}.194 \\
(9.23)\end{array}$ & $\begin{array}{l}-.007 \\
(1.55)\end{array}$ & .0137 & 2.41 & 11.7 \\
\hline 332 & 170 & $\begin{array}{r}.123 \\
(7.04)\end{array}$ & $\begin{array}{r}.004 \\
(0.60)\end{array}$ & .0133 & 2.30 & 2.9 \\
\hline 336 & 170 & $\begin{array}{r}.081 \\
(5.44)\end{array}$ & $\begin{array}{l}-.006 \\
(1.21)\end{array}$ & .0111 & 2.28 & 4.1 \\
\hline 341 & 191 & $\begin{array}{r}.095 \\
(12.90)\end{array}$ & $\begin{array}{l}-.003 \\
(0.51)\end{array}$ & .0159 & 1.97 & 6.3 \\
\hline
\end{tabular}

$t$-statistics are in parentheses.

a For 233 and $311 \hat{s}_{s}$ is the coefficient estimate of $B 2_{t}$ rather than $B 1_{t}$, and for 207,231 , and $341 \hat{\gamma}_{\mathrm{s}}$ is the coefficient estimate of $B 5_{t}$.

b Percentage of observations for which $B 1_{t}$ (or $B 2_{t}$ or $B 5_{t}$ ) was set equal to one. 
seem to indicate either that $\log H P_{2 w t}-\log H P_{2 w t-1}$ does not behave differently when it equals $\log H_{2 w t}-\log H_{2 w t-1}$ or, perhaps more likely, that $\mathrm{B} 1_{\mathrm{f}}$ (or $\mathrm{B} 2_{t}$ or $\mathrm{B} 5_{t}$ ) overestimates those times when $\log H P_{2 w t}-\log$ $H P_{2 w t-1}$ equals $\log H_{2 w t}-\log H_{2 w t-1}$, so that the test is not valid. The test is crude because the construction of $B 1$, was crude, and there is no way of knowing whether $B 1_{\mathfrak{r}}$ adequately reflects those times when $\log H P_{2 w t}-$ $\log H P_{2 w t-1}$ is equal to or nearly equal to $\log H_{2 w t}-\log H_{2 w t-1}$. The "production function constraint" may be binding on $H P_{2 w}$ for such a small fraction of the time, for example, as to have negligible effects on the equation determining $\log H P_{2 w t}-\log H P_{2 w t-1}$. The results achieved here are certainly not inconsistent with this idea.

It thus appears that eq. (7.2)' adequately explains the short-run demand for hours paid-for worker. The amount by which $H P_{2 w t-1}$ differs from the standard number of hours of work per worker, the amount of excess labor on hand, the time stream of expected future changes in output, and the condition of the labor market all appear to be significant determinants of this demand. In the next section possible "cyclical" variations in $\log H P_{2 w t}$ $\log H P_{2 w t-1}$ which have not been accounted for by eq. (7.2)' will be examined.

\subsection{Tests for cyclical variations in the short-run demand for hours paid-for per worker}

As was done for eq. (3.9) for production workers, a test was performed to see if eq. (7.2)' for hours paid-for per worker predicts differently than expected during general contractionary periods of output or during general expansionary periods. First, the variables $\left(\log P_{d t}-\log P_{d t-1}\right)_{+}$and $\left(\log P_{d t}-\right.$ $\left.\log P_{d t-1}\right)_{-}$were added to eq. (7.2) to determine whether the equation overpredicts during contractions and underpredicts during expansions. These two variables were described in $\S 5.3$. Briefly, $\log P_{d t}$ is the residual from the regression of $\log Y_{d \mathrm{r}}$ on twelve seasonal dummy variables and time, and the notation $\left(\log P_{d t}-\log P_{d i-1}\right)_{+}$, for example, indicates that this variable was set equal to $\log P_{d t}-\log P_{d t-1}$ when the latter was positive and set equal to zero otherwise.

In table 7.4 the results of adding $\left(\log P_{d t}-\log P_{d t-1}\right)_{+}$and $\left(\log P_{d t}-\right.$ $\left.\log P_{d t-1}\right)_{-}$to eq. (7.2)' are presented. The coefficients of these two variables are denoted as $\alpha_{4}$ and $\alpha_{5}$ respectively, and estimates of $\alpha_{4}$ and $\alpha_{5}$ are presented in table 7.4 along with the estimate of the coefficient $\gamma_{0}$ of $\log Y_{d t}-\log$ $Y_{d t-1}$. The estimates of $\alpha_{4}$ and $\alpha_{5}$ are expected to be negative if in fact eq. (7.2)' underpredicts during expansions and overpredicts during contractions. 
TABLE 7.4

Parameter estimates for eq. (7.2)' with the additional terms $\alpha_{4}\left(\log P_{a t}-\log P_{a t-1}\right)_{+}$and $\alpha_{5}\left(\log P_{a t}-\log P_{a t-1}\right)_{-}$. Estimates presented for $\%, \alpha_{4}$, and $\alpha_{5}$ only

\begin{tabular}{|c|c|c|c|c|c|c|}
\hline Industry & No, of obs. & $\hat{\gamma}_{0}$ & $\hat{x}_{4}$ & $\hat{\alpha}_{5}$ & SE & DW \\
\hline 201 & 192 & $\begin{array}{r}.270 \\
(6.86)\end{array}$ & $\begin{array}{c}-.058 \\
(0.99)\end{array}$ & $\begin{array}{c}.009 \\
(0.18)\end{array}$ & .0145 & 2.35 \\
\hline 207 & 136 & $\begin{array}{r}.091 \\
(9.90)\end{array}$ & $\begin{array}{r}.066 \\
(2.29)\end{array}$ & $\begin{array}{l}-.003 \\
(0.09)\end{array}$ & .0115 & 2.23 \\
\hline 211 & 136 & $\begin{array}{r}.334 \\
(4.29)\end{array}$ & $\begin{array}{r}.210 \\
(1.42)\end{array}$ & $\begin{array}{r}.359 \\
(2.68)\end{array}$ & .0331 & 1.89 \\
\hline 212 & 136 & $\begin{array}{r}.241 \\
(5.41)\end{array}$ & $\begin{array}{l}-.072 \\
(0.88)\end{array}$ & $\begin{array}{r}.080 \\
(1.22)\end{array}$ & .0232 & 2.13 \\
\hline 231 & 136 & $\begin{array}{r}.201 \\
(4.38)\end{array}$ & $\begin{array}{r}.029 \\
(0.48)\end{array}$ & $\begin{array}{l}-.045 \\
(0.94)\end{array}$ & .0201 & 2.31 \\
\hline 232 & 136 & $\begin{array}{r}.132 \\
(5.63)\end{array}$ & $\begin{array}{l}-.004 \\
(0.10)\end{array}$ & $\begin{array}{l}-.011 \\
(0.34)\end{array}$ & .0146 & 1.87 \\
\hline 233 & 136 & $\begin{array}{r}.120 \\
(4.12)\end{array}$ & $\begin{array}{l}-.080 \\
(1.35)\end{array}$ & $\begin{array}{l}-.010 \\
(0.18)\end{array}$ & .0256 & 2.16 \\
\hline 242 & 154 & $\begin{array}{r}.091 \\
(3.57)\end{array}$ & $\begin{array}{r}.052 \\
(0.88)\end{array}$ & $\begin{array}{r}.096 \\
(1.72)\end{array}$ & .0152 & 2.15 \\
\hline 271 & 166 & $\begin{array}{r}.079 \\
(4.13)\end{array}$ & $\begin{array}{l}-.031 \\
(0.73)\end{array}$ & $\begin{array}{r}.072 \\
(1.31)\end{array}$ & .0051 & 1.84 \\
\hline 301 & 134 & $\begin{array}{l}-.033 \\
(0.71)\end{array}$ & $\begin{array}{r}.292 \\
(3.47)\end{array}$ & $\begin{array}{r}.300 \\
(3.66)\end{array}$ & .0212 & 2.17 \\
\hline 311 & 170 & $\begin{array}{r}.004 \\
(0.12)\end{array}$ & $\begin{array}{c}.166 \\
(3.26)\end{array}$ & $\begin{array}{r}.123 \\
(2.55)\end{array}$ & .0094 & 2.19 \\
\hline 314 & 136 & $\begin{array}{r}.418 \\
(10.67)\end{array}$ & $\begin{array}{l}-.032 \\
(0.34)\end{array}$ & $\begin{array}{r}.015 \\
(0.19)\end{array}$ & .0170 & 1.84 \\
\hline 324 & 187 & $\begin{array}{r}.041 \\
(6.34)\end{array}$ & $\begin{array}{r}.010 \\
(0.42)\end{array}$ & $\begin{array}{r}.001 \\
(0.04)\end{array}$ & .0089 & 2.32 \\
\hline 331 & 128 & $\begin{array}{r}-157 \\
(3.53)\end{array}$ & $\begin{array}{c}-.008 \\
(0.16)\end{array}$ & $\begin{array}{r}.087 \\
(1.21)\end{array}$ & .0138 & 2.44 \\
\hline 332 & 170 & $\begin{array}{r}.023 \\
(0.61)\end{array}$ & $\begin{array}{c}.149 \\
(3.22)\end{array}$ & $\begin{array}{r}.100 \\
(1.96)\end{array}$ & .0129 & 2.44 \\
\hline 336 & 170 & $\begin{array}{r}.017 \\
(0.71)\end{array}$ & $\begin{array}{r}.062 \\
(1.54)\end{array}$ & $\begin{array}{r}.116 \\
(3.07)\end{array}$ & .0108 & 2.29 \\
\hline 341 & 191 & $\begin{array}{r}.102 \\
(10.90)\end{array}$ & $\begin{array}{l}-.007 \\
(0.27)\end{array}$ & $\begin{array}{l}-.024 \\
(1.15)\end{array}$ & .0159 & 1.93 \\
\hline
\end{tabular}

$t$-statistics are in parentheses. 
The estimate of $\alpha_{4}$ is negative for only seven industries, and the estimate of $\alpha_{5}$ is negative for only six industries. In none of these twelve cases is the estimate significant. Of the ten industries where the estimate of $\alpha_{4}$ is positive, it is significant for four of them, and of the eleven industries where the estimate of $\alpha_{5}$ is positive, it is significant for four of them. For industries $301,311,332$, and 336 the estimate of $\gamma_{0}$ has decreased in size from that in table 7.2 and is no longer significant. For all four of these industries the estimates of $\alpha_{4}$ and $\alpha_{5}$ are positive and, except in two cases, significant. For these industries the introduction of the "cyclical" variables $\left(\log P_{d t}-\right.$ $\left.\log P_{d t-1}\right)_{+}$and $\left(\log P_{d t}-\log P_{d t-1}\right)_{-}$has considerably reduced the influence of the current change in output variable, $\log Y_{d t}-\log Y_{d t-1}$.

The results indicate, then, that for at least four of the industries the behavior of firms with respect to short-run changes in the number of hours paid-for per worker is different during contractions and expansions than predicted by eq. (7.2), but in the opposite direction than that suggested above, i.e., for these industries the number of hours paid-for per worker appears to decrease more or increase less during contractions than predicted and conversely during expansions. The results also indicate, however, that for the majority of the industries there does not appear to be any difference in predicted behavior during the two periods.

In another test of the hypothesis that firms behave differently during contractions than predicted, the dummy variable $D_{t}$ was added to eq. (7.2)' The construction of $D_{t}$ was described in $\S 5.3$; it was set equal to one during the NBER defined contractions (NBER peak to trough) and zero otherwise. The results of adding $D_{t}$ to eq. (7.2) ${ }^{\prime}$ are presented in table 7.5. The coefficient of $D_{t}$ is denoted as $x_{6}$, and the estimate of $\alpha_{6}$ is presented in table 7.5 for each industry along with the estimate of $\gamma_{0}$. The estimate of $\alpha_{6}$ is expected to be positive if firms do in fact decrease hours paid-for per worker less or increase them more during contractions than eq. (7.2) ${ }^{\prime}$ predicts they should.

The estimate of $\alpha_{6}$ is not positive for any industry; it is zero for one industry and negative for the other sixteen. Of the sixteen industries for which it is negative, it is significant for three of them - 207, 332, and 336 . For all of the industries the effect on the standard error is small. These results indicate that, if anything, hours paid-for per worker decrease more or increase less during contractions than predicted, rather than the opposite, but generally the results seems to indicate that firms do not behave differently than predicted during the NBER defined contractions.

As was the case for workers, these two tests give no indication that firms "hoard" hours paid-for per worker during contractions or "dis-hoard" 
TABLE 7.5

Parameter estimates for eq. (7.2)' with the additional term $\alpha_{6} D_{t}$. Estimates presented for $\gamma_{0}$ and $\alpha_{6}$ only

\begin{tabular}{|c|c|c|c|c|c|}
\hline Industry & No. of obs. & $\hat{\gamma}_{0}$ & $\hat{\alpha}_{6}$ & SE & DW \\
\hline 201 & 192 & $\begin{array}{r}.242 \\
(7.43)\end{array}$ & $\begin{array}{l}-.004 \\
(1.58)\end{array}$ & .0145 & 2.30 \\
\hline 207 & 136 & $\begin{array}{r}.100 \\
(10.82)\end{array}$ & $\begin{array}{l}-.007 \\
(2.63)\end{array}$ & .0114 & 2.15 \\
\hline 211 & 136 & $\begin{array}{r}.501 \\
(8.85)\end{array}$ & $\begin{array}{l}-.006 \\
(0.72)\end{array}$ & .0341 & 1.91 \\
\hline 212 & 136 & $\begin{array}{r}.232 \\
(7.90)\end{array}$ & $\begin{array}{l}-.002 \\
(0.37)\end{array}$ & .0233 & 2.14 \\
\hline 231 & 136 & $\begin{array}{r}.189 \\
(5.77)\end{array}$ & $\begin{array}{l}-.008 \\
(1.58)\end{array}$ & ". .0199 & 2.32 \\
\hline 232 & 136 & $\begin{array}{r}.124 \\
(7.19)\end{array}$ & $\begin{array}{l}-.002 \\
(0.54)\end{array}$ & .0146 & 1.88 \\
\hline 233 & 136 & $\begin{array}{r}.093 \\
(4.47)\end{array}$ & $\begin{array}{l}-.012 \\
(1.96)\end{array}$ & .0253 & 2.13 \\
\hline 242 & 154 & $\begin{array}{r}.123 \\
(6.18)\end{array}$ & $\begin{array}{l}-.001 \\
(0.24)\end{array}$ & .0154 & 2.20 \\
\hline 271 & 166 & $\begin{array}{r}.083 \\
(4.32)\end{array}$ & $\begin{array}{r}.000 \\
(0.39)\end{array}$ & .0051 & 1.83 \\
\hline 301 & 134 & $\begin{array}{r}.136 \\
(3.90)\end{array}$ & $\begin{array}{l}-.008 \\
(1.23)\end{array}$ & .0232 & 1.87 \\
\hline 311 & 170 & $\begin{array}{r}.114 \\
(5.55)\end{array}$ & $\begin{array}{l}-.003 \\
(1.68)\end{array}$ & .0097 & 2.05 \\
\hline 314 & 136 & $\begin{array}{r}.412 \\
(11.20)\end{array}$ & $\begin{array}{l}-.004 \\
(0.95)\end{array}$ & .0169 & 1.84 \\
\hline 324 & 187 & $\begin{array}{r}.042 \\
(7.41)\end{array}$ & $\begin{array}{l}-.002 \\
(0.94)\end{array}$ & .0088 & 2.34 \\
\hline 331 & 128 & $\begin{array}{r}.181 \\
(7.61)\end{array}$ & $\begin{array}{c}-.004 \\
(0.94)\end{array}$ & .0137 & 2.43 \\
\hline 332 & 170 & $\begin{array}{r}.105 \\
(5.79)\end{array}$ & $\begin{array}{l}-.010 \\
(2.97)\end{array}$ & .0130 & 2.40 \\
\hline 336 & 170 & $\begin{array}{r}.069 \\
(4.62)\end{array}$ & $\begin{array}{l}-.006 \\
(2.24)\end{array}$ & .0109 & 2.29 \\
\hline 341 & 191 & $\begin{array}{r}.095 \\
(13.08)\end{array}$ & $\begin{array}{l}-.005 \\
(1.62)\end{array}$ & .0158 & 1.96 \\
\hline
\end{tabular}

$t$-statistics are in parentheses. 
them during expansions in the sense of eq. (7.2)' overpredicting during contractions and underpredicting during expansions. If anything, the opposite appears to be true for a few industries, butf or most industries there is little evidence that firms behave differently than predicted during expansions or contractions. The crudeness of these tests should again be emphasized, however.

\subsection{Summary}

The major conclusion of this chapter is that many of the same factors which influence the change in the number of workers employed also influence the change in the number of hours paid-for per worker. An equation similar to eq. (3.9) for workers was developed for hours paid-for per worker in which the change in the number of hours paid-for per worker was taken to be a function of the amount of excess labor on hand, the amount by which $H P_{2 w t-1}$ differs from the standard number of hours of work per worker, the time stream of expected future changes in output, and the condition of the labor market as measured by the unemployment rate. Firms were assumed because of worker morale problems and other possible adjustment costs to view fluctuations in the number of hours paid-for per worker in a similar manner as they view fluctuations in the number of workers employed. The unemployment rate variable was added to the equation on the hypothesis that in tight labor markets an added inducement to keep workers from looking for other jobs is to keep the number of hours paid-for per worker high while in loose labor markets less of this kind of inducement is needed.

The results presented in table 7.2 appear to be an important confirmation of the model. All of the factors listed above appear to be significant. The fact that the excess labor variable is highly significant in table 7.2 is especially important in that it adds support to the results presented in ch. 4 which indicate that the amount of excess labor on hand has a significant influence on a firm's employment behavior. The fact that the unemployment rate is significant in table 7.2 for most of the industries indicates that labor market conditions have more of an effect on the short-run demand for hours paidfor per worker than on the short-run demand for workers.

Two further tests were performed on eq. (7.2)'. The equation was tested to see if the behavior of $\log H P_{2 w t}-\log H P_{2 w i-1}$ is different when it equals $\log H_{2 w t}-\log H_{2 w t-1}$ than otherwise. This does not appear to be the case, although the test was quite crude since it was not clear whether $\log H P_{2 w i t}$ $\log H P_{2 w t-1}$ was equal to $\log H_{2 w t}-\log H_{2 w t-1}$ enough times to insure an 
adequate test. Eq. (7.2)' was also tested to see whether it overpredicts during contractions and underpredicts during expansions, and the results indicated that this is not the case. For a few industries the equation appeared to underpredict in contractions and overpredict in expansions, which is contrary to the hypothesis that firms "hoard" hours paid-for per worker in contractions and "dis-hoard" them in expansions. The evidence was not strong that this is in general true, however, although again these two tests were rather crude.

This concludes the discussion of the model of the short-run demand for hours paid-for per worker. In the next chapter a comparison of the results achieved in this chapter and the results achieved for workers in chs. 4 and 5 is made, and the short-run demand for total man-hours paid-for is discussed. 


\section{THE SHORT-RUN DEMAND FOR TOTAL MAN HOURS PAID-FOR}

\subsection{Introduction}

This chapter brings together the model of the short-run demand for workers developed in ch. 3 and the model of the short-run demand for hours paidfor per worker developed in ch. 7. In $\$ 8.2$ the results presented in table 4.3 of estimating the workers equation are compared with the results presented in table 7.2 of estimating the hours paid-for per worker equation, and in $\S 8.3$ the results in the two tables are combined to yield an explanation of the short-run demand for total man hours paid-for. From the discussion in $\S 8.3$ the advantages of estimating the workers and hours paid-for per worker equations separately instead of estimating a total man-hours paid-for equation directly are clearly seen. In $\S 8.4$ the economy-wide implications of the rather disaggregate results achieved in this study are discussed, and some tentative conclusions are offered.

\subsection{A comparison of the demand for workers and the demand for hours paid-for per worker}

In table 4.3 the basic results of estimating eq. (3.9) for production workers were presented, and in table 7.2 , under the same expectational hypothesis for each industry, the basic results of estimating eq. (7.2)' for hours paid-for per production worker were presented. The basic idea of the model developed in ch. 7 is the idea that many of the same factors which influence the shortrun demand for workers are also likely to influence the short-run demand for hours paid-for per worker, and the results presented in table 7.2 strongly confirmed this idea. Nevertheless, there are some important differences between the workers and hours paid-for per worker equations.

For every industry the estimate of the coefficient $\alpha_{2}$ of $\log H P_{2 w t-1}$ (or, more accurately, $\left.\log H P_{2 w t-1}-\log H S_{2 w t-1}\right)$ in the hours equation (7.2)' is considerably larger in absolute value than the estimate of the coefficient $\alpha_{1}$ of the excess labor variable, $\log M_{2 w t-1}-\log M_{2 w t-1}^{*} H_{2 w t-1}^{*}$ (or, more accurately, $\log M_{2 w t-1}-\log M_{2 w t-1}^{d}$ ), in the workers equation (3.9)'. This 
implies that the reaction of firms to the amount of excess labor on hand (with respect to changing the number of workers employed) is smaller than the reaction of firms to the amount by which the number of hours paid-for per worker differs from the standard number of hours of work per worker (with respect to changing the number of hours paid-for per worker).

It should also be noticed from eqs. (3.9) and (7.2) that the amount of excess labor on hand influences both the change in the number of workers employed and the change in the number of hours paid-for per worker, whereas the amount by which $H P_{2 w t-1}$ differs from the standard level $H S_{2 w t-1}$ influences only the change in the number of hours paid-for per worker. It was seen in $\S 5.2$ that there seems to be little theoretical reason why $\log H S_{2 w t-1}-\log H P_{2 w t-1}$ should influence the change in the number of workers employed other than at those times when $H P_{2 w t-1}$ equals $H_{2 w t-1}$ (i.e., when $\log H S_{2 w t-1}-\log H P_{2 w t-1}$ and the excess labor variable are the same). If $H P_{2 w t-1}$ differs from the standard number of hours of work per worker, the obvious thing for the firm to do is to change $H P_{2 w}$, and the firm is free to do this as long as $H P_{2 w t-1}$ does not equal $H_{2 w t-1}$. When $H P_{2 w t-1}$ equals $H_{2 w t-1}$ so that $\log H S_{2 w t-1}-\log H P_{2 w t-1}$ and the excess labor variable are equivalent, the firm must hire more workers if it wants to decrease $H P_{2 w}$, and this is exactly what the excess labor variable says the firm will do when $H_{2 w t-1}$ is greater than $H S_{2 w t-1}$. The results presented in table 5.1 confirmed the view that $\log H S_{2 w t-1}-\log H P_{2 w t-1}$ is not a significant determinant of the change in the number of workers employed other than at those times when it equals the excess labor variable.

There did seem to be, on the other hand, reasons why the amount of excess labor on hand should influence the change in the number of hours paid-for per worker. If firms view $H P_{2 w}$ in a similar manner as $M_{2 w}$ in the short run, they may be reluctant because of such things as worker morale problems to decrease $H P_{2 w}$, but they may be more likely to do this if there is a lot of excess labor on hand than otherwise. The results presented in table 7.2 strongly indicated that the amount of excess labor on hand is indeed a significant factor in the determination of the change in the number of hours paid-for per worker.

In summary, then, what the above results suggest is that in the short run firms react to a positive amount of excess labor on hand, other things being equal, by decreasing both the number of workers employed and the number of hours paid-for per worker, and that they react to hours paid-for per worker being greater than the standard level, other things being equal, by decreasing the number of hours paid-for per worker but not by increasing 
the number of workers employed (unless, of course, $H P_{2 w t-1}$ equals $H_{2 w t-1}$ so that $\log H S_{2 w t-1}-\log H P_{2 w t-1}$ and the excess labor variable are the same).

The results presented in tables 4.3 and 7.2 also suggest that expected future changes in output are more important in the determination of the change in the number of workers employed than in the determination of the change in the number of hours paid-for per worker. The size of the estimates of the $\gamma_{i}(i=1,2, \ldots)$ coefficients is in general larger for the workers equation than for the hours equation, and fewer of the $\gamma_{i}$ coefficient estimates are significant in the hours equation than in the workers equation. This is not unexpected, since it should be less costly for a firm to allow rapid changes in the number of hours paid-for per worker to occur than to allow rapid changes in the number of workers employed to occur. Expected future changes in man-hour requirements (and thus expected future changes in output) should, therefore, have less significance for current decisions on the number of hours to be paid per worker than for current decisions on the number of workers to employ.

As was mentioned in $\S 7.3$, with respect to the effects of labor market conditions on employment decisions the degree of tightness or looseness in the labor market appears to have more effect on decisions regarding the number of hours to pay each worker for than on decisions regarding the number of workers to employ. The estimate of the coefficient $\psi_{1}$ of $\log U_{2 w t}$ in the hours equation (7.2)' was significant for eleven of the seventeen industries, whereas the estimate of the coefficient $\psi_{0}$ of $\log U_{2 w r}-\log \bar{U}$ in the workers equation (5.1) was significant for only four industries. All but three of the estimates of $\psi_{0}$ were of the expected positive sign, however, and so there is some slight evidence that labor market conditions also influence decisions on the number of workers to employ. What the over-all results suggest, therefore, is that in tight labor markets firms increase the number of hours paid-for per worker more or decrease it less than they otherwise would as an inducement to keep workers from looking for other jobs, and that (perhaps) they also hire fewer worker or lay off fewer workers than they otherwise would since new workers are hard to find and workers once laid off may not be available for rehire when they are needed again. In loose labor markets the opposite takes place: the number of hours paid-for per worker is increased less or decreased more than otherwise, and (perhaps) more workers are hired or more are laid off than otherwise. 


\subsection{The short-run demand for total man hours paid-for}

From the workers equation (3.9) and the hours paid-for per worker equation (7.2) it is easy to derive the equation determining the change in total man hours paid-for, $\log M_{2 w t} H P_{2 w t}-\log M_{2 w t-1} H P_{2 w t-1}$. Since

$$
\begin{aligned}
\log M_{2 w t} H P_{2 w t} & -\log M_{2 w t-1} H P_{2 w t-1}= \\
& \log M_{2 w t}-\log M_{2 w t-1}+\log H P_{2 w t}-\log H P_{2 w t-1},
\end{aligned}
$$

the equation determining $\log M_{2 w t} H P_{2 w t}-\log M_{2 w t-1} H P_{2 w t-1}$ can be derived by merely adding eqs. (3.9) and (7.2). In table 8.1 results are presented of adding the estimates in table 4.3 with those in table 7.2 for each industry. The figures in table 8.1 are thus the derived estimates of the total man-hours paid-for equation. By using the results in table 4.3 as the estimates for the workers equation, the unemployment rate is assumed to have no effect on the change in the number of workers employed. In other words, $\psi_{0}$ in eq. (5.1) is assumed to be zero. The results discussed above suggest that $\psi_{0}$ may be positive, but since the evidence is not strong in this regard and in order to simplify matters somewhat, the results presented in table 4.3 are assumed to be the basic results for workers.

Looking at table 8.1 , it is seen that for every industry the derived estimate of the coefficient $\gamma_{0}$ of $\log Y_{d t}-\log Y_{d t-1}$ is less than one. Other things being equal, firms react in the short-run to a certain percentage change in output by changing man hours paid-for by less than this percentage and in most industries by substantially less than this percentage. This result is, of course, as expected from the results of the scatter diagrams in $\$ 3.2$.

It is also seen from table 8.1 that for every industry except 231 the derived estimate of the coefficient $\alpha_{1}$ of the excess labor variable, $\log M_{2 w t-1}-$ $\log M_{2 w t-1}^{d}$, is smaller in absolute value than the derived estimate of the coefficient $\alpha_{2}$ of $\log H P_{2 w t-1}-\log H S_{2 w t-1}$. (For industry 231 the two estimates are nearly equal, with the estimate of $x_{1}$ being slightly larger in absolute value.) This implies that firms react more strongly in changing total man hours paid-for when the number of hours paid-for per worker, $H P_{2 w t-1}$, differs from the standard level of hours, $H S_{2 w^{\prime} t-1}$, than when the number of workers employed, $M_{2 w-1}$, differs from the desired number, $M_{2 w i-1}^{d}$.

Another way of looking at the reaction is the following. By definition $M_{2 w t-1}^{d}$ is equal to $M_{2 w t-1}^{*} H_{2 w t-1}^{*} / H S_{2 w t-1}$, where $M_{2 w t-1}^{*} H_{2 w t-1}^{*}$ is the number of man hours required to produce the output during the second week of month $t-1$. The number of man hours which are paid-for but 
Sum of the coefficient estimates in table 4.3 and table 7.2: derived coefficient estimates for the total man-hours paid-for equation

\begin{tabular}{|c|c|c|c|c|c|c|c|c|c|c|c|c|c|c|c|c|c|}
\hline $\begin{array}{l}\stackrel{E}{E} \\
\text { 总 } \\
\stackrel{\Xi}{E}\end{array}$ & 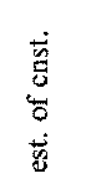 & $\hat{\alpha}_{1}$ & $\hat{\alpha}_{2}$ & 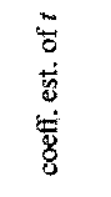 & $\hat{\beta}_{4}$ & $\hat{\beta}_{3}$ & $\hat{\beta}_{2}$ & $\hat{\beta}_{1}$ & $\hat{\gamma}_{0}$ & $\hat{\gamma}_{1}$ & $\hat{\gamma}_{2}$ & $\hat{\gamma}_{3}$ & $\hat{\gamma}_{4}$ & $\hat{\gamma}_{5}$ & $\hat{\gamma}_{6}$ & $\approx \hat{\delta}$ & $\hat{\psi}_{1}$ \\
\hline 201 & 1.080 & -.291 & -.458 & -.105 & & & .192 & .118 & .516 & .235 & .188 & .196 & .304 & .102 & .142 & .038 & -.0068 \\
\hline 207 & 1.559 & -.203 & -.456 & .155 & & & .064 & .091 & .356 & .205 & .135 & .119 & .034 & & & .063 & -.0027 \\
\hline 211 & .555 & -.520 & .612 & -.026 & & & & & .589 & .024 & .043 & & & & & -.010 & .0071 \\
\hline 212 & 1.828 & -.285 & -.583 & .065 & & & & .053 & .386 & & & & & & & & -.0174 \\
\hline 231 & .073 & -.445 & -.439 & .107 & & & .032 & .065 & .313 & .067 & .108 & .073 & & & & .020 & -.0132 \\
\hline 232 & .896 & -.219 & -.355 & -.055 & & & & .021 & .245 & .186 & .142 & .064 & & & & & -.0123 \\
\hline 237 & 3.791 & -.089 & -.733 & -.016 & & & & .129 & .259 & & & & & & & & -.0100 \\
\hline 242 & 1.994 & -.089 & -.417 & -.006 & .112 & .136 & .211 & .171 & .341 & .076 & .065 & & & & & & -.0067 \\
\hline 271 & 1.234 & -.098 & -.304 & -.082 & & & & & .201 & .081 & .067 & .095 & .030 & .083 & & & -.0005 \\
\hline 301 & .668 & -.277 & -.370 & -.010 & & & & & .204 & .127 & .063 & .103 & & & & & -.0199 \\
\hline 311 & .568 & -.288 & -.372 & -.021 & & & & & .309 & .125 & .176 & .116 & .076 & .056 & & & -.0093 \\
\hline 314 & .531 & -.305 & -.393 & .103 & & & & & .738 & .250 & .290 & .144 & & & & .211 & .0017 \\
\hline 324 & 2.637 &.- .142 & -.574 & .026 & & & & & .266 & .039 & .026 & .052 & .051 & & & .008 & -.0057 \\
\hline 331 & 2.555 & -.217 & -.633 & .129 & .044 & .067 & .037 & .121 & .376 & & & & & & & & -.0158 \\
\hline 332 & .261 & -.232 & .265 & .108 & & & & & .298 & .082 & .103 & .081 & .056 & & & & -.0132 \\
\hline 336 & 1.369 & -.156 & -.371 & .035 & & & & .090 & .242 & .120 & .121 & .111 & .044 & .027 & & & -.0168 \\
\hline 341 & 3.230 & -.138 & -.660 & .035 & & & & .038 & .277 & .089 & .044 & .036 & .022 & & & & -.0088 \\
\hline
\end{tabular}

a $\hat{\delta}$ is the coefficient estimate of $\log Y_{d t-1-1}-\log Y_{d t-1}$ under the non-perfect expectational hypothesis. 
which are not actually required is $M_{2 w t-1} H P_{2 w t-1}-M_{2 w t-1}^{*} H_{2 w t-1}^{*}$, and the variable $\log M_{2 w t-1} H P_{2 w t-1}-\log M_{2 w t-1}^{*} H_{2 w t-1}^{*}$ can be considered to be the "excess man-hours" variable analagous to the "excess labor" variable above. Analogous to eq. (3.9) for workers, an equation determining the change in total man hours paid-for could be specified in which log $M_{2 w t} H P_{2 w t}-\log M_{2 w t-1} H P_{2 w t-1}$ was taken to be a function of current and expected future changes in output and of the amount of excess man hours on hand as measured by $\log M_{2 w t-1} H P_{2 w t-1}-\log M_{2 w t-1}^{*} H_{2 w t-1}^{*}$. The difference between an equation like this and the equation for the change in total man hours paid-for derived from eqs. (3.9) and (7.2) has to do with the reaction of the firm to the amount of excess man hours on hand. By definition:

$$
\begin{aligned}
\log M_{2 w t-1} H P_{2 w t-1}-\log M_{2 w t-1}^{*} H_{2 w t-1}^{*} & \\
= & \log M_{2 w t-1}-\log M_{2 w t-1}^{*} H_{2 w t-1}^{*}+\log H P_{2 w t-1} \\
= & \log M_{2 w t-1}-\log M_{2 w t-1}^{*} H_{2 w t-1}^{*}+\log H S_{2 w t-1} \\
& \quad+\log H P_{2 w t-1}-\log H S_{2 w t-1} \\
= & \left(\log M_{2 w t-1}-\log M_{2 w t-1}^{d}\right)+\left(\log H P_{2 w t-1}-\log H S_{2 w t-1}\right)
\end{aligned}
$$

which says that the excess man-hours variable is the sum of the excess labor variable and the $\log H P_{2 w t-1}-\log H S_{2 w t-1}$ variable. If one estimated the man-hours paid-for equation directly using the excess man-hours variable, he would implicitly be assuming that the coefficients of $\log M_{2 w t-1}-$ $\log M_{2 w t-1}^{d}$ and $\log H P_{2 w t-1}-\log H S_{2 w t-1}$ are equal and thus that the reaction of the firm to the two variables is the same. The results presented in table 8.1 suggest that this is not the case, that the reaction of firms to the amount of excess man hours on hand depends on how the amount is distributed between the amount of excess labor on hand and the amount by which $H P_{2 w t-1}$ differ from $H S_{2 w t-1}$.

In summary, then, the change in total man hours paid-for is a function of current and expected future changes in output, of the degree of labor market tightness, of the amount by which the number of workers employed differs from the desired number, and of the amount by which the number of hours paid-for per worker differs from the standard level of hours.

\subsection{Economy-wide implications}

In an attempt to avoid aggregating vastly dissimilar firms and because of data limitations, this study was confined to the examination of short-run employment demand in only seventeen three-digit manufacturing industries. 
These industries constitute about eighteen percent of manufacturing by value added and of course a much smaller percent of the total economy. From this small sample it would be inappropriate to draw any firm conclusions about the behavior of the whole economy, but from the consistency of the above results a few tentative conclusions are in order.

Economy-wide contractions are usually defined to be periods of declining seasonally adjusted GNP or some similar aggregate output variable. Since seasonal fluctuations in output account for a large percentage of total short-run fluctuations, during the "seasonally adjusted" contractions actual output is not likely to be continually decreasing since it fluctuates seasonally as well. It was argued in $\S 2.3 .3$ that it is inappropriate to use seasonally adjusted data when attempting to estimate the parameters of a production function; a production function is not a relationship between seasonally adjusted inputs and a seasonally adjusted output. In $\S 3.6$ the production function parameter $\alpha_{2_{k, t}}$ was estimated from the interpolations of output per paid-for man hour from peak to peak, and the output and man-hours data which were used for the interpolations were seasonally unadjusted. The amount of excess labor on hand, which was constructed from the data on $\alpha_{2 w t}$, was thus the actual amount on hand and not the seasonally adjusted amount. Eqs. (3.9) and (7.2) and the other equations considered in the study were estimated using seasonally unadjusted data. In chs. 4 and 7 eqs. (3.9) and (7.2) were tested to see if the employment behavior of firms is different during general contractionary periods of output or during general expansionary periods than the equations predict it should be. The results were largely negative, and the two equations appear to explain adequately the "cyclical" behavior of the number of workers employed and the number of hours paid-for per worker as well as the seasonal behavior.

In the following discussion an attempt will be made to draw some tentative conclusions from the results achieved in the study about how the seasonally adjusted number of workers employed and the seasonally adjusted number of hours paid-for per worker behave during periods of rising and falling seasonally adjusted output. It should be kept in mind that the discussion which follows is somewhat loose in that the behavior of the actual number of workers employed and of the actual number of hours paid-for per worker is more complicated than that described for the seasonally adjusted numbers. During contractions, for example, the actual amount of output produced and the actual number of workers employed are sometimes rising, sometimes falling, and only on the average can output and employment be said to be falling. It should also be kept in mind that economy-wide contractions are 
likely to affect individual firms and industries differently, and since firms do not all behave in the same way, how aggregate employment responds to changes in aggregate output will depend on how the changes in aggregate output are distributed among the individual firms and industries.

Assuming then that the results achieved for the seventeen manufacturing industries considered in the study can be extended to the rest of the economy, they have the following implications for the behavior of employment during contractions and expansions. During a contraction as current and expected future changes in output become smaller than would have been the case without the contraction, more workers are laid off than otherwise. Because in the short run the percentage change in the number of workers employed is less than the percentage change in output, positive amounts of excess labor begin to build up. Firms begin tesponding to the increasing amounts of excess labor on hand by laying off more workers than otherwise, and gradually the number of workers employed is decreased. At the beginning of the contraction the drop in output per employed worker is likely to be quite sharp since the percentage change in the number of workers employed is considerably less than the percentage change in output. As the contractions continue, however, and more and more excess labor builds up, the number of workers laid off increases and so the decline in output per employed worker should be less as the contraction wears on than it was at the beginning.

The same type of thing happens to the number of hours paid-for per worker. As current and expected future changes in output decrease, the number of hours paid-for per worker decreases, but not as rapidly. As excess labor begins building up, the number of hours paid-for per worker decreases more. There are always forces at work, however, bringing the number of hours paid-for per worker back to the standard level, and the former never deviates too far from the latter. In the long run the number of workers is adjusted so that there is no excess labor on hand (which means that the number of hours worked per worker equals the standard level) and so that the number of hours paid-for per worker equals the standard level.

Combining these two results, the implications for the total number of man hours paid-for are the same. The percentage change in total man hours paid-for is less than the percentage change in output, and so at the beginning of expansions output per paid-for man hour drops sharply. As excess labor builds up, however, and more workers are laid off and hours paid-for per worker are decreased more, total man hours paid-for are decreased more, and so the decrease in output per paid-for man hour lessens as the contraction wears on. This conclusion is consistent with the empirical 
results achieved by Hultgren using seasonally adjusted data, where he found that output per paid-for man hour decreases during contractions, although less so near the end of the contractions. ${ }^{1}$

The implications for expansions are similar to those for contractions. As the expansion begins, current and expected future changes in output are larger than before and more workers are hired. Because the percentage change in the number of workers employed is less than the percentage change in output, part of the increasing man-hour requirements comes from drawing down excess labor. As the amount of excess labor falls (or even becomes negative), more workers are hired than otherwise, and gradually the number of workers employed is increased. Again, at the beginning of the expansion the increase in output per employed worker is likely to b $\geq$ quite sharp as excess labor is decreased rapidly at first, and then as the expansion continues and more workers are hired due to less (or negative) amounts of excess labor on hand, the increase in output per employed worker should lessen.

Likewise, the number of hours paid-for per worker increases as expected future changes in output increase, but not as rapidly. As excess labor falls, the number of hours paid-for per worker increases more, although again there are forces at work to bring the number back to the standard level. The implications for total man hours paid-for are the same. Since the percentage change in total man hours paid-for is less than the percentage change in output, the total number of man hours paid-for increases less at the beginning of the expansion than during the later phases when declining or negative amounts of excess labor on hand cause the increase in the total number of man hours paid-for to be greater. This implies that the increase in output per paid-for man hour should be sharp at the beginning of the expansion and lessen as the expansion continues. This is again consistent with the results achieved by Hultgren, where he found that output per (paid-for) man hour increases during expansions, but less so near the end of the expansions.

During contractions labor markets are likely to be growing looser, and since loose labor markets have a negative effect on the number of hours paid-for per worker (and thus on the number of total man hours paid-for), total man hours paid-for should decrease less from this source at the beginning of the contraction where labor markets are likely to be fairly

1. See the summary of Hultgren's findings in $\$ 2.4 .3$. 
tight than during the later phases of the contraction where labor markets are likely to be much looser. This reinforces the conclusion reached above about how output per paid-for man hour should behave during a contraction. During expansions labor markets are likely to be growing tighter, and so total man hours paid-for should increase less from the source at the beginning of the expansion than during the later phases. This again reinforces the conclusion reached above about how output per paid-for man hour should behave during an expansion.

This completes the discussion of the implications the results achieved in this study have for the behavior of the seasonally adjusted number of workers employed and the number of hours paid-for per worker during seasonally adjusted contractions and expansions. The implications seem to be consistent with the results achieved by Hultgren and others for broader sectors of the economy as to how output per (paid-for) man hour behaves during contractions and expansions. 


\section{FURTHER STATISTICAL RESULTS}

\subsection{Introduction}

This chapter consists of three somewhat unrelated discussions. In $\S 9.2$ serial correlation problems are discussed, and the residuals of eqs. (3.9)' and $(7.2)^{\prime}$ are examined for first-order serial correlation. In $\$ 9.3$ the question of the possible correlation between the residuals of eq. (3.9)' and the residuals of eq. (7.2)' for each industry is examined, and estimates using a technique developed by ZELLNER (1962) are presented. In this section the question of the possible correlation between the residuals of eq. (3.9)' or eq. (7.2)' for one industry and the residuals of eq. (3.9) ${ }^{\prime}$ or eq. (7.2) for another industry is also examined, and estimates using Zellner's technique are presented. Finally, in $\$ 9.4$ a brief comparison of the short-run demand for workers across industries is made.

\subsection{Tests for first-order serial correlation}

It is well known that the Durbin-Watson statistic is biased toward two when there is a lagged dependent variable among the regressors. ${ }^{1}$ For equations with lagged dependent variables the $\mathrm{DW}$ statistic is thus not a reliable indicator of whether or not the residuals are serially correlated. It is also well known that the least squares technique yields inconsistent estimates when used to estimate the coefficients of an equation with a lagged dependent variable and serially correlated errors. GRILICHES (1961) in fact has shown that for positively correlated errors the least squares estimate of the coefficient of the lagged dependent variable is likely to be too large. It was mentioned in $\S 4.3 .1$ that the excess labor variable in the workers equation (3.9)', $\log M_{2 w t-1}-\log M_{2 w t-1}^{*} H_{2 w t-1}^{*}$, is of the nature of a lagged dependent variable, but that because $M_{2 w t-1}^{*} H_{2 w t-1}^{*}$ has a large short-run

1 See NERLOVE and WaLLIS (1966). 
variance, the excess labor variable is by no means equivalent to a lagged dependent variable. It was also seen in $\S 4.3 .1$ that the excess labor variable definitely appears to be significant in its own right and not merely because it is of the nature of a lagged dependent variable. In the hours equation (7.2)' $\log H P_{2 w t-1}$ enter's the equation directly, and so for this equation there definitely is a lagged dependent variable among the regressors.

Fortunately, there are consistent and efficient methods of estimating equations with first-order serially correlated errors. Assume that the equation to be estimated is

$$
y=X \beta+\mu,
$$

where

$$
\mu_{t}=\rho \mu_{t-1}+\varepsilon_{t},|\rho|<1, t=2,3, \ldots, T
$$

and where $\varepsilon_{t}$ is assumed to be distributed with zero mean and constant variance $\sigma^{2}$ and to be uncorrelated with the variables in $\boldsymbol{X}$ and with its own past values. $y$ is a $T \times 1$ vector of observations on the dependent variable $y_{t}, \boldsymbol{X}$ is a $T \times K$ matrix of observations on the explanatory variables $x_{i t}, \beta$ is a $K \times 1$ vector of coefficients, $\boldsymbol{\mu}$ is a $T \times 1$ vector of disturbances $\mu_{t}$, and $\rho$ is the serial correlation coefficient. The variance-covariance matrix for $\mu$ can be seen to be

$$
E\left(\mu \mu^{\prime}\right)=\frac{\sigma^{2}}{1-\rho^{2}} \boldsymbol{\Omega}
$$

where

$$
\boldsymbol{\Omega}=\left[\begin{array}{lllllll}
- & \rho & \rho^{2} & \cdot & \cdot & \cdot & \rho^{T-1} \\
\rho & 1 & \rho & \cdot & \cdot & \cdot & \rho^{T-1} \\
\cdot & \cdot & \cdot & \cdot & & & \cdot \\
\cdot & \cdot & \cdot & & & & \cdot \\
\rho^{T-1} & \rho^{T-2} & \rho^{T-3} & . & . & . & 1
\end{array}\right] .
$$

If $\rho$ (and thus $\boldsymbol{\Omega}$ ) were known, then an efficient estimate of $\boldsymbol{\beta}$ in eq. (9.1) could be obtained by the use of Aitken's generalized least squares method, 
but since $\rho$ is usually not known a priori, it must be estimated along with the coefficients in $\beta$.

Let

$$
\left[\begin{array}{lllllllll}
\sqrt{1-\rho^{2}} & 0 & 0 & . & . & . & 0 & 0 & 0 \\
-\rho & 1 & 0 & . & . & . & 0 & 0 & 0 \\
. & . & . & & & & . & . & . \\
\cdot & . & . & & & & \cdot & . & . \\
. & . & . & & & & . & . & . \\
0 & 0 & 0 & . & . & . & -\rho & 1 & 0 \\
0 & 0 & 0 & . & . & . & 0 & -\rho & 1
\end{array}\right] .
$$

Then if eq. (9.1) is multiplied through by $\boldsymbol{P}$,

$$
P y=P X \beta+P \mu=P X \beta+v,
$$

the variance-covariance matrix of the error term $v$ in the resulting equation is seen to be

$$
\begin{aligned}
E\left(\boldsymbol{v} \boldsymbol{v}^{\prime}\right) & =E\left(\boldsymbol{P} \mu \mu^{\prime} \boldsymbol{P}^{\prime}\right) \\
& =\boldsymbol{P} E\left(\mu \mu^{\prime}\right) \boldsymbol{P}^{\prime} \\
& =\frac{\sigma^{2}}{1-\rho^{2}} \boldsymbol{P} \boldsymbol{\Omega} \boldsymbol{P}^{\prime} \\
& =\sigma^{2} I,
\end{aligned}
$$

where $I$ is the $T \times T$ identity matrix. The error term $v$ in the transformed equation (9.6) is thus seen to have a scalar variance-covariance matrix like the one assumed for the error term of the classical linear regression model.

Eq. (9.6) is non-linear in the coefficients $\beta$ and $\rho$, but the coefficients can be estimated by minimizing the sum of squared residuals in the equation using a minimization technique like the quadratic hill-climbing technique of Goldfeld, Quandt, and Trotter which was used to estimate eq. (5.1) in $\S 5.4$. If $v$ is normally distributed, then the estimates obtained by the minimization 
procedure will be maximum likelihood estimates. ${ }^{1}$ An estimate of the asymptotic variance-covariance matrix of the parameter estimates can thus be obtained as $\left(-\partial^{2} \log L / \partial \phi^{2}\right)^{-1}$, where $L$ is the likelihood function, $\phi^{\prime}$ is the $1 \times K+2$ vector $\left(\beta^{\prime} \rho \sigma^{2}\right)$, and where the derivatives are evaluated at the coefficient estimates. ${ }^{2}$ In the present context the asymptotic variancecovariance matrix of the parameters other than $\sigma^{2}$ is $2 \sigma^{2}\left(\partial^{2} v^{\prime} v / \partial \theta^{2}\right)^{-1}$, where $\theta^{1}$ is the $1 \times K+1$ vector $\left(\boldsymbol{\beta}^{\prime} \rho\right)$. The maximum likelihood estimate of $\sigma^{2}$ is $\hat{v} \hat{v} / T$, where $\hat{v}$ is the vector of calculated residuals. As was done in $\S 5.4$, however, the estimates presented below were adjusted for degrees of freedom to make them more comparable with the ordinary least squares estimates presented in chs. 4 and 7 . The estimate of $\sigma^{2}$ was thus taken to be $\hat{v}^{\prime} \hat{v} /$ $(T-K-1)$, and the estimate of the asymptotic variance-covariance matrix which was calculated was $2 \hat{v}^{\prime} \hat{v} /(T-K-1)\left[\partial^{2} v^{\prime} v / \partial \theta^{2}\right]^{-1}$, where the derivations are evaluated at $\theta=\hat{\theta}$. Notice that from this matrix an estimate of the standard error of the estimate of the serial correlation coefficient $\rho$ is available, as well as the estimates of the standard errors of the other coefficient estimates.

The technique just described can be applied to eqs. (3.9)' and (7.2)' to test the hypothesis implicitly made in the previous chapters that $\rho$ is zero. There is one difficulty which arises in using this technique, however, which is due to the fact that there are gaps in the periods of estimation. For most industries the July observations were omitted; for some industries the December observations were omitted as well; and for seven of the industries observations were omitted because of strikes. The Dw statistics presented

\footnotetext{
1. If there are no lagged dependent variables in $\boldsymbol{X}$, then the maximum likelihood estimates have the desirable properties of consistency and asymptotic efficiency. (DHRYMEs, 1966, has further proved that in the present case the estimates obtained by choosing various values of $\varrho$ between minus one and plus one in eq. (9.6), estimating the resulting equations, which are then linear in the parameters $\beta$, by ordinary least squares, and then choosing that value of $\varrho$ and the corresponding estimate of $\beta$ which yield the smallest sum of squared residuals are maximum likelihood estimates and possess the properties of consistency and asymptotic efficiency.) As mentioned in ch. 5, footnote 2, page 97, the properties of the maximum likelihood estimates are less well established when there are lagged dependent variables among the "independent" variables, but that the results which have been achieved indicate that the desirable properties are likely to be retained. In the present context, Malinvaud $(1966$, p. 469 , footnote $\dagger \dagger$ ), has outlined a proof of the statement that the technique of minimizing the sum of squared residuals of eq. (9.6) yields consistent estimates even when there is a lagged dependent variable in the $\boldsymbol{X}$ matrix.
}

2 See ch. 5, footnote 3, page 97. 
TABLE 9.1

Parameter estimates for eq. (3.9 ' ander the assumption of first-order serial correlation of the residuals

\begin{tabular}{|c|c|c|c|c|c|c|c|c|c|}
\hline $\begin{array}{l}\stackrel{3}{5} \\
\stackrel{5}{\Xi}\end{array}$ & $\begin{array}{l}\dot{8} \\
\stackrel{8}{0} \\
\stackrel{0}{0} \\
\dot{0} \\
\dot{Z}\end{array}$ & $a_{1} \log \bar{H}$ & $\hat{\alpha}_{1}$ & $1000 a_{1} \mu$ & $\hat{\beta}_{4}$ & $\hat{\beta}_{3}$ & $\hat{\beta}_{2}$ & $\hat{\beta}_{1}$ & $\hat{\gamma}_{0}$ \\
\hline \multirow[t]{2}{*}{201} & 192 & -1.041 & -.178 & -.077 & & & .074 & .067 & .265 \\
\hline & & (3.93) & $(3.93)$ & $(3.62)$ & & & $(3.73)$ & $(3.45)$ & $(9.26)$ \\
\hline \multirow[t]{2}{*}{207} & 136 & 0.653 & -.113 & .098 & & & .068 & .107 & .243 \\
\hline & & $(2.75)$ & $(2.74)$ & $(2.98)$ & & & $(5.91)$ & $(5.49)$ & (11.01) \\
\hline \multirow{2}{*}{$\begin{array}{r}211 \\
:\end{array}$} & 136 & -.797 & -.136 & -.051 & & & & & .087 \\
\hline & & $(5.46)$ & $(5.47)$ & $(3.08)$ & & & & & $(4.36)$ \\
\hline \multirow[t]{2}{*}{212} & 136 & -.638 & -.109 & -.038 & & & & .053 & .154 \\
\hline & & $(4.68)$ & $(4.66)$ & $(1.50)$ & & . & & $(4.53)$ & $(7.72)$ \\
\hline \multirow[t]{2}{*}{231} & 136 & -.892 & -.152 & .086 & & & .026 & .064 & .108 \\
\hline & & $(4.05)$ & $(3.94)$ & $(3.43)$ & & & $(2.33)$ & $(4.08)$ & $(3.40)$ \\
\hline \multirow[t]{2}{*}{232} & 136 &.- .564 & -.100 & -.069 & & & & .018 & .127 \\
\hline & & $(4.91)$ & $(4.96)$ & $(3.17)$ & & & & $(2.44)$ & $(8.26)$ \\
\hline \multirow[t]{2}{*}{233} & 136 & -.178 & -.028 & .019 & & & & .124 & .167 \\
\hline & & $(0.84)$ & $(0.74)$ & $(0.31)$ & & & & $(5.79)$ & $(7.12)$ \\
\hline \multirow[t]{2}{*}{242} & 154 & -.278 & -.047 & -.121 & .060 & .104 & .145 & .148 & .219 \\
\hline & & $(1.41)$ & $(1.40)$ & $(0.57)$ & $(4.55)$ & $(7.09)$ & $(8.29)$ & $(6.52)$ & $(13.52)$ \\
\hline \multirow[t]{2}{*}{271} & 166 & -.223 & -.038 & .000 & & & & & .112 \\
\hline & & $(2.48)$ & $(2.51)$ & $(0.32)$ & & & & & (7.53) \\
\hline \multirow[t]{2}{*}{301} & 134 & -.634 & -.109 & -.063 & & & & & .056 \\
\hline & & $(6.81)$ & $(6.79)$ & $(2.62)$ & & & & & $(2.84)$ \\
\hline \multirow[t]{2}{*}{311} & 170 & -1.004 & -.171 & -.055 & & & & & .190 \\
\hline & & $(6.65)$ & $(6.63)$ & (3.34) & & & & & $(8.22)$ \\
\hline \multirow[t]{2}{*}{314} & 136 & -.429 & -.073 & .043 & & & & & .309 \\
\hline & & $(1.60)$ & $(1.59)$ & $(2.44)$ & & & & & $(10.79)$ \\
\hline \multirow[t]{2}{*}{324} & 187 & -.655 & -.110 & .060 & & & & & .224 \\
\hline & & (6.13) & $(6.10)$ & $(2.41)$ & & & & & (16.31) \\
\hline \multirow[t]{2}{*}{331} & 128 & -.215 & -.036 & .017 & .044 & .067 & .037 & .121 & .181 \\
\hline & & $(2.93)$ & $(2.87)$ & $(1.01)$ & $(3.37)$ & $(4.71)$ & $(2.48)$ & $(6.30)$ & $(9.56)$ \\
\hline \multirow[t]{2}{*}{332} & 170 & -.727 & -.122 & .045 & & & & & .172 \\
\hline & & $(8.73)$ & $(8.70)$ & $(2.11)$ & & & & & $(8.31)$ \\
\hline \multirow[t]{2}{*}{336} & 170 & -.729 & -.124 & -.017 & & & & .083 & .171 \\
\hline & & $(5.11)$ & $(5.09)$ & $(0.62)$ & & & & $(4.20)$ & $(6.75)$ \\
\hline \multirow[t]{2}{*}{341} & 191 & -.370 & -.066 & -.060 & & & & .038 & .181 \\
\hline & & $(3.56)$ & $(3.58)$ & $(2.38)$ & & & & $(3.84)$ & (15.26) \\
\hline
\end{tabular}

$t$-statistics are in parentheses.

$\hat{\delta}$ is the coefficient estimate of $\log Y_{d t-1}-\log Y_{a t-13}$ under the non-perfect expectational hypothesis. 


\begin{tabular}{|c|c|c|c|c|c|c|c|c|}
\hline$\hat{\gamma}_{1}$ & $\hat{\gamma}^{2}$ & $\hat{\gamma}_{3}$ & $\hat{\gamma}_{4}$ & $\hat{\gamma}_{a}$ & $\hat{y}_{6}$ & ${ }^{a} \hat{\delta}$ & $\hat{\rho}$ & SE \\
\hline .171 & .118 & .138 & .159 & .087 & .073 & .039 & .016 & .0120 \\
\hline$(6.64)$ & $(4.80)$ & $(6.65)$ & $(9.29)$ & $(5.57)$ & $(4.04)$ & (2.19) & $(0.18)$ & \\
\hline .168 & .120 & .076 & .034 & & & .056 & -.202 & .0178 \\
\hline$(7.25)$ & $(7.13)$ & $(8.85)$ & $(3.76)$ & & & $(2.83)$ & $(2.09)$ & \\
\hline .025 & .043 & & & & & -.011 & .046 & .0102 \\
\hline \multirow[t]{2}{*}{$(1.90)$} & $(4.97)$ & & & & & $(0.65)$ & $(0.48)$ & \\
\hline & & & & & & & $\begin{array}{r}.011 \\
(0.12)\end{array}$ & .0159 \\
\hline .010 & .055 & .032 & & & & -.014 & -.179 & .0192 \\
\hline$(0.52)$ & $(3.70)$ & $(3.25)$ & & & & $(0.89)$ & $(1.78)$ & \\
\hline .098 & .066 & .021 & & & & & .140 & .0106 \\
\hline \multirow[t]{2}{*}{$(6.23)$} & $(5.95)$ & $(2.77)$ & & & & & $(1.28)$ & \\
\hline & & & & & & & $\begin{array}{r}.150 \\
(1.48)\end{array}$ & .0291 \\
\hline .076 & .066 & & & & & & .028 & .0127 \\
\hline$(5.23)$ & $(5.20)$ & & & & & & $(0.31)$ & \\
\hline .020 & .040 & .046 & .010 & .039 & & & -.137 & .0048 \\
\hline$(1.39)$ & $(3.20)$ & $(4.13)$ & $(0.97)$ & $(4.21)$ & & & $(1.61)$ & \\
\hline .062 & .033 & .035 & & & & & .072 & .0142 \\
\hline$(3.41)$ & $(1.92)$ & (2.19) & & & & & $(0.76)$ & \\
\hline .081 & .114 & .084 & .056 & .039 & & & -.033 & .0115 \\
\hline$(4.61)$ & $(7.57)$ & $(6.06)$ & $(4.56)$ & $(3.51)$ & & & $(0.39)$ & \\
\hline .085 & .126 & .041 & & & & .068 & -.183 & .0142 \\
\hline$(3.18)$ & $(6.91)$ & $(2.64)$ & & & & $(3.02)$ & $(1,63)$ & \\
\hline .039 & .026 & .052 & .051 & & & .008 & .005 & .0177 \\
\hline \multirow[t]{2}{*}{$(2.37)$} & $(1.59)$ & $(3.35)$ & $(3.34)$ & & & $(0.47)$ & $(0.06)$ & \\
\hline & & & & & & & $\begin{array}{r}.058 \\
(0.58)\end{array}$ & .0101 \\
\hline .049 & .057 & .042 & .034 & & & & -.038 & .0167 \\
\hline$(3.39)$ & $(4.56)$ & (3.49) & $(2.85)$ & & & & $(0.46)$ & \\
\hline .093 & .095 & .078 & .044 & .029 & & & .156 & .0174 \\
\hline$(4.76)$ & $(5.86)$ & $(5.67)$ & $(3.32)$ & $(2.28)$ & & & $(1.86)$ & \\
\hline .067 & .044 & .035 & .022 & & & & -.016 & .0181 \\
\hline (5.98) & $(4.59)$ & $(3.85)$ & $(2.41)$ & & & & $(0.20)$ & \\
\hline
\end{tabular}


Parameter estimates for eq. (7.2)' under the assumption of first-order serial correlation of the residuals

\begin{tabular}{|c|c|c|c|c|c|c|c|c|c|c|}
\hline 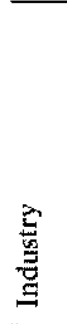 & $\begin{array}{l}\frac{8}{0} \\
0 \\
0 \\
0 \\
\dot{0}\end{array}$ & 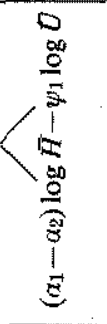 & $\hat{\alpha}_{1}$ & $\hat{\alpha}_{2}$ & $\frac{z}{3}$ & $\hat{\beta}_{4}$ & $\hat{\beta}_{3}$ & $\hat{\beta}_{2}$ & $\hat{\beta}_{1}$ & $\hat{\gamma}_{0}$ \\
\hline \multirow[t]{2}{*}{201} & 192 & 2.079 & -.071 & -.410 & -.012 & & & .128 & .052 & .236 \\
\hline & & $(4.21)$ & $(1.79)$ & $(5.67)$ & $(0.58)$ & & & $(5.45)$ & $(2.22)$ & (7.93) \\
\hline \multirow[t]{2}{*}{207} & 136 & 2.144 & -.042 & -.398 & .028 & & & & & .090 \\
\hline & & $(4.66)$ & $(2.20)$ & $(4.47)$ & $(1.29)$ & & & & & $(9.37)$ \\
\hline \multirow[t]{2}{*}{211} & 136 & .602 & -.202 & -.308 & .020 & & & & & .550 \\
\hline & & $(1.73)$ & $(3.58)$ & (4.19) & $(0.52)$ & & & & & $(10.42)$ \\
\hline \multirow[t]{2}{*}{212} & 136 & 1.837 & -.094 & -.397 & .091 & & & & & .276 \\
\hline & & $(5.35)$ & $(2.45)$ & $(5.04)$ & $(3.01)$ & & & & & $(8.67)$ \\
\hline \multirow[t]{2}{*}{231} & 136 & 1.092 & -.260 & -.430 & .022 & & & & & .182 \\
\hline & & $(2.50)$ & $(6.49)$ & $(5.98)$ & $(0.70)$ & & & & & $(5.54)$ \\
\hline \multirow[t]{2}{*}{232} & 136 & 2.660 & -.151 & -.583 & .054 & & & & & .146 \\
\hline & & $(2.32)$ & (5.69) & $(2.98)$ & $(0.87)$ & & & & & $(7.14)$ \\
\hline \multirow[t]{2}{*}{233} & 136 & 5.656 & -.122 & -1.079 & -.088 & & & & & .079 \\
\hline & & $(10.30)$ & $(3.74)$ & $(10.44)$ & $(1.23)$ & & & & & $(4.35)$ \\
\hline \multirow[t]{2}{*}{242} & 154 & 1.462 & -.031 & -.273 & .002 & .037 & .021 & .066 & .019 & .123 \\
\hline & & $(3.46)$ & $(1.06)$ & $(4.03)$ & $(0.08)$ & $(2.19)$ & $(1.27)$ & $(3.51)$ & $(0.82)$ & $(6.46)$ \\
\hline \multirow[t]{2}{*}{271} & 166 & 1.952 & -.065 & -.392 & -.106 & & & & & .097 \\
\hline & & $(2.96)$ & $(2.37)$ & (3.16) & (2.89) & & & & & (3.61) \\
\hline \multirow[t]{2}{*}{301} & 134 & 1.358 & -.173 & -.384 & .056 & & & & & .151 \\
\hline & & $(3.46)$ & $(5.17)$ & $(4.85)$ & $(1.24)$ & & & & & $(4.33)$ \\
\hline \multirow[t]{2}{*}{311} & 170 & 1.348 & -.103 & -.322 & .031 & & & & & .117 \\
\hline & & (3.83) & $(4.02)$ & $(4.59)$ & $(1.94)$ & & & & & $(5.96)$ \\
\hline \multirow[t]{2}{*}{314} & 136 & 1.195 & -.193 & -.395 & .061 & & & & & .417 \\
\hline & & $(2.35)$ & $(2.95)$ & $(4.45)$ & $(2.21)$ & & & & & $(11.16)$ \\
\hline \multirow[t]{2}{*}{324} & 187 & 1.612 & -.017 & -.283 & -.013 & & & & & .044 \\
\hline & & $(4.67)$ & $(3.86)$ & $(4.72)$ & $(1.47)$ & & & & & $(10.91)$ \\
\hline \multirow[t]{2}{*}{331} & 128 & 2.505 & -.167 & -.576 & .104 & & & & & .189 \\
\hline & & $(5.36)$ & $(5.21)$ & $(5.56)$ & (4.13) & & & & & $(9.18)$ \\
\hline \multirow[t]{2}{*}{332} & 170 & .751 & -.096 & -.214 & .052 & & & & & .124 \\
\hline & & (3.59) & $(6.18)$ & $(5.13)$ & $(2.96)$ & & & & & $(7.57)$ \\
\hline \multirow[t]{2}{*}{336} & 170 & 1.399 & -.035 & -.260 & .033 & & & & & .070 \\
\hline & & $(4.21)$ & (3.11) & $(4.50)$ & $(2.23)$ & & & & & $(5,00)$ \\
\hline \multirow[t]{2}{*}{341} & 191 & 4.318 & -.085 & -.791 & .110 & & & & & .101 \\
\hline & & $(5.50)$ & $(4.66)$ & $(5.49)$ & $(3.35)$ & & & & & $(11.01)$ \\
\hline
\end{tabular}

$t$-statistics are in parentheses.

$\mathfrak{a} \hat{\delta}$ is the coefficient estimate of $\log Y_{d t-1}-\log Y_{d t-13}$ under the non-perfect expectational hypothesis. 


\begin{tabular}{|c|c|c|c|c|c|c|c|c|c|}
\hline$\hat{\gamma}_{1}$ & $\hat{\gamma}_{2}$ & $\hat{\gamma}_{3}$ & $\hat{\gamma}_{4}$ & $\hat{\gamma}_{5}$ & $\hat{\gamma}_{6}$ & ${ }^{a} \hat{\delta}$ & $\hat{\psi}_{1}$ & $\hat{\rho}$ & SE \\
\hline .048 & .054 & .041 & .145 & .016 & .073 & .009 & -.0076 & -.228 & .0143 \\
\hline$(1.83)$ & $(2.02)$ & $(1.79)$ & $(6.62)$ & $(0.77)$ & (2.84) & $(0.49)$ & $(2.30)$ & $(2.43)$ & \\
\hline .022 & .009 & .038 & & & & .006 & -.0025 & -.106 & .0116 \\
\hline \multirow[t]{5}{*}{$(1.44)$} & $(0.90)$ & $(7.09)$ & & & & $(0.47)$ & $(0.78)$ & $(0.80)$ & \\
\hline & & & & & & & .0083 & -.428 & .0327 \\
\hline & & & & & & & (1.16) & $(4.52)$ & \\
\hline & & & & & & & -.0135 & -.359 & .0227 \\
\hline & & & & & & & $(2.41)$ & $(3.25)$ & \\
\hline .045 & .047 & .038 & & & & -.003 & -.0127 & -.030 & .0201 \\
\hline$(2.08)$ & $(2.92)$ & (3.63) & & & & $(0.14)$ & $(1.92)$ & $(0.28)$ & \\
\hline .106 & .083 & .045 & & & & & -.0245 & .375 & .0145 \\
\hline \multirow[t]{5}{*}{$(4.96)$} & $(5.46)$ & $(4.47)$ & & & & & $(1.85)$ & $(1.43)$ & \\
\hline & & & & & & & -.0118 & .450 & .0245 \\
\hline & & & & & & & $(1.05)$ & $(4,41)$ & \\
\hline & & & & & & & -.0038 & -.264 & .0151 \\
\hline & & & & & & & $(1.47)$ & $(2.48)$ & \\
\hline .071 & .038 & .060 & .031 & .055 & & & -.0004 & .200 & .0051 \\
\hline$(2.60)$ & $(1.55)$ & $(2.75)$ & $(1.55)$ & $(3.23)$ & & & $(0.25)$ & $(1.01)$ & \\
\hline .070 & .035 & .068 & & & & & -.0208 & .034 & .0233 \\
\hline$(2.29)$ & $(1.23)$ & $(2.60)$ & & & & & $(2.28)$ & $(0.30)$ & \\
\hline .039 & .060 & .032 & .021 & .022 & & & -.0083 & -.103 & .0097 \\
\hline$(2.67)$ & $(4.96)$ & $(2.85)$ & $(2,10)$ & $(2.10)$ & . & & $(2.97)$ & $(0.91)$ & \\
\hline .143 & .150 & .092 & & & & .134 & .0018 & .013 & .0169 \\
\hline \multirow[t]{5}{*}{$(4.23)$} & $(6.07)$ & $(4.20)$ & & & & $(4.48)$ & $(0.31)$ & $(0.12)$ & \\
\hline & & & & & & & -.0027 & -.435 & .0084 \\
\hline & & & & & & & $(2.27)$ & $(5.53)$ & \\
\hline & & & & & & & -.0140 & -.095 & .0138 \\
\hline & & & & & & & $(3.20)$ & $(0.76)$ & \\
\hline .027 & .043 & .039 & .024 & & & & -.0098 & -.173 & .0132 \\
\hline (2.29) & $(4.32)$ & $(4.24)$ & $(2.59)$ & & & & $(2.85)$ & $(1.87)$ & \\
\hline .027 & .027 & .038 & & & & & -.0116 & -.242 & .0109 \\
\hline$(2.54)$ & $(2.90)$ & $(4.68)$ & & & & & $(3.81)$ & $(2.48)$ & \\
\hline .022 & & & & & & & -.0103 & .170 & .0159 \\
\hline$(3.01)$ & & & & & & & $(2.99)$ & $(1.10)$ & \\
\hline
\end{tabular}


in the tables above were adjusted for these gaps, which means that in the formula for the $\mathrm{DW}$ statistic (where $\hat{\mu}_{t}$ is the calculated residual for month $t$ )

$$
\mathrm{DW}=\frac{\sum_{t=2}^{T}\left(\hat{\mu}_{t}-\hat{\mu}_{t-1}\right)^{2}}{\sum_{t=1}^{T} \hat{\mu}_{t}^{2}}
$$

if month 13, for example, were omitted from the sample period, then neither $\left(\hat{\mu}_{13}-\hat{\mu}_{12}\right)^{2}$ nor $\left(\hat{\mu}_{14}-\hat{\mu}_{13}\right)^{2}$ was included in the summation for the numerator and $\hat{\mu}_{13}^{2}$ was not included in the summation for the denominator. ${ }^{1}$ If this gap adjustment procedure were used in estimating eq. $(3.9)^{\prime}$ by the above technique, it would necessitate, for example, omitting the $\log$ $M_{2 w \text { Sept. }}-\log M_{2 \text { w Aug. }}$ observations from the period of estimation in addition to the already omitted $\log M_{2 w \mathrm{July}}-\log M_{2 w \mathrm{Jure}}$ and $\log M_{2 w \text { Aug }}$. $-\log M_{2 \text { wuly }}$ observations for those industries in which shutdowns occurred in July. Likewise, for the December shutdowns an extra observation would be lost each year, and an extra observation would be lost for every strike period.

Instead of losing all of these observations, a slightly different procedure was used when applying the above technique to eqs. (3.9)' and $(7.2)^{\prime}$. The first-order serial correlation of the residuals was assumed to be of such a nature that the residual for each included observation was correlated with the residual from the previous included observation instead of necessarily with the previous chronological observation. If, for example, the July-June and August-July observations were omitted, the residual for the SeptemberAugust observation was assumed to be correlated with the residual for the June-May observation. For those industries in which shutdowns occur in July and December this assumption saved two observations per year from having to be omitted, and for those industries in which no shutdowns occurred the assumption is equivalent to the normal assumption that the residuals are correlated chronologically. Since there was good reason for omitting the observations when shutdowns occurred, the assumption that the included residuals are correlated in the manner just described is not completely unrealistic, although because of the necessity of making this assumption, the

${ }^{1} \hat{\mu}_{13}$, of course, does not really exist if observation 13 has been omilted. 
tests for first-order serial correlation performed here are somewhat crude.

Eqs. (3.9)' and (7.2)' were thus estimated using the above techniques under the assumption that the included residuals are first-order serially correlated. The quadratic hill-climbing technique was used to minimize the sum of squared residuals, and the asymptotic variance-covariance matrix was estimated in the manner described above. The results of estimating eq. (3.9)' are presented in table 9.1 and the results of estimating eq. (7.2)' are presented in table 9.2. The same period of estimation and the same expectational variables were used here for each industry as were used for the results presented in tables 4.3 and 7.2 , and so the results presented in tables 9.1 and 9.2 are directly comparable with the results in tables 4.3 and 7.2.

Looking at the results of estimating eq. (3.9)' in table 9.1 first, it is seen that the estimate of the serial correlation coefficient $\rho$ is significant ( $t$ statistic greater than two) for only one of the seventeen industries - industry 207. The estimate of $\rho$ ranges from -.202 for industry 207 to .156 for industry 336. Seven of the seventeen estimates are negative (negative firstorder serial correlation). As expected from the work of GRILICHES (1961) mentioned above, when the estimate of $\rho$ is positive, the estimate of the coefficient $\alpha_{1}$ of the excess labor variable increases in absolute value from what it was in table 4.3, and when the estimate of $\rho$ is negative, the estimate $\alpha_{1}$ decreases in absolute value. Only for industry 314 has the estimate of $\alpha_{1}$ lost its significance from table 4.3 . The over-all results clearly indicate that first-order serial correlation of the residuals is not a serious problem for eq. (3.9)': the estimates of $\rho$ are small and insignificant, and the other coefficient estimates have been changed only slightly from what they were in table 4.3 .

Looking next at the results of estimating eq. (7.2)' in table 9.2, it is seen that the estimate of $\rho$ is significant for seven of the seventeen industries, and for six of these seven industries it is negative. The estimate ranges from -.435 in industry 324 to .450 in industry 233 . When the estimate of $\rho$ is positive, both the estimate of the coefficient $\alpha_{1}$ of the excess labor variable and the estimate of the coefficient $\alpha_{2}$ of $\log H P_{2 w t-1}$ increase in absolute value from what they were in table 7.2, and when the estimate of $\rho$ is negative, both of the estimates decrease in absolute value. For some of the industries the estimate of $\alpha_{2}$ has been changed considerably. For industry 211 , where the estimate of $\rho$ is -.428 , the estimate of $\alpha_{2}$ changes from -.612 in table 7.2 to -.308 in table 9.2 ; for industry 212 , where the estimate of $\rho$ is -.359 , the estimate of $\alpha_{2}$ changes from -.583 to -.397 ; for industry 233 , where the estimate of $\rho$ is +.450 , the estimate of $\alpha_{2}$ changes from -.733 to -1.079 ; 
and for industry 324 , where the estimate of $\rho$ is -.435 , the estimate of $\alpha_{2}$ changes from -.574 to -.283 . For none of the industries has the estimate of $\alpha_{2}$ lost its significance, however, and only for industry 201 has the estimate of $\alpha_{1}$ lost its significance from table 7.2.

For at least seven of the industries, therefore, serial correlation of the residuals of eq. (7.2) does appear to be a problem, with negative serial correlation being more pronounced than positive serial correlation. The conclusion reached in ch: 7 that the amount of excess labor on hand is a significant determinant of the change in the number of hours paid-for per worker does not appear to have been modified by the results presented in table 9.2, however, nor does the conclusion that the difference between the number of hours paid-for per worker and the standard number of hours of work per worker is also a significant determinant of this change. Only the size of the estimates of $\alpha_{1}$ and $\alpha_{2}$ appears to have been changed for any of the industries. This change in size, however, could have an affect on the conclusion reached in ch. 8 for the total man-hours paid-for equation that the sum of the estimates of $\alpha_{1}$ in eqs. (3.9)' and (7.2)' is less in absolute value than the estimate of $\alpha_{2}$ in eq. (7.2)' (i.e., that firms react more strongly in changing total

TABLE 9.3

Sum of the estimates of $\alpha_{1}$ in table 4.3 and table 9.2 and the estimate of $\alpha_{2}$ in table 9.2: derived coefficient estimates for the total man-hours paid-for equation

\begin{tabular}{ccc}
\hline Industry & $\hat{\alpha}_{1}$ & $\hat{\alpha}_{2}$ \\
\hline 201 & -.249 & -.410 \\
207 & -.193 & -.398 \\
211 & -.335 & -.308 \\
212 & -.202 & -.397 \\
231 & -.441 & -.430 \\
232 & -.241 & -.583 \\
233 & -.127 & -1.079 \\
242 & -.075 & -.273 \\
271 & -.109 & -.392 \\
301 & -.281 & -.384 \\
311 & -.277 & -.322 \\
314 & -.308 & -.395 \\
324 & -.127 & -.283 \\
331 & -.202 & -.576 \\
332 & -.219 & -.214 \\
336 & -.148 & -.260 \\
341 & -.152 & -.791 \\
\hline
\end{tabular}


man hours paid-for when the number of hours paid-for per worker differs from the standard level of hours than when the number of workers employed differs from the desired number). To see if this conclusion has been modified, the results of adding for each industry the estimate of $\alpha_{1}$ for eq. (7.2)' in table 9.2 and the estimate of $\alpha_{1}$ for eq. (3.9)' in table 4.3 are presented in table 9.3, along with the estimate of $\alpha_{2}$ for eq. (7.2)' in table 9.2. Comparing the results in tables 9.3 and 8.1 , it is seen that only for industries 211 and 332 has the estimate of $\alpha_{1}$ in the man-hours equation been changed from being less than the estimate of $\alpha_{2}$ in absolute value to being greater in absolute value. (For industry 231 the estimate of $\alpha_{1}$ is slightly greater in absolute value in both tables.) For the remaining fourteen industries the estimate of $\alpha_{1}$ remains smaller in absolute value, and the general conclusion reached in ch. 8 that the estimate of $\alpha_{1}$ is less in absolute value than the estimate of $\alpha_{2}$ in the total man-hours paid-for equation does not appear to have been modified.

In summary, then, some evidence has been found that the residuals of eq. $(7.2)^{\prime}$ are serially correlated for a few industries, with negative serial correlation predominating, but none of the conclusions reached in chs. 7 and 8 regarding the hours paid-for per worker equation or the total man-hours paid-for equation appears to have been changed for these industries. For the majority of the industries the estimate of $\rho$ for eq. (7.2)' is not significant. For eq. (3.9)' there is almost no evidence at all that $\rho$ is different from zero.

\subsection{More efficient estimates}

In the previous chapters two basic equations were estimated for each industry, one determining the short-run demand for workers and the other determining the short-run demand for hours paid-for per worker. It seems likely that for each industry the residuals from these two equations will be positively correlated, that a random disturbance for a given month which affects the residual of one of the equations in a certain way will also affect the residual of the other equation in a similar way. If these residuals are in fact correlated, then the two-stage Aitken estimator proposed by ZELLNER (1962) will yield more efficient estimates than the ordinary least squares method used in the previous chapters. The gain in efficiency is greater to the extent that the residuals are highly correlated and to the extent that the independent variables in the different equations are highly uncorrelated. The gain in efficiency is zero if the residuals of the different equations are not correlated or if the independent variables in the different equations are all the same. Basically, the two-stage method consists in first estimating the variance-covariance 
matrix of the residuals from the ordinary least squares estimates of each equation and then using this matrix to estimate all of the equations simultaneously by Aitken's generalized least squares method.

Assuming that the residuals from the workers and hours equations are not serially correlated but are contemporaneously correlated with each other, the two-stage Aitken estimator can be used to estimate the two equations simultaneously. ${ }^{1}$ With respect to the independent variables in eqs. $(3.9)^{\prime}$ and $(7.2)^{\prime}$, the hours equation (7.2) includes the $\log H P_{2 w t-1}$

\section{TABLE 9.4}

Correlation between the residuals of eq. (3.9)' and the residuals of eq. $(7.2)^{\prime}$ for each industry

\begin{tabular}{ccc}
\hline Industry & No. of obs. & $\begin{array}{c}\text { Correlation } \\
\text { coefficient }\end{array}$ \\
\hline 201 & 192 & .32 \\
207 & 136 & .19 \\
211 & 136 & .16 \\
212 & 136 & .22 \\
231 & 136 & .32 \\
232 & 136 & .56 \\
233 & 136 & .09 \\
242 & 154 & .33 \\
271 & 166 & .07 \\
301 & 134 & .19 \\
311 & 170 & .30 \\
314 & 136 & .62 \\
324 & 187 & .07 \\
331 & 128 & .16 \\
332 & 170 & .24 \\
336 & 170 & .11 \\
341 & 191 & .38 \\
\hline
\end{tabular}

1 Zeliner actually developed the two-stage Aitken estimator under the assumption that the "independent" variables are non-stochastic. This assumption is not met for the work here since there is a lagged dependent variable in eq. (7.2) and the excess labor variable, which is of the nature of a lagged dependent variable, in eq. (3.9)'. If there is no serial correlation nor cross serial correlation of the residuals in the equations, however, the two-stage Aitken estimator proposed by Zellner can be used for equations with lagged dependent variables as well. As was seen in the previous section, the residuals of eq. (3.9)' do not appear to be serially correlated, and the residuals of eq. (7.2) appear to be serially correlated only for a few industries. 
Parameter estimates for eq. (3.9)' using the two-stage Aitken estimator for each industry

\begin{tabular}{|c|c|c|c|c|c|c|c|c|c|c|c|c|c|c|c|}
\hline 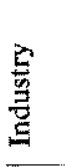 & $\begin{array}{l}\dot{8} \\
\dot{8} \\
4 \\
0 \\
\dot{0}\end{array}$ & $\widehat{u_{1}} \log \bar{H}$ & $\hat{\alpha}_{1}$ & $1000 \widehat{\alpha_{1} \mu}$ & $\hat{\beta}_{4}$ & $\hat{\beta}_{8}$ & $\hat{\beta}_{2}$ & $\hat{\beta}_{1}$ & $\hat{\gamma}_{0}$ & $\hat{y}_{1}$ & $\hat{\gamma}_{2}$ & $\hat{\gamma}_{3}$ & $\hat{\gamma}_{4}$ & $\hat{\gamma}_{B}$ & $\bar{\delta}$ \\
\hline 207 & 136 & $\begin{array}{l}-.898 \\
(3.54)\end{array}$ & $\begin{array}{r}-.156 \\
(3.53)\end{array}$ & $\begin{array}{r}.122 \\
(3.27)\end{array}$ & & & $\begin{array}{r}.062 \\
(5.29)\end{array}$ & $\begin{array}{r}.090 \\
(4.77)\end{array}$ & $\begin{array}{r}.262 \\
(11.80)\end{array}$ & $\begin{array}{r}.182 \\
(7.22)\end{array}$ & $\begin{array}{r}.126 \\
(7.37)\end{array}$ & $\begin{array}{r}.080 \\
(9.15)\end{array}$ & $\begin{array}{r}.036 \\
(4.03)\end{array}$ & & $\begin{array}{r}.055 \\
(2.60)\end{array}$ \\
\hline 211 & 136 & $\begin{array}{l}-.792 \\
(5.95)\end{array}$ & $\begin{array}{l}-.136 \\
(5.96)\end{array}$ & $\begin{array}{l}-.051 \\
(3.25)\end{array}$ & & & & & $\begin{array}{r}.088 \\
(4.59)\end{array}$ & $\begin{array}{r}.029 \\
(2.34)\end{array}$ & $\begin{array}{r}.042 \\
(4.97)\end{array}$ & & & & $\begin{array}{l}-.006 \\
(0.39)\end{array}$ \\
\hline 212 & 136 & $\begin{array}{l}-.636 \\
(4.77)\end{array}$ & $\begin{array}{l}-.108 \\
(4.74)\end{array}$ & $\begin{array}{l}-.038 \\
(1.52)\end{array}$ & & & & $\begin{array}{r}.054 \\
(4.68)\end{array}$ & $\begin{array}{r}.154 \\
(7.77)\end{array}$ & & & & & & \\
\hline 231 & 136 & $\begin{array}{r}-1.079 \\
(4.68)\end{array}$ & $\begin{array}{l}-.185 \\
(4.58)\end{array}$ & $\begin{array}{r}.086 \\
(2.93)\end{array}$ & & & $\begin{array}{r}.032 \\
(3.22)\end{array}$ & $\begin{array}{r}.063 \\
(3.98)\end{array}$ & $\begin{array}{r}.127 \\
(4.01)\end{array}$ & $\begin{array}{r}.021 \\
(1.00)\end{array}$ & $\begin{array}{r}.061 \\
(3.95)\end{array}$ & $\begin{array}{r}.035 \\
(3.57)\end{array}$ & & & $\begin{array}{l}-.018 \\
(1.08)\end{array}$ \\
\hline 232 & 136 & $\begin{array}{r}-.505 \\
(5.58)\end{array}$ & $\begin{array}{l}-.090 \\
(5.66)\end{array}$ & $\begin{array}{c}-.062 \\
(3.42)\end{array}$ & & & & $\begin{array}{r}.021 \\
(3.62)\end{array}$ & $\begin{array}{r}.118 \\
(9.59)\end{array}$ & $\begin{array}{r}.091 \\
(6.82)\end{array}$ & $\begin{array}{r}.061 \\
(6.33)\end{array}$ & $\begin{array}{r}.018 \\
(2.54)\end{array}$ & & & \\
\hline 233 & 136 & $\begin{array}{l}-.056 \\
(0.33)\end{array}$ & $\begin{array}{l}-.006 \\
(0.21)\end{array}$ & $\begin{array}{r}.041 \\
(0.77)\end{array}$ & & & & $\begin{array}{r}.126 \\
(5.97)\end{array}$ & $\begin{array}{r}.165 \\
(6.73)\end{array}$ & & & & & & \\
\hline 242 & 154 & $\begin{array}{l}\ldots .283 \\
(1.55)\end{array}$ & $\begin{array}{l}-.048 \\
(1.54)\end{array}$ & $\begin{array}{l}-.013 \\
(0.64)\end{array}$ & $\begin{array}{r}.060 \\
(4.58)\end{array}$ & $\begin{array}{r}.106 \\
(7.42)\end{array}$ & $\begin{array}{r}.146 \\
(8.63)\end{array}$ & $\begin{array}{r}.149 \\
(6.83)\end{array}$ & $\begin{array}{r}.219 \\
(13.72)\end{array}$ & $\begin{array}{r}.081 \\
(5.94)\end{array}$ & $\begin{array}{r}.068 \\
(5.68)\end{array}$ & & & & \\
\hline 324 & 187 & $\begin{array}{l}-.644 \\
(6.29)\end{array}$ & $\begin{array}{l}-.108 \\
(6.26)\end{array}$ & $\begin{array}{r}.059 \\
(2.39)\end{array}$ & & & & & $\begin{array}{r}.224 \\
(16.51)\end{array}$ & $\begin{array}{r}.038 \\
(2.30)\end{array}$ & $\begin{array}{r}.024 \\
(1.52)\end{array}$ & $\begin{array}{r}.052 \\
(3.40)\end{array}$ & $\begin{array}{r}.049 \\
(3.32)\end{array}$ & & $\begin{array}{r}.007 \\
(0.41)\end{array}$ \\
\hline 331 & 128 & $\begin{array}{l}-.206 \\
(3.01)\end{array}$ & $\begin{array}{l}-.034 \\
(2.95)\end{array}$ & $\begin{array}{r}.015 \\
(0.99)\end{array}$ & $\begin{array}{r}.043 \\
(3.32)\end{array}$ & $\begin{array}{r}.062 \\
(4.48)\end{array}$ & $\begin{array}{r}.041 \\
(2.80)\end{array}$ & $\begin{array}{r}.125 \\
(6.56)\end{array}$ & $\begin{array}{r}.182 \\
(9.81)\end{array}$ & & & & & & \\
\hline 336 & 170 & $\begin{array}{l}-.660 \\
(5.56)\end{array}$ & $\begin{array}{l}-.112 \\
(5.54)\end{array}$ & $\begin{array}{l}-.014 \\
(0.62)\end{array}$ & & & & $\begin{array}{r}.093 \\
(4.82)\end{array}$ & $\begin{array}{r}.162 \\
(6.46)\end{array}$ & $\begin{array}{r}.085 \\
(4.77)\end{array}$ & $\begin{array}{r}.091 \\
(5.97)\end{array}$ & $\begin{array}{r}.076 \\
(5.76)\end{array}$ & $\begin{array}{r}.043 \\
(3.37)\end{array}$ & $\begin{array}{r}.026 \\
(2.02)\end{array}$ & \\
\hline 341 & 191 & $\begin{array}{l}-.352 \\
(3.58)\end{array}$ & $\begin{array}{l}-.063 \\
(3.60)\end{array}$ & $\begin{array}{l}-.058 \\
(2.30)\end{array}$ & & & & $\begin{array}{r}.046 \\
(5.02)\end{array}$ & $\begin{array}{r}.180 \\
(15.78)\end{array}$ & $\begin{array}{r}.067 \\
(6.17)\end{array}$ & $\begin{array}{r}.041 \\
(4.65)\end{array}$ & $\begin{array}{r}.038 \\
(4.43)\end{array}$ & $\begin{array}{r}.027 \\
(3.24)\end{array}$ & & \\
\hline
\end{tabular}

$t$-statistics are in parentheses.

a $\hat{\delta}$ is the coefficient estimate of $\log Y_{a t t-1}-\log Y_{a t-13}$ under the non-perfect expectational hypothesis.

b For industries 201, 271, 301, 311, 314, and 332 the two-stage Aitken estimates were the same as the ordinary least squares estimates presented in table 4.3 . 
TABLE 9.6

Parameter estimates for eq. (7.2)' using the two-stage Aitken estimator for each industry

\begin{tabular}{|c|c|c|c|c|c|c|c|c|c|}
\hline 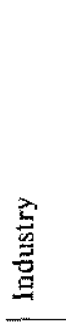 & $\begin{array}{l}\dot{8} \\
0 \\
\dot{0} \\
\dot{0} \\
\dot{2}\end{array}$ & 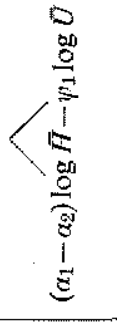 & $\hat{\alpha}_{1}$ & $\hat{x}_{2}$ & $\begin{array}{c}\frac{E}{8} \\
1 \\
\frac{8}{8} \\
\frac{8}{8}\end{array}$ & $\hat{\beta}_{4}$ & $\hat{\beta}_{3}$ & $\hat{\beta}_{2}$ & $\hat{\beta}_{1}$ \\
\hline 201 & 192 & $\begin{array}{r}1.982 \\
(4.33)\end{array}$ & $\begin{array}{l}-.110 \\
(2.31)\end{array}$ & $\begin{array}{l}-.434 \\
(7.15)\end{array}$ & $\begin{array}{l}-.030 \\
(1.26)\end{array}$ & & & $\begin{array}{r}.118 \\
(5.13)\end{array}$ & $\begin{array}{r}.050 \\
(2.16)\end{array}$ \\
\hline 207 & 136 & $\begin{array}{r}2.452 \\
(6.99)\end{array}$ & $\begin{array}{l}-.052 \\
(3.11)\end{array}$ & $\begin{array}{l}-.460 \\
(6.97)\end{array}$ & $\begin{array}{r}.033 \\
(1.50)\end{array}$ & & & & \\
\hline 211 & 136 & $\begin{array}{r}1.343 \\
(3.10)\end{array}$ & $\begin{array}{l}-.392 \\
(5.78)\end{array}$ & $\begin{array}{l}-.620 \\
(8.06)\end{array}$ & $\begin{array}{r}.023 \\
(0.41)\end{array}$ & & & & \\
\hline 212 & 136 & $\begin{array}{r}2.380 \\
(6.18)\end{array}$ & $\begin{array}{l}-.173 \\
(4.03)\end{array}$ & $\begin{array}{l}-.566 \\
(6.96)\end{array}$ & $\begin{array}{r}.098 \\
(2.41)\end{array}$ & & & & \\
\hline 231 & 136 & $\begin{array}{r}1.097 \\
(2.70)\end{array}$ & $\begin{array}{l}-.263 \\
(6.83)\end{array}$ & $\begin{array}{l}-.433 \\
(7.06)\end{array}$ & $\begin{array}{r}.022 \\
(0.68)\end{array}$ & & & & \\
\hline 232 & 136 & $\begin{array}{c}1.179 \\
(4.26)\end{array}$ & $\begin{array}{l}-.125 \\
(5.98)\end{array}$ & $\begin{array}{l}-.315 \\
(6.99)\end{array}$ & $\begin{array}{l}-.002 \\
(0.07)\end{array}$ & & & & \\
\hline 233 & 136 & $\begin{array}{r}3.682 \\
(7.95)\end{array}$ & $\begin{array}{l}-.078 \\
(2.66)\end{array}$ & $\begin{array}{l}-.702 \\
(8.30)\end{array}$ & $\begin{array}{l}-.055 \\
(1.17)\end{array}$ & & & & \\
\hline 242 & 154 & $\begin{array}{c}2.233 \\
(5.65)\end{array}$ & $\begin{array}{l}-.044 \\
(1.20)\end{array}$ & $\begin{array}{l}-.412 \\
(7.09)\end{array}$ & $\begin{array}{r}.007 \\
(0.25)\end{array}$ & $\begin{array}{r}.051 \\
(3.21)\end{array}$ & $\begin{array}{r}.030 \\
(1.73)\end{array}$ & $\begin{array}{r}.065 \\
(3.18)\end{array}$ & $\begin{array}{r}.021 \\
(0.80)\end{array}$ \\
\hline 271 & 166 & $\begin{array}{r}1.484 \\
(5.70)\end{array}$ & $\begin{array}{l}-.054 \\
(2.71)\end{array}$ & $\begin{array}{l}-.302 \\
(6.29)\end{array}$ & $\begin{array}{l}-.080 \\
(5.27)\end{array}$ & & & & \\
\hline 301 & 134 & $\begin{array}{r}1.383 \\
(4.42)\end{array}$ & $\begin{array}{l}-.176 \\
(5.82)\end{array}$ & $\begin{array}{l}-.392 \\
(6.38)\end{array}$ & $\begin{array}{r}.053 \\
(1.27)\end{array}$ & & & & \\
\hline 311 & 170 & $\begin{array}{c}1.628 \\
(5.68)\end{array}$ & $\begin{array}{l}-.116 \\
(4.79)\end{array}$ & $\begin{array}{l}-.380 \\
(7.26)\end{array}$ & $\begin{array}{r}.036 \\
(2.24)\end{array}$ & & & & \\
\hline 314 & 136 & $\begin{array}{c}1.016 \\
(2.30)\end{array}$ & $\begin{array}{l}-.171 \\
(2.92)\end{array}$ & $\begin{array}{l}-.342 \\
(5.06)\end{array}$ & $\begin{array}{c}.060 \\
(2.27)\end{array}$ & & & & \\
\hline 324 & 187 & $\begin{array}{r}3.273 \\
(8.59)\end{array}$ & $\begin{array}{l}-.032 \\
(5.68)\end{array}$ & $\begin{array}{l}-.571 \\
(8.65)\end{array}$ & $\begin{array}{l}-.034 \\
(2.62)\end{array}$ & & & & \\
\hline 331 & 128 & $\begin{array}{r}2.631 \\
(7.58)\end{array}$ & $\begin{array}{l}-.171 \\
(6.48)\end{array}$ & $\begin{array}{l}-.601 \\
(7.84)\end{array}$ & $\begin{array}{r}.109 \\
(4.50)\end{array}$ & & & & \\
\hline 332 & 170 & $\begin{array}{r}.955 \\
(4.71)\end{array}$ & $\begin{array}{l}-.108 \\
(6.76)\end{array}$ & $\begin{array}{l}-.258 \\
(6.62)\end{array}$ & $\begin{array}{r}.062 \\
(3.13)\end{array}$ & & & & \\
\hline 336 & 170 & $\begin{array}{c}2.053 \\
(6.60)\end{array}$ & $\begin{array}{l}-.044 \\
(3.27)\end{array}$ & $\begin{array}{l}-.375 \\
(6.90)\end{array}$ & $\begin{array}{r}.048 \\
(2.82)\end{array}$ & & & & \\
\hline 341 & 191 & $\begin{array}{r}3.426 \\
(10.22)\end{array}$ & $\begin{array}{l}-.067 \\
(6.22)\end{array}$ & $\begin{array}{r}-.627 \\
(10.19)\end{array}$ & $\begin{array}{r}.087 \\
(3.72)\end{array}$ & & & & \\
\hline
\end{tabular}

$t$-statistics are in parentheses.

a $\hat{\delta}$ is the coefficient estimate of $\log Y_{d t-1}-\log Y_{d t-1 s}$ under the non-perfect expectational hypothesis. 


\begin{tabular}{|c|c|c|c|c|c|c|c|c|}
\hline$\hat{\gamma}_{0}$ & $\hat{\gamma}_{1}$ & $\hat{\gamma}_{2}$ & $\hat{\gamma}^{3}$ & $\hat{\gamma}_{4}$ & $\hat{7}$ & $\hat{\gamma}_{6}$ & ${ }^{a} \vec{\delta}$ & $\hat{\psi}_{1}$ \\
\hline .253 & .068 & .070 & .057 & .146 & .018 & .072 & -.000 & -.0045 \\
\hline$(7.87)$ & $(2.32)$ & $(2.44)$ & $(2.43)$ & $(6.98)$ & $(0.88)$ & $(3.00)$ & $(0.01)$ & $(1.20)$ \\
\hline .094 & .023 & .010 & .039 & & & & .007 & -.0022 \\
\hline$(10.37)$ & $(1.47)$ & $(0.97)$ & $(7.44)$ & & & & $(0.54)$ & $(0.64)$ \\
\hline .501 & & & & & & & & .0082 \\
\hline$(8.91)$ & & & & & & & & $(0.82)$ \\
\hline .231 & & & & & & & & -.0157 \\
\hline$(7.92)$ & & & & & & & & $(2.19)$ \\
\hline .183 & .045 & .047 & .038 & & & & -.004 & -.0128 \\
\hline$(5.58)$ & $(2.05)$ & $(2.90)$ & $(3.68)$ & & & & $(0.19)$ & $(2.04)$ \\
\hline .126 & .094 & .080 & .047 & & & & & -.0102 \\
\hline$(7.51)$ & $(5.32)$ & $(6,20)$ & $(4.75)$ & & & & & $(2.47)$ \\
\hline .095 & & & & & & & & -.0074 \\
\hline$(4.55)$ & & & & & & & & $(0.90)$ \\
\hline .123 & & & & & & & & -.0072 \\
\hline$(6.33)$ & & & & & & & & $(2.53)$ \\
\hline .080 & .055 & .023 & .045 & .016 & .044 & & & -.0006 \\
\hline$(4.44)$ & $(3.01)$ & $(1,44)$ & $(3.32)$ & (1.37) & (3.94) & & & $(0.43)$ \\
\hline .151 & .068 & .033 & .067 & & & & & -.0193 \\
\hline$(4.55)$ & $(2.30)$ & $(1.19)$ & $(2.58)$ & & & & & $(2.35)$ \\
\hline .120 & .043 & .061 & .032 & .020 & .018 & & & -.0096 \\
\hline$(5.85)$ & $(2.82)$ & $(4.68)$ & $(2.68)$ & $(1.88)$ & $(1.91)$ & & & $(3.51)$ \\
\hline .410 & .143 & .156 & .099 & & & & .127 & .0010 \\
\hline (11.39) & $(4,69)$ & $(6.77)$ & $(5.00)$ & & & & $(4.48)$ & $(0.22)$ \\
\hline .042 & & & & & & & & -.0057 \\
\hline$(7.55)$ & & & & & & & & $(3.51)$ \\
\hline .191 & & & & & & & & -.0153 \\
\hline$(9.05)$ & & & & & & & & $(3.82)$ \\
\hline .125 & .032 & .045 & .040 & .023 & & & & -.0124 \\
\hline$(7.26)$ & $(2.71)$ & $(4.35)$ & $(4.18)$ & $(2,46)$ & & & & $(3.61)$ \\
\hline .079 & .034 & .030 & .035 & & & & & -.0161 \\
\hline$(5.36)$ & $(3.07)$ & $(3.03)$ & $(4.32)$ & & & & & $(5.30)$ \\
\hline .094 & .022 & & & & & & & -.0083 \\
\hline$(13.01)$ & $(2.98)$ & & & & & & & $(3.28)$ \\
\hline
\end{tabular}


variable and the $\log U_{2 w t}$ variable which the workers equation (3.9)' does not, and sometimes the workers equation includes expected future output change variables which the hours equation does not. In general, the number of different independent variables in the two equations is not large. With respect to the correlation of the residuals in the two equations, the correlation coefficient for each industry is presented in table 9.4. Notice that all of the coefficients in the table are positive, as expected, with a range of .07 to .62 .

In tables 9.5 and 9.6 the results of estimating eqs. (3.9)' and (7.2) using the two-stage Aitken estimator are presented for each industry. The same period of estimation and same expectational variables were used for these estimates as were used for the ordinary least squares estimates presented in tables 4.3 and 7.2 above. In table 9.5 the estimates for eq. (3.9) $)^{\prime}$ are presented and in table 9.6 the estimates for eq. (7.2)' are presented. For industries $201,271,301,311,314$, and 332 , eq. (3.9) ${ }^{\prime}$ included no independent variables which eq. (7.2) did not also include, and so for these industries the two-stage Aitken estimates for eq. (3.9)' were the same as the ordinary least squares estimates. In table 9.5 the Aitken estimates are not presented for these six industries since the estimates are the same as those presented in table 4.3.

Comparing the results in tables 9.5 and 9.6 with those in tables 4.3 and 7.2 , it is seen that the coefficient estimates are only slightly changed and that very little efficiency has been gained. The estimates in table 9.6 for the hours equation $(7.2)^{\prime}$ have been changed more than the estimates in table 9.5 for the workers equation $(3.9)^{\prime}$, but even in table 9.6 the results are only slightly changed from the results in table 7.2. It is a property of the two-stage Aitken estimator that the estimates of the standard errors of the coefficient estimates are never greater than the ordinary least squares estimates of the standard errors. Some of the $t$-statistics (ratios of the coefficient estimates to their standard errors) in tables 9.5 and 9.6 are less than the corresponding statistics in tables 4.3 and 7.2, however, and in these cases the two-stage Aitken coeffcient estimates decreased by a larger percentage than did the estimates of the standard errors. From the over-all results it is quite obvious that very little efficiency has been gained using the two-stage procedure.

The two-stage Aitken estimates can also be used to estimate equations of different industries simultaneously. It may be, for example, that a random disturbance for a given month which affects the residual of eq. (3.9) or $(7.2)^{\prime}$ in a specific way for one industry will also affect the residual of eq. $(3.9)^{\prime}$ or $(7.2)^{\prime}$ for another industry in a similar way. Economy-wide disturbances, for example, may affect different industries in a similar manner. 
For the work here not all of the equations of the seventeen industries could be estimated simultaneously because different periods of estimation were used for different industries, but three sets of industry equations were estimated using the two-stage Aitken estimator. In the first set eqs. (3.9)' and (7.2)' for the Tobacco industries 211 and 212 (giving a total of four equations) were estimated simultaneously; in the second set eqs. $(3.9)^{\prime}$ and $(7.2)^{\prime}$ for the Apparel industries 231, 232, and 233 (giving a total of six equations) were estimated simultaneously, and in the third set eqs. (3.9)' and (7.2)' for the Primary Metals industries 332 and 336 (giving a total of four equations) were estimated simultaneously. The gain in efficiency should be greater for these estimates than for the ones presented in tables 9.5 and 9.6 since the independent variables in the different industry equations are different except for the time-trend and unemployment-rate variable.

\section{TABLE 9.7}

Correlation between the residuals of eq. (3.9)' or eq. $(7.2)^{\prime}$ for one industry and the residuals of eq. (3.9)' or eq. (7.2)' for another industry

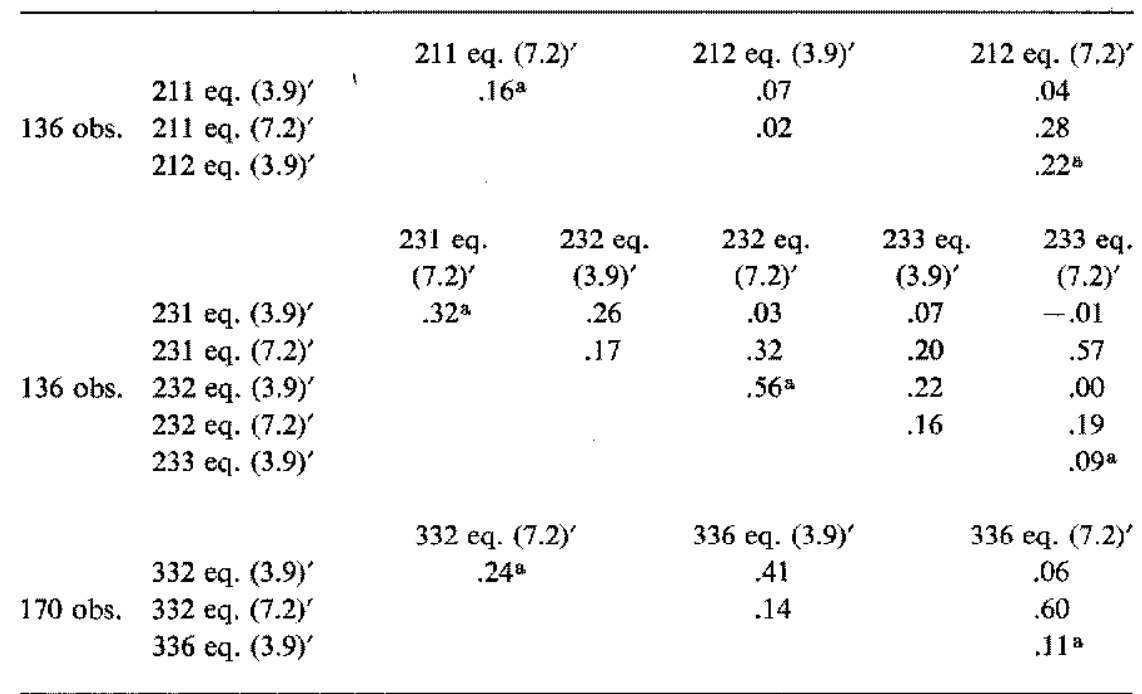

a Same as that given in table 9.4 .

With respect to the correlation of the residuals in the different equations, the correlation coefficients are presented in table 9.7. All but one of the coefficients are positive, as expected. For the Tobacco industries the corre- 
Parameter estimates for eq. $(3.9)^{\prime}$ using the two-stage Aitken estimator for three sets of industry groups

\begin{tabular}{|c|c|c|c|c|c|c|c|c|c|c|c|c|c|}
\hline 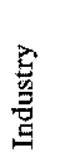 & $\begin{array}{l}\dot{0} \\
\dot{0} \\
\dot{0} \\
\dot{0} \\
\dot{Z}\end{array}$ & $\alpha_{1} \log \bar{H}$ & $\hat{\alpha}_{1}$ & $\widehat{1000 \widehat{\alpha_{1} \mu}}$ & $\hat{\beta}_{2}$ & $\hat{\beta}_{1}$ & $\hat{\gamma}_{0}$ & $\hat{\gamma}_{1}$ & $\hat{\gamma}_{2}$ & $\hat{\gamma}_{3}$ & $\hat{\gamma}_{4}$ & $\hat{f}_{5}$ & ${ }^{\mathrm{a}} \hat{\delta}$ \\
\hline 211 & 136 & $\begin{array}{l}-.777 \\
(5.85)\end{array}$ & $\begin{array}{l}-.133 \\
(5.87)\end{array}$ & $\begin{array}{l}-.051 \\
(3.22)\end{array}$ & & & $\begin{array}{r}.089 \\
(4.60)\end{array}$ & $\begin{array}{c}.030 \\
(2.37)\end{array}$ & $\begin{array}{r}.043 \\
(5.00)\end{array}$ & & & & $\begin{array}{l}-.005 \\
(0.34)\end{array}$ \\
\hline 212 & 136 & $\begin{array}{l}-.635 \\
(4.77)\end{array}$ & $\begin{array}{c}-.108 \\
(4.75)\end{array}$ & $\begin{array}{l}-.038 \\
(1.52)\end{array}$ & & $\begin{array}{r}.054 \\
(4.72)\end{array}$ & $\begin{array}{r}.155 \\
(7.80)\end{array}$ & & & & & & \\
\hline 231 & 136 & $\begin{array}{c}-.999 \\
(4.53)\end{array}$ & $\begin{array}{l}-.171 \\
(4.43)\end{array}$ & $\begin{array}{r}.081 \\
(2.78)\end{array}$ & $\begin{array}{r}.023 \\
(2.49)\end{array}$ & $\begin{array}{r}.052 \\
(3.48)\end{array}$ & $\begin{array}{r}.124 \\
(4.07)\end{array}$ & $\begin{array}{r}.021 \\
(1.00)\end{array}$ & $\begin{array}{r}.055 \\
(3.65)\end{array}$ & $\begin{array}{r}.032 \\
(3.30)\end{array}$ & & & $\begin{array}{l}-.008 \\
(0.48)\end{array}$ \\
\hline 232 & 136 & $\begin{array}{l}-.529 \\
(6.15)\end{array}$ & $\begin{array}{l}-.094 \\
(6.22)\end{array}$ & $\begin{array}{c}-.060 \\
(3.34)\end{array}$ & & $\begin{array}{r}.021 \\
(3.59)\end{array}$ & $\begin{array}{r}.113 \\
(9.64)\end{array}$ & $\begin{array}{r}.076 \\
(6.09)\end{array}$ & $\begin{array}{r}.047 \\
(5.11)\end{array}$ & $\begin{array}{r}.012 \\
(1.76)\end{array}$ & & & \\
\hline 233 & 136 & $\begin{array}{r}.078 \\
(0.47)\end{array}$ & $\begin{array}{r}.018 \\
(0.60)\end{array}$ & $\begin{array}{r}.064 \\
(1.23)\end{array}$ & & $\begin{array}{r}.137 \\
(6,68)\end{array}$ & $\begin{array}{r}.144 \\
(6.08)\end{array}$ & & , & & & & \\
\hline 332 & 170 & $\begin{array}{l}-.666 \\
(8.28)\end{array}$ & $\begin{array}{l}-.112 \\
(8.25)\end{array}$ & $\begin{array}{r}.044 \\
(1.98)\end{array}$ & & & $\begin{array}{r}.158 \\
(7.92)\end{array}$ & $\begin{array}{r}.050 \\
(3.61)\end{array}$ & $\begin{array}{r}.059 \\
(4.81)\end{array}$ & $\begin{array}{r}.041 \\
(3.54)\end{array}$ & $\begin{array}{r}.033 \\
(2.92)\end{array}$ & & \\
\hline 336 & 170 & $\begin{array}{l}-.597 \\
(5.29)\end{array}$ & $\begin{array}{l}-.102 \\
(5.26)\end{array}$ & $\begin{array}{l}-.011 \\
(0.46)\end{array}$ & & $\begin{array}{r}.085 \\
(4.80)\end{array}$ & $\begin{array}{r}.146 \\
(6.13)\end{array}$ & $\begin{array}{c}.084 \\
(4.86)\end{array}$ & $\begin{array}{r}.089 \\
(6,07)\end{array}$ & $\begin{array}{r}.074 \\
(5.82)\end{array}$ & $\begin{array}{r}.045 \\
(3.63)\end{array}$ & $\begin{array}{r}.020 \\
(1.75)\end{array}$ & \\
\hline
\end{tabular}


Parameter estimates for eq. (7.2)' using the two-stage Aitken estimator for three sets of industry groups

\begin{tabular}{|c|c|c|c|c|c|c|c|c|c|c|c|c|}
\hline $\begin{array}{l}\text { 兽 } \\
\text { 总 }\end{array}$ & $\begin{array}{l}\dot{0} \\
\text { ப் } \\
\dot{0} \\
\dot{z}\end{array}$ & 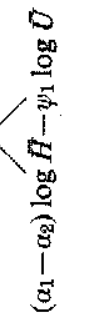 & $\hat{Q}_{1}$ & $\hat{\alpha}_{2}$ & 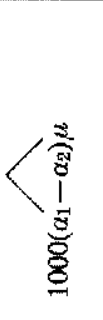 & $\hat{\gamma}_{0}$ & $\hat{\gamma}_{1}$ & $\hat{\gamma}_{2}$ & $\hat{\gamma}_{3}$ & $\hat{\gamma}_{4}$ & $a \hat{\delta}$ & $\hat{\psi}_{1}$ \\
\hline 211 & 136 & $\begin{array}{r}1.612 \\
(3.86)\end{array}$ & $\begin{array}{l}-.354 \\
(5.43)\end{array}$ & $\begin{array}{l}-.627 \\
(8.45)\end{array}$ & $\begin{array}{c}.034 \\
(0.63)\end{array}$ & $\begin{array}{r}.489 \\
(9.04)\end{array}$ & & & & & & $\begin{array}{c}.0069 \\
(0.68)\end{array}$ \\
\hline 212 & 136 & $\begin{array}{r}2.621 \\
(7.06)\end{array}$ & $\begin{array}{l}-.159 \\
(3.84)\end{array}$ & $\begin{array}{l}-.591 \\
(7.54)\end{array}$ & $\begin{array}{r}.113 \\
(2.81)\end{array}$ & $\begin{array}{r}.243 \\
(8.61)\end{array}$ & & & & & & $\begin{array}{l}-.0177 \\
(2.48)\end{array}$ \\
\hline 231 & 136 & $\begin{array}{r}.909 \\
(2.84)\end{array}$ & $\begin{array}{l}-.219 \\
(7.14)\end{array}$ & $\begin{array}{l}-.362 \\
(7.59)\end{array}$ & $\begin{array}{r}.030 \\
(0.96)\end{array}$ & $\begin{array}{r}.127 \\
(4.83)\end{array}$ & $\begin{array}{r}.030 \\
(1.70)\end{array}$ & $\begin{array}{r}.036 \\
(2.72)\end{array}$ & $\begin{array}{r}.027 \\
(3.19)\end{array}$ & & $\begin{array}{l}-.013 \\
(0.90)\end{array}$ & $\begin{array}{l}-.0083 \\
(1.40)\end{array}$ \\
\hline 232 & 136 & $\begin{array}{r}1.255 \\
(4.79)\end{array}$ & $\begin{array}{l}-.111 \\
(5.60)\end{array}$ & $\begin{array}{l}-.314 \\
(7.40)\end{array}$ & $\begin{array}{r}.010 \\
(0.38)\end{array}$ & $\begin{array}{r}.106 \\
(6.65)\end{array}$ & $\begin{array}{r}.076 \\
(4.57)\end{array}$ & $\begin{array}{r}.062 \\
(5.05)\end{array}$ & $\begin{array}{r}.038 \\
(4.01)\end{array}$ & & & $\begin{array}{l}-.0097 \\
(2.39)\end{array}$ \\
\hline 233 & 136 & $\begin{array}{r}3.291 \\
(8.42)\end{array}$ & $\begin{array}{l}-.068 \\
(2.85)\end{array}$ & $\begin{array}{l}-.627 \\
(8.87)\end{array}$ & $\begin{array}{l}-.043 \\
(0.97)\end{array}$ & $\begin{array}{r}.079 \\
(4.52)\end{array}$ & & 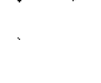 & & & & $\begin{array}{l}-.0052 \\
(0.65)\end{array}$ \\
\hline 332 & 170 & $\begin{array}{r}.977 \\
(5.53)\end{array}$ & $\begin{array}{l}-.095 \\
(6.99)\end{array}$ & $\begin{array}{l}-.249 \\
(7.58)\end{array}$ & $\begin{array}{r}.059 \\
(3.07)\end{array}$ & $\begin{array}{r}.116 \\
(7.58)\end{array}$ & $\begin{array}{r}.025 \\
(2.28)\end{array}$ & $\begin{array}{r}.038 \\
(4.03)\end{array}$ & $\begin{array}{r}.037 \\
(4.14)\end{array}$ & $\begin{array}{r}.020 \\
(2.67)\end{array}$ & & $\begin{array}{l}-.0120 \\
(3.76)\end{array}$ \\
\hline 336 & 170 & $\begin{array}{r}1.869 \\
(7.02)\end{array}$ & $\begin{array}{l}-.024 \\
(2.04)\end{array}$ & $\begin{array}{l}-.326 \\
(7.17)\end{array}$ & $\begin{array}{r}.045 \\
(2.72)\end{array}$ & $\begin{array}{r}.076 \\
(5.83)\end{array}$ & $\begin{array}{r}.027 \\
(2.65)\end{array}$ & $\begin{array}{r}.021 \\
(2.36)\end{array}$ & $\begin{array}{r}.029 \\
(3.94)\end{array}$ & & & $\begin{array}{l}-.0139 \\
(5.06)\end{array}$ \\
\hline
\end{tabular}

$t$-statistics are in parentheses.

a $\hat{\delta}$ is the coefficient estimate of $\log Y_{d t-1}-\log Y_{d i t-13}$ under the non-perfect expectational hypothesis. 
lation between the residuals of eq. (3.9)' for 211 and the residuals of eq. (3.9)' for 212 is .07, and for eq. (7.2) the correlation is .28. For the Apparel industries the correlation is $.26, .07$, and .22 respectively between the residuals of eq. (3.9)' for 231 and 232, 231 and 233, and 232 and 233; and the correlation is $.32, .57$, and .19 respectively between the residuals of eq. (7.2)' for 231 and 232, 231 and 233, and 232 and 233. For the Primary Metals industries the correlation between the residuals of eq. (3.9)' for 332 and 336 is .41 , and for eq. (7.2) the correlation is .60. It appears from table 9.7 that there is more correlation among the residuals in the Primary Metals industries than in the other two industry groups.

In tables 9.8 and 9.9 the results of estimating the three sets of industry equations using the two-stage Aitken method are presented: in table 9.8 the results for eq. (3.9)' and in table 9.9 the results for eq. (7.2)'. These results are directly comparable with the ordinary least squares results in tables 4.3 and 7.2. Comparing the results in tables 9.8 and 9.9 with those in tables 4.3 and 7.2 , three conclusions seem to emerge. The estimates are changed more here than they were in tables 9.5 and 9.6, which is as expected, although the extent of the change for either the coefficient estimates or the standard errors is not very great; the estimates for the hours equation have been changed more than the estimates for the workers equation; and there is a tendency, especially in the Apparel and Primary Metals industries, for the size of the coefficient estimates to decrease in absolute value. From the over-all results the gain in efficiency does not appear to have been very large using the two-stage Aitken estimator, and none of the conclusions reached in the previous chapters appears to need changing from the results achieved here.

\subsection{A comparison of the short-run demand for workers across industries}

So far very few across industry comparisons have been made from the results presented above. The model of the short-run demand for workers developed in ch. 3 was estimated for seventeen three-digit manufacturing industries, and the results were consistently good for all of the industries. The size of the parameter estimates do differ from industry to industry, however, and the purpose of this section is to examine whether any of these differences across industries can be explained. Attention will be concentrated on the estimate of the coefficient $\gamma_{0}$ of $\log Y_{d t}-\log Y_{d t-1}$ presented in table 4.3 for each industry. This coefficient is a measure of how strongly firms react, other things being equal, to current changes in output: the 
larger $\gamma_{0}$ is the larger is the percentage change in the number of workers employed corresponding to a given percentage change in output. Three hypotheses will be tested regarding the size of $\gamma_{0}$ for an industry. The first hypothesis is that the size of $\gamma_{0}$ for an industry is related to the amount of specific training required in the industry; the second hypothesis is that the size of $\gamma_{0}$ is related to the degree of unionization in the industry; and the third hypothesis is that the size of $\gamma_{0}$ is related to the average wage level in the industry.

With respect to the first hypothesis that the size of $\gamma_{0}$ for an industry is related to the amount of specific training required in the industry, one would expect the size of $\gamma_{0}$ to be inversely related to the amount of specific training required. If the amount of specific training is high, for example, one would expect the short-run employment reaction to be smaller than otherwise since firms will presumably be more reluctant to lay off workers for fear of not being able to hire them back when they are needed and of having to train new workers. From the work of EckHAus (1964) data are available for 1950 on specific industry training requirements in number of years required for most of the industries considered in this study. ${ }^{1}$ In order to use these data the Apparel industries 231, 232, and 233 had to be grouped together, as did the Tobacco industries 211 and 212 . Some of the other data on training requirements were for industries slightly more aggregated than the threedigit industries considered in this study, but these data were used as proxies for the unavailable three-digit industry data. For the industries which were grouped together, a weighted average of the estimates of $\gamma_{0}$ was taken to represent the grouped industry reaction, the weights being the number of production workers employed in each industry in 1958 as a percent of the total number of production workers employed in the group in 1958. There were a total of fourteen observations. The data for these fourteen industries are presented in table 9.10 .

The Kendall Tau rank correlation coefficient was calculated using the fourteen observations presented in table 9.10. The coefficient was -.30 , which is of the expected negative sign (the larger the amount of specific training required the smaller the employment reaction to current output changes) and which is significant at the ten-percent confidence level but not at the five-percent level. There is thus some slight indication from this

1. HAMERmesh (1967) has also used these data and the data on unionization described below in a comparison of industry behavior. 
TABLE 9.10

Estimates of $\gamma_{0}$ and of the amount of specific training required for fourteen industry groups

Estimate or weighted estimate Specific training required

Industry or industry group of $\%$ (from table 4.3) in years

\begin{tabular}{lrr}
\hline 201 & .265 & .73 \\
207 & .262 & .70 \\
211 and 212 & .118 & .63 \\
231,232 and 233 & .141 & .64 \\
242 & .218 & .78 \\
271 & .120 & 2.79 \\
301 & .055 & .97 \\
311 & .190 & .79 \\
314 & .322 & .55 \\
324 & .224 & 1.05 \\
331 & .184 & 1.23 \\
332 & .172 & 1.15 \\
336 & .164 & 1.24 \\
341 & .182 & 1.26 \\
\hline
\end{tabular}

rather small sample that those industries which have higher specific training requirements have lower employment reactions.

With respect to the second hypothesis that the size of $\gamma_{0}$ for an industry is related to the degree of unionization in the industry, one would expect the size of $\gamma_{0}$ to be inversely related to the degree of unionization. Highly unionized industries may have less freedom of action regarding short-run employment decisions, and they may thus react less to current output changes than industries which have less union pressure. From a study by DouTy (1960) data are available at the two-digit industry level for 1958 on the percent of workers employed in establishments in which the majority of workers are unionized. In order to use these data, the three-digit industries considered in this study had to be grouped into their respective two-digit industries by weighting the estimates of $\gamma_{0}$ in the manner described above. This meant grouping the Food industries 201 and 207 together, the Tobacco industries 211 and 212 together, the Apparel industries 231, 232, and 233 together, the Leather industries 311 and 314 together, and the Primary Metals industries 331,332 , and 336 together. This gave a total of ten groups for which weighted estimates of $\gamma_{0}$ and figures on the percent of workers in 
TABLE 9.11

Estimates of $\gamma_{0}$ and of the percent of workers employed in establishments in which the majority of workers are unionized for ten industry groups

\begin{tabular}{lll}
\hline Industry or industry group & $\begin{array}{c}\text { Estimate or weighted estimate } \\
\text { of } \gamma_{0} \text { (from table 4.3) }\end{array}$ & Percent \\
\hline 201 and 207 & .264 & 68.1 \\
211 and 212 & .118 & 62.6 \\
231,232 and 233 & .141 & 59.7 \\
242 & .218 & 43.8 \\
271 & .120 & 65.3 \\
301 & .055 & 80.6 \\
311 and 314 & .304 & 49.3 \\
324 & .224 & 77.9 \\
331,332 and 336 & .180 & 88.6 \\
341 & .182 & 70.6 \\
\hline
\end{tabular}

establishments in which the majority of workers are unionized were available. The data for these ten industry groups are presented in table 9.11.

The Kendall Tau rank correlation coefficient was calculated using the ten observations presented in table 9.11 . The coefficient was -.20 , which is of the right sign (the larger the degree of union pressure the smaller the employment reaction to current output changes) but which is not significant at even the ten-percent level. The hypothesis that the degree of unionization and the size of the employment reaction are inversely correlated, therefore, is not confirmed from the test. The test is based on only a small number of observations, however, and any conclusion must remain tentative.

With respect to the third hypothesis that the size of $\gamma_{0}$ for an industry is related to the average wage level in the industry, the expectation as to whether the size of $\gamma_{0}$ should be positively or negatively related to the average wage level is not unambiguous. On the one hand, a high wage level means that it is expensive to hold excess labor, and this may lead to a larger reaction to current output changes. On the other hand, a high wage level means that the workers are likely to be more skilled and perhaps more specifically trained, and this may lead to a smaller reaction to current output change since firms may be reluctant to lay off these workers for fear of not being able to get them back when they are needed again.

Average yearly wage levels are available for the seventeen three-digit 
industries considered in this study from the US DEPARTMENT OF COMMERCE (1967b), and these data were collected for the year 1958. There were thus a total of seventeen industries for which observations on the size of $\gamma_{0}$ and on the average wage level were available. These observations are presented in table 9.12 .

TABLE 9.12

Estimates of $\gamma_{0}$ and of the average wage level for the seventeen industries

\begin{tabular}{lll}
\hline Industry & $\begin{array}{c}\text { Estimate of } \gamma_{0} \\
\text { (from table 4.3) }\end{array}$ & $\begin{array}{c}\text { Average wage level } \\
\text { for 1958 }\end{array}$ \\
\hline 201 & .265 & 2.18 \\
207 & .262 & 1.68 \\
211 & .086 & 2.08 \\
212 & .154 & 1.40 \\
231 & .127 & 1.74 \\
232 & .118 & 1.29 \\
233 & .164 & 1.61 \\
242 & .218 & 1.59 \\
271 & .120 & 2.80 \\
301 & .055 & 2.92 \\
311 & .190 & 2.10 \\
314 & .322 & 1.56 \\
324 & .224 & 2.45 \\
331 & .184 & 3.10 \\
332 & .172 & 2.41 \\
336 & .164 & 2.39 \\
341 & .182 & 2.65 \\
& & \\
\hline
\end{tabular}

The Kendall Tau rank correlation coefficient was calculated using the seventeen observations presented in table 9.12. The coefficient was -.07 , the sign of which implies that a high wage level corresponds to a smaller employment reaction. The coefficient is not significant at even the tenpercent confidence level, however, and there seems to be little relationship between the average wage level in an industry and the employment reaction in the industry.

In summary, then, the size of an industry's employment reaction to current output changes appears to be inversely related to the amount of 
specific training required in the industry, but does not appear to be related to the degree of union pressure nor the average wage level in the industry. Since the results were based on very small samples, however, and the tests using simple rank correlations were rather crude, the conclusions reached here must remain very tentative. 


\section{THE SHORT-RUN DEMAND FOR NON-PRODUCTION WORKERS}

\subsection{Introduction}

This study has been chiefly concerned with explaining short-run fluctuations in the number of production workers employed and the number of hours paid-for per production worker. It is the purpose of this chapter to examine briefly the short-run fluctuations in the number of non-production workers employed to see whether the short-run demand for non-production workers is influenced by any of the same factors which influence the short-run demand for production workers. An equation similar to (3.9) is derived and estimated, and the results are compared with those in table 4.3 for production workers.

KUH (1965b), DHRYmes (1966), and others have observed that nonproduction workers are probably more like a fixed factor in the short run than are production workers, and this seems to be confirmed for the seventeen industries considered in this study from an examination of time series plots of the number of non-production workers employed. For almost all of the industries the short-run fluctuations in the number of non-production workers employed were quite small; most of the plots were characterized by relatively smooth upward trends. These results suggest that non-production workers are indeed more like a fixed factor in the short run, and the purpose of this chapter can be looked upon as trying to determine whether the small short-run fluctuations in the number of non-production workers employed are subject to any systematic tendencies at all.

\subsection{The model}

The model developed and tested here for non-production workers is essentially the same as the model developed in ch. 3 for production workers. The change in the number of non-production workers employed is taken to be a function of the amount of excess (non-production) labor on hand, past changes in output, and expected future changes in output. Let $N_{2 w t}$ denote the number of non-production workers employed during the second week of month $t$ and $N_{2 w t}^{d}$ the desired number employed for that week. Then the 
basic equation determining the short-run demand for non-production workers is taken to be

$$
\begin{aligned}
\log N_{2 w t}-\log N_{2 w t-1} & =\alpha_{1}\left(\log N_{2 w t-1}-\log N_{2 w t-1}^{d}\right) \\
& +\sum_{i=1}^{m} \beta_{i}\left(\log Y_{2 w t-i}-\log Y_{2 w t-i-1}\right) \\
& +\gamma_{0}\left(\log Y_{2 w t}^{e}-\log Y_{2 w t-1}\right) \\
& +\sum_{i=1}^{n} \gamma_{i}\left(\log Y_{2 w t+i}^{e}-\log Y_{2 w t+i-1}^{e}\right) .
\end{aligned}
$$

Eq. (10.1) is the non-production workers analogue to eq. (3.9). As before, the past change in output variables are added to help depict the reaction of firms to the amount of excess labor on hand. $\log N_{2 w t-1}-\log N_{2 w t-1}^{d}$ is taken to be the measure of the amount of excess non-production labor on hand during the second week of month $t-1$.

Eq. (10.1) cannot be estimated the way it is since many of the variables are not directly observed. As before, the (observed) average daily rate of output for the month, $Y_{d}$, can be used as a proxy for the (unobserved) amount of output produced during the second week, $Y_{2 w}$, and the equation can be estimated using one of the expectational hypotheses discussed in ch. 3 . This still leaves $N_{2 w t-1}^{d}$ unobserved in the equation, however, and some approximation to it must be found. $N_{2 w-1}^{d}$ was constructed in a manner similar to that used for the construction of $M_{2 w t-1}^{d}$ in ch. 3, except that one additional assumption had to be made due to lack of data on the number of hours paid-for per non-production worker.

Let $H_{2 w t}^{N}$ denote the average number of hours worked per non-production worker during the second week of month $t$. The short-run production function postulated in eq. (3.5) is now expanded to include non-production workers, and the assumptions of constant returns to scale and no substitution possibilities among the number of non-production workers, the number of production workers, and the number of machines are made. The production function is thus postulated to be

$$
Y_{2 w t}=\min \left\{\alpha_{2 w t} M_{2 w t} H_{2 w t}, \beta_{2 w t} K_{2 w t} H_{2 w t}^{K}, \gamma_{2 w t} N_{2 w t} H_{2 w t}^{N}\right\} .
$$

$N_{2 w t} H_{2 w t}^{N}$ in eq. (10.2) is the total number of non-production worker hours used in the production of $Y_{2 w t}$. The $2 w t$ subscripts on the parameters $\alpha$, $\beta$, and $\gamma$ indicate that these parameters may be a function of time. Indeed, $\alpha_{2 w t}$ was assumed in ch. 3 to move smoothly through time from peak to 
peak of the output per paid-for man-hour series. In the production function (10.2) non-production workers are treated in a manner exactly analogous to that for production workers. It is assumed that for any one period of time a given number of non-production worker hours is required to produce the output of the period. The production process is thus rather broadly defined to include managerial, clerical, sales, and other "non-production" activities.

The assumption that non-production worker hours enters as an input in the production function in an analogous manner as production worker hours may not be realistic. It may be, for example, that in the short run an increase in output requires little or no increase in the number of nonproduction worker hours and that a decrease in output does not reduce the number of non-production worker hours required. In other words, in the short run the number of managerial and clerical hours required in the production process may not be directly proportional to the amount of output produced. Remember, however, that it is non-production worker hours which is under discussion and not non-production workers alone. A secretary sitting at her desk doing nothing is not considered to be working unless, for example, she is also a receptionist and must be at her desk at all times. If she is not also a receptionist, then when work is slow (due, say, to less output being produced) and she has nothing to do during part of the day or week, her work could presumably be scheduled so that she needs to be at work only part of the day or week. Only her actually working (nonidle) hours are counted in $N_{2 w t} H_{2 w t}^{N}$ in (10.2). The assumption that nonproduction worker hours enters as an input in the production function in the manner specified in (10.2) thus requires that there be no receptionist type workers whose hourly work is not directly related to the amount of output produced. To the extent that there are a lot of these types of workers, the assumption that $N_{2 w t} H_{2 w t}^{N}$ enters the production function as specified in (10.2) is unrealistic, and the construction of the excess (non-production) labor variable below, which is based on (10.2), is inaccurate.

Data on $N_{2 w t}$ are available, but unlike for production workers, data are not available on the average number of hours paid-for per non-production worker. Consequently, output per paid-for (non-production) man hour could not be plotted and interpolated as was done for production workers. For present purpose something slightly different was thus done. Output per non-production worker employed, $Y_{d t} / N_{2 w_{r}}$, was plotted for each industry for the 1947-1965 period. (Note that $Y_{d t}$ was used as the output variable as a proxy for $Y_{2 w t}$. At each of the peaks of this series for each industry 
it is assumed that the number of hours worked per non-production worker, $H_{2 w t}^{N}$, is equal to the same constant, denoted as $\bar{H}^{N}$. Remember that for production workers it was assumed that at the peaks of the output per paidfor man-hour series the number of hours worked per production worker equals the number of hours paid-for per production worker, whereas here the rather stronger assumption is made that at each of the peaks of the output per non-production worker series the number of hours worked per nonproduction worker is the same. ${ }^{1}$

Using eq. (10.2) and the above assumption, an estimate of $\gamma_{2 w r} \bar{H}^{N}$ is available at each of the peaks:

$$
\gamma_{2 w t} \widetilde{H}^{N}=Y_{d t} / N_{2 w t}
$$

These values of $\gamma_{2 w t} \bar{H}^{N}$ were then interpolated from peak to next higher or lower ${ }^{2}$ peak in a manner similar to that done for $\alpha_{2 w t}$ in ch. 3. From these interpolations estimates of $\gamma_{2 w t} \bar{H}^{N}$ are then available for each month of the nineteen-year period.

Let $H S_{2 w t-1}^{N}$ denote the standard number of hours of work per nonproduction worker for the second week of month $t-1$. Analogous to eq. (3.7) for production workers, $N_{2 w t-1}^{d}$ is assumed to be

$$
N_{2 w t-1}^{d}=N_{2 w t-1} H_{2 w t-1}^{N} / H S_{2 w t-1}^{N}
$$

and analogous to eq. (3.11) for production workers, $H S_{2 w t-1}^{N}$ is assumed to be a constant or a slowly trending variable:

$$
H S_{2 w t-1}^{N}=\bar{H} e^{\mu t}
$$

Eq. (10.4) states that the desired number of non-production workers employed for the second week of month $t-1$ is equal to the number of non-production worker hours required in the production process for that week divided by the standard number of hours of work per non-production worker.

${ }^{1}$ For ease of exposition no distinction is made in this chapter between employed and non-idle non-production workers, as was made for production workers in ch. 3 . Only for the interpolations is this distinction important, and here it must be assumed that there are no completely idle workers at the interpolation peaks.

${ }^{2}$ In some industries the trend in $Y_{a t} / N_{2 w t}$ was downward - output per non-production worker decreasing through time - and for these industries the interpolation lines were slowly decreasing. 
The above assumptions are now sufficient for the estimation of eq. (10.1). The excess labor variable in the equation becomes

$$
\begin{aligned}
& \alpha_{1}\left(\log N_{2 w t-1}-\log N_{2 w t-1}^{d}\right) \\
& =\alpha_{1}\left(\log N_{2 w t-1}-\log N_{2 w t-1}-\log H_{2 w t-1}^{N}+\log H S_{2 w t-1}^{N}\right)[\operatorname{from}(10.4)] \\
& =\alpha_{1}\left(-\log Y_{d t-1}+\log \gamma_{2 w t-1}+\log N_{2 w t-1}+\log H S_{2 w t-1}^{N}\right)[\operatorname{from}(10.3)] \\
& =\alpha_{1}\left(\log N_{2 w t-1}-\log Y_{d t-1}+\log \gamma_{2 w t-1}+\log \bar{H}^{N}-\log \bar{H}^{N}+\log H S_{2 w t-1}^{N}\right) \\
& =\alpha_{1}\left(\log N_{2 w t-1}-\log Y_{d t-1}+\log \gamma_{2 w t-1} \bar{H}^{N}-\log \bar{H}^{N}+\log H S_{2 w t-1}^{N}\right) \\
& =\alpha_{1}\left(\log N_{2 w t-1}-\log Y_{d t-1}+\log \gamma_{2 w t-1} \bar{H}^{N}\right)-\alpha_{1} \log \bar{H}^{N} \\
& \left.\quad \quad \quad \quad \quad \quad \quad \alpha_{1} \log \bar{H}+\alpha_{1} \mu t \quad(10.5)\right] .
\end{aligned}
$$

Since data on $Y_{d t-1}$ and $N_{2 w t-1}$ are available, data on the expression in parentheses in the last line in (10.6) are available (remember that data on $\gamma_{2 w t} \bar{H}^{N}$ are available from the interpolations), and $-\alpha_{1} \log \bar{H}^{N}+\alpha_{1} \log \bar{H}$ in (10.6) can be absorbed in the constant term in eq. (10.1). Using (10.6) and $Y_{d}$ as a proxy for $Y_{2 w}$, eq. (10.1) becomes

$$
\begin{aligned}
\log N_{2 w t}-\log N_{2 w t-1}= & \alpha_{1}\left(\log N_{2 w t-1}-\log Y_{d t-1}+\log \gamma_{2 w t-1} \bar{H}^{N}\right) \\
& +\left(\alpha_{1} \log \bar{H}-\alpha_{1} \log \bar{H}^{N}\right) \\
& +\alpha_{1} \mu t+\sum_{i=1}^{m} \beta_{i}\left(\log Y_{d t-i}-\log Y_{d t-i-1}\right) \\
& +\gamma_{0}\left(\log Y_{d t}^{\mathrm{e}}-\log Y_{d t-1}\right) \\
& +\sum_{i=1}^{n} \gamma_{i}\left(\log Y_{d t+i}^{e}-\log Y_{d t+i-1}^{e}\right) .(10.1)^{\prime}
\end{aligned}
$$

Eq. $(10.1)^{\prime}$ is now in a form in which it can be estimated, given some assumption about how expectations are formed.

\subsection{The results}

For each industry, the expectational hypothesis which gave the better results for the production workers equation (see table 4.3) was assumed to be the correct one for that industry and was used in the estimation of equation (10.1) for non-production workers. As was done for production workers, the past output change variables were carried back and the expected future output change variables were carried forward until in general they lost their significance. The current output change variable was included even if it was not significant, however, and a few of the expected future 
output change variables which were included in the final equation were not significant. The same periods of estimation were also used here as were used for production workers.

The results of estimating eq. $(10.1)^{\prime}$ for each of the seventeen industries are presented in table 10.1. The coefficient $\delta$ denotes the coefficient of $\log$ $Y_{d t-1}-\log Y_{d t-13}$ for those industries for which future output expectations were significant and for which the non-perfect expectational hypothesis was used.

For all seventeen industries the estimate of the coefficient $\alpha_{1}$ of the excess labor variable is negative, and for all but four industries - 212, 231, 232, and 233 - it is significant. The amount of excess non-production labor on hand does appear to be a significant factor in determining short-run changes in the number of non-production workers employed. Regarding the construction of the excess labor variable, for every industry the estimate of the constant term is positive, which combined with the fact that the estimate of $\alpha_{1}$ is negative for every industry implies that the number of hours worked per non-production worker at the interpolation peaks, $\bar{H}^{N}$, is greater than $\vec{H}$ (the standard number of hours of work per non-production worker less trend). This seems to be consistent with the above construction, since at the peaks (which are generally peaks in output as well) the number of hours worked per worker is likely to be greater than the standard number.

For all but industry 271 the estimate of the coefficient $\gamma_{0}$ of $\log Y_{d t}^{e}-$ $\log Y_{d t-1}$ is positive, but it is only significant for eight of the industries. For every industry the size of the estimate of $\gamma_{0}$ is smaller for non-production workers than it is for production workers in table 4.3. These results suggest that at least in some industries short-run changes in the number of nonproduction workers employed respond to current output changes, but that the tendency is much less pronounced here than it was for changes in the number of production workers employed.

Only for 201 and 242 were any of the past output change variables significant. These variables do not appear to be a help in depicting the reaction of firms to the amount of excess non-production labor on hand. For a few industries the expected future output change variables were significant, but again this tendency is much less pronounced here than it was for production workers.

Very little of the variance of $\log N_{2 w t}-\log N_{2 w t-1}$ has been explained here. For all but industry 271 less than twenty percent has been explained, and in industries like 212 and 231 none of the coefficient estimates are significant. In about half of the industries there appears to be evidence of 
Parameter estmates for eq. $(\text { IO.I })^{\prime}$

\begin{tabular}{|c|c|c|c|c|c|c|c|c|}
\hline 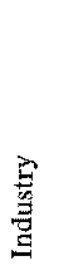 & $\begin{array}{l}\dot{0} \\
0 \\
0 \\
0 \\
\dot{Z}\end{array}$ & $\frac{2}{5}$ & $\hat{\alpha}_{1}$ & $1000 \widehat{\alpha_{1} \mu}$ & $\hat{\beta}_{2}$ & $\hat{\beta}_{1}$ & $\hat{\gamma}_{0}$ & $\hat{\gamma}_{1}$ \\
\hline 201 & 192 & $\begin{array}{r}.014 \\
(2.54)\end{array}$ & $\begin{array}{l}-.036 \\
(2.12)\end{array}$ & $\begin{array}{l}-.050 \\
(2.31)\end{array}$ & & $\begin{array}{r}.033 \\
(2.16)\end{array}$ & $\begin{array}{r}.034 \\
(1.88)\end{array}$ & $\begin{array}{r}.004 \\
(0.24)\end{array}$ \\
\hline 207 & 136 & $\begin{array}{r}.014 \\
(2.23)\end{array}$ & $\begin{array}{l}-.046 \\
(3.60)\end{array}$ & $\begin{array}{r}.044 \\
(1.20)\end{array}$ & & & $\begin{array}{r}.027 \\
(2.09)\end{array}$ & \\
\hline 211 & 136 & $\begin{array}{c}.046 \\
(3.93)\end{array}$ & $\begin{array}{r}-.187 \\
(3.74)\end{array}$ & $\begin{array}{l}-.079 \\
(1.36)\end{array}$ & & & $\begin{array}{r}.026 \\
(0.41)\end{array}$ & $\begin{array}{r}.064 \\
(1.85)\end{array}$ \\
\hline 212 & 136 & $\begin{array}{r}.020 \\
(1.39)\end{array}$ & $\begin{array}{l}-.073 \\
(1.88)\end{array}$ & $\begin{array}{l}-.089 \\
(1.11)\end{array}$ & & & $\begin{array}{r}.064 \\
(1.18)\end{array}$ & \\
\hline 231 & 136 & $\begin{array}{r}.008 \\
(1.33)\end{array}$ & $\begin{array}{l}-.033 \\
(1.81)\end{array}$ & $\begin{array}{l}-.010 \\
(0.30)\end{array}$ & & & $\begin{array}{r}.007 \\
(0.32)\end{array}$ & \\
\hline 232 & 136 & $\begin{array}{r}.008 \\
(1.53)\end{array}$ & $\begin{array}{l}-.025 \\
(1.28)\end{array}$ & $\begin{array}{l}-.003 \\
(0.13)\end{array}$ & & & $\begin{array}{r}.041 \\
(2.87)\end{array}$ & \\
\hline 233 & 136 & $\begin{array}{r}.009 \\
(1.53)\end{array}$ & $\begin{array}{l}-.010 \\
(0.64)\end{array}$ & $\begin{array}{r}-.022 \\
(0.73)\end{array}$ & & & $\begin{array}{r}.038 \\
(2.46)\end{array}$ & \\
\hline 242 & 154 & $\begin{array}{r}.021 \\
(3.13)\end{array}$ & $\begin{array}{l}-.071 \\
(3.12)\end{array}$ & $\begin{array}{l}-.075 \\
(2.52)\end{array}$ & $\begin{array}{r}.043 \\
(2.27)\end{array}$ & $\begin{array}{l}-.035 \\
(1.62)\end{array}$ & $\begin{array}{r}.062 \\
(2.75)\end{array}$ & $\begin{array}{r}.044 \\
(2.10)\end{array}$ \\
\hline 271 & 166 & $\begin{array}{r}.007 \\
(4.48)\end{array}$ & $\begin{array}{c}-.045 \\
(3.75)\end{array}$ & $\begin{array}{l}-.001 \\
(0.11)\end{array}$ & & & $\begin{array}{l}-.006 \\
(0.63)\end{array}$ & $\begin{array}{r}.001 \\
(0.06)\end{array}$ \\
\hline 301 & 134 & $\begin{array}{r}.008 \\
(2.63)\end{array}$ & $\begin{array}{l}-.023 \\
(2.87)\end{array}$ & $\begin{array}{l}-.029 \\
(1.97)\end{array}$ & & & $\begin{array}{r}.007 \\
(0.61)\end{array}$ & \\
\hline 311 & 170 & $\begin{array}{c}.024 \\
(3.49)\end{array}$ & $\begin{array}{l}-.146 \\
(4.56)\end{array}$ & $\begin{array}{l}-.050 \\
(1.59)\end{array}$ & & & $\begin{array}{r}.017 \\
(0.38)\end{array}$ & $\begin{array}{r}.091 \\
(2.79)\end{array}$ \\
\hline 314 & 170 & $\begin{array}{r}.016 \\
(2.83)\end{array}$ & $\begin{array}{l}-.064 \\
(2.80)\end{array}$ & $\begin{array}{c}-.030 \\
(1.39)\end{array}$ & & & $\begin{array}{r}.080 \\
(3.98)\end{array}$ & $\begin{array}{r}.027 \\
(1.28)\end{array}$ \\
\hline 324 & 187 & $\begin{array}{r}.008 \\
(2.26)\end{array}$ & $\begin{array}{l}-.032 \\
(2.25)\end{array}$ & $\begin{array}{r}.016 \\
(0.73)\end{array}$ & & & $\begin{array}{r}.040 \\
(3.17)\end{array}$ & $\begin{array}{r}.019 \\
(1.24)\end{array}$ \\
\hline 331 & 128 & $\begin{array}{r}.003 \\
(0.52)\end{array}$ & $\begin{array}{l}-.060 \\
(3.95)\end{array}$ & $\begin{array}{r}.069 \\
(1.45)\end{array}$ & & & $\begin{array}{r}.023 \\
(0.49)\end{array}$ & \\
\hline 332 & 170 & $\begin{array}{c}.006 \\
(2.81)\end{array}$ & $\begin{array}{l}-.037 \\
(5.95)\end{array}$ & $\begin{array}{r}.008 \\
(0.52)\end{array}$ & & & $\begin{array}{c}.046 \\
(3.26)\end{array}$ & \\
\hline 336 & 170 & $\begin{array}{r}.034 \\
(3.31)\end{array}$ & $\begin{array}{l}-.082 \\
(3.80)\end{array}$ & $\begin{array}{l}-.124 \\
(2.22)\end{array}$ & & & $\begin{array}{r}.113 \\
(2.30)\end{array}$ & \\
\hline 341 & 191 & $\begin{array}{r}.014 \\
(2.70)\end{array}$ & $\begin{array}{c}-.038 \\
(3.96)\end{array}$ & $\begin{array}{r}.029 \\
(1.11)\end{array}$ & & & $\begin{array}{r}.018 \\
(1.94)\end{array}$ & $\begin{array}{r}.038 \\
(3.90)\end{array}$ \\
\hline
\end{tabular}

$t$-statistics are in parentheses.

a $\hat{\delta}$ is the coefficient estimate of $\log Y_{d t-1}-\log Y_{d t-13}$ under the non-perfect expectational hypothesis. 


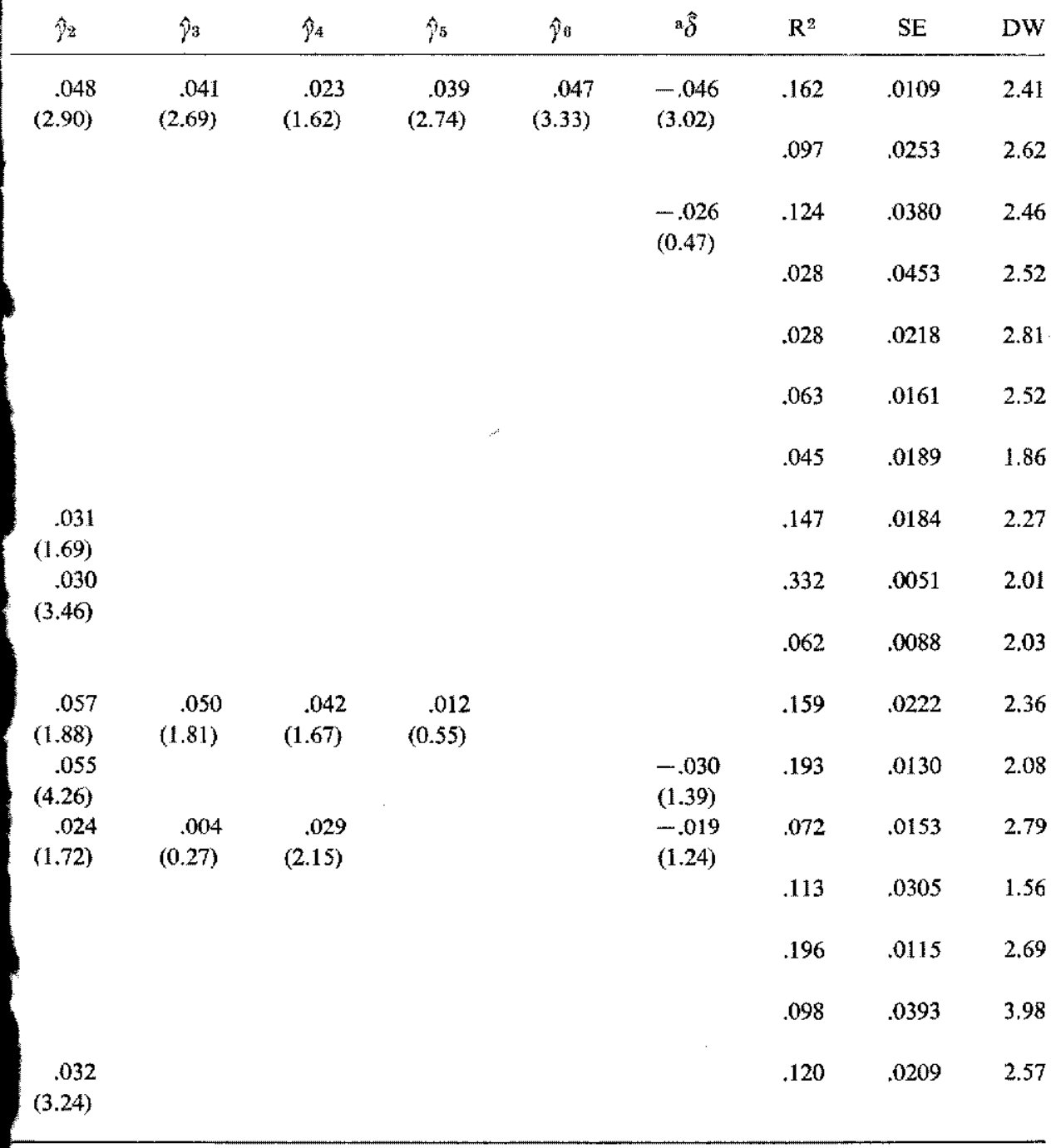


negative first-order serial correlation. The model developed in this study has obviously been much less successful in explaining the short-run demand for non-production workers than in explaining the short-run demand for production workers. The over-all results indicate that changes in the number of non-production workers employed are only marginally influenced by the same factors which influence changes in the number of production workers employed. Remember, of course, that the variance of $\log N_{2 w t}-$ $\log N_{2 w:-1}$ is small to begin with, and the fact that only a small percentage of this variance appears capable of being explained does not imply that $N_{2 w^{t}}$ cannot be adequately predicted for most purposes. 


\section{SUMMARY AND CONCLUSIONS}

\subsection{Summary}

One of the objectives of this study was to provide an explanation of the widely observed phenomenon of increasing returns to labor services or of increasing short-run returns to scale. It was seen in ch. 2 that the basic model of previous studies, which is based on the postulation of a short-run production function and a lagged adjustment process, yielded unrealistically large estimates of the production function parameter $\alpha$ of the labor input variable. These results achieved in ch. 2 using seasonally unadjusted monthly data for the seventeen three-digit United States manufacturing industries considered in this study were not unique to the type of data used; the same kinds of results have also been achieved in previous studies using seasonally adjusted quarterly data for more aggregated industry groups. Previous studies which have not developed a model of short-run employment demand but have examined the short-run relationship between output and output per man hour directly have found the relationship to be positive in almost all cases. Further results presented in ch. 3 showed that the short-run relationship between output and output per man hour was positive in most cases even at high rates of output, where presumably there should be very little slack. All of these findings appear to be inconsistent with the law of diminishing marginal productivity of classical economic theory.

The explanation of these results which was given in this study is based on the idea that firms hold positive amounts of "excess labor" during much of the year and that the true production function inputs are not observed. It was contended that the observed number of hours paid-for per worker is a poor proxy for the unobserved number of hours actually worked per worker except perhaps at peak rates of output. If this is true, then the properties of the short-run production function cannot be estimated from the available data, and the estimates obtained in previous studies and the estimates obtained in ch. 2 should not be interpreted as estimates of production function parameters.

Another objective of this study was to develop a model of the short-run 
demand for the number of workers employed. The model was based on the idea that firms do hold both positive and negative amounts of excess labor during much of the year, and the demand for workers was assumed to be a function of the amount of excess labor on hand and of expected future output changes. The model was not derived from the minimization of a short-run cost function, but it did rely heavily on the idea that there are serious costs involved (including such things as worker morale problems) in changing the size of the work force in the short run. There have been many reasons put forth as to why these adjustment costs are likely to be large, some of which were listed in $\$ 3.4$. In the model developed here the firm was conceived as attempting to smooth the fluctuations in its work force relative to fluctuations in output under the constraint that holding either positive or negative amounts of excess labor is costly.

Before the model could be estimated and tested, the amount of excess labor on hand had to be measured, and assumptions about how expectations are formed had to be made. Much of ch. 3 was concerned with these two points. The amount of excess labor on hand was defined to be the (logarithmic) difference between the actual number of workers employed and the desired number, where the desired number of workers employed was assumed to be equal to total man-hour requirements divided by the standard number of hours of work per worker. In order to get an estimate of man-hour requirements, assumptions about the properties of the short-run production function had to be made, since the properties could not be estimated because the appropriate data were not available. The short-run production process was assumed to be of such a nature that a fixed number of workers is required per machine and that there are constant returns to scale both with respect to changes in the number of workers and machines used and with respect to changes in the number of hours worked per worker and machine. In other words, the short-run production function was assumed to be one of fixed proportions.

Using these assumptions, estimates of man-hour requirements were made by interpolating plots of output per paid-for man hour from peak to next higher peak, assuming that at the peaks output per paid-for man hour equals output per worked man hour so that an estimate of the production function parameter $\alpha$ of the labor input variable is available at each of the peaks, assuming that $\alpha$ moves smoothly through time from peak to peak, and then using the estimates of $\alpha$ and the data on output to compute estimates of man-hour requirements. Assuming that the standard number of hours of work per worker is a smoothly trending variable, estimates of the desired 
number of workers employed were then available, and so from these estimates and the data on the number of workers employed, estimates of the amount of excess labor on hand were available. It was shown in ch. 3 that the logarithmic difference between the number of workers employed and the desired number is equal to the logarithmic difference between the standard number of hours of work per worker and the actual number of hours worked per worker. The amount of excess labor on hand can thus be looked upon in two different ways. No direct verification of the accuracy of the estimates of the amount of excess labor on hand could be made, and only the indirect verification of how well the over-all model performs was available.

With respect to the assumptions about how expectations are formed, two basic expectational hypotheses were proposed and tested. One of the hypotheses was that expectations are perfect, that firms are quite accurate in forecasting the amount of output they are going to produce over the next few months. The other hypothesis was that firms expect output in a future month to be what output was during the same month of the previous year, adjusted by a factor to take into account whether output has been increasing or decreasing in the current year relative to the previous year. Again, no direct verification of these hypotheses was available, but only how well each of them does when used in the estimation of the over-all model.

The results of estimating the model using the estimates of the amount of excess labor on hand under the different expectational hypotheses were presented in $\mathrm{ch}$. 4 . The model was estimated using seasonally unadjusted monthly data for seventeen three-digit United States manufacturing industries. There are strong reasons for using seasonally unadjusted data when estimating models which are based either directly or indirectly on a production function, and the use of monthly as opposed to quarterly data has obvious advantages in a study of short-run behavior. Likewise, the use of three-digit industry data should lessen the problems of aggregating vastly dissimilar firms. The results presented in ch. 4 appeared to be an important confirmation of the model. The results indicated rather strongly that both the amount of excess labor on hand and the time stream of expected future output changes are significant determinants of the shortrun demand for workers, and the model produced substantially better fits than did the basic model of previous studies. The excess labor variable definitely appeared to be significant in its own right and not merely because it is of the nature of a lagged dependent variable. With respect to the expecta- 
tional hypotheses, the perfect expectational hypothesis gave somewhat better over-all results than did the hypothesis which assumed perfect expectations for the current level of output but non-perfect expectations for the future levels of output. The latter gave slightly better results for six of the fourteen industries where future output expectations were significant, however, and it was chosen to be used for these industries.

In ch. 5 various hypotheses regarding the short-run demand for workers were developed and tested, and for the most part they were rejected. Briefly, the previous level of hours paid-for per worker did not appear to be a significant determinant of the short-run demand for workers, which was as expected; the behavior of firms did not appear to be different during general contractionary periods of output or during general expansionary periods of output from what the model predicted it should be; the reaction of firms to the amount of excess labor on hand appeared to be adequately specified in the model, as tests of more complicated reaction behavior did not yield significant results; and the behavior of firms did not appear to be different, other things being equal, at high rates of output than otherwise. The one hypothesis which had some evidence in its favor was the hypothesis that in tight labor markets fluctuations in the number of workers employed are damped and that in loose labor markets the fluctuations are increased, although the evidence on this score was not strong.

In ch. 6 the question of whether production decisions should be assumed to be exogenous in a study of short-run employment behavior was examined. The Holt, Modigliani, Muth, and Simon (HMMs) model, which treated sales instead of production as exogenous and which was based on the minimization of a short-run cost function, was introduced, and it was seen to be based on an unrealistic approximation to overtime costs. An alternative model to the one developed in ch. 3 was developed which incorporated the HMMS idea that sales rather than production should be treated as exogenous but avoided their overtime cost approximation. These models were estimated using data on shipments and inventories for four of the seventeen industries, and the alternative model developed in ch. 6 produced better results than the HMMs model, as expected, but neither of the models produced results as good as the results achieved using the model developed in ch. 3 in which production was assumed to be exogenous. Similar results were also achieved using Bureau of Census data. The major conclusion of ch. 6 was thus that models which specify a one-way causality from decisions on production to decisions on employment appear to be more realistic than models which assume that production and employment decisions are made simultaneously. 
In ch. 7 a model of the short-run demand for the number of hours paidfor per worker was developed and estimated. Because of the properties assumed about the short-run production function, once the change in the number of workers employed has been determined, the change in the number of hours worked per worker is automatically determined. This, however, does not mean that the change in the number of hours paid-for per worker is then determined as well. The model of the short-run demand for hours paid-for per worker was based on the idea that with respect to such things as worker morale problems firms view short-run fluctuations in the number of hours paid-for per worker in a similar manner as they view fluctuations in the number of workers employed and thus that many of the same factors which influence the short-run demand for workers are also likely to influence the short-run demand for the number of hours paid-for per worker. Reasons were also advanced as to why the difference between the number of hours paid-for per worker and the standard number of hours of work per worker is likely to be a significant factor in determining the short-run demand for hours paid-for per worker, and why the condition of the labor market is likely to be a significant factor as well.

The short-run demand for the number of hours paid-for per worker was thus taken to be a function of the amount of excess labor on hand, the time stream of expected future output changes, the difference between the past level of hours paid-for per worker and the standard number of hours of work per worker, and the degree of labor market tightness as measured by the unemployment rate. The unemployment rate variable was added on the hypothesis that in tight labor markets an added inducement to keep workers from looking for other jobs is to keep the number of hours paid-for per worker high, while in loose labor markets less of this kind of inducement is needed.

The results of estimating the model were quite good. The amount of excess labor on hand definitely appeared to be a significant determinant of the short-run demand for hours paid-for per worker, as did the amount by which the past level of hours paid-for per worker differs from the standard number of hours of work per worker. The current output change variable was highly significant, as in many cases were the expected future output change variables, and the unemployment rate variable appeared to be significant as well. Two further hypotheses regarding the short-run demand for hours paid-for per worker were developed and tested, and neither one appeared to be confirmed. The change in the number of hours paid-for per worker did not appear to be different than the model predicted it should 
be when it also equaled or nearly equaled the change in the number of hours worked per worker, and it did not appear to be different during general expansionary periods of output or during general contractionary periods of output than the model predicted it should be

Comparing the demand for workers and the demand for hours paid-for per worker in ch. 8 , it was seen that the reaction of firms to the amount of excess labor on hand (with respect to changing the number of workers employed) is smaller than the reaction of firms to the amount by which the level of hours paid-for per worker differs from the standard number of hours of work per worker (with respect to changing the number of hours paid-for per worker). It was also seen that expected future changes in output are more significant in determining the short-run demand for workers than in determining the short-run demand for hours paid-for per worker, which was as expected.

The equation determining the change in total man hours paid-for can be derived by adding the equations determining the change in the number of workers employed and the change in the number of hours paid-for per worker, and the results of adding the two estimated equations together were presented in ch. 8. It was seen from these results that firms react more strongly in changing total man hours paid-for when the number of hours paid-for per worker differs from the standard number of hours of work per worker than when the number of workers employed differs from the desired number of workers employed. This was seen to mean that the reaction of firms to the amount of "excess man hours" on hand (man hours paid-for less man-hour requirements) depends on how the amount is distributed between the amount of excess labor on hand and the amount by which the number of hours paid-for per worker differs from the standard number of hours of work per worker.

The economy-wide implications of the results achieved in this study were described in $\S 8.4$, and since this was a summary in itself, it will not be summarized further. The implications for what should happen during economy-wide contractions and expansions did appear to be consistent with the results obtained by Hultgren and others.

In ch. 9 some further statistical results were presented. The workers equation and the hours paid-for per worker equation were examined for first-order serial correlation of the residuals. There was no evidence that the residuals of the workers equation were serially correlated, but there was some evidence that for a few industries the residuals of the hours paid-for per worker were serially correlated, with negative first-order serial correlation 
being more pronounced than positive serial correlation. None of the conclusions reached in chs. 7 and 8 regarding the hours paid-for per worker equation or the total man-hours paid-for equation was modified for these industries, however, and for the majority of the industries serial correlation did not appear to be a problem for the hours paid-for per worker equation either.

The possible correlation of the residuals of the workers equation with those of the hours paid-for per worker equation for each industry was examined in ch. 9, as well as the possible correlation of the residuals of the workers or hours equation of one industry with those of the workers or hours equation of another industry. These correlations were positive, as expected, and in an attempt to achieve more efficient estimates, the equations were estimated using the two-stage Aitken estimator developed by Zellner. There was very little gain in efficiency when the Zellner technique was used to estimate the workers and hours equations together for each industry, which was as expected since the number of different independent variables in the two equations was small. The gain in efficiency appeared to be greater when the technique was used to estimate the equations of different industries together, although even here the gain was not substantial. None of the conclusions reached in earlier chapters needed modification from the results achieved using the two-stage Aitken estimator.

Finally in ch. 9 a comparison of the short-run demand for workers across industries was made using the estimates presented in table 4.3 as a starting point. The size of an industry's employment reaction to current output changes appeared to be inversely related to the amount of specific training required in the industry, but it did not appear to be related to the degree of union pressure in the industry nor to the average wage level in the industry. All of the results were based on small samples, however, and not too much reliance should be put on the conclusions.

Short-run fluctuations in the number of non-production workers employed are quite small, but in ch, 10 a model similar to the model developed for production workers was developed for non-production workers to see if the small short-run fluctuations in the number of non-production workers employed could be explained by any of the same factors which explain fluctuations in the number of production workers employed. The short-run demand for non-production workers was assumed to a function of the amount of excess non-production labor on hand and of expected future changes in output. The empirical results suggested that the amount of excess non-production labor on hand is a significant determinant of the 
change in the number of non-production workers employed and that the current and expected future changes in output in some industries are significant as well. The change in the number of non-production workers employed was only marginally influenced by these factors, however, and for most industries only a small percentage of the variance of this series was explained.

\subsection{Concluding remarks}

In conclusion, it should be emphasized that in this study an attempt was made to explain the short-run fluctuations in the number of workers employed and the number of hours paid-for per worker and to explain how the number of workers employed, the number of hours paid-for per worker, and the number of hours worked per worker are related to each other in the short run, but that no attempt was made to develop a model which was capable of predicting these variables ex ante. In order to use the model of the shortrun demand for workers developed in this study for prediction purposes, for example, it would be necessary to know the expected future changes in output in advance, and at least for those industries in which expectations appear to be quite accurate (and not based merely on past output behavior) this would require knowledge of the industry which an economic forecaster (as opposed to an individual manager in the industry) does not have at his disposal. Also, in this study an effort was made to use as disaggregate and homogeneous a body of data as possible to lessen the problems of aggregating vastly dissimilar firms, but to forecast aggregate employment from the three-digit industry level would be a tremendous task, even if all of the necessary data were available. For forecasting aggregate employment more aggregated data would have to be used.

Nevertheless, if the model developed in this study can be taken to be a valid representation of the structure of the employment sector of the economy with respect to short-run fluctuations in the number of workers employed and the number of hours paid-for per worker, then the information contained in this model should be of considerable use to someone attempting to develop an aggregate forecasting model of the employment sector of the economy. It was seen in $\$ 8.4$, for example, that the model developed in this study provides an explanation of the relationship between seasonally adjusted output and seasonally adjusted output per paid-for man hour which has been observed by Hultgren and others during economy-wide contractions and expansions. 


\section{DATA APPENDIX}

In this appendix the basic sources of data are given and the adjustments which were made in the data are described. First, the data sources and adjustments which were common to nearly all of the seventeen industries are discussed, and then each industry is discussed individually.

All of the data which were used in this study were monthly data, seasonally unadjusted. The basic time period considered was 1947-1965.

For all of the industries the data on the number of production workers employed during the second week of month $t, M_{2 w t}$, on the average number of hours paid-for per production worker during the second week of month $t, H P_{2 w t}$, and on the number of non-production workers (all employees minus production workers) employed during the second week of month $t$, $N_{2 w}$, were taken from the Bureau of Labor Statistics (BLS) publication, Employment and Earnings Statistics for the United States 1909-65. No adjustments were made in any of these data.

The data on the unemployment rate during the second week of month $t$, $U_{2 w t}$, for both the durable goods and non-durable goods industries were unpublished and were obtained directly from the BLS for the 1948-1965 period. The mean of $U_{2 w t}$ for the 1948-1965 period, denoted as $\bar{U}$ in the text, was 5.30 for the durable goods industry and 5.42 for the non-durable goods industry.

The dummy variable $D_{t}$, which was set equal to one during contractions and zero otherwise, was constructed using the monthly peaks and troughs as defined by the National Bureau of Economic Research (NBER). The NBER peak and trough months were taken from the July 1967 issue of Business Cycle Developments of the Department of Commerce.

For all of the industries except 301 and 324, the data on the average daily rate of output for month $t, Y_{d t}$, were taken from the Federal Reserve Board (FRB) publication, Industrial Production 1957-59 Base, and the November 1966 supplement. These data were in index number form, with base period 1957-1959. For industry 331, Blast furnace and basic steel products, there were two relevant FRB indices, the index for Blast furnaces and steel works and the index for Steel mill products. The total index for industry 331 was 
obtained by computing a weighted average of these two indices, the weights corresponding to the relative 1957-1959 proportions (by value added) of the two indices in the over-all FRB index of industrial production. The weights were .658 for the Blast furnaces and steel works index and .342 for the Steel mill products index. For the Tires and inner tubes industry 301 the output data were taken from publications of the Rubber Manufacturers Association (RMA), and for the Cement industry 324 the output data were taken from publications of the Bureau of Mines. These data are discussed under the relevant industry headings below.

For eight of the industries there were strikes involving 10,000 or more workers during the 1947-1965 period, and as mentioned in $\$ 4.2$, adjustments were made in the FRB output series for three of these industries, 242, 271, and 341 . These adjustments are presented under the industry headings below.

The output per paid-for man-hour interpolations discussed in ch. 3 and the output per non-production worker interpolations discussed in ch. 10 were unavoidably somewhat subjective in nature, and for reference purposes the months which were used as "peak" months in the interpolations are listed below for each industry. As mentioned in $\$ 3.6$, for the beginning of each period the interpolation line was taken to be a horizontal line from the first month to the first peak, and for the end of each period the interpolation line was taken to be a horizontal line from the last peak to the last month.

For industries 301 and 324 data on the stock of inventories at the end of the month were available from publications of the RMA and the Bureau of Mines respectively, and from these data and the above mentioned data on production, data on shipments were constructed. (Actually, independent shipments data were available from the RMA and Bureau of Mines. These data did not exactly agree with the constructed shipments data because of such things as reshipments not being netted out of the shipments series. The two shipments series did not differ by much, however, and for each industry the constructed shipments series was taken to be the better measure of net shipments.) For industries 211 and 212 data on production and shipments were available from publications of the Internal Revenue Service (IRS), and from these data, data on the stock of inventories were constructed in the manner discussed in $\S 6.3$. For industries 201, 301, 331, and 332 unpublished data on the value of shipments and value of inventories at the end of the month were obtained directly from the Bureau of Census. From these data, data on the value of production were constructed. The RMA and Bureau of Mines data on production and inventories and the IRS data on production and shipments are not available in a convenient summary any- 
where, and so these data are presented in tabular form below. The Bureau of Census data are not published because of the questionable reliability of some of the figures.

The production and shipments data which were obtained or constructed from sources other than the FRB referred to the amount (or value) of goods produced or shipped during the month rather than to the average daily rate for the month. All of these figures were converted to average daily rates for the month by dividing them by $d_{t}$, the number of working days in the month. For each of the industries $d_{t}$ was constructed using the FRB estimate of the number of working days in the week for the industry. The FRB estimates were taken from Industrial Production 1957-59 Base. If, for example, the number of working days in the week was $5 \frac{1}{2}, d_{t}$ was taken to be the number of weekdays in month $t$ plus one-half the number of Saturdays in the month. For industry $331 d_{t}$ was computed by taking the above men.

\section{TABLE A-1}

Industries for which data were converted to average daily rates

Number of working days

Industry in the week Data which were converted to average daily rates

201

$5 \frac{1}{2}$

211

5

212

5

301

$51 / 2$

324

331

332
7

7 for $65.8 \%$ of industry

$5 \frac{1}{2}$ for $34.2 \%$ of industry
Census data on the value shipped and the constructed data on the value produced.

IRs data on the amount produced and the amount shipped.

IRS data on the amount produced and the amount shipped.

RMA data on the amount produced and the constructed data on the amount shipped.

Census data on the value shipped and the constructed data on the value produced.

Bureau of Mines data on the amount produced and the constructed data on the amount shipped. Census data on the value shipped and the constructed data on the value produced.

Census data on the value shipped and the constructed data on the value produced. 
tioned weighted average of the $d_{t}$ for the Blast furnaces and steel works industry and the $d_{t}$ for the Steel mill products industry. In table A-1 the data which were converted to average daily rates are presented for each industry, along with the FRB estimates of the number of working days in the week.

With respect to the periods of estimation presented below, usually two or three observations before and after a strike were omitted in addition to the actual strike observations. When more than one period of estimation was used for an industry, all of the periods which were used are presented below.

In the discussion which follows 4701 refers to January 1947,4702 to February 1947, and so on.

\section{Industry 201: Meat products}

Months used as peaks in the output per paid-for man-hour interpolation: 4711 , 4901, 5101, 5201, 5501, 5601, 5902, 6001, 6203, 6303, 6404.

Months used as peaks in the output per non-production worker interpolation: 4701, 4812, 4912, 5012, 5601, 5910, 6010, 6310, 6410 .

Period of estimation: 4809-6506, excluding 5906-6003; 192 obs.

Data used for the estimates presented in ch. 6. Data on value of shipments and value of inventories at the end of the month were unpublished and were obtained directly from the Bureau of Census for the 4801-6512 period.

Months used as peaks in the output per paid-for man-hour interpolation when Census data were used: 4902, 5104, 5402, 5702, 5803, 5811, 6104, 6302, $6502,6510$.

Period of estimation when Census data were used: 4907-6506, excluding 5906-6003; 182 obs.

\section{Industry 207: Confectionery and related products}

Months used as peaks in the output per paid-for man-hour interpolation: 4703, 4710, 4909, 5009, 5109, 5509, 5609, 5909, 6009, 6109, 6209, 6309, 6409.

Months used as peaks in the output per non-production worker interpolation: $4710,4810,5609,5709,6009,6109,6209,6309,6509$.

Period of estimation: 4809-6506, excluding all July, August, December, and January observations; 136 obs.

\section{Industry 211: Cigarettes}

Months used as peaks in the output per paid-for man-hour interpolation: 4703, 4905, 5008, 5110, 6102, 6304, 6506.

Months used as peaks in the output per non-production worker interpolation: 
4701, 4710, 4804, 5106, 5302, 5408, 5506, 5608, 5808, 6008, 6110, 6405, 6506 . Period of estimation: 4809-6506, excluding all July, August, December, and January observations; 136 obs.

\section{TABLE A-2}

Internal Revenue Service data on the number of cigarettes produced and shipped

Number of small cigarettes produced per month in millions of cigarettes ${ }^{\mathrm{a}}$

Jan. Feb. March April May June July Aug. Sept. Oct. Nov. Dec. $\begin{array}{llllllllllllll}1952 & 37598 & 32247 & 33028 & 34694 & 36135 & 36873 & 36667 & 40213 & 39693 & 41745 & 33563 & 33091\end{array}$

$\begin{array}{llllllllllllll}1953 & 34848 & 34732 & 38035 & 34234 & 33293 & 36453 & 33110 & 37651 & 36885 & 37974 & 33829 & 32052\end{array}$ $\begin{array}{llllllllllllll}1954 & 32045 & 29226 & 35420 & 33166 & 34220 & 38026 & 31553 & 36816 & 35714 & 34034 & 32864 & 28772\end{array}$ $\begin{array}{llllllllllllll}1955 & 34106 & 30796 & 36216 & 31233 & 36792 & 38882 & 30447 & 39219 & 34888 & 35798 & 34768 & 29332\end{array}$ $\begin{array}{llllllllllllll}1956 & 35911 & 32723 & 35066 & 32523 & 38851 & 37323 & 33314 & 40387 & 33500 & 39910 & 36557 & 28181\end{array}$ $\begin{array}{llllllllllllll}1957 & 39258 & 34550 & 35216 & 34909 & 40638 & 37499 & 38217 & 40519 & 37564 & 40944 & 33997 & 29016\end{array}$ $\begin{array}{llllllllllllll}1958 & 39508 & 33732 & 35898 & 38271 & 40301 & 41142 & 39795 & 42263 & 41393 & 44234 & 37418 & 36116\end{array}$ $\begin{array}{llllllllllllll}1959 & 39357 & 37031 & 38772 & 41418 & 40458 & 41276 & 43418 & 44000 & 42770 & 45553 & 39090 & 36722\end{array}$ $\begin{array}{llllllllllllll}1960 & 40824 & 38412 & 43745 & 39716 & 44469 & 47408 & 37575 & 47997 & 44214 & 43637 & 43457 & 35489\end{array}$ $\begin{array}{llllllllllllll}1961 & 42865 & 40751 & 45589 & 40210 & 47992 & 48253 & 37932 & 50680 & 43075 & 49494 & 46518 & 34973\end{array}$ $\begin{array}{llllllllllllll}1962 & 45353 & 39860 & 45981 & 41801 & 49311 & 44905 & 41934 & 50993 & 43848 & 48756 & 47090 & 35663\end{array}$ $\begin{array}{lllllllllllllll}1963 & 47471 & 41470 & 43050 & 45574 & 52507 & 45331 & 45264 & 50836 & 45516 & 51247 & 44653 & 37638\end{array}$ $\begin{array}{lllllllllllllll}1964 & 45830 & 31943 & 41497 & 46836 & 44966 & 48746 & 46183 & 48060 & 47707 & 50778 & 45057 & 42305\end{array}$ $\begin{array}{lllllllllllll}1965 & 44167 & 43297 & 51196 & 47069 & 45183 & 51366 & 42659 & 50755 & 48709 & 45170 & 47790 & 39444\end{array}$

Number of small cigarettes (taxable and tax-exempt) shipped per month in millions of cigarettes $^{\mathrm{a}}$

Jan. Feb. March April May June July Aug. Sept. Oct. Nov. Dec.

$\begin{array}{lllllllllllll}1952 & 37273 & 32282 & 32985 & 34662 & 36268 & 36876 & 36670 & 40338 & 39275 & 41666 & 33794 & 33925\end{array}$

$\begin{array}{lllllllllllll}1953 & 35147 & 34605 & 37961 & 34310 & 33245 & 36434 & 33253 & 37428 & 37183 & 37673 & 33873 & 32675\end{array}$

$\begin{array}{lllllllllllll}1954 & 31558 & 29314 & 35160 & 32984 & 34350 & 37796 & 31718 & 37069 & 35359 & 34065 & 32997 & 29456\end{array}$

$\begin{array}{lllllllllllllll}1955 & 33082 & 31171 & 36367 & 31187 & 36739 & 38371 & 30931 & 38992 & 35013 & 35386 & 35060 & 29927\end{array}$

$\begin{array}{llllllllllllll}1956 & 34962 & 32865 & 34994 & 32615 & 38915 & 37244 & 33529 & 40441 & 33357 & 39867 & 36170 & 29226\end{array}$

$\begin{array}{llllllllllllll}1957 & 38696 & 34151 & 35489 & 34780 & 40633 & 37486 & 38227 & 40776 & 37503 & 40894 & 34120 & 29497\end{array}$

$\begin{array}{llllllllllllll}1958 & 38856 & 33891 & 35592 & 38273 & 40410 & 41321 & 39660 & 42608 & 41071 & 44186 & 37477 & 36664\end{array}$ $\begin{array}{llllllllllllll}1959 & 38878 & 37288 & 38279 & 41313 & 40226 & 41653 & 43422 & 43929 & 42635 & 45463 & 39043 & 37380\end{array}$ $\begin{array}{lllllllllllllll}1960 & 40348 & 38268 & 43506 & 39571 & 44532 & 47310 & 38259 & 47576 & 44120 & 43327 & 43526 & 36790\end{array}$ $\begin{array}{lllllllllllllll}1961 & 41999 & 40301 & 45996 & 40324 & 47812 & 47721 & 38741 & 50764 & 42684 & 49093 & 45909 & 36323\end{array}$ $\begin{array}{llllllllllllll}1962 & 44413 & 39119 & 46173 & 41817 & 48819 & 44831 & 42584 & 50928 & 43711 & 48682 & 46207 & 38247\end{array}$ $\begin{array}{lllllllllllll}1963 & 45884 & 41307 & 42983 & 45754 & 52356 & 44828 & 45761 & 50873 & 45572 & 50480 & 44833 & 40044\end{array}$ $\begin{array}{llllllllllllll}1964 & 44324 & 32402 & 41069 & 46830 & 44840 & 48798 & 46461 & 48128 & 47289 & 50707 & 44785 & 44455\end{array}$ $\begin{array}{lllllllllllll}1965 & 41174 & 43590 & 51090 & 47497 & 44760 & 50909 & 43399 & 50744 & 48105 & 45518 & 47140 & 41773\end{array}$

n Figures are rounded to the nearest million. 
Data used for the estimates presented in ch. 6: Data on the number of small cigarettes produced per month and on the number of small cigarettes (taxable and tax-exempt) shipped per month were obtained for the 5201-6512 period from the annual IRs publication, Alcohol and Tobacco Summary Statistics. The data are presented in table A-2. (Note: The FRB index of production for industry 211 is computed using the IRs data.)

Period of estimation when IRs data were used: 5309-6506, excluding all July, August, December, and January observations; 96 obs.

\section{Industry 212: Cigars}

Months used as peaks in the output per paid-for man-hour interpolation: 4705 , $4710,5010,5510,5610,5710,5810,6110,6302,6310,6410,6508$.

Months used as peaks in the output per non-production worker interpolation: $4710,4810,5511,5609,5810,5904,5910,6302,6306,6308,6310,6410$.

Period of estimation: 4809-6506, excluding all July, August, December, and January observations; 136 obs.

Data used for the estimates presented in ch. 6: Data on the number of cigars (small and large) produced per month and on the number of cigars (small and large, taxable and tax-exempt) shipped per month were obtained for the 5201-6512 period from the annual IRs publication, Alcohol and Tobacco Summary Statistics. The data are presented in table A-3. (Note: The FRB index of production for industry 212 is computed using the IRS data.)

Period of estimation when IRs data were used: 5204-6506, excluding all July, August, December, and January observations; 107 obs.

\section{Industry 231: Men's and boys' suits and coats}

Months used as peaks in the output per paid-for man-hour interpolation: 4708 , 4908, 5008, 5405, 5505, 5904, 6004, 6108, 6410.

Months used as peaks in the output per non-production worker interpolation: 4703, 4708, 5010, 5305, 5508, 5608, 5908, 6504.

Period of estimation: 4809-6506, excluding all July, August, December, and January observations; 136 obs.

\section{Industry 232: Men's and boys' furnishings}

Months used as peaks in the output per paid-for man-hour interpolation: $4702,4804,5202,5303,5404,5504,5605,5702,5803,6004,6303,6402$, $6502,6510$.

Months used as peaks in the output per non-production worker interpolation: $4702,4804,5103,5303,5602,5904,6004,6108,6303,6402,6408,6502,6504$. 
Period of estimation: 4809-6506, excluding all July, August, December, and January observations; 136 obs.

TABLE A-3

Internal Revenue Service data on the number of cigars produced and shipped

Number of cigars (small and large) produced per month in millions of cigars ${ }^{\text {a }}$

Jan. Feb. March April May June July Aug. Sept. Oct. Nov. Dec. $\begin{array}{lllllllllllll}1952 & 502.1 & 484.2 & 495.5 & 485.9 & 503.9 & 476.7 & 434.9 & 484.6 & 519.9 & 585.5 & 490.2 & 428.6\end{array}$

$\begin{array}{lllllllllllll}1953 & 479.1 & 524.9 & 513.9 & 499.2 & 506.1 & 509.8 & 435.9 & 498.0 & 518.3 & 565.0 & 514.0 & 439.3\end{array}$

$\begin{array}{lllllllllllll}1954 & 468.7 & 476.9 & 524.3 & 468.6 & 472.2 & 523.2 & 393.9 & 531.2 & 533.9 & 548.2 & 532.8 & 404.4\end{array}$

$\begin{array}{lllllllllllll}1955 & 445.1 & 461.1 & 524.5 & 446.6 & 496.4 & 530.3 & 368.4 & 542.1 & 526.5 & 532.4 & 536.5 & 412.9\end{array}$

$\begin{array}{llllllllllllll}1956 & 488.8 & 491.9 & 491.7 & 474.6 & 510.6 & 488.0 & 390.0 & 544.0 & 468.3 & 575.4 & 533.7 & 375.0\end{array}$

$\begin{array}{lllllllllllll}1957 & 498.0 & 482.5 & 497.7 & 484.4 & 511.7 & 477.3 & 399.2 & 544.8 & 521.3 & 598.6 & 524.1 & 406.9\end{array}$

$\begin{array}{lllllllllllll}1958 & 520.5 & 477.9 & 490.2 & 490.3 & 518.4 & 513.3 & 456.0 & 553.3 & 588.4 & 677.8 & 603.9 & 503.7\end{array}$

$\begin{array}{lllllllllllll}1959 & 610.9 & 645.2 & 626.4 & 663.0 & 584.2 & 596.7 & 506.0 & 584.2 & 608.7 & 660.6 & 591.2 & 461.6\end{array}$

$\begin{array}{lllllllllllll}1960 & 557.1 & 576.7 & 629.8 & 549.7 & 602.3 & 609.5 & 430.7 & 655.0 & 619.4 & 632.5 & 632.0 & 422.2\end{array}$

$\begin{array}{lllllllllllll}1961 & 534.1 & 519.9 & 569.1 & 499.7 & 557.3 & 575.6 & 388.9 & 643.0 & 583.1 & 657.6 & 629.3 & 454.9\end{array}$

$\begin{array}{lllllllllllll}1962 & 583.8 & 551.6 & 543.3 & 555.0 & 617.2 & 572.2 & 416.4 & 648.3 & 552.8 & 674.2 & 607.4 & 376.5\end{array}$

$\begin{array}{lllllllllllll}1963 & 574.6 & 541.9 & 560.8 & 536.1 & 608.3 & 559.6 & 479.4 & 657.6 & 611.3 & 714.6 & 600.1 & 489.6\end{array}$

$\begin{array}{lllllllllllll}1964 & 640.0 & 819.5 & 890.4 & 911.7 & 1047.8 & 786.4 & 710.2 & 818.0 & 824.4 & 900.5 & 773.8 & 579.5\end{array}$

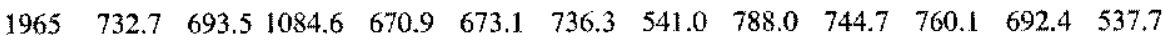

Number of cigars (small and large, taxable and tax-exempt) shipped per month in millions of cigars ${ }^{a}$

Jan. Feb. March April May June July Aug. Sept. Oct. Nov. Dec.

$\begin{array}{lllllllllllll}1952 & 465.7 & 454.1 & 453.8 & 477.1 & 494.1 & 502.0 & 476.4 & 510.4 & 515.8 & 571.9 & 539.8 & 458.7\end{array}$

$\begin{array}{llllllllllllll}1953 & 440.3 & 429.1 & 481.8 & 490.0 & 516.0 & 514.5 & 478.5 & 511.9 & 531.0 & 550.5 & 560.4 & 459.2\end{array}$

$\begin{array}{lllllllllllll}1954 & 417.4 & 423.0 & 487.8 & 458.8 & 494.8 & 522.1 & 444.2 & 538.5 & 515.2 & 514.7 & 587.2 & 438.5\end{array}$

$\begin{array}{llllllllllllll}1955 & 419.4 & 412.2 & 480.0 & 455.4 & 527.9 & 525.2 & 425.8 & 549.4 & 546.9 & 563.0 & 624.0 & 442.4\end{array}$

$\begin{array}{lllllllllllll}1956 & 462.9 & 472.4 & 511.2 & 512.2 & 565.8 & 490.6 & 438.6 & 528.3 & 466.9 & 562.0 & 641.5 & 373.1\end{array}$

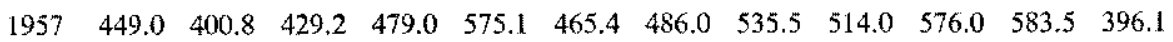

$\begin{array}{lllllllllllll}1958 & 453.9 & 404.9 & 451.0 & 499.4 & 550.8 & 516.0 & 521.5 & 549.2 & 561.4 & 624.0 & 668.8 & 461.2\end{array}$

$\begin{array}{llllllllllllll}1959 & 524.7 & 558.3 & 607.1 & 608.7 & 696.0 & 698.4 & 533.3 & 547.5 & 573.4 & 584.3 & 686.5 & 459.1\end{array}$

$\begin{array}{lllllllllllll}1960 & 485.0 & 508.0 & 552.5 & 521.8 & 649.6 & 596.8 & 524.0 & 647.3 & 603.4 & 601.5 & 698.6 & 385.9\end{array}$

$\begin{array}{lllllllllllll}1961 & 490.0 & 462.0 & 584.6 & 501.9 & 624.5 & 563.5 & 550.2 & 621.4 & 572.9 & 633.4 & 691.8 & 381.7\end{array}$

$\begin{array}{lllllllllllll}1962 & 508.6 & 449.7 & 542.1 & 533.3 & 651.5 & 562.8 & 537.4 & 626.9 & 537.9 & 654.9 & 687.8 & 350.7\end{array}$

$\begin{array}{lllllllllllll}1963 & 521.4 & 483.6 & 509.3 & 581.3 & 675.0 & 540.0 & 599.9 & 647.9 & 598.4 & 692.5 & 690.0 & 440.5\end{array}$

$\begin{array}{lllllllllllll}1964 & 661.4 & 791.2 & 844.6 & 822.2 & 904.5 & 756.6 & 743.7 & 784.0 & 751.3 & 840.4 & 839.7 & 497.5\end{array}$

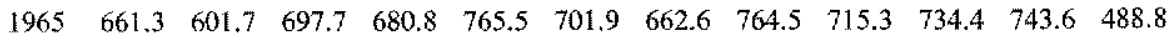

a Figures are rounded to the nearest million. 


\section{Industry 233: Women's, misses', and juniors' outerwear}

Months used as peaks in the output per paid-for man-hour interpolation: 4702 , 4707, 4807, 4907, 5006, 5206, 5703, 6102, 6402.

Months used as peaks in the output per non-production worker interpolation: $4702,5403,5703,5902,6004,6203,6502$.

Period of estimation: 4809-6506, excluding all July, August, December, and January observations; 136 obs.

\section{Industry 242: Sawmills and planing mills}

Adjustments made in the FRB output series because of strikes:

5205: 103.5 changed to 113.2 .

5406: 108.5 changed to 122.1 .

5407: 93.0 changed to 113.7 .

5408: 100.5 changed to 128.2 .

5409: 112.9 changed to 123.6 .

5410: 122.1 changed to 125.9 .

Months used as peaks in the output per paid-for man-hour interpolation: 4703, $4805,5004,5304,5402,5405,5609,5703,5706,5808,6003,6104,6202$, 6303,6402 .

Months used as peaks in the output per non-production worker interpolation: $4705,4806,5008,5506,5808,6209,6309,6402,6503,6509$.

Period of estimation: 4809-6506, excluding 5203-5208, 5404-5412, 6304. 6310, and all July and August observations; 154 obs.

\section{Industry 271: Newspaper publishing and printing}

Adjustments made in the FRB output series because of strikes:

6212: 100.0 changed to 109.5 .

6301: 86.6 changed to 101.9 .

6302: 90.3 changed to 107.3 .

6303: 92.5 changed to 112.9 .

6509: 120.9 changed to 127.9 .

Months used as peaks in the output per paid-for man-hour interpolation: 4704, 4711, 4810, 5011, 5404, 5510, 5903, 5911, 6111, 6305, 6311, 6505, 6512.

Months used as peaks in the output per non-production worker interpolation: $4704,4711,4810,4910,5004,5010,5511,5611,5911,6011,6111,6311,6404$, $6411,6511$.

Period of estimation: 4805-6506, excluding 6210-6305 and all December and January observations; 166 obs. 
Rubber Manufacturers Association data on the number of tires produced and held in inventory

Number of automobile pneumatic tires produced per month in thousands of tires ${ }^{\mathrm{a}}$

Jan. Feb. March April May June July Aug. Sept. Oct. Nov. Dec.

$\begin{array}{lllllllllllll}1947 & 8507 & 7915 & 8576 & 8333 & 8104 & 7583 & 6789 & 7164 & 7918 & 8888 & 7716 & 8049\end{array}$

$\begin{array}{llllllllllllll}1948 & 7852 & 6386 & 6931 & 6574 & 6931 & 7584 & 6667 & 6957 & 6909 & 6734 & 6084 & 5701\end{array}$

$\begin{array}{llllllllllllll}1949 & 5898 & 5893 & 6580 & 6758 & 6933 & 7391 & 6263 & 6228 & 5622 & 6488 & 6036 & 6271\end{array}$

$\begin{array}{llllllllllllll}1950 & 6811 & 6674 & 7311 & 7556 & 8612 & 8455 & 8296 & 8193 & 7833 & 8667 & 7520 & 6818\end{array}$

$\begin{array}{lllllllllllll}1951 & 6748 & 5874 & 6678 & 6531 & 7106 & 7212 & 6718 & 7533 & 7413 & 7771 & 7374 & 6441\end{array}$

$\begin{array}{lllllllllllll}1952 & 7870 & 7462 & 7785 & 7183 & 7429 & 7356 & 7092 & 6928 & 7387 & 8635 & 7360 & 7919\end{array}$

$\begin{array}{llllllllllllll}1953 & 8230 & 8228 & 9397 & 9278 & 9002 & 8587 & 8153 & 7398 & 7131 & 7665 & 6566 & 6481\end{array}$

$\begin{array}{lllllllllllll}1954 & 6298 & 7040 & 7978 & 8065 & 7965 & 8796 & 6358 & 5426 & 7277 & 7867 & 7623 & 8441\end{array}$

$\begin{array}{lllllllllllll}1955 & 9036 & 8741 & 10078 & 9143 & 9939 & 10692 & 9020 & 8710 & 9118 & 9554 & 9602 & 8477\end{array}$

$\begin{array}{lllllllllllll}1956 & 8974 & 8893 & 9189 & 8832 & 8985 & 7928 & 6740 & 8048 & 7798 & 8799 & 7636 & 8538\end{array}$

$\begin{array}{lllllllllllll}1957 & 9503 & 9169 & 9765 & 8946 & 9486 & 8485 & 8440 & 8914 & 8637 & 9702 & 8243 & 7610\end{array}$

$\begin{array}{llllllllllllll}1958 & 7816 & 7314 & 7571 & 7478 & 7656 & 8297 & 7295 & 7768 & 8282 & 9349 & 8394 & 9377\end{array}$

$\begin{array}{lllllllllllll}1959 & 10192 & 10278 & 11360 & 8036 & 7805 & 10377 & 11229 & 9689 & 10108 & 10893 & 8353 & 9649\end{array}$

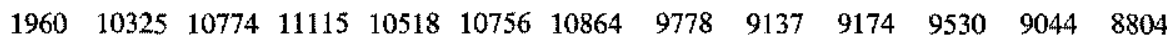

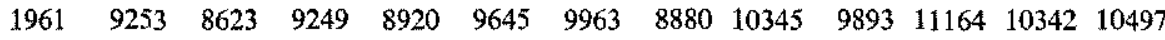

$\begin{array}{llllllllllllll}1962 & 11500 & 10369 & 11277 & 10928 & 11711 & 11974 & 10410 & 10721 & 10651 & 12857 & 10844 & 10622\end{array}$

$\begin{array}{lllllllllllll}1963 & 12430 & 11709 & 12541 & 12547 & 12123 & 11186 & 10182 & 9368 & 10540 & 13442 & 11503 & 11497\end{array}$

$\begin{array}{lllllllllllll}1964 & 12684 & 11838 & 12566 & 13333 & 13215 & 14042 & 11510 & 13235 & 14356 & 14894 & 12799 & 13634\end{array}$ $\begin{array}{lllllllllllll}1965 & 13884 & 14126 & 15242 & 14632 & 13228 & 13460 & 12174 & 12821 & 13920 & 15330 & 14194 & 14838\end{array}$

Number of automobile pneumatic tires held in inventory at the end of the month in thousands of tires ${ }^{8}$

Jan. Feb. March April May June July Aug. Sept. Oct. Nov. Dec.

$\begin{array}{lllllllllllll}1947 & 3322 & 3864 & 4515 & 5608 & 6425 & 6571 & 5838 & 5464 & 5189 & 5513 & 5277 & 6949\end{array}$

$\begin{array}{lllllllllllll}1948 & 8805 & 10171 & 11357 & 10940 & 11611 & 11435 & 10206 & 9352 & 9802 & 9905 & 10477 & 10698\end{array}$

$\begin{array}{lllllllllllll}1949 & 11339 & 12385 & 13071 & 13190 & 13301 & 13135 & 11716 & 9969 & 8930 & 8697 & 9541 & 10638\end{array}$

$\begin{array}{llllllllllllll}1950 & 11366 & 11796 & 12320 & 12337 & 12367 & 10791 & 7004 & 4794 & 4374 & 4382 & 4810 & 3793\end{array}$

$\begin{array}{lllllllllllll}1951 & 3551 & 3307 & 2803 & 3046 & 2992 & 3507 & 3585 & 4032 & 4739 & 5513 & 6887 & 8764\end{array}$

$\begin{array}{lllllllllllll}1952 & 10038 & 11370 & 13035 & 13295 & 13263 & 11650 & 11647 & 10636 & 9963 & 10821 & 12271 & 14110\end{array}$

$\begin{array}{llllllllllllll}1953 & 14117 & 15295 & 16468 & 16872 & 16973 & 16305 & 14882 & 13549 & 13279 & 13446 & 14854 & 15705\end{array}$

$\begin{array}{llllllllllllll}1954 & 14976 & 15708 & 16077 & 15905 & 15503 & 15252 & 12640 & 9984 & 11192 & 12799 & 13675 & 14761\end{array}$

$\begin{array}{llllllllllllll}1955 & 14949 & 15367 & 15596 & 14889 & 14935 & 15454 & 14683 & 13907 & 14677 & 16163 & 17726 & 17746\end{array}$

$\begin{array}{lllllllllllll}1956 & 19516 & 20933 & 21563 & 21131 & 21296 & 19961 & 17393 & 16794 & 17693 & 18774 & 18802 & 19903\end{array}$

$\begin{array}{lllllllllllll}1957 & 20489 & 21008 & 21743 & 21307 & 21629 & 20797 & 19316 & 18477 & 19420 & 20984 & 22170 & 23236\end{array}$

$\begin{array}{lllllllllllll}1958 & 22785 & 23408 & 23461 & 22669 & 21845 & 20942 & 18629 & 18535 & 18948 & 19931 & 20422 & 21025\end{array}$

$\begin{array}{lllllllllllll}1959 & 21416 & 23042 & 23890 & 20893 & 18744 & 19109 & 19890 & 21745 & 22567 & 23169 & 25154 & 26964\end{array}$

$\begin{array}{lllllllllllll}1960 & 25943 & 26473 & 27932 & 27401 & 26966 & 26380 & 26107 & 26297 & 25935 & 25498 & 26290 & 27576\end{array}$

$\begin{array}{lllllllllllll}1961 & 27681 & 29337 & 29382 & 25047 & 26502 & 24800 & 24098 & 24126 & 24096 & 24195 & 24915 & 26365\end{array}$

$\begin{array}{lllllllllllll}1962 & 26799 & 28108 & 28527 & 27837 & 27506 & 27617 & 26030 & 26533 & 26072 & 26050 & 26039 & 27865\end{array}$

$\begin{array}{lllllllllllll}1963 & 29054 & 31692 & 33189 & 32137 & 31919 & 31326 & 28829 & 28651 & 27820 & 27468 & 28271 & 29451\end{array}$

$\begin{array}{lllllllllllll}1964 & 29544 & 31089 & 31777 & 31091 & 31011 & 30645 & 29968 & 31979 & 32499 & 34731 & 36607 & 37552\end{array}$

$\begin{array}{lllllllllllll}1965 & 38253 & 40531 & 41467 & 40600 & 39514 & 37206 & 35035 & 36094 & 35110 & 34441 & 35082 & 37059\end{array}$

a The figures are not rounded to the nearest thousand; the last three digits of the figures published by the RMA were merely truncated. 


\section{Industry 301: Tires and inner tubes}

Data used for the output variable: Data on the number of automobile pneumatic tires produced per month were obtained for the period 4701-6512 from past reports and bulletins of the RMA. The data are presented in table A-4. (Note: The FRB index of production for industry 301 is computed using the RMA data.)

Months used as peaks in the output per paid-for man-hour interpolation: $4703,4710,4906,5010,5305,5406,5506,5806,5902,6004,6202,6302,6502$. Months used as peaks in the output per non-production worker interpolation: 4703, 4710, 5005, 5506, 5910, 6002, 6206, 6303, 6406, 6410, 6502.

Basic period of estimation: 4809-6503, excluding 4906-4912, 5403-5412, $5607-5708,5805-5808,5812-5909$, and all July and August observations; 134 obs. (Note: 5805 and 5806 were omitted from the period of estimation by accident.)

Period of estimation used when testing the "non-perfect" expectational hypothesis: 4809-6503, excluding 4906-5011, 5403-5511, 5607-5808, 5812-6008, and all July and August observations; 99 obs.

Data used for the estimates presented in ch. 6: Data on the number of automobile pneumatic tires held in inventory at the end of the month were obtained for the period 4701-6512 from past reports and bulletins of the RMA. The data are presented in table A-4.

Data on the value of shipments and value of inventories at the end of the month were unpublished and were obtained directly from the Bureau of Census for the 4801-6512 period.

Months used as peaks in the output per paid-for man-hour interpolation when Census data were used: 4902, 5010, 5103, 5502, 5706, 5802, 5806, $6004,6104,6304,6504$.

\section{Industry 311: Leather tanning and finishing}

Months used as peaks in the output per paid-for man-hour interpolation: 4702, $5305,5502,5602,5702,5905,6104,6405$.

Months used as peaks in the output per non-production worker interpolation: 4704, 4711, 4902, 5102, 5602, 5811, 6210.

Period of estimation: 4809-6506, excluding all July and August observations; 170 obs. 


\section{TABLE A-5}

Bureau of Mines data on the amount of cement produced and held in inventory

Amount of portland cement produced per month in thousands of 376 pound barrels

Jan. Feb. March April May June July Aug. Sept. Oct. Nov. Dec.

$\begin{array}{lllllllllllll}1947 & 13406 & 12618 & 14205 & 14566 & 13389 & 15971 & 16342 & 17480 & 17319 & 18300 & 16814 & 16123\end{array}$

$\begin{array}{llllllllllllll}1948 & 14541 & 13347 & 14502 & 16041 & 17740 & 17757 & 18721 & 18961 & 18605 & 19349 & 18435 & 17425\end{array}$

$\begin{array}{lllllllllllll}1949 & 15261 & 13751 & 15439 & 17682 & 18622 & 18279 & 18856 & 18715 & 19181 & 19070 & 18040 & 16967\end{array}$

$\begin{array}{llllllllllllll}1950 & 15174 & 13070 & 14238 & 18088 & 19950 & 20007 & 20709 & 21884 & 20945 & 22488 & 20226 & 19116\end{array}$

$\begin{array}{lllllllllllll}1951 & 17434 & 15201 & 18708 & 20184 & 21924 & 21984 & 22439 & 22514 & 22269 & 22997 & 20737 & 19874\end{array}$

$\begin{array}{lllllllllllll}1952 & 17039 & 16545 & 18095 & 19817 & 21829 & 20748 & 21342 & 23573 & 23010 & 24164 & 22048 & 20881\end{array}$

$\begin{array}{lllllllllllll}1953 & 18856 & 17325 & 20215 & 21802 & 23399 & 22698 & 24134 & 24289 & 23795 & 24738 & 22529 & 20243\end{array}$

$\begin{array}{lllllllllllll}1954 & 17769 & 16895 & 20097 & 21730 & 23279 & 22802 & 25482 & 25698 & 25522 & 25887 & 23826 & 22290\end{array}$

$\begin{array}{lllllllllllll}1955 & 20223 & 17611 & 22340 & 24818 & 27031 & 26762 & 27332 & 27861 & 26958 & 27924 & 24894 & 23075\end{array}$

$\begin{array}{lllllllllllll}1956 & 21440 & 19578 & 23386 & 26134 & 29606 & 28771 & 29498 & 30055 & 28643 & 29051 & 25869 & 24429\end{array}$

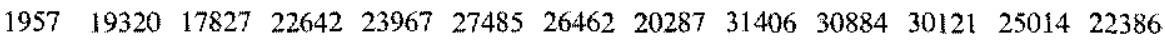

$\begin{array}{lllllllllllll}1958 & 18320 & 14125 & 18038 & 24001 & 29274 & 30078 & 29833 & 31675 & 31597 & 32847 & 28031 & 23590\end{array}$

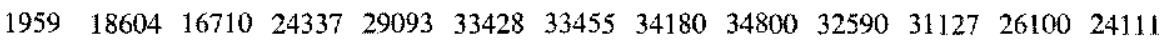

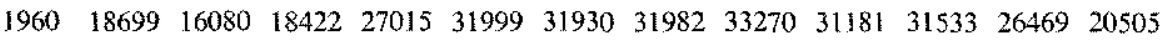

$\begin{array}{lllllllllllll}1961 & 16744 & 15038 & 21851 & 26463 & 31102 & 31594 & 32511 & 33262 & 31474 & 32348 & 27625 & 23393\end{array}$

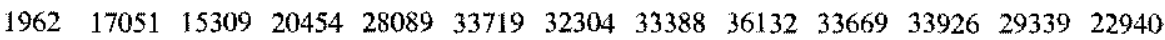

$\begin{array}{llllllllllllll}1963 & 18289 & 14750 & 21525 & 29314 & 34497 & 34992 & 36802 & 37452 & 34682 & 36624 & 30377 & 23993\end{array}$

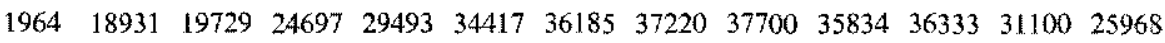

Amount of portland cement held in inventory at the end of the month in thousands of of 376 pound barrels

Jan. Feb. March April May June July Aug. Sept. Oct. Nov. Dec.

$\begin{array}{lllllllllllll}1947 & 15931 & 20112 & 22178 & 21331 & 19388 & 17095 & 13337 & 10452 & 7921 & 5688 & 6209 & 9975\end{array}$

$\begin{array}{lllllllllllll}1948 & 15336 & 20340 & 20886 & 17880 & 16086 & 12422 & 10149 & 8355 & 7061 & 6094 & 6399 & 11084\end{array}$

$\begin{array}{lllllllllllll}1949 & 17591 & 22206 & 23104 & 22977 & 22170 & 19785 & 19313 & 14381 & 10797 & 8569 & 9352 & 14706\end{array}$

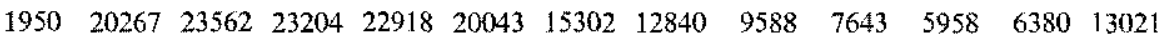

$\begin{array}{lllllllllllll}1951 & 18222 & 22234 & 23250 & 22511 & 19566 & 16630 & 14812 & 11491 & 10499 & 7162 & 9910 & 17993\end{array}$

$\begin{array}{lllllllllllll}1952 & 22336 & 24519 & 26622 & 24672 & 23220 & 18896 & 15158 & 12819 & 9602 & 6546 & 8823 & 15957\end{array}$

$\begin{array}{lllllllllllll}1953 & 21294 & 24464 & 23865 & 24773 & 25247 & 21542 & 19204 & 16445 & 12859 & 10049 & 13083 & 19231\end{array}$

$\begin{array}{lllllllllllll}1954 & 25869 & 27562 & 28905 & 27045 & 25412 & 19674 & 17524 & 14408 & 10909 & 9667 & 10732 & 16731\end{array}$

$\begin{array}{lllllllllllll}1955 & 23437 & 27087 & 26516 & 26106 & 23672 & 18855 & 16727 & 12731 & 9779 & 8754 & 11664 & 17516\end{array}$

$\begin{array}{lllllllllllll}1956 & 25454 & 28939 & 29868 & 28679 & 26204 & 22685 & 20598 & 17068 & 15532 & 13007 & 15973 & 22440\end{array}$

$\begin{array}{lllllllllllll}1957 & 29828 & 32382 & 34277 & 34893 & 33176 & 29885 & 24345 & 20018 & 20250 & 19213 & 23187 & 28729\end{array}$

$\begin{array}{lllllllllllll}1958 & 33235 & 36383 & 36734 & 35170 & 33673 & 33350 & 30646 & 27883 & 24449 & 20415 & 23686 & 30800\end{array}$

$\begin{array}{lllllllllllll}1959 & 34838 & 36680 & 36381 & 36378 & 36527 & 33605 & 30415 & 28102 & 25308 & 23913 & 27794 & 31328\end{array}$

$\begin{array}{llllllllllllll}1960 & 37284 & 38553 & 39165 & 38554 & 40101 & 37667 & 36611 & 33244 & 30505 & 28841 & 30095 & 35525\end{array}$

$\begin{array}{lllllllllllll}1961 & 37939 & 38531 & 38237 & 39999 & 39789 & 37346 & 37889 & 33768 & 31785 & 28437 & 30382 & 36343\end{array}$

$\begin{array}{lllllllllllll}1962 & 39725 & 40624 & 39811 & 39916 & 40000 & 38684 & 36461 & 31964 & 32522 & 29901 & 32324 & 38531\end{array}$

$\begin{array}{lllllllllllll}1963 & 42282 & 42293 & 42333 & 41416 & 40668 & 40322 & 38057 & 35209 & 33236 & 28485 & 32491 & 39556\end{array}$

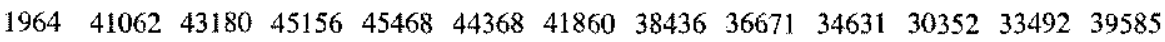




\section{Industry 314: Footwear, except rubber}

Months used as peaks in the output per paid-for man-hour interpolation: 4703, $4710,4910,5004,5204,5404,5410,5604,5703,5803,6303,6502$.

Months used as peaks in the output per non-production worker interpolation: 4703, 4710, 5103, 5208, 5602, 5902, 6202, 6502, 6508.

Period of estimation: 4809-6506, excluding all July, August, December, and January observations; 136 obs.

\section{Industry 324: Cement, hydraulic}

Data used for the output variable: Data on the amount of portland cement produced per month were obtained for the period 4701-6412 from past publications of the Bureau of Mines. (The Bureau of Mines ended its collection of these data in 1964.) The data are presented in table A-5. (Note: the FRB index of production for industry 324 before 1965 was computed using the Bureau of Mines data on production; since 1965 the FRB index has been computed using a Bureau of Mines series on shipments.)

Months used as peaks in the output per paid-for man-hour interpolation: 4710 , $4809,4909,5010,5109,5209,5310,5409,5505,5605,5708,5810,5906$, $6008,6108,6208,6310,6410$.

Months used as peaks in the output per non-production worker interpolation: 4709, 4807, 5010, 5106, 5506, 5605, 5810, 5908, 6208.

Period of estimation: 4805-6408, excluding 5703-5711; 187 obs.

Data used for the estimates presented in ch. 6: Data on the amount of portland cement held in inventory at the end of the month were obtained for the period 4701-6412 from past publications of the Bureau of Mines. The data are presented in table A-5.

\section{Industry 331: Blast furnace and basic steel products}

Months used as peaks in the output per paid-for man-hour interpolation: 4703, 4903, 5004, 5108, 5303, 5503, 5603, 5703, 5903, 6202, 6305, 6503.

Months used as peaks in the output per non-production worker interpolation: 4704, 4902, 5111, 5505, 5905, 6305, 6504.

Period of estimation: 4809-6506, excluding 4907-5004, 5106-5108, 51115301, 5604-5701, 5903-6004, and all July and August observations; 128 obs. Data used for the estimates presented in ch. 6: Data on the value of shipments and value of inventories at the end of the month were unpublished and were obtained directly from the Bureau of Census for the 4901-6512 period. Months used as peaks in the output per paid-for man-hour interpolation 
when Census data were used: $4902,5109,5211,5306,5308,5511,5611$, 5904, 6306.

Period of estimation when Census data were used: 5005-6506, excluding 5106-5108, 5111-5301, 5604-5701, 5903-6004, and all July and August observations; 118 obs.

\section{Industry 332: Iron and steel foundries}

Months used as peaks in the output per paid-for man-hour interpolation: 4703, 4810, 4904, 5004, 5402, 5504, 5810, 5905, 6306.

Months used as peaks in the output per non-production worker interpolation: 4703, 4810, 5010, 5510, 5905, 6405, 6505.

Period of estimation: 4809-6506, excluding all July and August observations; 170 obs.

Data used for the estimates presented in ch. 6: Data on value of shipments and value of inventories at the end of the month were unpublished and were obtained directly from the Bureau of Census for the 5301-6512 period. Months used as peaks in the output per paid-for man-hour interpolation when Census data were used: 5302, 5402, 5502, 5606, 5609, 5706, 5905, $6002,6204,6405$.

Period of estimation when Census data were used: 5309-6506, excluding all July and August observations; 120 obs.

\section{Industry 336: Non-ferrous foundries}

Months used as peaks in the output per paid-for man-hour interpolation: 4702, $4802,4810,5004,5410,5504,5902,6402$.

Months used as peaks in the output per non-production worker interpolation: 4703, 5012, 5503, 5602, 5905, 6503.

Period of estimation: 4809-6506, excluding all July and August observations; 170 obs.

\section{Industry 341: Metal cans}

Adjustments made in the FRB output series because of strikes: $5312: 45.8$ changed to 74.6 .

Months used as peaks in the output per paid-for man-hour interpolation: 4708 , 4908, 5510, 5609, 5808, 5908, 6108, 6209.

Months used as peaks in the output per non-production worker interpolation: 4708, 4809, 5208, 5308, 5609, 5909, 6108, 6408, 6508.

Period of estimation: 4805-6410, excluding 5309-5403; 191 obs. 


\section{BIBLIOGRAPHY}

Ball, R. J. and St Cyr, E. B. A. (1966). "Short Term Employment Functions in British Manufacturing Industry", The Review of Economic Studies, (July 1966), pp. 179-207.

Board of Governors of the Federal Reserve System (1962). Industrial Production 1957-59 Base, Washington D.C.

Brechling, Frank (1965). "The Relationship Between Output and Employment in British Manufacturing Industries", The Review of Economic Studies, (July 1965), pp. 187-216. Brechling, Frank and O'Brien, Peter (1967). "Short-Run Employment Functions in Manufacturing Industries: An International Comparison", The Review of Economics and Statistics, (August 1967), pp. 277-287.

Dhrymes, Phoebus J. (1966). "On the Treatment of Certain Recurrent Non-Linearities in Regression Analysis", The Southern Economic Journal, (October 1966), pp. 187-196. Dhrymes, Phoebus J. (1967). "A Model of Short Run Labor Adjustment", mimeographed. Douty, H. M. (1960). "Collective Bargaining Coverage in Factory Employment, 1958", Monthly Labor Review, (April 1960), pp. 345-349.

Eckhaus, R. S. (1964). "Economic Criteria for Education", The Review of Economics and Statistics, (May 1964), pp. 181-190.

Goldberger, Arthur S. (1964). Econometric Theory, New York: John Wiley.

Goldfeld, S. M., Quandt, R.E. and Trotter, H. F. (1966). "Maximization by Quadratic Hill-Climbing", Econometrica, (July 1966), pp. 541-551.

Goldfeld, S. M., Quandt, R. E. and Trotter, H. F. (1968). "Maximization by Improved Quadratic Hill-Climbing and Other Methods", Econometric Research Program, Research Memorandum No. 95, (April 1968), Princeton University.

Griliches, Zvi (1961). "A Note on the Serial Correlation Bias in Estimates of Distributed Lags", Econometrica, (January 1961), pp. 65-73.

Hamermesh, Daniel S. (1967). "Spectral Analysis of the Relation Between Employment Changes and Output Changes, 1958-1966", Cowles Foundation Discussion Paper No. 226, (June 23, 1967).

Holt, Charles C., Modigliani, Franco, Muth, John F. and Simon, Herbert A. (1960). Planning Production, Inventories, and Work Force, Englewood Cliffs, N. J.: Prentice-Hall. Hultgren, Thor (1960). Changes in Labor Cost During Cycles, New York: National Bureau of Economic Research.

Hultgren, Thor (1965). Costs, Prices, Profits: Their Cyclical Relations, New York: National Bureau of Economic Research.

Ireland, N. J. and Smyth; D. J. (1967). "The Specification of Short-Run Employment Models and Returns to Labour", Discussion Paper A82, March 1967, Faculty of Commerce and Social Science, University of Birmingham, England.

Jorgenson, Dale W. (1966). "Rational Distributed Lag Functions", Econometrica, (January 1966), pp. 135-149. 
Koopmans, Tjalling C. and Hood, Wm. C. (1953). "The Estimation of Simultaneous Linear Economic Relationships", in Wm. C. Hood and Tjalling C. Koopmans, Studies in Econometric Method, Cowles Commission Monograph No. 14, New York: Joln Wiley.

Kuh, Edwin (1960). "Profits, Profit Markups, and Productivity", Study Paper No. 15, US Joint Economic Committee, Study of Employment Growth, and Price Levels.

Kuh, Edwin (1965a). "Cyclical and Secular Labor Productivity in United States Manufacturing", The Review of Economics and Statistics, (February 1965), pp. 1-12.

Kuh, Edwin (1965b). "Income Distribution and Employment Over the Business Cycle", in James S. Duesenberry, Gary Fromm, Lawrence R. Klein and Edwin Kuh, The Brookings Quarterly Econometric Model of the United States, Chicago: Rand McNally.

Lovell, Michael (1961). "Manufacturers' Inventories, Sales Expectations, and the Acceleration Principle", Econometrica, (July 1961), pp. 293-314.

Malinvaud, E. (1966). Statistical Methods of Econometrics, Amsterdam: North-Holland Publishing Company.

Masters, Stanley H. (1967). "The Behavior of Output per Man During Recessions: An Empirical Study of Underemployment", The Southern Economic Journal, (January 1967), pp. $388-394$.

Neild, R. R. (1963). Pricing and Employment in the Trade Cycle, London: Cambridge University Press.

Nerlove, Marc and Wallis, Kenneth F. (1966). "Use of the Durbin-Watson Statistic in Inappropriate Situations", Econometrica, (January 1966), pp. 235-238.

Raines, Fredric Q. (1963). "An Econometric Study of Labor Productivity in Manufacturing and the Total Private Nonfarm Economy", American Statistical Association Proceedings, pp. $182-199$.

Smyth, D. J. and Ireland, N. J. (1967). "Short-Term Employment Functions in Australian Manufacturing", The Review of Economics and Statistics, (November 1967), pp. 537-544.

Soligo, Ronald (1966). "The Short Run Relationship Between Employment and Output", Yale Economic Essays, (Spring 1966), pp. 160-215.

Solow, Robert M. (1964). "Draft of Presidential Address on the Short-Run Relation of Employment and Output", mimeographed.

us Department of Commerce (1967a). Business Cycle Developments, July 1967.

us Department of Commerce (1967b). Industry Profiles 1958-1965, us Government Printing Office.

us Department of Labor, Bureau of Labor Statistics (1965). Employment and Earnings Statistics for the United States 1909-65, Bulletin No. 1312-3, us Government Printing Office.

Wilson, Thomas A. and Eckstein, Otto (1964). "Short-Run Productivity Behavior in US Manufacturing", The Review of Economics and Statistics, (February 1964), pp. 41-54.

Zellner, A. (1962). "An Efficient Method of Estimating Seemingly Unrelated Regressions and Tests for Aggregation Bias", Journal of the American Statistical Association, (June 1962), pp. 348-368. 


\section{INDEX}

Aitken's generalized least squares method, 167,178

Ball, R. J., 1n, 9-12, 18, 19, 22, 25, 40

basic model of previous studies development of, 6-8 estimates of, 22-26

Brechling, F., 1n, 8-9, 18, 19, 20, 22

Bureau of Labor Statistics, 36, 60, 98, 209

Bureau of Mines, 65, 119, 210, 220

Bureau of the Census, 127-128, 210

capacity constraints, 107-109

cost-minimizing assumptions

necessity for the basic model, 18-20

role in the HMMs model, 113-115

role in the present model, 50

cyclical variations

in demand for hours, 150-154

in demand for workers, $90-95$

data used, 59-65, 119-121

demand, short-run

comparison across industries, 186-191

comparison for workers and hours, 139-144

cyclical variation in, 90-95

for hours paid-for per worker, 139-144

for non-production workers, 192-196

for production workers, $50-55$

for total man hours paid-for, 159-161

Dhrymes, P., 1n, 15-16, 18, 20, 52, 59, 169n, 192

distributed lags, 102-107

Douty, H. M., 188

Durbin-Watson statistic, 25-26, 72, 166, 169,174

Eckhaus, R. S., 187

Eckstein, O., 1n, 27-29

economy-wide implications, 161-165

employment reaction, comparison across industries, 186-191 excess labor

concept of, $37-40$

for non-production workers, 193-196 measurement of, 47-50

results for, $69,72-76,103-107,145$

role in the demand for hours, $139-140$

role in the demand for workers, 51

two expressions for, $49-50$

excess man hours, 161

expectational hypotheses

development of, $55-57$

tests of, 77-84

Federal Reserve Board, 60, 209, 211

Goldberger, A. S., 97n

Goldfeld, S. M., 97, 168

Griliches, Z., 166, 175

Hamermesh, D. S., 187

Holt, C. C., 3, 50, 112-115, 204

Hood, W. C., 97n

hours paid-for per worker

constraint on, 141-142

demand for, 139-144

results for, 144-150

hours worked per worker, estimate of, $135-139$

Hultgren, T., 1n, 29-30, 59, 164, 165, 206, 208

Internal Revenue Service, 120, 214

inventory, desired stock of, 116-118

Ireland, N. J., 1n, 12-13, 18, 19, 25, 26, 31, 32

Jorgenson, D. W., 102

Koopmans, T. C., 97n

Kuh, E., 1n, 16-17, 18, 22, 32, 59, 85, 87, $90,140,192$

lagged adjustment model, 100-102

Lovell, M., 81n 
Malinvaud, E., 169

Masters, S. H., 1n, 29-30

Modigliani, F., 3, 50, 112-115, 204

Muth, J, F., 3, 50, 112-115, 204

National Bureau of Economic Research, 93, 152, 209

Neild, R. R., 1n, 26

Nerlove, M., 26, 166n

non-linear estimation, 97-100, 168-169,175

non-production workers

demand for, 192-196

results for, 196-200

notation

for ch. 2,6

for ch. 3 and beyond, 36-37

for ch. 6,120

O'Brien, P., 1n, 9

output per paid-for man hour

fluctuations in, 33-36, 44-46

interpolation of, $47-49$

periods of estimation, $62-65$

production function, short run

appropriate data for, 21-22

assumed properties of, 41-47

incorporation of technical progress, 48

production workers

demand for, $50-55$

results for, $65-77$

Quandt, R. E., 97, 168

Raines, F. Q., 1n, 29-30

Rubber Manufacturers Association, 65, $119,210,218$ seasonal adjustment questions, 20-22, 162 serially correlated errors, 166-177

Simon, H. A., 3, 50, 112-115, 204

Smyth, D. J., 1n, 12-13, 18, 19, 25, 26, 31,32

Soligo, R., 1n, 13-14, 18, 22, 39

Solow, R. M., 1n, 2n, 13, 18, 22, 39-40

standard hours of work, assumption about, 54

St Cyr, E. B. A., 1n, 9-12, 18, 19, 22, 25, 40

substitution of hours for workers, $85-90$

technical progress

effect on demand for workers, 53

in production function, 48

total man hours paid-for, demand for, 159-161

training requirements, effect of, 187-188

Trotter, H. F., 97, 168

t-statistic, 69 n, 98

unemployment rate

effect on demand for hours, 143, 145-

148

effect on demand for workers, 95-100

union pressure, effect of, 188-189

us Department of Commerce, 93, 190, 209

wage rates, influence of, 52-53, 189-190

Wallis, K. F., 26, 166n

Wilson, T. A., 1n, 27-29

Zellner, A., 4, 166, 177, 178, 207 